\title{
The myth of gender-neutral power
}

Citation for published version (APA):

Merkle, O. (2018). The myth of gender-neutral power: corruption and gender norms. [Doctoral Thesis, Maastricht University]. Boekenplan. https://doi.org/10.26481/dis.20181205om

Document status and date:

Published: 01/01/2018

DOI:

10.26481/dis.20181205om

Document Version:

Publisher's PDF, also known as Version of record

\section{Please check the document version of this publication:}

- A submitted manuscript is the version of the article upon submission and before peer-review. There can be important differences between the submitted version and the official published version of record.

People interested in the research are advised to contact the author for the final version of the publication, or visit the DOI to the publisher's website.

- The final author version and the galley proof are versions of the publication after peer review.

- The final published version features the final layout of the paper including the volume, issue and page numbers.

Link to publication

\footnotetext{
General rights rights.

- You may freely distribute the URL identifying the publication in the public portal. please follow below link for the End User Agreement:

www.umlib.nl/taverne-license

Take down policy

If you believe that this document breaches copyright please contact us at:

repository@maastrichtuniversity.nl

providing details and we will investigate your claim.
}

Copyright and moral rights for the publications made accessible in the public portal are retained by the authors and/or other copyright owners and it is a condition of accessing publications that users recognise and abide by the legal requirements associated with these

- Users may download and print one copy of any publication from the public portal for the purpose of private study or research.

- You may not further distribute the material or use it for any profit-making activity or commercial gain

If the publication is distributed under the terms of Article $25 \mathrm{fa}$ of the Dutch Copyright Act, indicated by the "Taverne" license above, 


\section{GENDER EJPA POWER}



THE MYTH OF GENDER-NEUTRAL POWER:

CORRUPTION AND GENDER NORMS

Ortrun Merkle 
(C) copyright Ortrun Merkle, Maastricht 2018

Cover illustration: Melanie Waidler

Publisher: Boekenplan, Maastricht

www.boekenplan.nl

ISBN 9789086664641

All rights reserved. No part of this publication may be reproduced, stored in a retrieval system, or transmitted in any form or by any means, electronic, mechanical, photocopying, recording or otherwise, without the written permission from the author. 
THE MYTH OF GENDER-NEUTRAL POWER: CORRUPTION AND GENDER NORMS

\section{DISSERTATION}

to obtain the degree of Doctor at Maastricht University, on the authority of the Rector Magnificus, Prof. Dr. Rianne M. Letschert in accordance with the decision of the Board of Deans, to be defended in public on

Wednesday 5 December 2018, at 10.00 hours

by

Ortrun Merkle 


\section{Supervisor}

Prof. Dr. Khalid Koser

Co-Supervisor

Dr. Lutz Krebs

\section{Assessment Committee}

Prof. Dr. Arjen Leerkes (Chair)

Prof. Dr. Michael Johnston (Colgate University)

Dr. Monica Kirya (Chr. Michelsen Institute)

Dr. Michaella Vanore

Financial support for this dissertation was received from the German Academic Exchange Service (DAAD) and the Universiteitsfonds Limburg/SWOL. 
To Silvia, Lydia, and Insea - the strong female role models in my life

To my parents who taught me to have strong principles, a good heart, and a strong backbone. Your unconditional love and support made it all possible. 

The discussion of gender and corruption is one full of extremes- women as the new perfect anti-corruption force on the one hand or as the defenseless victims of corruption on the other. Nevertheless, a thorough understanding of the nuances in this relationship is still missing. The existing academic debate on the topic is broadly centered around three questions: a) are women less corrupt than men? b) does corruption have different effects on women and c) how can women help in fighting corruption? In this dissertation, I argue that a major aspect which is too often missing in the analysis is the role of gender norms.

Corruption is most commonly defined as the "abuse of entrusted power for private gain" (Transparency International), and while definitions are widely debated they agree that power or authority plays an important role. Yet, even in the discussion on the relationship of corruption and gender 'power' is still largely considered a gender-neutral concept and entirely centered around men as the norm. The four essays that constitute this dissertation challenge this notion and investigate how gender norms shape forms, experiences, and persistence of corruption.

The first chapter provides a theoretical discussion on the forms of corruption that women experience and how they are shaped by gendered power structures. This chapter specifically focuses on sextortion as an example. Using data from the World Value Survey for five Sub-Saharan countries, the next chapter investigates how patriarchal views on women's participation in politics are related to views on corruption. The third chapter is based on extensive fieldwork in Georgia. It continues the discussion by investigating how (benevolent) sexism is used to exclude women from clientelistic networks. The last chapter focuses on the gendered experiences of corruption. Based on interviews with irregular migrants and experts, the study explores how migrants experience corruption and how this is influenced by patriarchal structures. 

"When you've worked hard, and done well, and walked through that doorway of opportunity, you do not slam it shut behind you. You reach back."

$\overline{\text { Michelle Obama }}$

Completing a Ph.D. truly is a journey that is hard to describe. Starting this adventure, many of us are torn between the romantic notion of being an academic, surrounded by books and research, brilliant people and fascinating discussions and the fears of the imposter syndrome, failing science, and vicious competition. Looking back, I can say the truth, for me, lies somewhere in the middle. The journey has been wonderful and hard, challenging and rewarding, full of incredible people who helped me succeed and some who wanted to see me fail. To all of them, I owe thanks. You all have made my research better, taught me my strengths and weaknesses and made me more resilient. Hence, is my pleasure to use this space to acknowledge the many people who have played an important role in the completion of my Ph.D. research.

First and foremost, I would like to thank my supervisor and 'Doktorvater', Prof. Khalid Koser. Your guidance, patience, and criticism throughout the Ph.D. and other academic endeavors have been invaluable. You gave me a chance to prove myself and encouraged me to believe in my capabilities and venture outside traditional academia to find what I am passionate about. I am also indebted to my second supervisor, Dr. Lutz Krebs, for allowing me to freely develop my research interest, introducing me to the fascinating world of academic conferences, encouraging me to teach at Maastricht University and supporting me especially in the final stages of the Ph.D.

I would like to specifically thank the members of the assessment committee Prof. Arjen Leerkes, Prof. Michael Johnston, Dr. Monica Kirya and Dr. Michaella Vanore whose thoughtful, critical and constructive comments have significantly improved this dissertation and have given me much food for thought for future research projects. I appreciate the members of the Corona, Prof. Shyama Ramani, Dr. Tatiana Skripka and Prof. Lies Wesseling for taking the time to critically examine my dissertation. I am also thankful to Prof. Cynthia Enloe, whose brilliant thinking on patriarchy and genuine interest in my work have greatly shaped this 
dissertation. My colleagues at the Research School on Peace and Conflict at the Peace Research Institute Oslo (PRIO), especially Theresa, Sladjana, Anette, and Frangis, for the long discussions on fieldwork ethics and all the different people who took time to give me feedback on my research during my visiting research stay at PRIO. I am grateful to Prof. Melissa Siegel, who took an interest in the new research area of corruption and migration and who offered me a Post-Doc to explore this topic in more depth. Lastly, I would like to thank Jørgen Johansen for encouraging me to apply for a Ph.D. in the first place.

I received financial support for this dissertation from the German Academic Exchange Service (DAAD) and the Universiteitsfonds Limburg/SWOL which made much of the fieldwork possible. Much of the dissertation research was financed through teaching, supervising, academic advising and coaching at different faculties of Maastricht University. I am immensely grateful to have had these opportunities to learn from colleagues and my students and discover how much I enjoy teaching. I look forward to continuing many of these activities in the next years.

This Ph.D. would not exist without all the people who took the time to participate in interviews and opened up about their experiences of and views on corruption. I am grateful to all of you for sharing your views and sharing sensitive and sometimes contentious information. Michaella, thank you for taking the time to introduce me to the excitement and struggle of doing fieldwork in Georgia. Your advice has been indispensable. I am very grateful to my colleagues and students, Julia,Clara, Harres, and Vitto, who worked with me on the corruption and migration research, and without whom it would not have been possible to collect such interesting data. Clara and Julia, I look forward to doing exciting research with you in the years to come.

My research would not have been the same without the colleagues at the UNUGender Equality Studies and Training Programme (UNU-GEST). Kristjana, Erla, Petúr and Irma, my research visit with you, our blog series and getting a chance to teach in your great program, shaped my research and strengthened my commitment to taking a true gender focus in my discussions. Anne, I am very happy we had a chance to work together and become friends, and I look forward to collaborating more closely.

The UNU-MERIT community has strongly shaped the last few years and without the help and support of all the staff, this dissertation would not have been possible. I want to especially thank Susan and Marc, for your willingness to deal with 
impossible questions and Herman and Mourik Jan for your patience to deal with any panicked computer problems. It has been a great pleasure to work closely with the communications team over the last few years. Howard, thank you for supporting innovative ideas and all your help to communicate my research findings to the outside world. I really have learned a great deal from you. Sueli, your genuine interest in my research and your willingness to travel to Paris and Brussels with me to support and promote me have been truly wonderful. Ingrid, Ingeborg, and Mieke, thank you for always having an open ear and a big smile to start every day better. Liesbeth, thank you for opening your heart and home. Last, but definitely not least, Eveline, who has been the first to welcome me to UNUMERIT and whose policy of having an open door, an open heart, and a free hug at any time has been a lifesaver more than once.

I started this year with the best batch one could ask for: Anthony, Andres, Andy, Charlotte, Conny, Craig, Eleni, George, Julieta, Katrin, Lorena, Rhena, Simone, Tash, and Yesuf, it has been wonderful to start this journey together and to learn from all of you. I am especially grateful to Conny, Rhena, and Tash, - you were there for me when the world came crumbling down, and I miss you dearly. Katrin, I am so happy we did not only start but also finish this turbulent ride together. I could not have asked for a better friend to share all aspects of this journey with. From our wonderful conference trips to endless coffee brainstorming sessions to late night deadlines, I am grateful you were by my side and will be next to me as my paranymph when I close this chapter. I look forward to seeing where this road we're on is taking us next.

This journey would not have been the same without Hampton and Diego, the best research group that never officially existed. It has been a pleasure to work with you, innovating, pushing boundaries and pulling off things, that no one thought we were capable of. Your friendship throughout the years has been an important factor in shaping my Ph.D. journey, and I am looking forward to seeing what we can come up with next.

I have been lucky enough to share an office with many admirable people. Mira, Stefania, Julieta, and Paula, thank you for many laughs and fruitful discussions. You have inspired me and kept me sane through many difficult times. I am lucky to have met many incredible people throughout my time at UNU-MERIT, especially Alison, Andrea, Ayla, Ayo, Biljana, Cheng, Dana, Dorcas, Elaine, Elisa, Eszter, Francesca, Hibret, Ibrahima, Inez, Irina, Iulia, Jennifer W., Karen, Mary, Maty, Mindel, Nora, Nyasha, Racky, Shuan, Tamara, Tatiana, and Tigist. And I am 
grateful to Alejandro, Nasser, and Octave for being part of my Maastricht journey outside the Ph.D.

This dissertation is the culmination of a long education adventure, which has been filled with many wonderful people. Babsi, Belli, Dani and Lena, our life might have taken very different directions since our school days, but I am incredibly grateful that you are still part of mine. Going abroad in high school probably has been one of the most formative experiences of my life. I will forever be grateful to the Pettigrews and Cases who took me into their family and made me one of their own. You truly shaped where I am today. Lauren, Heather, and Marissa, our friendship has overcome many miles and years, and I wouldn't want to miss it.

My first university adventures took me to Passau, where I met many friends who have supported me throughout the years. "The Gang" and especially Jutta and Meli, you made me feel right at home and showed me the ropes of being a university student. Caro and Kathi, no matter how far you are, your friendship means the world to me. The Passau crew, Marius, Kathrin, Caro, Inga, Jana, Julian, Martha, Matze, Michi, Sebi, and Wetze, who took 'study hard and party harder' to a whole new level and showed that helping each other is the best way to succeed. For my Masters, I moved to icy Upstate New York and was blessed to meet many friends to keep my heart warm. Kim and Derek, Sarah, Holly, Jac, Zhenia, Jorge, Ploy, Andy, Ayse, Becky and Stef you will always be the Syracuse family.

Most importantly this thesis would not have been possible without my family. I want to thank my Godmother, Insea for always cheering me on, building me up and being one of the strong female role models I was lucky enough to have. My father, who would have been proud to see this journey come to an end. Thank you for making me fiercely political, teaching me to be analytical and critical and always encouraging me to venture into the unknown. To my mother, there are no words to express my gratitude for your support throughout this journey. Thank you for teaching me leadership and empathy, always encouraging me to be curious and reaching out to those that need a helping hand. Thank you for being my biggest cheerleader, my staunchest ally and the best role model I could have over the years. And my final thank you goes to Iman whose love, support and patience made it all worthwhile. 


\section{Table of Contents}

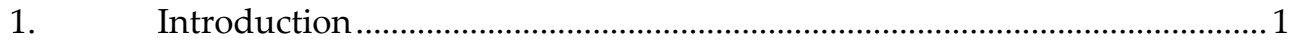

1.1. The male as the norm in corruption research …………............................ 1

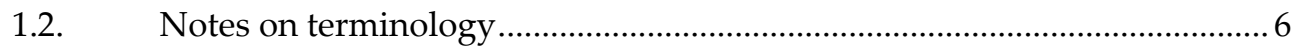

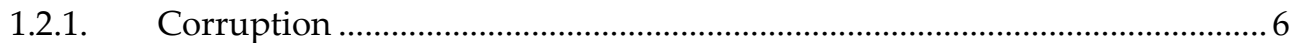

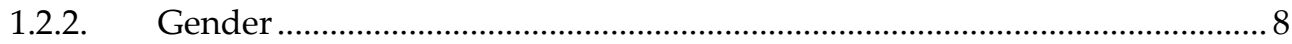

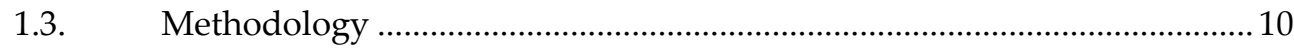

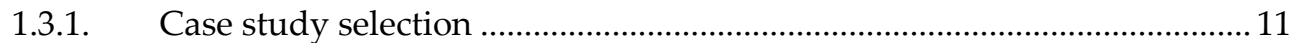

1.3.2. Ethical considerations and researcher positionality.................................... 13

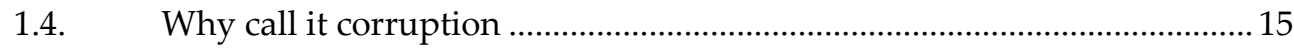

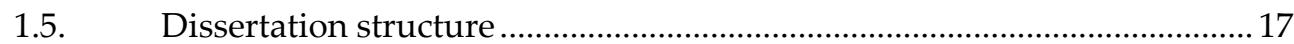

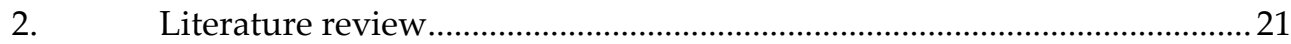

2.1. Gender and corruption - is there a link? .................................................. 21

2.2. Are women less corrupt than men?

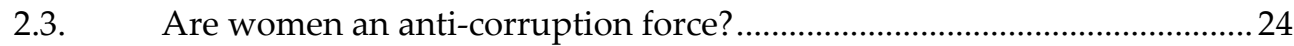

2.4. How are men and women differently affected by corruption.....................25

2.4.1. Gendered effects of corruption - economic security ....................................2 28

2.4.2. Gendered effects of corruption - political security ……………………........33

2.4.3. Gendered effects of corruption - personal security ...................................... 38

2.4.4. Gendered effects of corruption - community security ………………….... 43

2.4.5. Gendered effects of corruption - environmental security............................ 44

2.4.6. Gendered effects of corruption - food security .......................................... 46

2.4.7. Gendered effects of corruption - health security ………………………...... 47

2.5. Gendered effects of corruption - a framework ........................................... 49

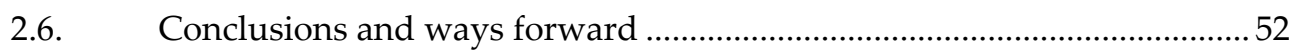

3. The abuse of power as a gendered concept: the case of sextortion............53

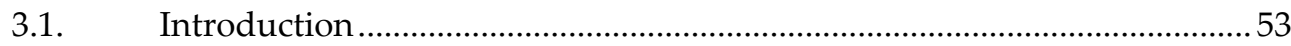




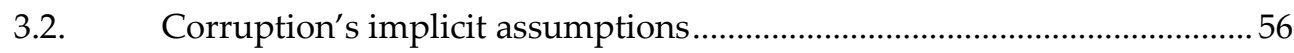

3.3. Corruption and power structures - a black box ………………………......... 58

3.3.1. Power, patriarchy, and corruption, bridging the gaps in the literature ... 59

3.3.2. Misrecognition reinforces power structures ................................................. 62

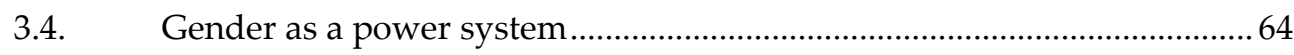

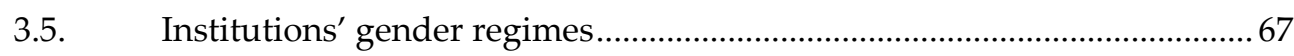

3.6. Sextortion as a gendered form of corruption ............................................... 69

3.6.1. Sextortion is the expression of gender and power relations ........................ 72

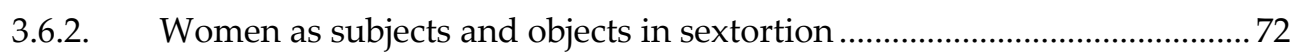

3.6.3. Violence against women as a product of hegemonic masculinity ……...... 74

3.7. Language as a reinforcement of stereotypes ............................................... 76

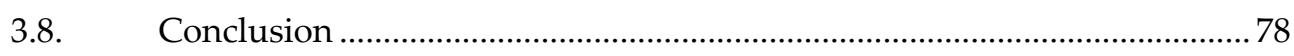

4. It is all about power - corruption, patriarchy and the political

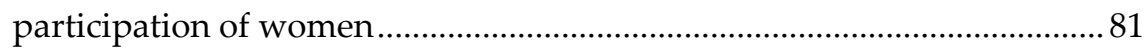

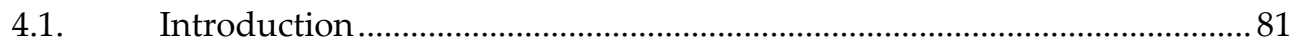

4.2. Corruption and patriarchy as asymmetric power relations........................ 83

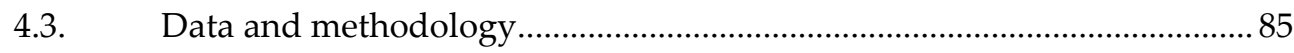

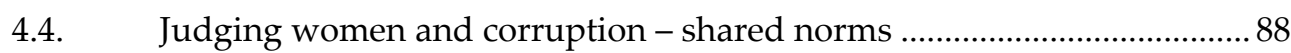

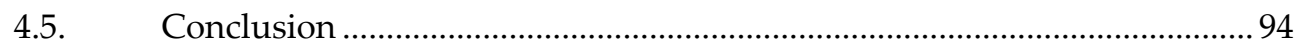

5. Dainty women - dirty politics: the role of sexism in political

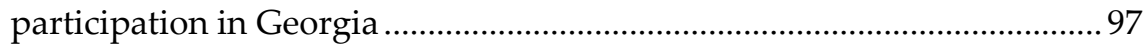

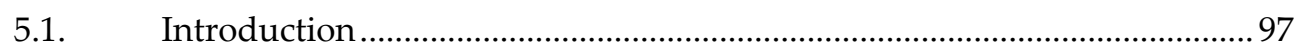

5.2. Georgia - clientelism is alive and well...................................................... 101

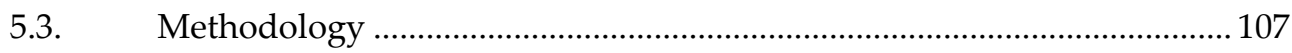

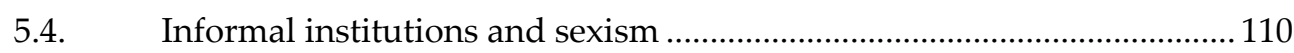

5.5. Political parties in Georgia - informal rules................................................ 113

5.6. Women are just not made for this - the role of sexism

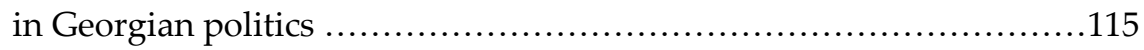

5.7. Stick with what you know - limited space for participation of women 119 


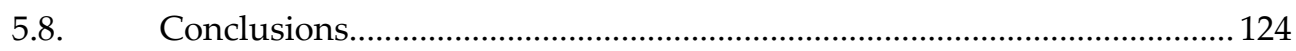

6. How female migrants pay a heavy toll: experiences of corruption ........ 127

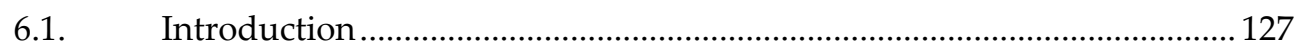

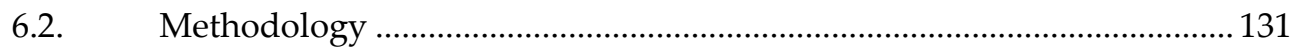

6.3. Experiences of corruption during migration ......................................... 133

6.3.1. Shaping the migration path- corruption in the home country ………..... 135

6.3.2. Facilitator and hindrance - corruption throughout the

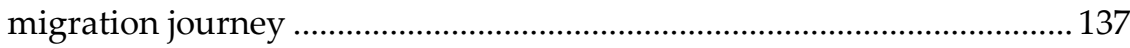

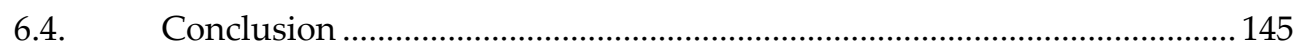

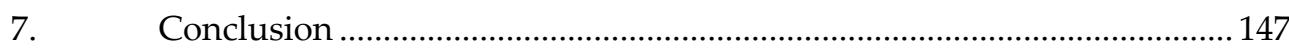

7.1. The myth of gender-neutral power - what did we learn? ....................... 147

7.2. Corruption researchers - we need to talk patriarchy ………………........ 149

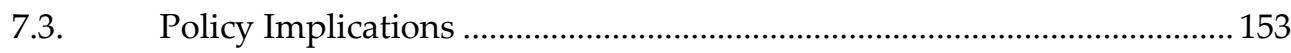

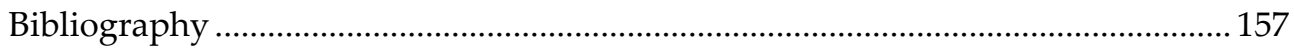

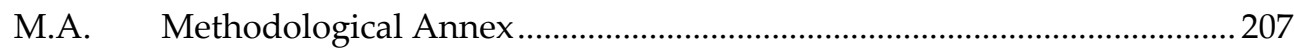

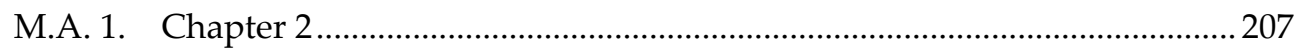

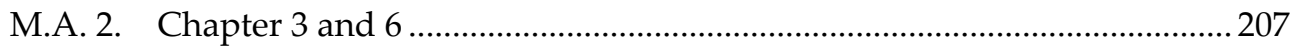

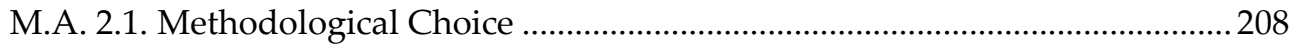

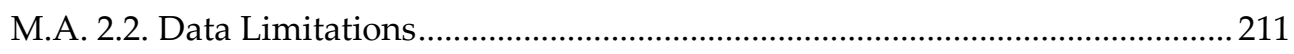

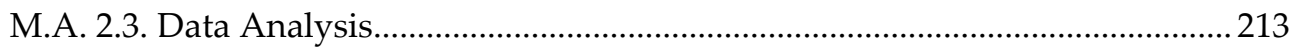

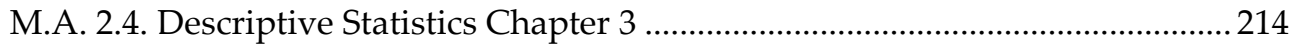

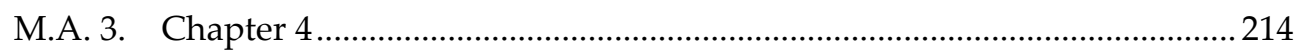

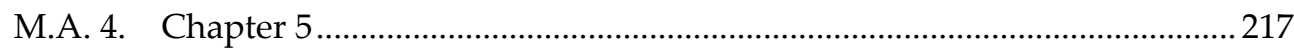

M.A. 4.1. Interview respondents (extended information) ......................................... 218

M.A. 4.2. Data analysis and limitations ………………………………………..... 220

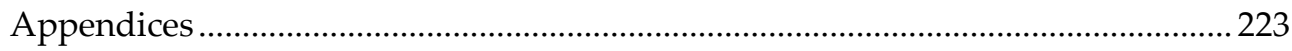

A. Overview over human security dimensions ......................................................... 223

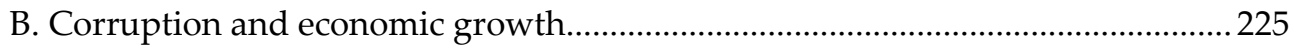

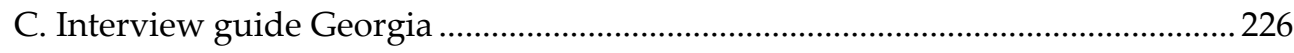


D. Overview expert interviews.

E. Interview guide corruption as a push factor for migration.................................. 232

F. Interview guide gendered experiences of corruption ...........................................235

\section{List of Tables}

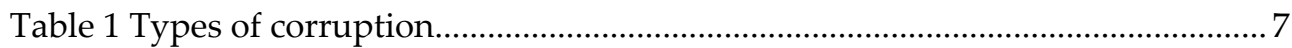

Table 2 Overview empirical dissertation chapters .................................................... 10

Table 3 Participation of women and corruption............................................................ 86

Table 4 Relationship between attitude towards women as political leaders

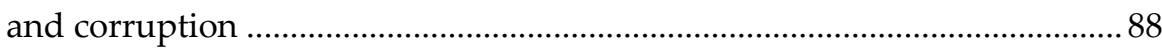

Table 5 Percentage of women in parliament since independence ............................ 105

Table 6 Members of the parliament of Georgia by factions 2014 ……..................... 106

Table 7 Composition of the government of Georgia December 2014 …………....... 106

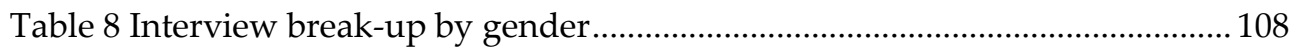

Table 9 Gender and country of origin of migrants interviewed ............................. 132

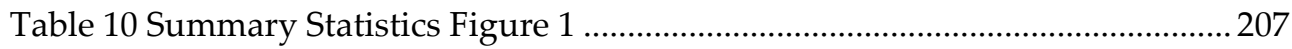

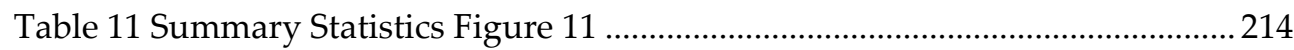

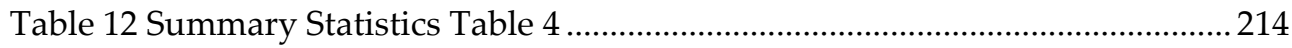

Table 13 The seven components of human security and its threats as defined by

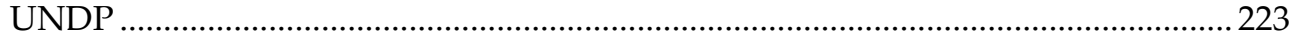

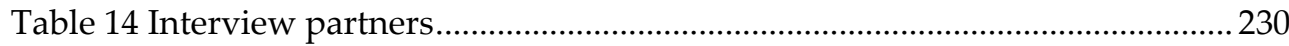

\section{List of Figures}

Figure 1 Gender inequality and control of corruption ............................................. 22

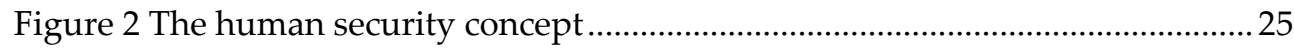

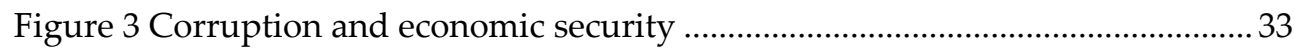

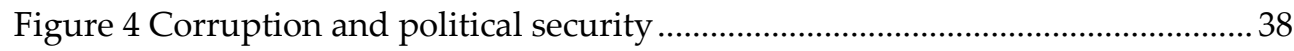

Figure 5 Corruption and personal security …………............................................ 42

Figure 6 Corruption and community security ………….......................................... 44

Figure 7 Corruption and environmental security …………...................................... 45

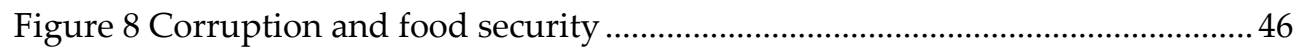

Figure 9 Corruption and health security ……………............................................... 48

Figure 10 Gendered effects of corruption............................................................... 50

Figure 11 Corruption and the gender security index.................................................5 55

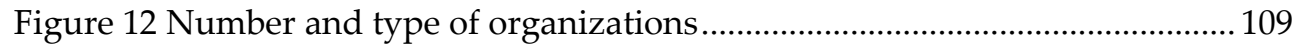

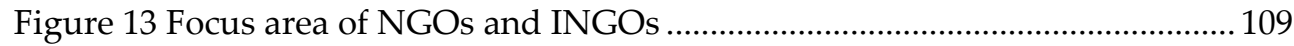

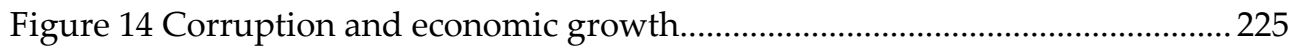




\section{Introduction}

'[P]atriarchy' is not merely a colourful term used by feminists to rebuke men. It is not a thing of bygone days, nor a rhetorical flourish. It is an important dimension of the structures of modern societies, whether capitalist or state socialist. It is a living reality, a system that quite observably shapes the life and differentiates the chances of women and of men.

(Cockburn, 1991, p. 18)

\subsection{The male as the norm in corruption research}

The release of the Panama Papers rocked the world in 2015, and journalists, academics, and watchdogs were toiling to analyze the magnitude of tax evasion and corruption presented in these documents. Large-scale corruption once again made international headlines throughout the world. The Panama Papers might have brought about a new rise in attention to the issue, but it has been long known that corruption is not a small-scale problem. The measurements that are available show the dramatic impact corruption has on people and the economy of countries. According to the most recent Bribery Barometer, in 2015 an estimated 75 million people have paid bribes in Sub-Saharan Africa (Pring, 2015), one in three people in the Middle East and North Africa have paid a bribe to receive access to basic services (Pring, 2016a), and one in three citizens in Europe and Central Asia consider corruption as their country's biggest challenge (Pring, 2016b). According to a study by UNODC and the World Bank (2007) \$20-\$40 billion per year are estimated to be spent on bribes to public officials in developing and transition economies. This is equal to $20-40 \%$ of Official Development Assistance (ODA), and this figure is likely to have increased significantly in the intervening ten years since the study was published. Another study by the Center of Strategic and International Studies estimates that in 105 developing countries (representing 22\% of Global GDP) private sector corruption costs over \$500 billion in 2012 (Hameed \& Magpile, 2014, p. 3). Even though measurements of corruption can be critiqued, for several reasons; for example, the question must be raised how one can measure an 


\section{Introduction}

act that often takes place in hiding or, what people report exactly when they are asked about bribe payments as is the case in the Barometer data. However, while the exact scale of the problem might be difficult to determine, there is agreement among academics, policymakers, governments and international organizations that corruption is detrimental to development efforts all around the world and harms especially the poorest (e.g., Gupta, Davoodi, \& Alonso-Terme, 2002). The importance of fighting corruption to foster development is also reflected in the Sustainable Development Goals (SDG 16) which call for a substantial reduction in corruption and bribery in all their forms (SDG 16.5).

Over the last 25 years, the fight against corruption has risen to the top of the agenda for many state and non-state actors and research on the causes and consequences of corruption have increased drastically. However, somewhat surprisingly there are still topics within corruption research that have received surprisingly little coverage. Looking back at the Panama Papers, one interesting aspect that the Panama Papers revealed only attracted attention in a small segment of the media - the gender disparity in those who benefit from this large-scale corruption and tax evasion. ${ }^{1}$ While some powerful women have been named by the Papers, the vast majority of tax evaders were rich, powerful men. ${ }^{2}$

What this shows quite illustratively is that benefits and burdens of corruption are unequally divided when one talks about corruption, not only between rich and poor but also between men and women. ${ }^{3}$ Corruption is fundamentally one about power and as this dissertation will argue in more detail power, despite what many believe, is not gender neutral. As this dissertation will show, corruption cannot be understood in a gender vacuum but rather, must include a thorough discussion of how the gendered nature of power does shape acts of corruption and their consequences.

The significance of gender in corruption research is not new and has been recognized as early as 2001 in two seminal papers (Dollar, Fisman, \& Gatti, 2001;

\footnotetext{
${ }^{1}$ This has been discussed by news outlets analyzing the papers (e.g. Capraro \& Rhodes, 2016) but not yet academic literature.

${ }^{2}$ For information on the power players in the Panama Papers see the International Consortium of Investigative Journalists https://www.icij.org/investigations/panama-papers/the-power-players/ (last accessed 27.07.2018).

${ }^{3}$ Corruption diverts money that should be used for public spending in for example health care. It is often women who have to compensate for the gap in public spending, and often through unpaid work E.g. women worldwide still are responsible for the majority of unpaid care work which also has long term consequences on their economic stability (e.g. Ferrant, Pesando, \& Nowacka, 2014).
} 
Swamy, Knack, Lee, \& Azfar, 2001). Current explorations on the topic are largely centered around three major questions (Wängnerud, 2014): Are women less corrupt than men? How does corruption affect men and women differently? And how do women help in the fight against corruption?

However, the existing research, in large parts concentrates solely on women rather than on gender as such, i.e., socially constructed roles, activities, attributes, behavior's, personality traits, relationships, power and influence that a society conceptually attributes to men and women (Prince, 2005). However, to understand how power is gendered within a society and how this influences corruption, the focus needs to be expanded.

Therefore, this dissertation builds on the existing discussions by studying how patriarchic structures, are shaping forms, patterns, and consequences of corruption. Feminist research has long discussed the gendered aspect of who has power and has coined the term patriarchy to name the system of male domination and female subordination. Patriarchy here needs to be understood as a social arrangement that ideologically and structurally gives power to men as a group over women" (Hapke, 2013, p. 12; Hunnicutt, 2009; Walby, 1990). Importantly, despite its sometimes-bad reputation patriarchy is not a simplistic concept of "bad" men having power over "poor" women, on the contrary, it is a complex system of power relationships. Within this power system the amounts of power that men and women have vary widely, this includes powerful women having power over less powerful men and certain men being dominated by other men (Hunnicutt, 2009, p. 565). Patriarchy should also not be seen as a static system, but rather as a dynamic, constantly evolving system of ideas and relationships.(Enloe, 2017 , p. 16). This requires constant investigation, of which this dissertation presents one.

Importantly it focuses on social arrangements and social systems that reinforce domination and rather than looking at individual men's motivation to dominate takes a look at societal structures (Hunnicutt, 2009). This is also helpful in corruption research, where, while important to understand, it is not enough to look at individuals' propensity to be corrupt, but one needs to understand the structural factors allowing for corruption to occur. This is not a new idea, research has shown multiple structural factors that play a role ${ }^{4}$, e.g., ethnic diversity can lead to increases in corruption (e.g., Treisman, 2000), globalization has been discussed as a

\footnotetext{
${ }^{4}$ For an overview of the most current debate see Dimant and Tosato (2018).
} 


\section{Introduction}

structural factor in corruption, even though the direction of the effect is still debated (e.g. Charron, 2009; Lalountas, Manolas, \& Vavouras, 2011). One factor that has been almost entirely neglected in the discussions, however are power dynamics.

Therefore, one of the major questions this dissertation raises is related to the concept of power. While different definitions of corruption use different terminology to define the position that is abused for a corrupt act, e.g., holder of a public office (Kurer, 2005; Treisman, 2000) or authority (Norad, 2012), all definitions of corruption include the understanding that a corrupt act involves the abuse of some form of power (Philp, 2016). This element has been studied very little until now in the corruption literature. Even more importantly, the majority of discussions has not given any attention to the question of how power itself is gendered and therefore, its abuse is as well. This dissertation shows that it is not enough to talk about the type of power (e.g., bureaucratic or political) but that a true understanding of corruption needs a deeper understanding of how power is structured within society. Especially in the context of the relationship of gender and corruption one needs to understand that power itself is a gendered phenomenon and the gendered effects of corruption cannot be discussed without understanding that corruption itself is a gendered phenomenon. This dissertation, therefore, analyses how corruption and patriarchy are related and mutually reinforcing.

Patriarchy is a concept that has been widely debated and even been declared obsolete. This dissertation, however, follows the scholars that argue that patriarchy still is an important and useful analytical concept. As Pateman (1988, p. 20) discusses:

Some have argued that the problems with the concept are so great that it should be abandoned. To follow such a course would mean that, to the best of my knowledge, feminist political theory would then be without the only concept that refers specifically to the subjection of women, that singles out the form of political right that all men experience by virtue of being men. If the problem has no name, patriarchy can all too easily slide back the back into obscurity beneath the conventional categories of political analysis. 
Most corruption research to date relies on a seemingly gender-neutral ${ }^{5}$ understanding of power, which is what this dissertation sets out to challenge. Hence, it is essential for the discussion to rely on a concept that moves away from the gender-neutral terminology and names men as the structurally dominant and powerful group. Just because a gender-neutral term is used, does not mean that it is indeed a gender-neutral concept. Often, gender-neutral rather represents the male norm and distracts from the scrutiny of this understanding.

As Simone de Beauvoir (2010) discussed, the male is traditionally considered both as the positive and the neutral, which leaves the women as the "other". This is something that can also be seen in discussions on corruption. Like many other areas, research on corruption often still considers men as the norm and women as a deviation from that norm and neglects to examine this norm itself closely. At the same time, women have been idolized as less corrupt and more honest. This myth of inherently less corrupt women, as will also be discussed in more detail later, leads to the reinforcement of gender stereotypes (UNDP, 2012). One can see that "[t]he very traits that traditionally branded women as deficient in moral development, their concern to help and to please, are now seen as a functional for good governance reforms in developing and transitional societies" (Goetz, 2007, p. 91). Hazarika (2016) continues this argument and notes that "traits ascribed to women once viewed as making for moral weakness are now seen as cornerstones of moral strength, that is, the definition of morality has changed. It may make little sense to consider women morally superior if notions of morality are mutable. Perhaps it is more useful to speak of honesty than morality" (p.8). What needs to be understood, however, is that even the question if women are more honest is one of gender stereotypes and seems to be missing an essential point by focusing on a seemingly gender-neutral concept of power.

Therefore, the discussions in this dissertation focus on gendered power by analyzing the role of patriarchy in shaping gendered forms (chapter 3) and experiences (chapter 6) of corruption as well as discussing how patriarchal views on women and corruption are interlinked (chapter 4 ) and patriarchal gender roles are utilized to exclude women from clientelistic networks (chapter5). Presenting different angles that show the importance of including a discussion of gendered power in research on corruption.

\footnotetext{
${ }^{5}$ It is important to note that the view on power that most corruption researchers seem to have is not only gender neutral but in general it is considered a neutral concept that does not require more in-depth discussion.
} 


\section{Introduction}

As a caveat, this dissertation explicitly refers to the role of women and men and does not follow the frequent use of "women and children/girls" as "[w]omen and children are not synonymous, they do not share the same needs, rights or agency, and they do not require the same protections. Combining the two in such fashion risks infantilizing women and failing to afford children the recognition they need, both as children and as gendered beings"(Turner, 2016, p. 195).

\subsection{Notes on terminology}

\subsubsection{Corruption}

Corruption is a complex and multi-layered phenomenon, which is usually defined as "the misuse of public office for private gain" (e.g., Treisman, 2000). While this dissertation follows this definition, there are several issues that the researcher has to keep in mind. The first question, which is raised repeatedly, especially when discussing corruption in non-Western societies, is whose standards and morals apply to this definition.

The countries researched in this dissertation are not only in different parts of the world and different stages of development, there is also a vast array of local and international non-governmental organizations (NGOs) and international organizations working in the countries, whose perceptions of what is corruption and what are legitimate acts will often differ significantly from those of the local population (Cheng \& Zaum, 2008). Also, many times there is not even a consensus among the local population of what defines the duties of public office (Philp, 2008). All this leads to potential problems with survey and interview results (Johnsøn \& Mason, 2013), especially when comparing across different countries and populations. This has to be kept in mind when analyzing the results of the dissertation. This issue has been taken into consideration in the data collection by including questions about how interview partners themselves define, conceptualize and experience corruption.

A further problem is that definitions of corruption (as do most indices) often consider corruption equivalent to the issue of bribery (and extortion) but do not include other issues such as nepotism, patronage, official theft, fraud, and conflict of interests problems and focus on bureaucratic corruption over political corruption (Johnston, 2005). To understand the gendered effects and forms of corruption one cannot limit the research to such a narrow understanding of the definition. Therefore, this dissertation adheres to a wide definition of corruption including different types. In this context, it is important to note that the reward for 
corruption, i.e., the 'personal gain' does not have to be monetary (Bayley, 1966) it can also include for instance benefits for group members or political parties, or as will be discussed in the later chapters, sexual favors. Hence, the discussions in this dissertation include traditional concepts such as bribery and nepotism but also more recently discovered phenomenon such as sexual extortion ('sextortion') (Transparency International, 2016b) which women face frequently. For an overview of different forms of corruption see Table 1. A further distinction is the question of political (grand) and bureaucratic corruption. Political corruption involves the highest political decision makers, and bureaucratic corruption involves the policy implementation level (Andvig, Fjeldstad, Amundsen, Søreide, \& Sissener, 2000). This differentiation is important not only for the understanding of linkages but also for the possibility of measuring corrupt acts. What differentiates this dissertation from many other studies is its comprehensive approach to corruption. Chapters 3 and 6 focus more on bureaucratic corruption, chapters 2 and 5 explore political corruption. Additionally, chapters 3 and 6 examine an understudied gendered form of corruption, sextortion.

Table 1 Types of corruption

\begin{tabular}{|c|c|c|}
\hline Type of Corruption & Definition & Group of Terms \\
\hline Bribery & $\begin{array}{l}\text { Payment (in money or kind) } \\
\text { that is given or taken in a } \\
\text { corrupt relationship }\end{array}$ & $\begin{array}{l}\text { Kickbacks, gratuities, } \\
\text { "commercial arrangements, } \\
\text { baksheesh, sweeteners, pay-offs, } \\
\text { speed- or grease money }\end{array}$ \\
\hline Embezzlement & $\begin{array}{l}\text { Theft of resources by people } \\
\text { who are put to administer it }\end{array}$ & Straddling, official theft \\
\hline Fraud & $\begin{array}{l}\text { Economic crime that } \\
\text { involves some kind of } \\
\text { trickery, swindle or deceit }\end{array}$ & $\begin{array}{l}\text { Involvement in illegal trade } \\
\text { networks, counterfeit, racketing, } \\
\text { forgery, smuggling }\end{array}$ \\
\hline Extortion & $\begin{array}{l}\text { Money and other resources } \\
\text { extracted by the use of } \\
\text { coercion, violence or the } \\
\text { threats to use force }\end{array}$ & \begin{tabular}{llr} 
Blackmail, & \multicolumn{2}{c}{ protection or } \\
security & money, informal \\
taxation, & sextortion & (sexual \\
extortion) & & \\
\end{tabular} \\
\hline Favoritism & $\begin{array}{l}\text { Mechanism of power abuse } \\
\text { implying 'privatization' and } \\
\text { a highly biased distribution } \\
\text { of state resources. }\end{array}$ & $\begin{array}{l}\text { Cronyism, nepotism, } \\
\text { clientelism, bias, patronage }\end{array}$ \\
\hline
\end{tabular}

Source: adapted from Andvig et al. (2001, p. 8ff) 


\section{Introduction}

In corruption research, there is an ongoing discussion on how to measure something that often takes place in hiding. Different, arguably more objective measures of corruption have been used, for example, corruption conviction rates (e.g., Fiorino, Galli, \& Petrarca, 2012; Hill, 2003) or press reports on corruption (e.g., Rehren, 1996). These measures have not become very popular as they are mostly unsystematic and therefore create great validity and reliability problems (Morris, 2008, p. 390). The most commonly used measures are still subjective measures such as the perceived level of corruption, which is usually assessed by foreign experts (Svensson, 2003) (for instance the Corruption Perception Index by Transparency International), or measures of corruption participation (Morris, 2008, p. 390). The advantages and deficits of different measurements of corruption data have been thoroughly discussed in the literature (e.g., Kis-Katos \& Schulze, 2013; Sequeira, 2012), but no consensus on the optimal measurement has been reached. The most important message seems to be that researchers need to be aware of the shortcomings of the measurement they are using and aspire for a coherent measurement. Authors using corruption data should point out the shortcomings of the data, yet as Blackburn et al. (2010, p. 5) argue since all the major indices not only show a high correlation with each other but also with the key economic variables the existing measures can be considered reliable. To test the relationship between corruption and gender, due to a lack of other available data this dissertation will focus on people's perception of corruption and their views of corrupt acts. ${ }^{6}$

\subsubsection{Gender}

Gender refers to the socially constructed roles, activities, attributes, behaviors, personality traits, relationships, power and influence that a society conceptually attributes to men and women. While sex refers to the biological differences between men and women in sexual and reproductive functions, gender refers to the differences in roles and opportunities associated with being male or female as well as the relationships between women and men (Prince, 2005).

It is important to note that "[t]hese attributes, opportunities and relationships are socially constructed and are learned through socialization processes. They are context/ time-specific and changeable. Gender determines what is expected, allowed and

\footnotetext{
${ }^{6}$ For detailed reviews of the literature on corruption refer to Andvig, Fjieldstad, Amundsen, Søreide \& Sissener (2001), Kis-Katos \& Schulze (2013) Lambsdorff \& Schulze (2015) and Olken \& Pande (2012).
} 
valued in a woman or a man in a given context. In most societies there are differences and inequalities between women and men in responsibilities assigned, activities undertaken, access to and control over resources, as well as decision-making opportunities" (UN WOMEN Training Center, 2017, sec. 1).

Gender, however, goes beyond identity and learned gender roles, it is rather a social phenomenon where social relations of inequality are organized by the social practice of categorizing people as men and women (Ridgeway \& Correll, 2004, p. 510). Gender hence is an institutionalized "multilevel system of differences and disadvantages that includes socioeconomic arrangements and widely held cultural beliefs at the macro level, ways of behaving in relation to others at the interactional level, and acquired traits and identities at the individual level" (Ridgeway, 1997, p. 219). Gender roles are also not fixed over time but like all social constructs are dynamic, where ideologies and practices change with economic, political and social changes and developments (Donato, Gabaccia, Holdaway, Manalansan, \& Pessar, 2006). Therefore, throughout this dissertation, it is essential that the experiences and roles of women cannot be studied in isolation but always have to be analyzed within this gender system of patriarchy.

Patriarchy here needs to be understood as a social arrangement that ideologically and structurally gives power to men as a group over women" (Hapke, 2013, p. 12; Hunnicutt, 2009; Walby, 1990). Hunnicutt (2009) identifies important conditions of patriarchy to understand in the context of this dissertation. Patriarchy is a dynamic system that is shaped by context specific factors and patriarchal structures also include discussions around how men relate to other men and not all men benefit from the patriarchal system at all times. Furthermore, "[a] theory of patriarchy must contend with the potential divergence of structure and ideology. Varieties of patriarchal ideology may exist apart from structural conditions. Patriarchal ideology may endure despite structural gains in gender equality." (Hunnicutt, 2009 , p. 555). Last but not least, patriarchy should be discussed with other systems of oppression by using, what Crenshaw (1989, 1990) coined 'intersectionality'. While this dissertation focuses on a first exploration of the role of patriarchy, i.e., gender as a system of oppression, further studies need to include more discussions around other systems of oppression such as race, class, ability and others. 


\section{Introduction}

\subsection{Methodology}

This dissertation contains four stand-alone empirical chapters, covering different aspects of the relationship between corruption and gender and using different methodological approaches. This section presents an overview of the methodologies utilized in the studies, case study selections and ethical considerations made in the fieldwork stages. Table 2 gives a short overview of the methods used and research questions for each chapter. Chapter 3, 5 and 6 are based on semi-structured interviews collected by the author, and chapter 4 utilizes quantitative data from the World Value Survey wave 6.

Table 2 Overview empirical dissertation chapters

\begin{tabular}{|c|c|c|c|c|}
\hline & Chapter 3 & Chapter 4 & Chapter 5 & Chapter 6 \\
\hline $\begin{array}{l}\text { Research } \\
\text { question }\end{array}$ & $\begin{array}{l}\text { How and why is } \\
\text { power a } \\
\text { gendered } \\
\text { phenomenon in } \\
\text { corruption } \\
\text { research? }\end{array}$ & $\begin{array}{l}\text { To what extent } \\
\text { are views on } \\
\text { the role of } \\
\text { women in } \\
\text { society linked } \\
\text { to corruption? }\end{array}$ & $\begin{array}{l}\text { How do } \\
\text { patriarchal } \\
\text { norms shape } \\
\text { women's access } \\
\text { to clientelistic } \\
\text { networks? }\end{array}$ & $\begin{array}{l}\text { How are } \\
\text { experiences of } \\
\text { corruption } \\
\text { gendered during } \\
\text { migration and to } \\
\text { what extent are } \\
\text { they influenced by } \\
\text { patriarchal } \\
\text { structures? }\end{array}$ \\
\hline $\begin{array}{l}\text { Corruption } \\
\text { Focus }\end{array}$ & $\begin{array}{l}\text { Forms of } \\
\text { corruption }\end{array}$ & $\begin{array}{l}\text { Patterns of } \\
\text { corruption }\end{array}$ & $\begin{array}{l}\text { Patterns of } \\
\text { corruption }\end{array}$ & $\begin{array}{l}\text { Consequences of } \\
\text { corruption }\end{array}$ \\
\hline $\begin{array}{l}\text { Regional } \\
\text { Focus }\end{array}$ & $\begin{array}{l}\text { General/ } \\
\text { Mediterranean } \\
\text { Route }\end{array}$ & $\begin{array}{l}\text { Rwanda, } \\
\text { South Africa, } \\
\text { Zimbabwe } \\
\text { Ghana, } \\
\text { Nigeria }\end{array}$ & Georgia & $\begin{array}{l}\text { Mediterranean } \\
\text { Route }\end{array}$ \\
\hline Data & $\begin{array}{l}\text { Semi-structured } \\
\text { interviews with } \\
\text { experts and } \\
\text { migrants }\end{array}$ & $\begin{array}{l}\text { World Value } \\
\text { Survey Wave } 6\end{array}$ & $\begin{array}{l}\text { Semi-structured } \\
\text { interviews with } \\
\text { political leaders, } \\
\text { civil society and } \\
\text { international } \\
\text { organizations }\end{array}$ & $\begin{array}{l}\text { Semi-structured } \\
\text { interviews with } \\
\text { experts and } \\
\text { migrants }\end{array}$ \\
\hline $\begin{array}{l}\text { Data } \\
\text { collection } \\
\text { period }\end{array}$ & $\begin{array}{l}\text { November 2016- } \\
\text { May } 2017\end{array}$ & $2010-2014$ & $\begin{array}{l}\text { July } 2014 \text {-May } \\
2015\end{array}$ & $\begin{array}{l}\text { November 2016- } \\
\text { May } 2017\end{array}$ \\
\hline
\end{tabular}




\subsubsection{Case study selection}

Corruption is a global phenomenon, and therefore it is useful to study it not only from different theoretical but also geographical perspectives. The chapters in this dissertation have three different geographic foci: The Mediterranean migration route from Sub-Saharan Africa to Europe (chapter 1 and 6), five Sub-Saharan African Countries (Chapter 4) and the country of Georgia (chapter 5).

Case study selection has been an iterative process. Importantly when choosing case studies, they need to be one the one hand a representative sample on the other hand there needs to be useful variation on the dimensions of theoretical interest (Seawright \& Gerring, 2008, p. 296). Cases were chosen for their diversity in the variables of interest (gender norms, corruption levels). This set of diverse cases is especially useful for exploratory studies that focus on a particular relationship of the variable of interests. Yet, this brings about the limitation of only being minimally representative in the "sense of representing the full variation of the population" (Seawright \& Gerring, 2008, p. 297). This dissertation is a collection of independent essays exploring the overall relationship between corruption and gender norms. All of the cases selected for this dissertation have a particular value to the study of corruption as they show very different features and therefore help to analyze the topic of this dissertation from different angles.

Chapter 3 utilizes data collected for a project on gendered experiences of corruption (chapter 6) and starts with a thorough discussion of the importance of including patriarchy in corruption research. The chapter focuses on a gendered form of corruption, the abuse of power to obtain a sexual favor, i.e., sextortion (IAWJ, 2012). The experiences of corruption during migration have shown to be a good case study for this. The difference of experiences between men and women has been especially stark, and so are the power imbalances. Hence, the interviews collected for chapter 6 have served as a vivid illustration of the importance of understanding gendered forms of corruption and including gendered power in the discussion.

Chapter 4 takes a closer look at Sub Saharan Africa to see how views on corruption and the view on the political participation of women are related. The region is especially interesting for a case study on this topic as it has a wide variety of corruption levels ranking from Botswana (34 of 180 in the Corruption Perception Index) to South Sudan and Somalia (ranking 179 and 180 respectively) (Transparency International, 2018). Similarly, the political participation of women varies widely, where Rwanda leads worldwide with over $61 \%$ of seats in 


\section{Introduction}

parliament being filled by women while Nigeria has barely $5.6 \%$ of female parliamentarians (Inter-Parliamentary Union, 2018b). This variation in corruption and political participation makes for an interesting analysis regarding the relationship of views on corruption and the participation of women.

Chapter 5 continues the discussion on the relationship between corruption and the political participation of women with a case study of Georgia. Georgia is frequently named as an example of the most dramatic and successful anticorruption reforms ever (Mungiu-Pippidi, 2016), at the same time political participation rates are extremely low (at about 16\% (Inter-Parliamentary Union, $2018 b)$. This makes it a case study to add to the ongoing discussion about the linkages of corruption and political participation of women and giving a different perspective on a potential relationship.

Last but not least, Chapter 6 moves the focus away from political corruption and takes a look at the real-life experiences of corruption of men and women adding to the very limited literature on this issue (e.g. Ellis, Manuel, \& Blackden, 2006; Justesen \& Bjørnskov, 2014; Leach, Dunne, \& Salvi, 2014). While most agree that experiences of corruption are gendered, there has been surprisingly little focus on understanding the differences in and, even more importantly, the underlying causes of these differences. Once migrants leave their home, they still have to frequently interact with state officials, from border guards to police to health care providers. However, unlike before all of these interactions are likely to take place outside their personal network for both men and women. Additionally, the vulnerability to corruption for all irregular migrants is increased by the lack of a clear legal status which does make them easier targets to exploitation but also requires them to use different means such as corruption to continue their journey. For example, when a legal border crossing is not possible because the migrant does not have the appropriate papers, corruption can be a way out. As male and female migrants both face an increased risk of corruption throughout this journey, this provides a good case study on how and if the experience of corruption is still gendered in this unusual situation and to highlight some of the factors that can lead to these differences. The chapter puts a particular focus on the role of patriarchal structures in shaping corruption experiences.

The fundamentally different case studies selected for this dissertation complement each other by showing how patriarchy and the understanding of the gendered nature of corruption play a role in all aspects of corruption research, both on the societal and individual level and across geographical areas. 


\subsubsection{Ethical considerations and researcher positionality}

Studying corruption across different geographical areas ethical considerations should always be included throughout the research process, from designing the research question to data collection, analysis and writing as each phase shows its specific ethical dilemmas (Creswell, 2007). One concern that has been raised continuously is that of a colonial/Western perspective on corruption ignoring realities in the context that are being discussed. Similarly to the danger of imposing external, largely Western liberal capitalist defined models of statehood (Zoellick, 2008) when discussing fragile states, as discussed above corruption research has often been accused of imposing a Western standard of morals and statehood on non-Western societies. (Lancaster \& Montinola, 2001). The research for this thesis is mitigating this risk by asking respondents on their definitions of corruption to cross-check the authors definitions (Chapter 3,5, and 6) and using data (the World Value Survey) that asked respondents for their views on corruption without including a definition, therefore allowing the respondents own definition to be reflected in the data. Triangulating findings with previous findings and including non-Western literature in the study also adds in this.

Researching the experiences of irregular migrant, especially in the context of (sexual) abuse requires a more detailed ethical discussion. The men and women interviewed for this research currently face a difficult political and legal status and "have often suffered serious physical, psychological and emotional trauma" (Leaning, 2001; Mackenzie, McDowell, \& Pittaway, 2007, p. 4) which makes their situation especially vulnerable. The migrants included in this study still are in a vulnerable position where their legal status is not yet determined, and families are often not aware of the circumstances of their trip. This latter is especially problematic for women traveling alone, who already travel with more pressure from families and who in the case of the Nigerian women have been threatened by a juju spell, threatening their families. Therefore, the interviews were conducted in collaboration with trusted non-governmental organizations working on migrant protection and used to the difficult situation of the migrants. Informed oral and written consent (depending on the preferences of the interview partner) was obtained, and questions were phrased in a way to allow for the interview partner to decide how much information he or she wants to give on his or her experiences. Interviewees were reminded that they could stop the interview at any time and information on organizations that could help in the location was provided wherever possible. The ethical concerns for this research go hand in hand with researcher positionality. The power discrepancies between the researcher and the 


\section{Introduction}

migrant interviewee had to be considered. For one it had to be made clear to all parties involved that the interviewer could not influence the current situation of the migrant (neither good nor bad) and that no state organization or NGO would be informed about anything that had been discussed. Additionally, no compensation was paid to the interview partners which also was communicated early on. All this information was given to the partnering NGOs to communicate to potential interview partners and was repeated at the beginning of the interview. At the same time, the power discrepancies might have led to some interview partners feeling obliged to answer questions. Best efforts were taken to reassure the interview partner that he or she did not have to answer questions. Additionally, the questions were framed accordingly and no follow up questions were asked about (potential) abuse. The research also underwent ethical review by Maastricht University. Due to the insecure situation of the population of interest in their current country and the extremely sensitive topic of (sexual) abuse, the number of migrants interviewed remained very limited. The project, instead, focused in large parts on expert, including psychologists and NGOs working with refugees and migrants who were able to give an overview of the situation and avoided that migrants were asked to recount dramatic experiences.

The data collection in Georgia also required ethical considerations. Where the political landscape is deeply divided, and corruption is a frequently used method to discredit the political opposition the research had to take great care that no information about specific interviews was given to other interview partners (NGO or political activists) and many interview partners requested that their participation would not be revealed at all. To ensure that no interview partners are revealed the researcher decided to exclude names and other identifying information from the analysis.

Researcher positionality also played an important role in the data collection in Georgia. Being a young, female, western researcher strongly influenced the interview partners perception of the interviewer and the seriousness of the interview itself. At the early stages of the interviews, as they were carried out in Tbilisi where people are not only used to foreign researchers but also have expectations of how one should interact with these internationals, socially desired responses had to be expected. To mitigate this potential problem, the interview guide included many follow up questions and tried to discuss issues from different angles as to get to the opinion of the interview partner rather than hearing what is the 'expected answer'. For most interview partners the differentiation between what they thought the interviewer wanted to hear and what seemed to be their 
actual opinion became clear rather quickly, even though for different reasons. After each interview notes were taken on not just the interview but also how the interview partner reacted to the interviewer, apparent personal connections or dislikes and anything else that was noticeable. As personality also has been shown to have an influence on the interview process (Moser, 2008) these notes were used to reflect on potential biases concerning that.

Civil Society in Georgia is largely dominated by young, educated women who connected quickly with a young female interviewer and therefore opened up about their opinions quickly. In these instances, it was especially important for the interviewer to keep professional neutrality despite an apparent closeness with the interview partner. For many male (often older) interview partner the age and gender had a different effect. It became quickly apparent that they often took the researcher less serious which lead to a relatively quick transition from socially desirable answers to 'real opinion'. This shows the importance of considering not only gender but also age in the researcher positionality discussion (Tarrant, 2014) To avoid interviewer bias for either interview group, the data was triangulated as much as possible with publications of other researchers and organizations.

The highly politicized situation in Georgia makes it important to carefully choose both gatekeepers and a translator. While the research does not deal with interview partners who are classically considered a vulnerable population, the political tensions in the country warrants for caution. To avoid being affiliated with a political direction, no translator was used, but interviews were conducted one on one. In addition, the research took special care to include different gatekeepers with different political backgrounds. Still, being recommended by a specific person often brought about assumptions about who the researcher is affiliated with, which had to be discussed at the beginning of the interview. This was focused on in the informed consent discussion at the beginning of each interview.

\subsection{Why call it corruption}

Arguably, not all the abuses of powers should be discussed under the umbrella of corruption. One could argue that framing the issues presented in this dissertation in this way might actually have a negative effect by normalizing them and minimizing their importance. The discussions of corruption already suffer from many misunderstandings and including gendered abuses of power easily can 


\section{Introduction}

divert from the real issue. ${ }^{7}$ This calls for a fundamental rethinking of our approach to corruption research as a whole. However, as long as the main narrative within academia and the policy world is moving towards a greater focus on women and corruption, including focusing on sextortion as a form of corruption, and the role of women as an anti-corruption force, it is necessary to challenge the narrative within the corruption discourse.

This is where one of the main contributions of this Ph.D. dissertation lies. It is the at first glance simple, but important fact that narratives matter. As Pitkin (1967, p. 1) discusses: "Since human beings are not merely political animals but also language-using animals, their behavior is shaped by their ideas. What they do and how they do it depends upon how they see themselves and their world, and this in turn depends upon the concepts through which they see." This surely is not a new argument within either the academic or the policy world, yet it has often been neglected in discussions around corruption and especially in those around corruption and gender. This dissertation shows for multiple areas how important it is to reconsider concepts, discuss language that is being used and reexamine arguments used in anti-corruption initiatives. This conversation needs to first and foremost be led within the corruption. This is the only way challenges to existing concepts can be carried forward.

The research in this book is consistently challenging the existing narrative around gender and corruption. Unfortunately, the research on the relationship to this date largely centers around two extreme views of women. On the one hand the helpless female victims of corruption on the other, in large parts due to two seminal studies published by the World Bank, the myth of women as incorruptible heroes. As this thesis discusses, these views do not only limit our understanding of corruption they are also extremely harmful to any efforts of achieving gender equality, for example by reducing the importance of achieving gender equality in political participation to the potential of women as corruption fighters, rather than a question of equality and human rights.

Previous research (e.g., Goetz, 2007) has discussed that focusing on women as the anti-corruption force might, in the long run, threaten the political participation of women. If the need for women in parliament is based on their non-corrupt nature, any instance of corruption involving a female parliamentarian can be expected to lead to a large backlash against women in parliament overall. Chapter 5 adds to

\footnotetext{
7 Thank you to Prof. Michael Johnston for raising this important question.
} 
this discussion by focusing on the narrative that is often used by anti-corruption and women's rights activist. This chapter shows how the seemingly positive argument of "women are the better, cleaner (i.e., less corrupt) sex and should, therefore, be more involved in politics" is used to limit the space for women who are in politics to supposedly 'feminine' political areas. Simultaneously, the same argumentation is used to exclude women from politics from the onset, as those women who are truly clean, should not get mixed up in "dirty politics". This finding is of fundamental importance for anti-corruption and women's organizations worldwide who need to rethink how the current narrative they use might hurt their goals in the long run.

The research that is presented in this dissertation argues that women per se are neither saviors nor victims, but rather, men and women are part of an intricate system of gender norms, i.e., patriarchy, that shape opportunity and limitations for both. Importantly, a patriarchal system neither oppresses all women equally nor does it empower all men equally and at all times. While there are women who are "foot soldiers of the patriarchy", i.e., who actively participate in upholding the patriarchal system and often benefit from it, men also are oppressed by the system. By defining gender roles for both men and women, and determining what is acceptable for either, the space for all is limited. As the discussion in this dissertation shows, to truly understand the relationship between gender and corruption, research and discussions on corruption need to move away from looking only at men or women but rather at gender and underlying gender norms. The thesis argues that gender should not merely be a variable that is included in the research or policy agenda but that the prism through which one looks at corruption needs to be changed. Taking a true gender focus does indeed fundamentally alter our understanding of corruption and the societal structures that enable it and forces academics and policymakers to rethink definitions and concepts.

\subsection{Dissertation structure}

The four stand-alone chapters in this dissertation show multiple ways in which gender norms and corruption are related. The chapters discuss how the gendered nature of power impacts the shaping of the corrupt act itself (Chapter 3), how corruption is viewed (Chapter 4 ), how it benefits or limits a certain group, in this case, women to access clientelistic networks (Chapter 5) and last but not least, how it shapes how corruption is experienced (Chapter 5). 


\section{Introduction}

Following the introduction, Chapter 2 reviews the literature on corruption and gender. The chapter shows the current state of the academic debate centered around three main questions: a) are women inherently less corrupt b) are they a new anti-corruption force c) how are women and men differently affected by corruption? The introduction also maps how each of the empirical chapters of the dissertation adds to the existing literature. As the literature on the latter is still extremely scarce, the chapter provides an initial framework on the potential pathways through which the effects of corruption can be gendered. Using the seven human security dimensions the ways in which corruption can endanger an individual's human security are mapped. This is intended as an overview and a roadmap to future research. The chapter does not only present the present state of the literature but also how the four empirical chapters of this dissertation contribute to different aspects of the ongoing debate.

Having identified the gaps in understanding gendered power in the context of corruption, Chapter 3 takes a closer theoretical look at why the abuse of power that is corruption cannot be seen as a gender-neutral phenomenon. Analyzing a form of corruption that disproportionally affects women - sextortion- the paper uses literature on gender-based violence to link patriarchic structures and corruption. This chapter concludes that power itself is not gender neutral and hence its abuse cannot be either. Therefore, the chapter advocates that patriarchy and corruption are closely linked and should be studied in more detail.

Building on this conclusion, chapter 4 then takes a look at the relationship between views on corruption and the participation of women in politics. Arguing that the opinion that men are better politicians than women is a representation of underlying patriarchal structures, the chapter further explores the relationship between patriarchy and corruption. Using data from the World Value Survey the paper expands the literature by showing that a positive view on corruption and a negative view on the political participation of women are related which supports the argument that both are manifestations of an underlying patriarchal system.

Chapter 5 continues the discussion on the political participation of women and corruption but shifts the angle. While the discussion around gender and corruption frequently goes around the potential role of female politicians in the fight against corruption, this chapter adds to the small literature analyzing how corrupt networks prevent women from entering the political sphere. Looking at the unique case study of Georgia, this chapter shows how clientelistic male network use their patriarchal power to exclude women from the political sphere. This chapter shows 
how patriarchal norms prevent women from entering politics and how benevolent and hostile sexism is used to secure clientelistic male networks at the top. Additionally, the current patriarchal rhetoric on women's role in society and politics mirroring their traditional roles in society put a limit on the political arenas women are allowed to engage in. At the same time they put a double burden on female politicians, "since they embody the norm, it is not a necessity for male politicians to either push for 'men's interests' or for gender issues in order to maintain legitimacy as politicians" (Bergqvist, Bjarnegård, \& Zetterberg, 2016, p. 4).

Having discussed how patriarchal power shapes the forms of corruption that women experience (chapter 3), patriarchal views are related to corruption (chapter 4) and how patriarchy is used to exclude women from clientelistic networks, the last chapter turns to the study of gendered experiences of corruption and how these are gendered. Chapter 6 analyzes the experiences of corruption of migrants and how these depend on patriarchy in the home and transit country. This chapter brings together the findings from the previous chapters and shows how patriarchy influences forms and experiences of corruption not only for the high level (i.e., politically active women) but also for the most vulnerable. The chapter shows that not only are the forms of corruption that migrants experience different depending on their gender. The extent of corruption that a migrant faces and the associated violence are also determined by underlying gender structures both in the country of origin and the transit countries.

The conclusion discusses the overall findings, policy implications, and potential ways forward in research. 



\section{Literature review}

Corruption indicates the presence of shadowy arrangements that benefit the already privileged and those who are part of close-knit networks, which in most countries tend to be men.

(Bjarnegård, 2018, p. 257)

\subsection{Gender and corruption - is there a link?}

Does corruption have any relationship with gender? At first glance data on the control of corruption and gender inequality suggests a correlation between the two (Figure 1), yet, this gives no indication about the type of the relationship. Taking a closer look at how corruption and gender are intertwined is not a new phenomenon. The first attempts to disentangle the link were conducted in 2001 by two research groups - Dollar, Fisman and Gatti and Swamy, Knack and Lee.

Since then three essential questions have been discussed in the literature: (1) Are women and men equally corrupt? (2) What are the effects of corruption on women and how are they different from men? (3) How can women help in fighting corruption? This literature review will show the existing research along these questions and present the contributions of the empirical chapters of this dissertation for each of these questions. 
Figure 1 Gender inequality and control of corruption

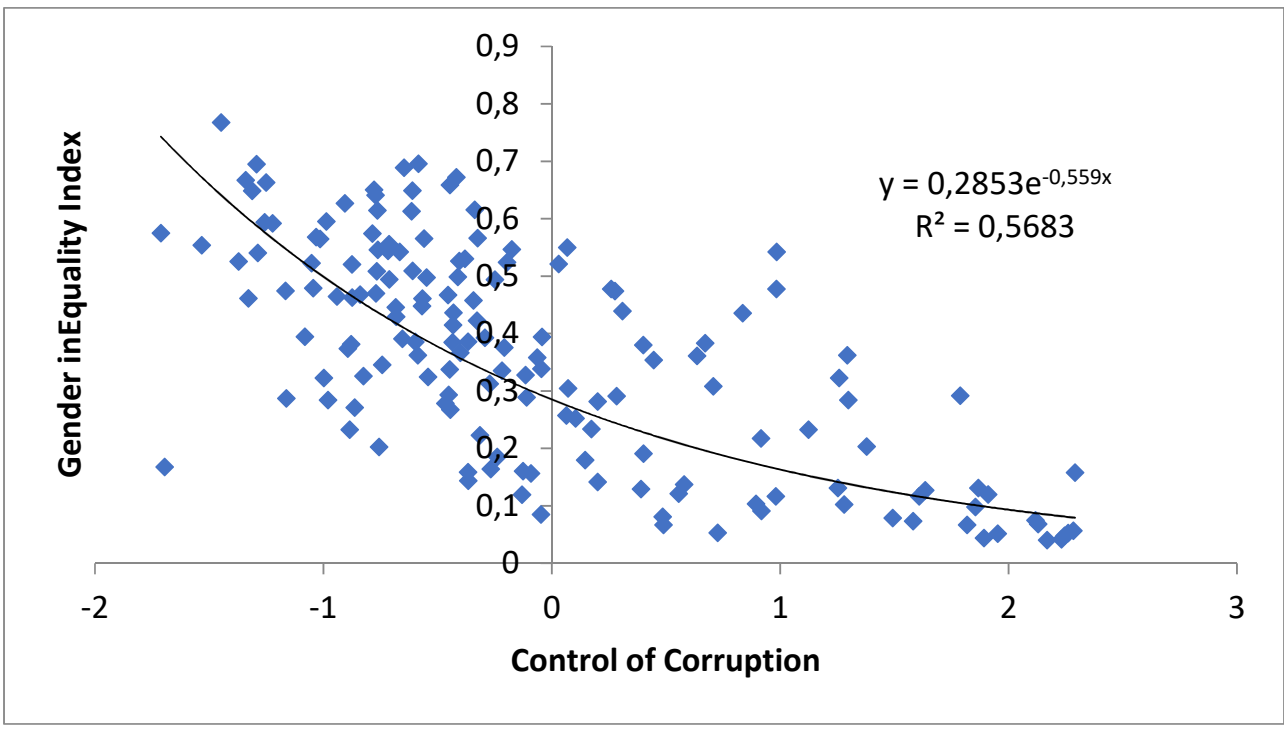

Source: Gender Inequality Index (GII) 2015 (UNDP, 2016); Control of Corruption 2015 (World Bank, 2016)

\subsection{Are women less corrupt than men?}

The two seminal papers by Dollar et al. (2001) and Swamy et al. (2001) for the first time explored how levels of corruption might be impacted by gender. Analyzing a considerable number of studies, they find that higher numbers of women in Parliament are linked to lower levels of corruption - the implications of these studies, namely, that women are less corrupt than men, had a large impact on development programs in the coming years, which identified women as the "new anti-corruption cleaner force"'(Goetz, 2007) (section 2.3).

The idea that women are inherently less corrupt than men is largely based on behavior studies, showing that women have higher scores on integrity tests (Ones \& Viswesvaran, 1998) and showcase higher norms of ethical behavior (Glover, Bumpus, Logan, \& Ciesla, 1997; Reiss \& Mitra, 1998). Dollar et al. (2001) hypothesize that women are more likely to sacrifice personal gains for the common good and therefore less prone to be involved in corrupt behaviour. Other studies argue that women are less corrupt because of differences in self-control (Swamy et al., 2001), risk aversion (Byrnes, Miller, \& Schafer, 1999; Eckel \& Füllbrunn, 2015; Harris, Jenkins, \& Glaser, 2006) and willingness to engage in interactions with criminal or corruption officials (Frank, Lambsdorff, \& Boehm, 2011), or because 
they are simply less prone to criminal behavior (including corruption) (Rothstein, 2016). Surprisingly, despite all these discussions the simplistic 'women are less corrupt' approach is still pushed forward by prominent scholars like Rothstein (2016) who argues "I can see no reason why I should not recommend this 'cure' [more women in parliament] even if I am not certain about how the micro-level causal mechanism(s) operate"(p.12). The argument that women are inherently less corrupt has been increasingly criticized for reinforcing gender stereotypes and oversimplifying the relationship.

Continuing to investigate the relationship of corruption and female political participation Sung (2003) argues that is not a causal relationship, rather both, low levels of corruption and high levels of political participation of women, should be attributed to "the presence of functioning liberal democratic institutions" (p.719). This argument is furthered by Esarey and Chirillo (2013) who show that female participation only has an impact on corruption levels when strong political institutions already exist. It might even be the case that only less corrupt governments are actually willing to include women in decision making roles (Wängnerud, 2014), for example, because they are less based on tight networks but rather on merit. Looking at gender differences in attitudes toward corruption, Alhassan-Alolo (2007) showed that male and female public servants in Ghana have similar attitudes toward corruption and are equally likely to engage in it. $\mathrm{He}$ hypothesizes that the question of whether an individual engages in corruption is a question of opportunity, networks and social norms, rather than one of gender differences. Alatas et al. (2009) came to similar conclusions. Using an experimental study in India and Indonesia, the authors find that there are no significant gender differences in attitudes toward corruption. Vijayalakshmi (2008) also finds that there is no difference in rent-seeking attitudes or actual levels of corruption between male and female elected representatives in India.

Many scholars also argue that it is simply a question of access to opportunities for corrupt behavior (e.g., Alhassan-Alolo, 2007; Bjarnegård, 2013; Goetz, 2007). For many aspects of corruption, a network is essential, for example, clientelism in democratic structures by definition contains a network (Stokes, 2007). Women often do not have access to these clientelistic networks (Bjarnegård, 2013), as this corruption relies on 'homosocial' capital, a type of social capital, which is built on the relationship of men.

Chapter 4 and 5 of this dissertation further investigate this matter and explore how underlying patriarchal structures are linked to corruption. While chapter 4 


\section{Literature review}

analyses how views on corruption and views on the role of women in society, i.e., the question if women should be active in politics, are related, chapter 5 looks at how patriarchal norms are used to prevent women from entering corrupt networks in high-level politics.

\subsection{Are women an anti-corruption force?}

The focus on the inherent gender differences in susceptibility to corruption is not just a theoretical discussion but has fundamental impacts on women's lives and anti-corruption initiatives.

The myth of inherently less corrupt women leads to the reinforcement of gender stereotypes (UNDP, 2012), where "[t]he very traits that traditionally branded women as deficient in moral development, their concern to help and to please, are now seen as a functional for good governance reforms in developing and transitional societies" (Goetz, 2007, p. 91). Hazarika (2016) continues this argument and notes that "traits ascribed to women once viewed as making for moral weakness are now seen as cornerstones of moral strength, that is, the definition of morality has changed. It may make little sense to consider women morally superior if notions of morality are mutable. Perhaps it is more useful to speak of honesty than morality" (p.8). Echazu (2010) argues that differences in corruption are much more rooted in power imbalances. Where one group is dominant, the other group will be much more intolerant to this group's misbehavior. Without changing the system, simply increasing the number of women might therefore even have the opposite effect and lead to more corruption. While the verdict on the discussion of the role women can and should play in anti-corruption work is still out, it is clear that this discussion of how women can be an anti-corruption force often deflected attention from the big question of gendered impacts of corruption (Goetz, 2007; UNDP, 2012).

The discussion in chapter 5 of this dissertation shows how ill-informed the focus on the seemingly 'better' qualities of women as a reason for increasing the number of women in politics can be. It explores how benevolent sexism is used to exclude women from clientelistic networks and large policy areas and how only women who are "liked" by the men's networks will be allowed to enter the political field. This brings a double burden on women who do not fall into the category. For one, they would have to fight a tight-knit network of corruption men, which by itself is already a big task. However, at the same time, they have to fight the patriarchal structures that are used to not only exclude them but also work on 'dishonoring' 
them when they are attempting to challenge male power. And lastly, as previous research has indicated, the failure to deliver on the anti-corruption promise could have detrimental effects on the participation of women.

\subsection{How are men and women differently affected by corruption}

While discussions on corruption do argue that men and women are differently impacted by corruption (e.g., Chêne, Clench, \& Fagan, 2010; Ellis et al., 2006; Leach et al., 2014), most research remains focused on a single sector or element where gendered effects can be found. This severely understates how important an analysis of gendered effects is by easily suggesting that they are anecdotal rather than systemic. Therefore, the review in this section sets out to show a) the large impact of corruption on each aspect of an individual's life and b) how each of these effects can be gendered. To systematically discuss these effects, the literature review creates a framework, using human security as a basis to structure the analysis. Human Security is a useful tool here for two reasons. For one it is an approach which puts the individual at the center of the analysis but also includes societal and household factors in the reasoning. Where corruption occurs at the

Figure 2 The human security concept

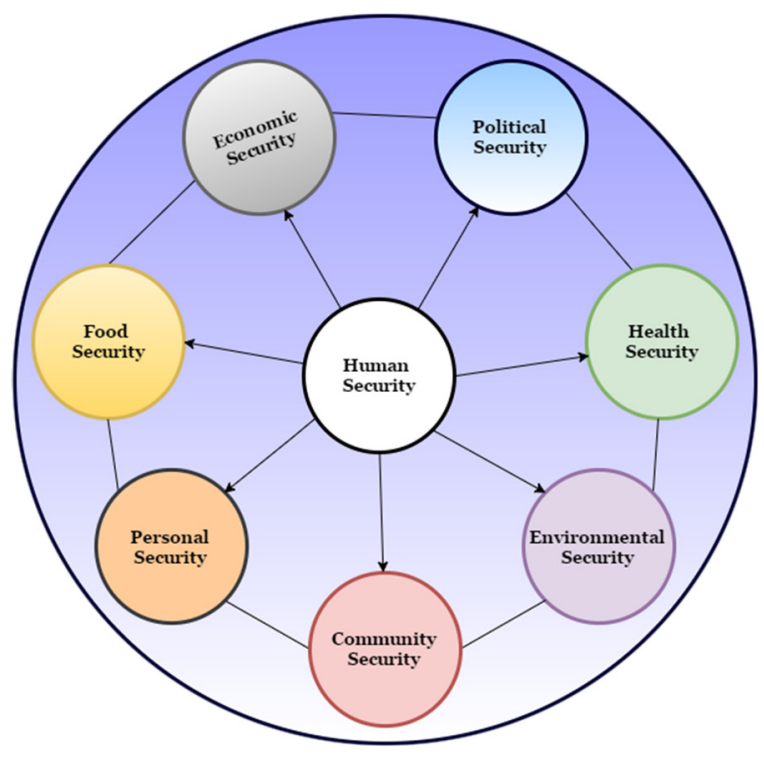

macro (state), meso (organization) and micro (individual corrupt agent) level, it can through this potentially affect every level of an individual's life. Therefore, using a holistic lens, such as human security is a useful tool. Secondly, the human security framework gives a clear structure to follow for a comprehensive discussion of the gendered effects.

For the purpose of this review, the broad definition as introduced by the United Nations

Development Programme (UNDP) in the 1994 Human Development 
Report is employed. The 1994 Human Development Report emphasizes the need for security to be defined in a broader and people-based sense rather than in terms of the nation-state and hard security concepts. Human security relates to the "legitimate concerns of ordinary people" (UNDP, 1994, p. 22) and is comprised of seven components, which may overlap and are heavily interlinked, namely economic, food, health, environmental, personal, community and political security (Figure 2). A variety of issues can threaten the security of an individual in any of these dimensions (see Annex B for definitions of the components and a nonexhaustive list of possible threats). The review of gendered effects of corruption will be structured along these seven components. Importantly for many of the effects, no literature on the gendered aspect is available. Therefore, this compilation should be read as a guide to rethink the relationships and use a gendered lens when analyzing them.

A second aspect to be considered for the discussion of gendered effects of corruption is that these can be direct and indirect. A direct effect can be any event where an individual is directly participating in a corrupt act, from being asked to pay a bribe to receive a government service to sexual extortion. However, equally important are the indirect effects corruption can have, since a corrupt act does not only affect the parties involved but "its externalities usually indirectly affect third parties, including the general population, taxpayers, specific professions, or communities"(Boehm \& Sierra, 2015, p. 2). Hence, the gendered effect of corruption must also be looked at from two perspectives: direct and indirect.

The reason why men and women can be affected differently, both directly and indirectly, by corruption are unequal power relationships within societies and resulting gender roles. Where some roles are typically dominated by men, others are assigned to women and each of them will lead to different exposures to corruption. If men are traditionally more active in some roles they are likely to encounter more corruption in those spheres in absolute terms, yet, women can "still be proportionally more vulnerable" (Boehm \& Sierra, 2015, p. 2). Ellis, Manuel and Blackden (2006) for example show that even though more men work in the Ugandan private sector, women are targeted more frequently by corruption. Interestingly, there is little data available on the question why women are often more vulnerable to corruption than men as this goes beyond the question of exposure to corruption (Boehm \& Sierra, 2015). This is a gap that chapter 6 is adding to by discussing how women and men are differently affected by corruption during migration and which factors play a role in this. 
Several areas have been identified where the effect of corruption differs for women and men. Corruption disproportionately affects the poor, by taking up a larger share of their income (Hunt \& Laszlo, 2012; Justesen \& Bjørnskov, 2014). Gender plays a large role in poverty, where "[l] ower proportions of women than men have their own cash income from labour as a result of the unequal division of paid and unpaid work" and women, especially when they have dependent children and no partners are more likely to be poor than men (United Nations, 2015, p. xiv). Access to basic public services is an area where women are affected differently. Women in developing countries often do not have the financial resources to pay for bribes as the control over the household resources lies with the men and therefore are frequently denied service (Nyami Musembi, 2007). As women spend more time in the health care system, during pregnancy and child care, they are also more exposed to corruption in this sector than men (Chêne et al., 2010). The type of corruption that women and girls are exposed to can also differ, for instance in the education sector in high corruption countries girls frequently face demands for sexual favours which makes school attendance increasingly difficult (Leach et al., 2014). In addition, women may face sexual extortion in the work place (Transparency International, 2016).

Economic, social and political roles are largely shaped by gender and therefore, corruption can also be experienced differently in these areas. The framework represents different areas where gendered effects of corruption have been researched or should be expected, yet for many areas more nuanced analysis is still needed. For example, only little research has been done on the question of how corruption impacts indigenous communities, but the authors agree that those communities are especially vulnerable to corrupt exploitation. Importantly this is not a simplistic relationship and one can assume that this significantly also depends on other factors, such as gender, disability and citizenship status and therefore needs more detailed discussion. However, this framework sets out to get an understanding of the possible direct and indirect ways in which corruption can have gendered effects. The following sections will first review the literature on the impact of corruption on the seven human security dimensions and include gendered effects in the discussion. The impact of corruption will be mapped for each dimension and in a last step will be put together in a comprehensive framework. Each section includes a graphical representation of the main effects of corruption, the arrows should be read as relationship and not as implying a positive or negative impact, as often it is not possible to make this distinction as the relationship depends on numerous other factors and can change over time. This 
framework should be understood as a tool to create more in-depth case studies or larger scale data collections to show the precise gendered impacts of corruption in more detail.

\subsubsection{Gendered effects of corruption - economic security}

Economic security is a multi-layered issue depending on many micro and macro level factors and corruption has been shown to have an impact on many of them. One of the first strands of corruption literature focused on the question of corruption and economic growth. Economic growth, usually measured in Gross Domestic Product (GDP) is closely linked to overall development of a country. While economic growth can have negative externalities, it has been linked closely to poverty reduction, higher employment and other human development indicators (DFID, 2008). The discussion about the impact of corruption on economic growth develops around the 'grease or sand the wheels' debate (Méon \& Sekkat, 2005). While some scholars argue that corruption can 'grease the wheels' of business (Huntington, 1968; Leff, 1964; Leys, 1965; Méon \& Weill, 2010) and therefore have a positive effect on economic growth, others find it to have a clear negative effect (Mauro, 1995; Ugur \& Dasgupta, 2011).

Even though there are indications that in some instances corruption might have a positive impact on growth, the majority of the literature agrees that corruption overall has a negative effect (Campos, Dimova, \& Saleh, 2010; d'Agostino, Dunne, \& Pieroni, 2016; Ugur, 2014). Research has also shown that there are a multitude of mediating factors which affect the relationship of corruption and economic growth, which need to be examined to gain a clear picture of the economic situation of a country. One such important factor is institutions. The quality of state institutions as well as social arrangements, have a large direct impact on economic growth (Rodrik, 2004, p. 11ff). At the same time, the quality of institutions also impacts the effect of corruption. Therefore, De Vaal and Ebben (2011) point out that corruption can have a positive or negative effect on economic growth, depending on the current institutional setting and simply removing corruption without other institutional reforms might alter the 'web of formal and informal institutions' and therefore have a negative effect on economic growth (p.109). Mo (2001) on the other hand argues that corruption impacts economic growth via the channel of political instability, where corruption leads to lower political stability and lower political stability in return leads to less economic growth.

Additionally, corruption has also been shown to be a transmission channel for other factors influencing the rule of law and therefore economic growth. Haggard and Tiede (2011) identify four causal mechanisms through which the rule of law (or lack thereof) influences economic growth: security of person, security of 
property and enforcement of contracts, checks on government and checks on corruption and government capture (p. 673). Interestingly, while research on the impact of gender inequality (or lack thereof) on economic growth has received wide spread attention (Agénor \& Canuto, 2015; e.g. Seguino, 2000; Seguino \& Were, 2014) the reverse relationship has been discussed less. However, it is well known that scarcity of resources leads to a worse position of women in all areas especially jobs, education and health care, hence a lack of economic growth can be expected to impact women's standing in society negatively (Kabeer \& Natali, 2013).

Annex $\mathrm{B}$ gives a graphical overview over the relationship between corruption and economic growth. Which factors are most prominent in each country depends on the country context. Many countries with high levels of corruption will experience a mix of all of the factors, but with varying degrees and consequences. The lack of functioning state institutions and bureaucratic oversight can for example lead to a decreased ability of the state to collect taxes (Tanzi \& Davoodi, 2000) and therefore a lack of public investment, which in return leads to lower economic growth (Gupta \& Ogada, 2016). The impact of corruption on economic growth, including all the intermediary channels is a crucial factor in assessing the gendered impact of corruption. Economic growth or the lack thereof as well as many programs to boost economic growth have gendered impacts (Seguino \& Were, 2014) as will be discussed.

A crucial relationship for development is the impact of corruption on income inequality and poverty. Many studies show that corruption does lead to higher inequality (Apergis, Dincer, \& Payne, 2009; Foellmi \& Oechslin, 2007; Gupta et al., 2002; Uslaner, 2008) and also disproportionately affects the poor, by taking up a larger share of their income (Hunt \& Laszlo, 2012; Justesen \& Bjørnskov, 2014) and decreasing spending on public services (Gupta, Davoodi, \& Tiongson, 2000), social expenditures (Croix \& Delavallade, 2008; Delavallade, 2006) and also diverts funds away from projects and infrastructure that would help the poor (Lovei \& McKechnie, 2000). Poverty does not affect everyone the same. While both men and women experience poverty, research shows that single mothers and older women alone face a higher risk of poverty than man in similar households(UNSD, 2015). Due to gender roles, which often see women as home keepers, women also frequently have less access to resources and are more dependent on public services. As funds get diverted to projects that provide more opportunity to collect and hide bribes, such as big infrastructure projects (Shleifer \& Vishny, 1993), systems such as social security are underfunded.

Social security entails that states redistribute resources "across ages, classes, occupations and genders" (Lynch, 2004, p. 1) in the form of social programs, 


\section{Literature review}

including for example unemployment benefits and pensions. These programs usually have very high monetary value (van Stolk \& Tesliuc, 2010) and are therefore an 'interesting target' for corruption and leave those most vulnerable without protection. Previous research shows that women usually are the ones that have to absorb the shocks the household is facing when state level spending is cut (Blackden \& Wodon, 2006; Sewpaul, 2008).

Social security is not the only public good that cannot be properly provided within a corrupt system (Bardhan, 1997; Rose-Ackerman \& Palifka, 2016). Another sector that suffers tremendously from this distortion is education, both quality of and access to education. Education, however, is an essential aspect of economic security as it impacts both employment opportunities and future income. Corruption in the education sector is unfortunately not a rare phenomenon and plays a role on different levels, such as entrance exams and admission, raising grades, receiving government benefits and research falsification ${ }^{8}$. Corruption also lowers government spending in the education sector (Mauro, 1995). Using the case of Uganda, Reinikka and Svensson (2005) support this argument and show that implementing transparency measures, decreased the amount of funds diverted to private pockets and increased student enrolment and learning in Uganda. This does not only hamper educational success but corruption in the education sector also has a negative impact on the overall economic situation of the country. It lowers the quality of education, which in return lowers economic growth and decreases the economic rates of return to higher education (Heyneman, 2011, p. 19). A particularly problematic aspect of corruption in the education sector is 'sextortion' or the demanding of sexual favors, which makes school attendance especially difficult for girls (Leach et al., 2014). Heyneman (2011) sums up why corruption in the education sector is especially problematic: "Systemic education corruption (that which is beyond a few individuals 'behaving badly') must be of concern because, more so than corruption in the police, customs service, or other areas, it contains both immoral and illegal elements, involves minors or young people, and damages the ability of education to serve a public good, most notably the selection of future leaders on fair and impartial basis [...]" (p.13).

One of the most essential aspects of economic security is the role of employment. Research agrees that the poor will often not benefit from economic growth if they are not able to participate in functioning labor markets (Jütting \& de Laiglesia, 2009). In many developing countries, informal employment ${ }^{9}$ or the shadow

\footnotetext{
${ }^{8}$ For a detailed overview of types and perpetrators of education corruption see Heyneman (2011) and Heyneman et al. (2008).

9 Informal employment entails both, informal employment in the informal sectors and informal employment in the formal sector (Hussmanns, 2004).
} 
economy (Schneider, 2005) ${ }^{10}$ is an essential part of creating employment (Dutta, Kar, \& Roy, 2011), yet the effects of informal employment on the individual and society as a whole are often negative (Jütting \& de Laiglesia, 2009). The informal sector offers mixed benefits for workers, while some might see better opportunities than they would in the formal sector, for others it is a last resort to avoid unemployment (Günther \& Launov, 2012) and often workers are facing precarious working conditions with "various risks - health, safety at work, loss of earnings without adequate protection" (Jütting \& de Laiglesia, 2009, p. 18). Women in many countries are overrepresented in this sector (Chen, 2001). In patriarchal societies girls frequently do not have the same access to education and vocational training and therefore are limited to the informal sector for employment and often end up in more and more precarious working conditions, in for example domestic work (Otobe, 2017).

The informal sector is also closely linked to poverty, where participants in the informal sector are on average poorer and the lack of social protection makes the situation even more perilous (Timofeyev, 2012). And this connection is especially strong for women not only because they are overrepresented in the sector but also because they often have even less chance of voice and representation than men employed in the same sector might have (Chen, 2001; Otobe, 2017).

The thought that there is a connection between corruption and informality is not novel (e.g. Eric Friedman, Johnson, Kaufmann, \& Zoido-Lobaton, 2000; Johnson, Kaufmann, \& Zoido-Lobatón, 1998). While the exact links have not finally been determined, research suggests that "corruption and informality complement each other and are jointly determined by several firm level as well as economy level variables" (Mishra \& Ray, 2010, p. 22). Corruption can lead to the growth of the informal sector as costs of doing business in the formal sector (Dutta et al., 2011) as well as the time needed to set up businesses (Svensson, 2005) are increased through bribes that have to be paid to for example bureaucrats and regulators. Employment is not just affected in the shadow economy but also in the formal sectors. As discussed jobs are lost in the informal sector because firms move into the informal sector. Yet, also without this development corruption can negatively affect employment opportunities. Nepotism and patronage networks can exclude qualified individuals from employment both in the public and private sector. Nepotism in the private sector has not received wide spread attention in the academic debate, yet anecdotal evidence indicates that "nepotism is a wellestablished part of business culture" (Mulgan, 2000). Looking at the case of China, Wang (2013) finds that the lack or loss of a network can lead to significant earning

\footnotetext{
${ }^{10}$ For a more detailed survey see e.g. Schneider and Enste (2013).
} 
losses. Another example is discussed by Morano Foadi (2006), who finds that corruption (especially patronage and nepotism) are considered especially burdensome in Italian academia and leads to many academics searching for jobs outside of Italy. Nepotism and patronage are much better researched in the public sector and are a common concern in many bureaucracies. A lack of meritocratic recruitment has two effects on the economic security of individuals. First, it reduces the chances of qualified individuals to get employed. Second, it has drastic consequences for societal factors overall. Bureaucracies without meritocratic recruitment tend to have higher overall levels of corruption (Dahlström, Lapuente, \& Teorell, 2011) and overall worse bureaucratic performance (Rauch \& Evans, 2000). This impacts not only service delivery, which as has been discussed above influences education, poverty levels and inequality but also overall economic growth. Not only is more research needed on the connection between informal and precarious employment overall but even more importantly a gender lens needs to be employed as corruption in the informal sector can be hypothesized to have a disproportionate effect on women.

Large development interventions are especially prone to corruption (e.g. Tanzi \& Davoodi, 1998): they are large enough to hide corrupt acts; they are unique enough to make estimates difficult; the involvement of government allows for discretion; many actors are involved and each of them allows for corrupt interactions; and the complexity of the projects allows to hide bribes, to only name a few (Locatelli, Mariani, Sainati, \& Greco, 2017, p. 257). These projects, despite all their potential, can also often have negative social side-effects, where people have to be resettled and the new land that they are settled on often does not offer the same livelihood opportunities as the old home (Caspary, 2007). At the same time, as discussed above, weak bureaucratic structures allow public servants to use their discretion for their personal benefit: this might lead to incentives to execute more development interventions, regardless if they are useful or not. Additionally, money intended to compensate (forcibly) displaced populations can be skimmed through corruption and further decreases the economic security of the populations. While the immediate effects of development induced displacement are considered less serious than disaster induced or forced displacement, its outcomes are generally less reversible (Terminski, 2012). The loss of livelihoods and community people face as a consequence of disaster and development induced displacement is therefore almost always permanent and often leads to precarious living and working conditions especially also for women.

Overall the impact of corruption on economic security is multi-layered and very complex. At the same time, economic security has large gendered effects and the framework below shows the most prominent channels. These channels can vary in country contexts. As expert interviews showed, there are different ways through 
which corruption can lead to unemployment. One example could be that in many rural areas, money for infrastructure projects gets diverted into private pockets. The lack of infrastructure then leads to lack of trade and employment opportunities and which in return pushes people to migrate to find jobs elsewhere. Another example could be that the cost of doing business in a region is so high because of the expected bribe payments for sustaining a business that entrepreneurs decide that they can no longer run their business or move to the informal sector. Both scenarios often put women in especially precarious situations as they have less financial security and more responsibility for the other household members. The exact connections need to be considered in the individual country context. The framework presented below can be a tool to start this analysis.

Figure 3 Corruption and economic security

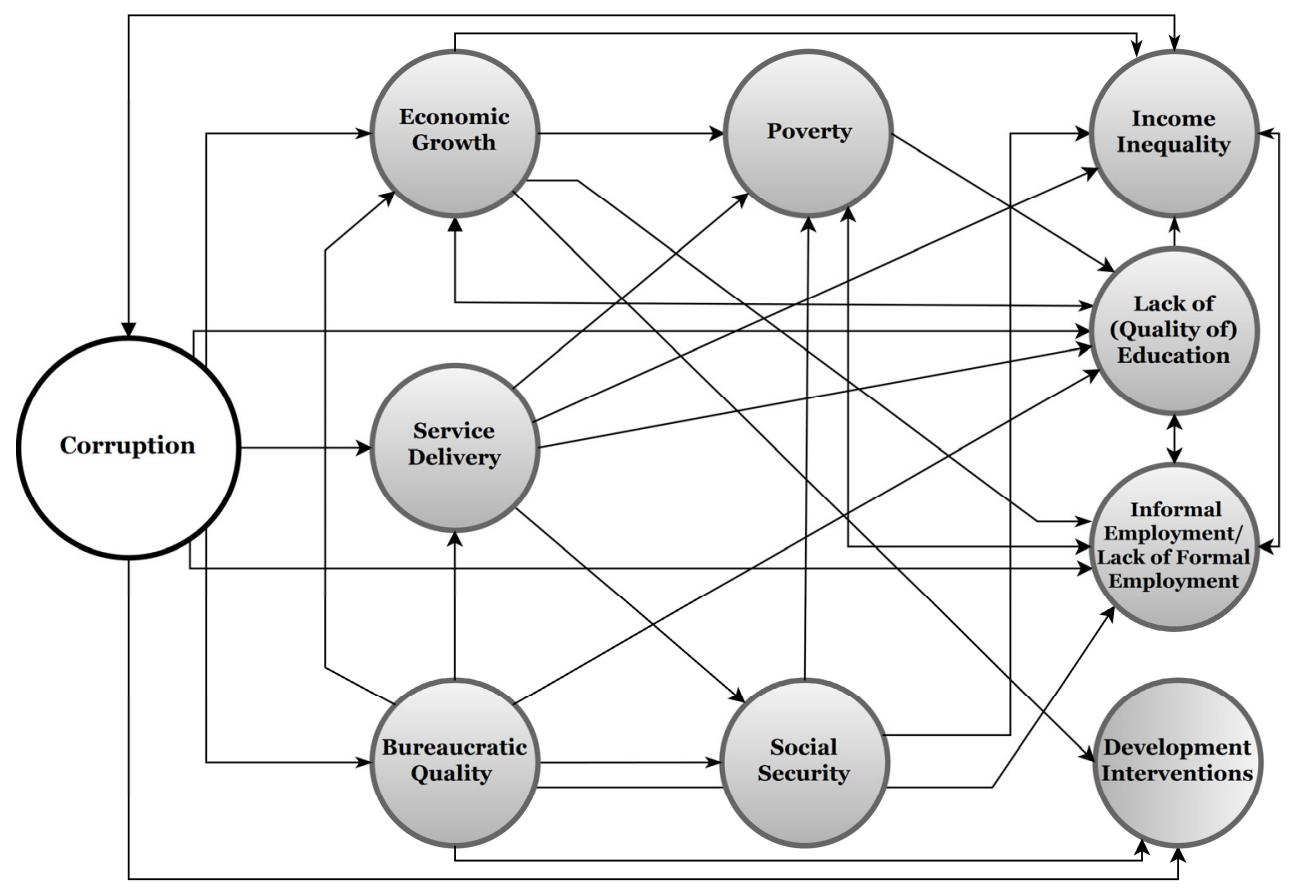

\subsubsection{Gendered effects of corruption - political security}

Political security contains different aspects such as the level of democratic participation, protections against state repression and protection of human rights.

An integral part of political security and democratic processes is the participation of all groups in the process (OSCE/ODIHR, 2007). Corruption not only subverts democratic checks and balances (McMillan \& Zoido, 2004), but also hinders the 
political participation in a democratic environment. Corruption in electoral process has also been shown to be a serious problem and election fraud often results in violence (e.g. Kenya in 2007; (Durojaye, 2010). Corruption is often rampant in young democracies, where politicians are seen as not credible and "high targeted spending, high rent seeking, and low levels of non-targeted good provision" are the norm (Keefer, 2007, p. 820). If the selection of leaders is not done based on merit but through other criteria such as corrupt acts, this can lead to significant economic losses (Klitgaard, 1986; Piñera \& Selowsky, 1981) as discussed in section 2.4.1 for bureaucrats.

Bjarnegård (2013) further points out that clientelism itself severely restricts the political participation for different groups in the society (p.8). One very essential group is the participation of women. There is no shortage of empirical evidence finding that greater gender equality is associated with various desirable social outcomes. For example, giving women basic rights and entitlements has significant positive effects on economic development (Byrne, 1995, 1996; Sen, 2001). Researches find that societies with more equality and female political representation tend to have better human rights protection (Melander, 2005) and are less likely to engage in interstate (Caprioli, 2000; Caprioli \& Boyer, 2001; Tessler \& Warriner, 1997) and intrastate (Caprioli, 2005) violence.

A second aspect of political security that plays an important role is lack of state legitimacy, which is often linked directly to the emergence of violent conflict.

State legitimacy plays an important role in the likelihood of conflict. Wimmer, Cederman and Min (2009) for example find that a high degree of ethnic exclusion, lowers political legitimacy of the state and therefore increases the probability of conflict. Corruption itself has also been shown to undermine the legitimacy of the government (Rose-Ackerman, 1996) and undermining the legitimacy of the state, may of itself also encourage citizens towards rebellion (Clausen, Kraay, \& Nyiri, 2011), e.g. the 'rose revolution' in Georgia which has been strongly influenced by corruption allegations against the incumbent regime. In general four sources of state legitimacy can be identified: input or process as agreement upon procedures and law, output as the capacity to deliver services, shared beliefs and international legitimacy as the commonality of assumptions underpinning formal and informal structures and the state's perception abroad (OECD, 2010).

Corruption and the continued popular legitimacy of the state can co-exist, they are not antithetical, as Dix, Hussmann and Walton (2012) exemplify in Liberia, Nepal and Columbia. However, Poskitt and Dufranc (2011) surveying the Balkans, Philippines and Zimbabwe using desk research and qualitative purposive samples found patronage accepted as the norm and corruption to buy off otherwise disaffected groups widely tolerated. Through access to patronage political elites 
and entrepreneurs determine the state's de facto legitimacy by the extent to which they support and/or control it and it is when available rents, from whatever source, dry up that break-down occurs (Orre \& Mathisen, 2008). When this is calibrated with levels of endemic social violence, the likelihood of recurring conflict is likely to increase because corruption often pre-dates and contributes to the initial conflict (Le Billon, 2008). Unless corruption is tackled at the peace-building stage, corrupt elites become entrenched, only exacerbating popular unrest.

Where action against corruption has been a platform for support in any movement of liberation but followed by non-application of anti-corruption laws (Le Billon, 2008) populist disenchantment can destabilize the regime. However, operating 'zero tolerance' strategies in fragile states is also seen as impractical, unrealistic and hypocritical (Orre \& Mathisen, 2008) and likely to lead to renewal of conflict.

When power has not been entrusted by the entire population, including countries where 'democratic' elections have been held but manipulated to maintain elites in power, state legitimacy is inevitably compromised (Orre \& Mathisen, 2008). Using Côte d'Ivoire as its example the DIIS Policy Brief explains how, when rents and spoils decreased, the neo-patrimonial system was no longer able to deliver to patronage receivers and consequently failed. External, non-culpable explanations may be offered, such as sanctions rather than predatory corruption as posing the threat to state survival, as in Zimbabwe (DiJohn, 2010; Poskitt \& Dufranc, 2011).

Unless a governance system can be constructed that controls corruption, long-term legitimacy cannot be assured and recurring conflict will become endemic (Galtung \& Tisné, 2009). Less corruption should build a stronger peace and less likelihood of degeneration into (re-) occurrence of conflict (Le Billon, 2008). Citing Afghanistan, Bosnia, Mozambique and Nicaragua, Orre and Mathisen (2008) demonstrate how, unless action is taken, corrupt elites may merely entrench themselves, establishing quasi-legitimate predatory structures that siphon funds. Both, Spector (2012) focusing on the case of Afghanistan and the OECD (2010) in a more general analysis come to the same conclusion, that aid donors in fragile states require a more pragmatic, sensitive and realistic assessment both of populist legitimacy and the relationship of contending elites with the state.

Furthermore, political participation of women is directly linked to state legitimacy, as a state can only have legitimacy if all groups are included in the political process (Thomas, 2005). In democracies both men and women perceive the government to be more democratically legitimate if a sufficient number of women is represented, since the proper representation of disadvantaged groups indicates that majority can trust their interests to be properly heard as well (Schwindt-Bayer \& Mishler, 2005). Yet, clientelistic networks in the political process keep women from 
participating and therefore have a negative effect on the well-being of citizens and state legitimacy.

In fragile states created from within colonially imposed arbitrary boundaries, clan or tribal affiliations may be opportunistically transmuted into corruption (Johnston, 2010), but the key to continued legitimacy is output driven. It is the extent to which the state is able to deliver long-term services, including law to the majority of its people, and in the short term to satisfy the demands of key position oligarchs.

In cases where states are so fragile, they can no longer deliver law. Alternative providers such as Hezbollah in Lebanon or the Taliban in Afghanistan may step into the vacuum, increasing likelihood that conflict in form of civil war will recur. Alternatively, co-opting traditional power sources to the state but without deepening its dependence on patronage - corruption - is an extremely complex and difficult process, which the OECD Report (2010) terms grounded legitimacy, citing the Kgolala in Botswana and elders in Somaliland as examples helping to maintain stability.

In some instances, elites who dominate the country may have no vested interest in maintaining the state's legitimacy because it is not the source of their patronage and strengthening it could risk compromising their status and rents. Where funds are available, through control of exportable natural resources or collusion in external donor fund dissemination, the state has little value for them and so good governance leading to enhanced legitimacy is not wanted (Grindle, 2011).

However, as Orre and Mathisen (2008) acknowledge, failing to address the corruption issue enables corrupt elites to entrench themselves within the mechanisms of the state using it for their own ends, compromising its governance and undermining its legitimacy for the population at large. Populist movements driven initially by an anti-corruption agenda, or co-opting this to political and/or religious movements (L. Anderson, 2011), have also required the state's military agency to defect from the regime and to shift its support to the popular, anticorruption movement as in the 'Arab Spring' in Tunisia and Egypt (Lutterbeck, 2013). It may be possible to overthrow the regime, but a subsequent failure to 'deliver' generates cynicism and conflict within what had been, heretofore relatively stable states. Farzanegan and Witthun (2016) add an interesting nuance to the relationship of corruption and political stability. They find that corruption has an especially detrimental effect on political stability when the level of youth population is high.

In the context of political security, one must also take a look at the state institutions that are in charge of ensuring security of the people, the police. Policing is an 
essential cornerstone of democratic governance and police corruption undermines the trust in state institutions, can violate the state's monopoly of violence and decreases the protection of rights (Pyman, Cohen, \& Boardman, 2012). The police is also the very institution that is supposed to control corruption (Seligson, 2006) and which citizens turn to with safety concerns (Marenin, 1996), which makes it's behavior even more important. This institutional importance and specific properties of police work warrant a closer look at what police corruption entails. Police corruption is defined as "an officer knowingly doing or not doing something that is against his or her duty for some form of financial or material gain or promise of such gain" (Punch, 2009, p. 18). Police work is inherently an ethical issue where the line between corrupt and non-corrupt behavior is sometimes difficult to draw and depends largely on circumstances and the nature of the observed conduct (Newburn, 2015). Conduct can be corrupt even if it is not illegal and sometimes illegal means might be employed to achieve legitimate outcomes (Punch, 1985). For the purpose of this discussion, one should follow Kleinig's (1996) definition where "[p]olice officers act corruptly when, in exercising or failing to exercise their authority, they act with the primary intention of furthering private or departmental/divisional advantage" (p.166). ${ }^{11}$ For police corruption it is especially obvious that it encompasses both receiving bribes from those that should be facing punishment as well as extorting payments from the innocent (Andvig \& Fjeldstad, 2008).

Effects of police corruption are also often gendered. Due to their societal roles man might face a higher quantity of police corruption as they have more contact with them. Women on the other hand might face different forms of corruption, such as sextortion and might be less likely to seek help from domestic or sexual violence because of fears of corruption and/or lack of resources. When human rights are not protected and police violence is rampant people can face danger to life and limb. This can be especially the case when police corruption and brutality target specific groups such as political opposition or religious, sexual and ethnic minorities. Closely linked is the problem of corruption in the judicial sector, which violates the civil, political, economic, social and cultural rights of people (Kumar, 2005, p. 418). The independence of the judiciary is the most fundamental cornerstone of the rule of law and corruption directly obstructs this independence (Dakolias \& Thachuk, 2000). Gathii (2009) argues that poor and marginalized groups are especially vulnerable as they are most often denied access to a fair judicial system and safeguarding their basic rights is not in the (monetary) interest of a corrupt

${ }^{11}$ For a more detailed discussion of definitional issues of police corruption see Newburn (2015), Punch (2009) and Kutnjak Ivkovic (2005). 


\section{Literature review}

judiciary. Corruption therefore has an effect on the human rights protection of individuals and may lead to state sponsored violence.

Figure 4 Corruption and political security

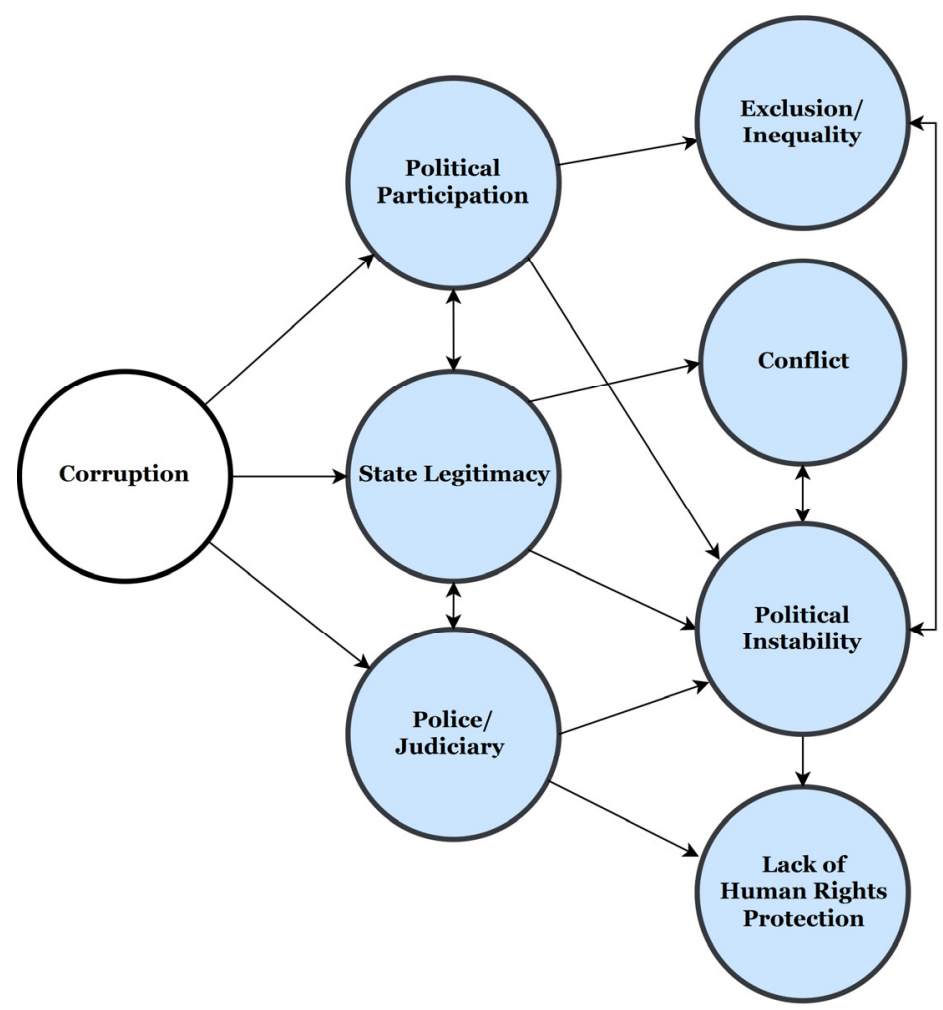

\subsubsection{Gendered effects of corruption - personal security}

As discussed in section 2.4.2, political instability is one major cause of conflict which has been widely shown to have gendered effects. Yet, this is not the only mechanism through which corruption can fuel violence from conflict. Corruption is also closely linked to arms trafficking. While there are different ways through which arms can enter the illicit trade ${ }^{12}$, one of the most important is corrupt officials who allow exports from or through a country that would normally be illegal or who sell government stockpiles that are not properly secured (Stohl, 2005). These actions are also directly linked to other organized crime activity, such

\footnotetext{
12 Stohl (2005) identifies 9 ways, the others are: violation of sanctions or embargos, lacking stockpile security, plundering of arsenals during periods of instability, arms are lost from government stockpiles, soldiers sell weapons, theft from legitimate owners, lax domestic laws, organizations produce their own weapons.
} 
as illicit narcotics trade and human trafficking where government officials have to be bribed to successfully traffic across the border (Holmes, 2010; Shelley, 2012). These criminal activities are also often intertwined with terrorist activities (both funding and weapons trade) (Shelley, 2004).

In addition, state agencies can be more actively involved in these criminal activities through so called 'state-sponsored protection rackets'13, which are complicated arrangements between law enforcement agencies and criminal groups to hide and/or protect criminal activity. These arrangements do not always lead to violence (Snyder \& Duran-Martinez, 2009), but of course have negative effects on the personal security of citizens as they are exposed to criminal activity and cannot rely on the protection of the police. This type of corruption can also lead to giving criminal groups more authority. As the Small Arms Survey (2010, p. 115f) notes: "When officials in leadership positions or the armed forces conspire with gangswhether through corruption or political opportunism - the gang becomes something other than a traditional gang. Indeed, the provenance of their small arms is a useful test of whether a group is a gang, a militia, a paramilitary organization, or something else. Patronage makes them similar to organizations such as many Afghan militias or the Colombian paramilitaries - semi-autonomous groups with connections to crime and the state [...]" (p.115). It is well known that effects and experiences of conflict are highly gendered (e.g. M. Hossain et al., 2014; McKay, 1998; Swaine, 2015)and that these experiences also shape the post-conflict live of both men and women very differently (e.g. Cahn, 2005; MacKenzie, 2009; Zuckerman \& Greenberg, 2004).

State sponsored violence is another serious impediment for personal security. Groups in countries with corrupt police departments are often using torture as a way to extort money from citizens (Bohara, Mitchell, Nepal, \& Raheem, 2008). Gilinskiy (2011) argues that torture can also be encouraged to increase the number of solved cases to give appearance of a more successful law enforcement agency. Again, citizens are even more vulnerable to this kind of violence during conflict, where Bohara et al.(2008) find that high levels of corruption and high level of state torture are often linked.

As discussed in section 2.4.2 police and judicial corruption are prominent in many countries and have detrimental effects. Even though research until now is sparse on the topic, one must hypothesize that these are also linked to violence, not only

13 "[I]nformal institutions, through which public officials refrain from enforcing the law or, alternatively, enforce it selectively against the rivals of a criminal organization, in exchange for a share for the profits generated by the organization" (Snyder \& Duran-Martinez, 2009, p. 254). 
through extortion but also by allowing for torture and hindering the prosecution of gender-based violence.

Another important element of personal security that concerns mostly forced migrants and forcedly displaced individuals is humanitarian assistance (as can be seen in chapter 6 , the connection between migration and corruption needs to be research in much more detail as well). While humanitarian assistance is designed to alleviate suffering caused by among other things war and violence, corruption can prevent it from being effective. Humanitarian assistance, often in the context of fragile and post-conflict situations, is an integral part of addressing various human insecurities and is not peculiar to a specific security dimension. The following remarks therefore equally apply to other human security dimensions such as environment, food and health security. Despite arguably noble intentions, corruption is as much an issue within humanitarian assistance as within any other industry and therefore humanitarian assistance is not always able to improve the personal, environment, health and food security of the individual. What makes humanitarian assistance particularly vulnerable to corrupt practices are its unique characteristics and unique contexts in which it is performed. This is also why it can be abused in many different ways, including different sectors, support functions and stages of the program cycle (Ewins, Harvey, Savage, \& Jacobs, 2006; Maxwell et al., 2008; Transparency International, 2016a).

Before defining different forms of corrupt practices in various areas of humanitarian assistance, it is important to better understand the unique character of humanitarian assistance. First, humanitarian assistance is required in fragile contexts including most often natural disasters or war and conflict in complex political environments. It is therefore important for aid agencies to act fast and quickly produce results because often human lives are in danger and donors as well as the media put additional pressure on aid agencies (Maxwell et al., 2008; Transparency International, 2016a). Adequate responses usually require an extensive scale-up of ongoing programs, including financial and human resources. Taking action is further complicated because in emergency situations normal services and infrastructure are damaged or even completely destroyed. This oftentimes involves a weak rule of law, lack of transparency and accountability as well as asymmetric distribution of power and resources (Maxwell et al., 2008; Transparency International, 2016a). Furthermore, it has been established that humanitarian assistance is required in "disproportionately more corrupt countries" (Maxwell et al., 2008, p. 9). What makes this situation even more difficult for aid agencies is unfamiliarity with the local environment in which assistance is 
required, including cultural and social norms, values, standards and practices (Maxwell et al., 2008; Transparency International, 2016a). Locals may have a different understanding of corruption and even view certain corrupt practices as normal or appropriate (Ewins et al., 2006; Maxwell et al., 2008).

Hence, humanitarian assistance can be seen as a balancing act between quick action and control of correct practices, including the prevention of corruption. Its presence increases the opportunities and motivations for corrupt practices for instance as survival strategies (Maxwell et al., 2008).

It is therefore not surprising that the existing literature on corruption and humanitarian assistance identifies a number of different financial and non-financial forms of corruption, including bribery, extortion, patronage, nepotism, favoritism, cronyism and sextortion (Willitts-King \& Harvey, 2005). It is important to note that the risks of corrupt practices depend on the context and needs to be analyzed on a case by case basis even though similarities across different cases exits. Corruption risks may depend on the type of emergency, organizational characteristics of aid agencies (e.g. size, funding source, accountability mechanisms, human resources, familiarity with the local context and perceptions of beneficiaries), partner organizations, host governments and multi-level governance structures ( to see how different contexts can lead to different effects of corruption, see for example a case study on Uganda (Bailey, 2008) and Afghanistan (Savage, Delesgues, Martin, \& Ulfat, 2007).

Corruption can occur in all program sectors, including food and nutrition; water and sanitation; construction and shelter; cash transfer systems; health care and refugee and IDP camps and is therefore related to various aspects of human security. Particularly the management of the latter provides countless opportunities for corruption. Among these are access to camps, accommodating or reuniting family members and allowing temporary leave and subsequent return. It is both likely that officials request bribes and that refugees offer them for the implementation of regulations and/or for allowing non-compliance. In addition, corruption in the context of refugee camps may be used for food distribution, resettlement to third countries and non-investigation of domestic violence (Ewins, 2006).

Program support functions vulnerable to corruption involve financial management, procurement, human resources, transport and asset management, and logistics and supply chain management (Ewins et al., 2006; Maxwell et al., 2008; Transparency International, 2016). 


\section{Literature review}

It has been identified that all parts of the program cycle are at risk of corruption, including needs assessment; fund-raising; resource allocation; selection of partners; coordination among partners and other actors; as well as monitoring, evaluation and closure of programs. According to Bailey (2008) the most problematic area is the targeting and registering of beneficiaries.

Costs of corruption can be devastating because hampering the effectiveness of humanitarian assistance programs goes beyond mere economic losses but may actually mean loss of human lives (Maxwell et al, 2008). Furthermore, corruption affects the quality and quantity of aid resources, increases costs of goods and services, and puts the reputation of aid agencies at risks (Maxwell et al., 2008; Transparency International, 2016a). This is also an area where more research from a gender perspective is needed. Women might be more vulnerable to sexual and other extortion and their physical security can be several endangered.

Figure 5 Corruption and personal security

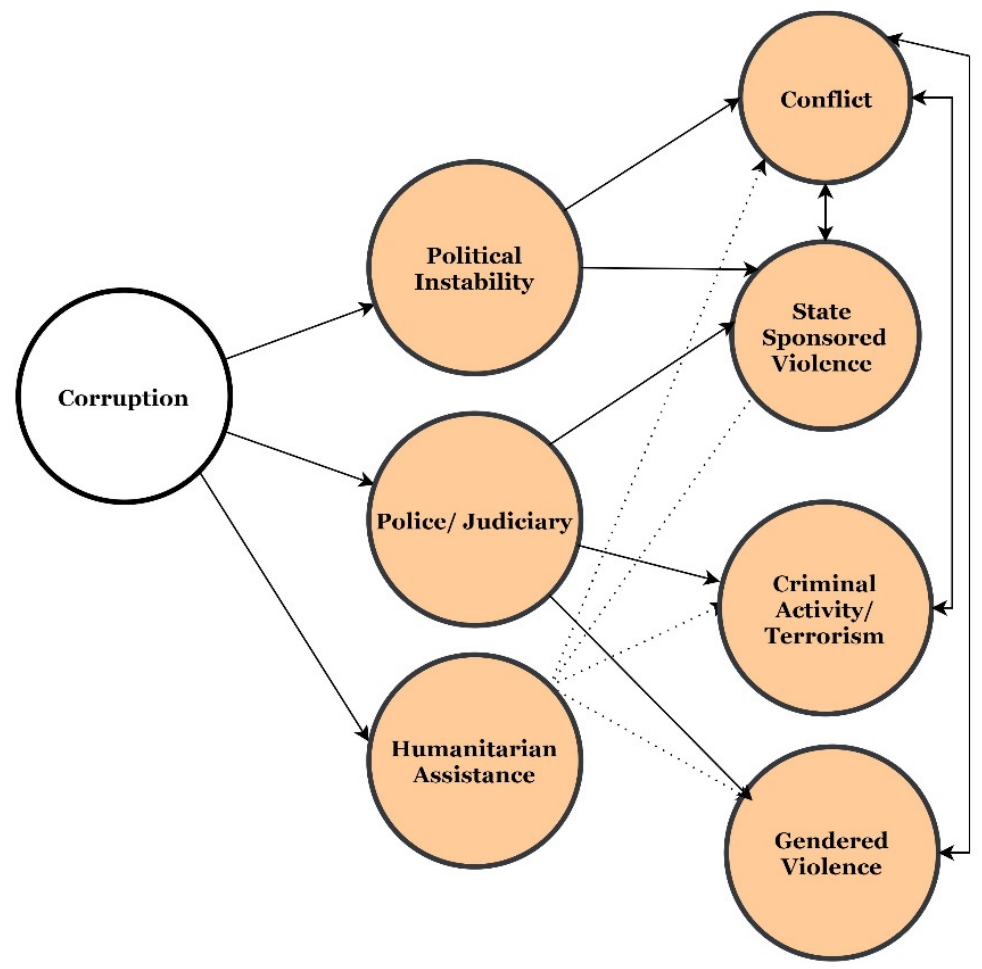




\subsubsection{Gendered effects of corruption - community security}

Ethnic and religious minorities often face threats to their community security. As discussed in sections 2.4.1 and 2.4.2 corruption can lead to marginalization of these groups both in the economic and political sphere. Existing economic networks often benefit a selected few or a certain ethnic or religious group and not society at large (Fisman, 2001) and corruption in the education and employment sector lead to even more economic and social inequality. Roma in Ukraine for example still face discrimination in many different areas and still face violence ${ }^{14}$. Access to health care and education is often difficult or the services are of lower quality and registration procedures can be difficult to obtain (OSCE/ODIHR, 2014). The problems are often exacerbated by corruption. As interviewees noted, Roma are especially vulnerable to be extorted to receive government services. Many Roma have also been displaced by the conflict in Ukraine which makes them even more vulnerable to discrimination and extortion and hence, large-scale community insecurity.

As previously discussed, this large inequality also leads to political instability as groups feel disadvantaged and are more likely to engage in violence and political upheaval. While in early studies the focus was mostly on income inequality (Alesina \& Perotti, 1996), which could by itself not explain the emergence of conflict, the shift to a focus on horizontal inequality ${ }^{15}$ (social, economic and other inequality) proves as a good predictor of social conflict (Gubler \& Selway, 2012; Koubi \& Böhmelt, 2014; Østby, 2008). In the context of community security, a focus must be on ethnic divisions. Neudorfer and Theuerkauf (2014) find that corruption significantly increases the risk of ethnic conflict. They link this finding to the exclusiveness of ethnic networks, and the incentives in high corruption societies to secure benefits for the own ethnic group.

Corruption has also been linked to the facilitation of terrorism by weakening the defense sector because of the diversion of funds, bribery of law enforcement agencies and facilitating terrorism financing (OECD, 2016). Terrorism creates political instability (Gassebner, Jong-A-Pin, \& Mierau, 2008) Once again, both the short and long term effects of terrorism as well as the act itself are highly gendered phenomena (e.g. Berko \& Erez, 2007; Ray, 1996; Sjoberg \& Gentry, 2011).

\footnotetext{
${ }^{14}$ http://www.nytimes.com/2016/08/31/world/europe/ukraine-roma.html

${ }^{15}$ For a discussion of horizontal inequality see e.g. Stewart (2009).
} 


\section{Literature review}

Figure 6 Corruption and community security

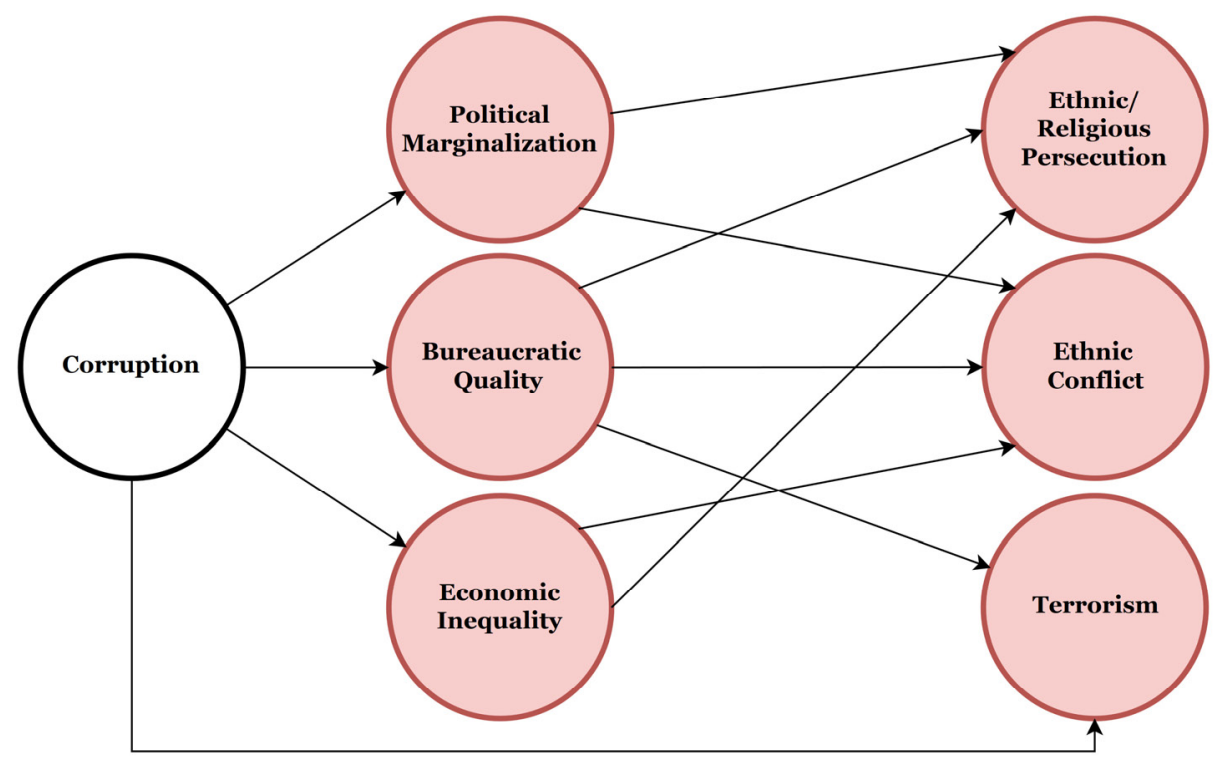

\subsubsection{Gendered effects of corruption - environmental security}

Corruption has a clearly negative effect on environmental policy enforcement (Robbins, 2000) and stringency (Damania, Fredriksson, \& List, 2003; López \& Mitra, 2000; Pellegrini \& Gerlagh, 2006). As all policies, environmental policies require oversight by bureaucrats. Therefore, these policies might lose effectiveness if the bureaucracy is very corrupt (Damania, 2002). This often leads to environmental degradation, which in turn affects the livelihoods of people. It is important to note that corruption also leads to higher death tolls of natural disasters (Kahn, 2005).

The use of natural resources in a country is severely impacted by corruption. For example, corruption is directly linked to illegal logging (Smith, Obidzinski, Subarudi, \& Suramenggala, 2003), which leads to overexploitation of natural resources (Casson \& Obidzinski, 2002) and impacts not only biodiversity but also the living environment. Illegal logging has also been linked to floods, landslides and forest fires. This overexploitation of natural resources and the resulting natural or man-made disasters such as oil or chemical spills are a major reason for forced migration worldwide.

The land sector is also often impacted by corruption, which does not only risk environmental security, but is at the same time closely linked to economic and food security. Bribery makes the transfer of land very costly and hampers the 
possibilities of protection of land (Transparency International, 2011). Land rights are already highly gendered and corruption might exacerbate these differences. Also, disputes over land fueled by nepotism and patronage can lead to conflicts between different (ethnic) groups. Conflict over resources has long been a major cause of instability across the world (Humphreys, 2005) and increasingly potential conflicts over fundamental resources such as water become a major concern (e.g. Jury \& Vaux Jr., 2007). As discussed in previous sections, corruption and bribery are also linked to pollution, where businesses can bribe their way out of environmental and safety standards. This has been supported by research analysis, where, for instance Welsch (2004) finds that the effect of corruption on the level of pollution is particularly strong in low income countries.

Another factor where corruption plays a huge role in environmental disasters is disaster preparation. Funds that should be used for protection and preparation are funneled into private pockets. Therefore, even if the disaster itself does not lead to negative outcomes, the lack of preparedness, which is often caused by corruption, will.

Figure 7 Corruption and environmental security

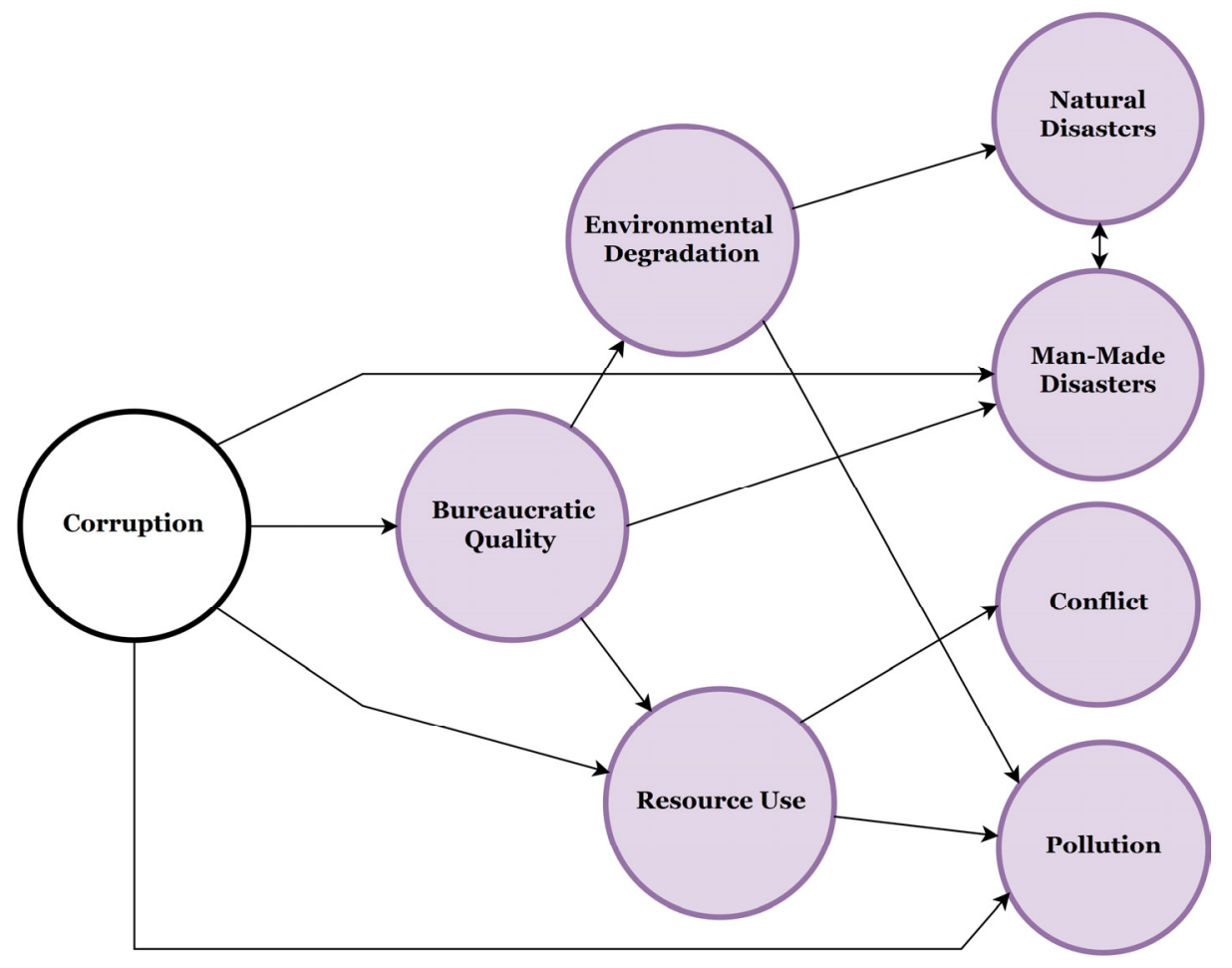




\section{Literature review}

\subsubsection{Gendered effects of corruption - food security}

Food security is a fundamental part of human security that is closely linked with other human security dimensions. It is rooted in "combinations of political instability, environmental marginality and economic powerlessness" (Vogel \& Smith, 2002, p. 316). The paper has already discussed how political stability and economic security can be threatened by corruption and this has severe consequences on food security, both due to conflict and loss of economic income. Corruption has been clearly linked to malnutrition, where conflict and droughts take the livelihood of the poorest and has been identified among the most important factors that prevent proper policy responses to food shortages (Bain et al., 2013; Pulfrey, 2006). Once again society's poorest suffer most from distortions in public service delivery. Repeatedly government corruption proves to be one of the major obstacles to food aid distribution including humanitarian assistance $(\mathrm{H}$. Lee, 2004) (For a more detailed discussion on humanitarian assistance see section 2.4.3.

Figure 8 Corruption and food security

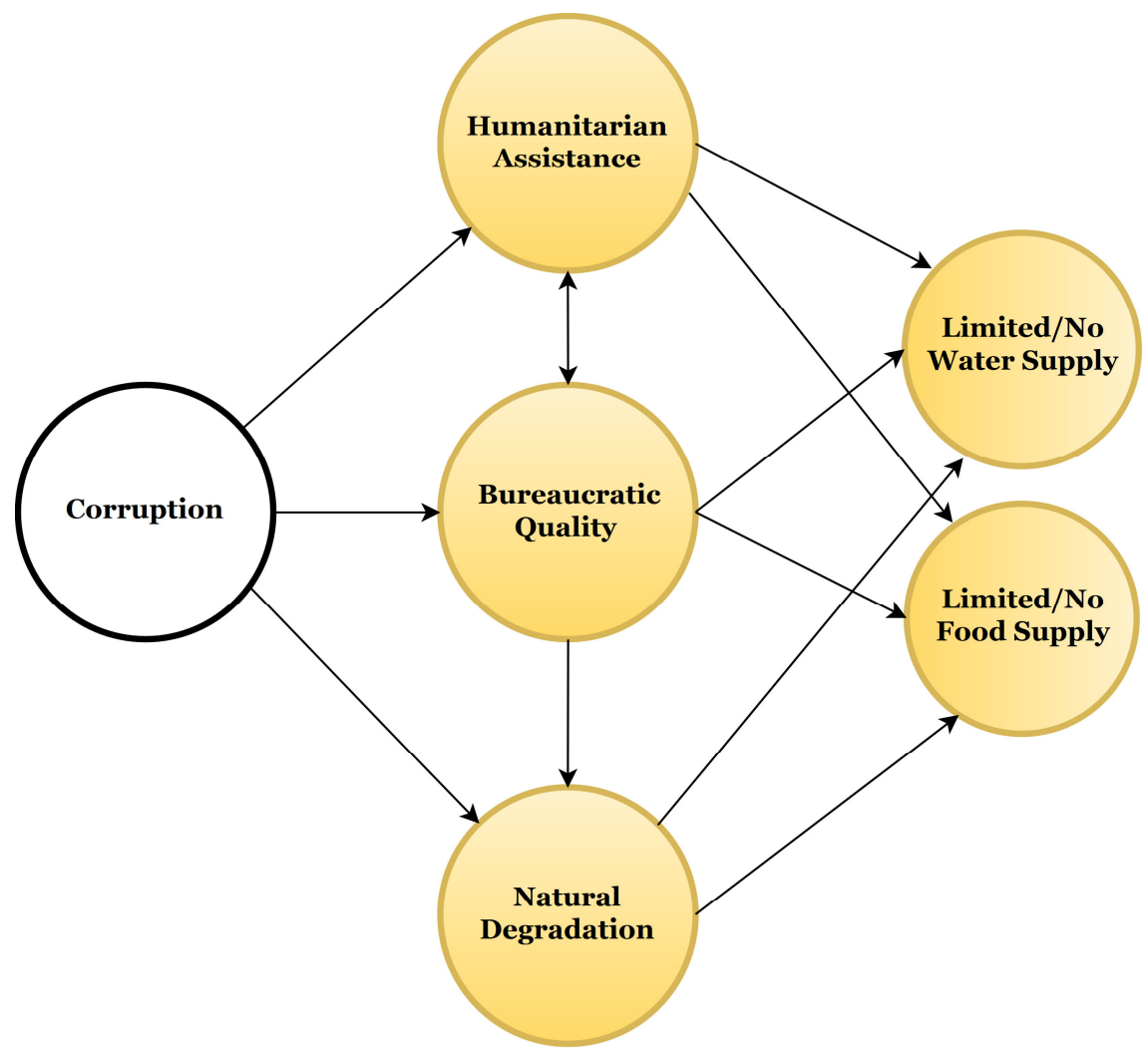




\subsubsection{Gendered effects of corruption - health security}

A country's level of corruption is overall linked to lower levels of life expectancy, higher rates of child mortality and other health measures such as the subjective health feeling (Holmberg \& Rothstein, 2011). Corruption overall increases the cost of health care as citizens have to pay an extra charge, when they need to bribe health care providers (Gupta et al., 2000) and as discussed in previous section, corruption in the bureaucracy funnels funds towards private gain away from public services such as health care facilities, equipment, supplies and personnel (Gathii, 2009, p. 174). Savedoff and Hussmann (2006, p. 5ff) identify several reasons why the health care sector is particularly vulnerable: uncertainty (about who gets sick and with what illness and what treatments are available), asymmetric information and a wide array of actors spread out over the whole country. Corruption in this sector disproportionally affects women during their reproductive years as they spend more time in the health system as men. Other health risks like malnutrition and humanitarian assistance have already be discussed in section 2.4.3. A recent example for a health crisis that where corruption played a major role is the outbreak of Ebola in West Africa in 2014, killing over 11000 people (CDC, 2014). Corruption in the health sector in the years prior weakened the health care system and eroded the populations' trust in the system. Once Ebola broke out corruption also slowed down the response of the governments and reduced the ability to contain the disease (Dupuy \& Divjak, 2015). In Sierra Leone', for example, one third of the Ebola budget has been mismanaged (Audit Service Sierra Leone, 2014; O'Carroll, 2015). Corruption in the health sector can have a detrimental effect not only on the individual's but population health as a whole and can also be partially responsible for larger pandemics and the inability to control them. This in return can lead to major movement of people fleeing in search of better health. This once again often affects women and men differently.

One fundamental area of health security is access to clean water and sanitation, which would be one of the "most effective means to improve public health and save lives" (Montgomery \& Elimelech, 2007, p. 17). Yet, many people in developing countries still do not have sufficient access to water. "The main problem in providing people with safer water is not a lack of technical solutions (dams, sewages, water cleaning stations, etc.) or natural supply of clean water. Instead the problem lies mostly in dysfunctional administrative institutions" (Holmberg \& Rothstein, 2011, p. 533). As has been discussed with other public services, such as education or social security, corruption prevents delivery of clean water to those who need it (J. Davis, 2004). The water sector is particularly vulnerable to corrupt practices as it usually is a monopoly with management being often the sole responsibility of public authorities (Feuerstein et al., 2013, p. 14). Its impact on 


\section{Literature review}

society is dangerous since there is no substitute for water and people heavily depend on water services for drinking, sanitation, food, agriculture and energy (Feuerstein et al., 2013; Zinnbauer \& Dobson, 2008).

Figure 9 Corruption and health security

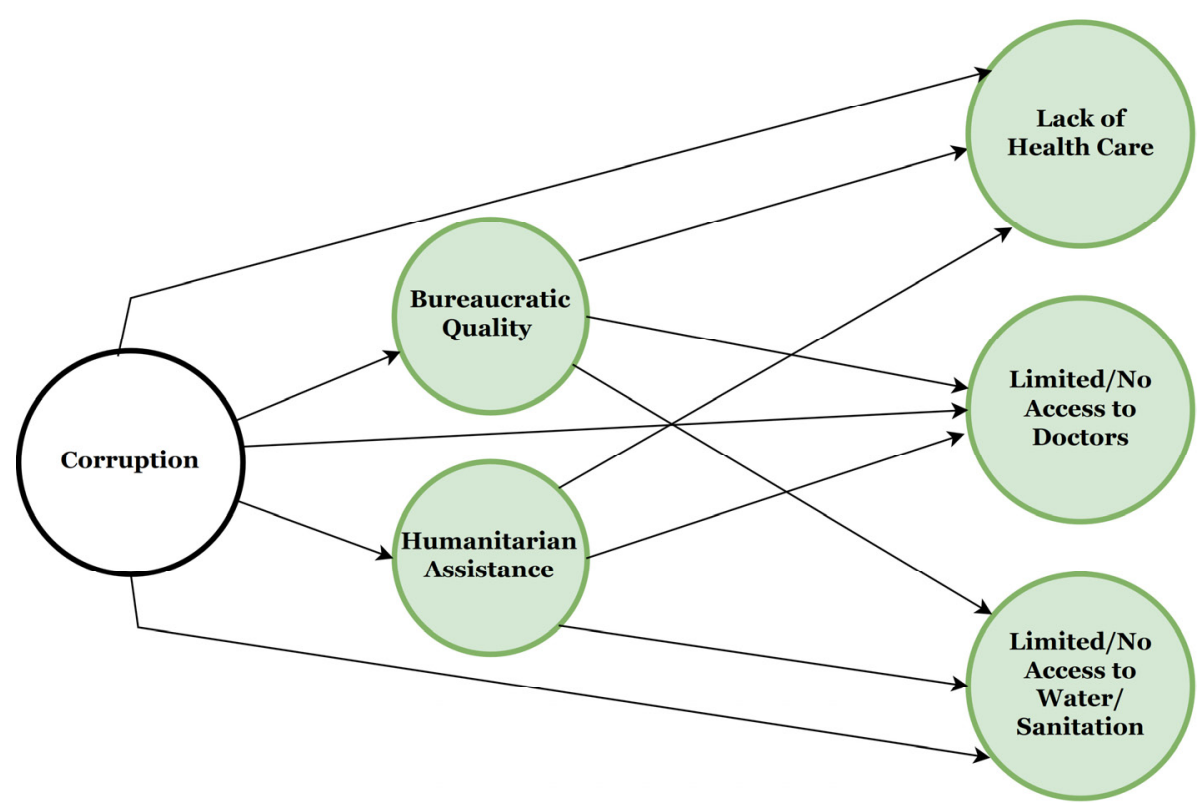

Transparency International dedicated it's 2008 Global Corruption Report to the issue and emphasizes that fighting corruption in the water sector has become more urgent as it affects "economic and human development, the destruction of vital ecosystems, and the fueling of social tension or even conflict over this essential resource" (Feuerstein et al., 2013, p. xxiii). One should stress that especially poor households suffer from this as "corruption significantly increases the cost of services"(Feuerstein et al., 2013) and deprives them of their already limited financial income. This can be considered a violation of the human right to water and negatively affects the services delivered, in terms of both quality and quantity. In addition, estimates suggest that the financial impact of corruption in the water sector is particularly high, which implies that a huge amount of money that should help for instance to improve the water infrastructure is lost. Furthermore, clientelism may prevent to allocate resources based on the peoples' needs when it comes to improving water infrastructure for instance through building dams. Moreover, corruption in the water sector can negatively impact the environment, increase environmental degradation and increase pollution, for instance when thinking of illegal permits for discharging wastewater or excessive abstraction and 
use of water. Corruption, hence, undermines laws and regulations to protect the environment. These aspects increase the vulnerability of local populations even more (Feuerstein et al., 2013; Zinnbauer \& Dobson, 2008). Increased environmental pollution (see section 2.4.5) is also related to corruption and leads to grave health risks.

\subsection{Gendered effects of corruption - a framework}

This framework should be considered a starting point for the discussion on the gendered effects of corruption. Chapter 6 in this dissertation will analyze parts of it when discussing how men and women are affected differently by corruption throughout their journey. The experience during migration is especially interesting for several reasons. For one, it shows that both men and women are disproportionally affected by corruption if they are in a vulnerable position. Second, the example shows the importance of gender norms in shaping these experiences and despite the similar underlying vulnerabilities the large differences in experiences. Lastly, it illustrates, what will be discussed in more detail in chapter 3 , the gendered forms of corruption, especially sextortion. 


\section{Literature review}

Figure 10 Gendered effects of corruption

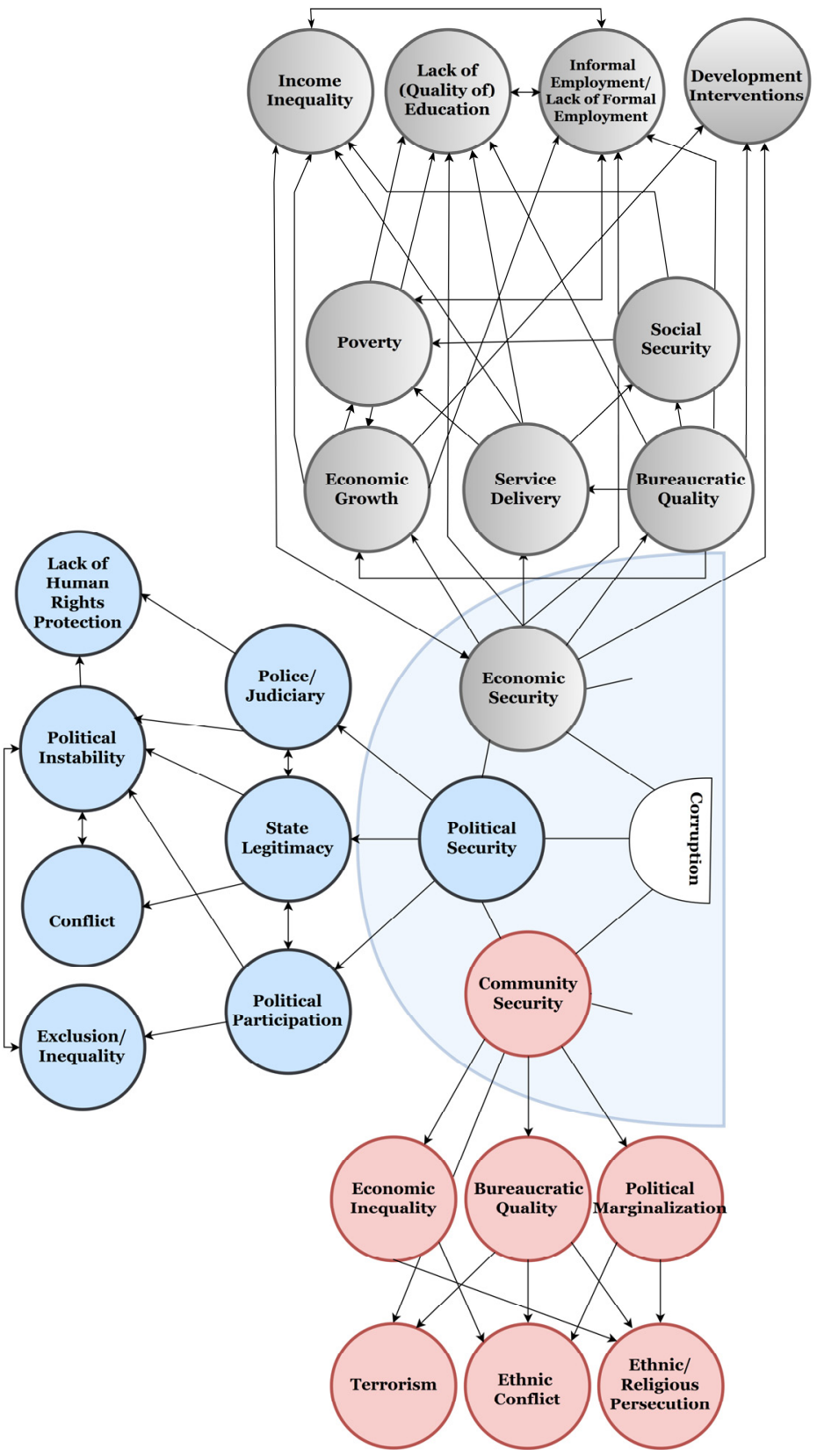




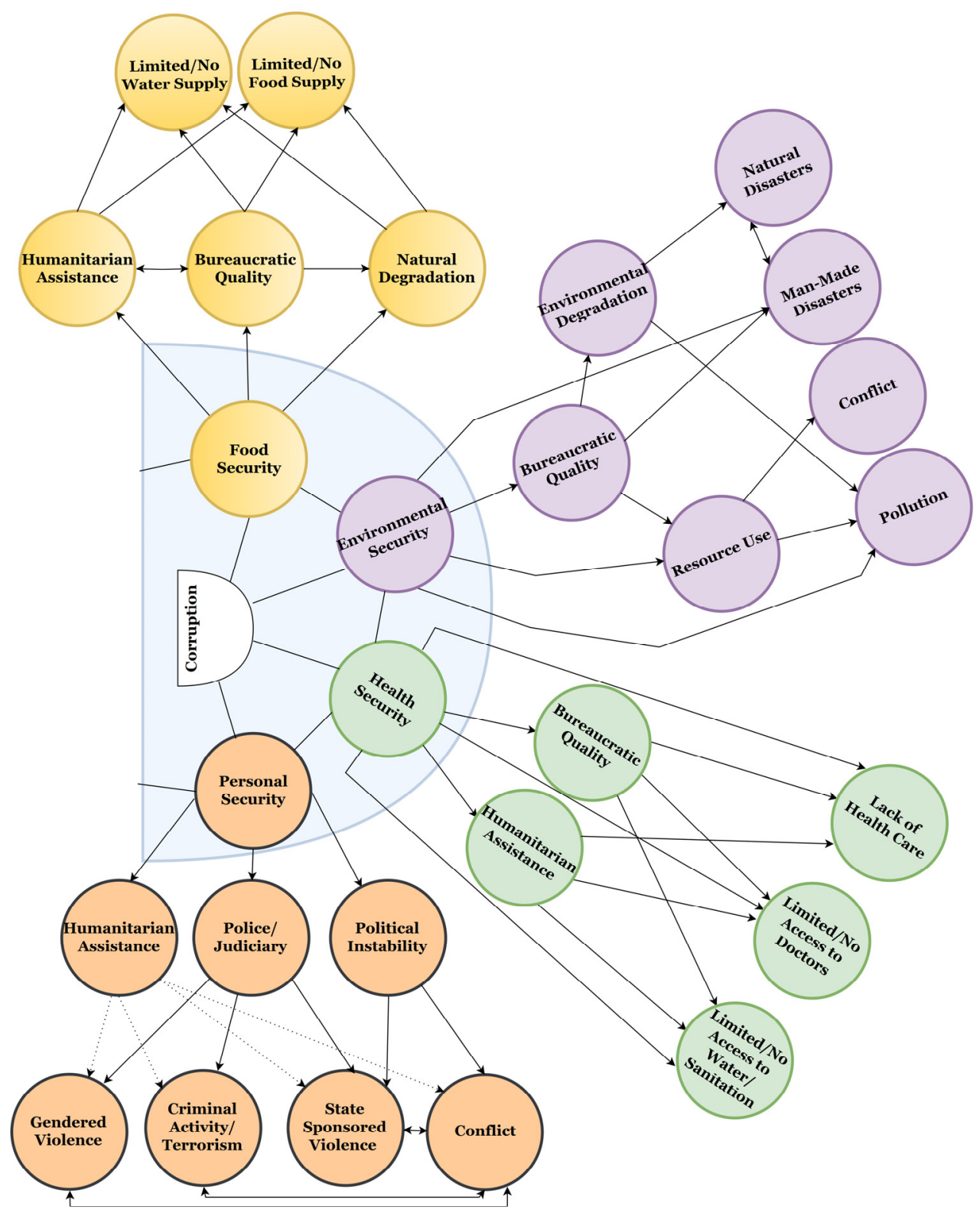




\subsection{Conclusions and ways forward}

While many advances have been made in researching the relationship of corruption and gender, much still needs to be understood. While three main central questions have frequently been discussed several problems remain unanswered which will, in part, be covered by the empirical chapters in this dissertation.

For one, the question of experiences of corruption. The presented framework is aimed at identifying the different connections between corruption and an individual's human security and how these can potentially be gendered. This framework should be thought of as a first guide to identify potential new research areas and show the importance of this line of research. Chapter 6 will pick up on this discussion with an analysis of the gendered effects of corruption and the role patriarchy plays in it.

As has been identified one of the major shortcomings of existing research on gender and corruption is the focus on the effect of women in politics on corruption and the treatment of women as a homogeneous group. To fully understand the gendered effects of corruption it is not enough to study the effects on men versus the effects on women, rather one must understand how corruption is linked to the complex gender system. Therefore, this dissertation explores how patriarchy is related to corruption on different levels. While chapter 3 discusses the importance of understanding how power itself is gendered and hence an abuse of power can never be understood as a gender-neutral phenomenon and introduces the importance of patriarchy in corruption research. Chapter 4 further explores this relationship by analyzing how views on the role of women as potential politicians and views on corruption are related to an underlying patriarchal system. In chapter 5 the discussion turns to the question of how patriarchy is used to prevent women from participating in political life and clientelistic political networks and how patriarchal norms are used to cement this exclusion. The last chapter turns to the question of experiences of corruption, looking at corruption during the migration journey and the role gender norms play in shaping these experiences. 


\section{The abuse of power as a gendered concept: the case of sextortion}

Of course, everything is different for women and men, so corruption wouldn't be an exception. Female experiences are shaped by the fact that, if they have nothing, they still have female bodies. So, corruption really takes place differently on female bodies.

$\overline{(\text { Expert Interview) }}$

\subsection{Introduction ${ }^{16}$}

The discussion of gender and corruption is one full of extremes - women as the new perfect anti-corruption force on the one hand or as the defenseless victims of corruption on the other, yet, the nuances of this relationship are still debated. As discussed in the previous chapter, in the last decade numerous studies have emerged helping to untangle the relationship, yet a question which interestingly has been largely neglected is how gender dynamics shape the forms and experiences of corruption of both men and women in society. Research on gender in other areas has long shown that rather than being a singular variable gender is a multidimensional and complex concept. Gender is about much more than biological differences of being a man or a woman; rather it is about the socially constructed roles associated with being male or female and the different opportunities, relationships, and power and influence attributed to men and women (Prince, 2005). However, corruption research up to date still focuses on an often-simplistic understanding of gender as a lateral and one-dimensional variable to be included in the analysis. Because of this narrow conception, gender has too often been used as an equivalent of "women". To this date, only very little research has considered how masculinities and the relative position of men in societies affect attitudes towards and experiences of corruption(e.g., Bjarnegård, 2013, 2018).

\footnotetext{
16 This chapter is based on the forthcoming working paper: Merkle, O. and Alberola, C.: Sextortion - a case for including gender in corruption research?
} 
Additionally, while research has shown that the effects of corruption can be gendered the act of corruption itself is mostly discussed as a gender-neutral phenomenon. This chapter argues that this is a fundamental misconception and leads to a male-centric understanding of corruption, which limits both our understanding of how and why corruption occurs as well as which acts should be considered corrupt. Hence, this chapter highlights the importance of including a thorough understanding of the gendered nature of power, in the discussion of the abuse of power, i.e., corruption and sets the stage for the discussions in the following chapters.

This chapter developed out of research on the experiences of corruption of migrants on their journey to Europe. During the fieldwork for this research it quickly became apparent that two essential questions have remained largely unanswered in the current debate on corruption: a) a more nuanced analysis of how corruption experiences are gendered (which will be discussed in detail in chapter 6 and b) a detailed discussion on the impact underlying gender regimes, i.e. patriarchy, have on corruption experiences. To illustrate the importance of including patriarchy and an understanding about the gendered nature of power in corruption research, the discussion in this chapter is centered around a relatively new concept, sexual extortion ('sextortion'), which has been defined as the "the abuse of power to obtain a sexual favor"(IAWJ, 2012, p. 9). This specific form of corruption was chosen for two reasons. Firstly, it is a phenomenon that shows the importance of broadening the classical male-centric view of corruption focusing on the exchange of money and goods. Secondly, as the discussion will show it is an example of the problematic implicit assumption of power hierarchies in corruption itself which have not been studied in enough detail until now. This chapter thus discusses how underlying gender power structures can be linked to corruption. One of the most paradigmatic gendered abuses of power is sexual and genderbased violence (SGBV), which as feminist research has shown, is embedded in a very particular power system that legitimizes and perpetuates such violence; the power system of patriarchy.

Patriarchy here refers to the "set of social arrangements that privilege men, in which men as a group dominate women as a group, structurally and ideologically"(Hapke, 2013, p. 12; Hunnicutt, 2009; Walby, 1990) and is a complex system of power relationships where "both men and women wield varying types and amounts of power" (Hunnicutt, 2009, p. 565). Importantly it focuses on social arrangements and social systems that reinforce domination and rather than looking at individual men's motivation to dominate takes a look at societal 
structures. (Hunnicutt, 2009) Patriarchy as a concept has a fundamental advantage. Unlike other terms that are frequently used that are presented as a gender-neutral category (such as 'gender regimes' or 'gender relations' among others) it "provides a permanent reminder that men rather than women are the dominant and structurally privileged gender group" (Bryson, 1999, p. 320).

Therefore, the discussion in this chapter discusses in how far corruption as an abuse of power is also a patriarchal phenomenon. Using the example of sextortion, it argues that corruption, like SGBV, should be seen as expressions of the patriarchal power system: both are abuses of power that are systematically exerted towards a relatively powerless group. As will be explained further later, corruption and SGBV are abuses that derive from the same source of power in its most violent form: hegemonic masculinity. Therefore, they are two co-existing phenomena within patriarchy, which can overlap or be intertwined such as in the case of sextortion.

A first look at the data on corruption and SGBV shows that there is a correlation yet, this data tells us nothing about the causality of the relationship (Figure 11). The figure below plots the corruption perception index of 2016 (Transparency International, 2017) against the Gender Security Index, one of the dimensions in the Women, Peace and Security Index (WPS) of 2017 for 165 countries with available data (GIWPS and PRIO, 2017). The security index is composed of three indicators; lifetime intimate partner violence, women's perception of community safety and lastly, organized violence.

Figure 11 Corruption and the gender security index

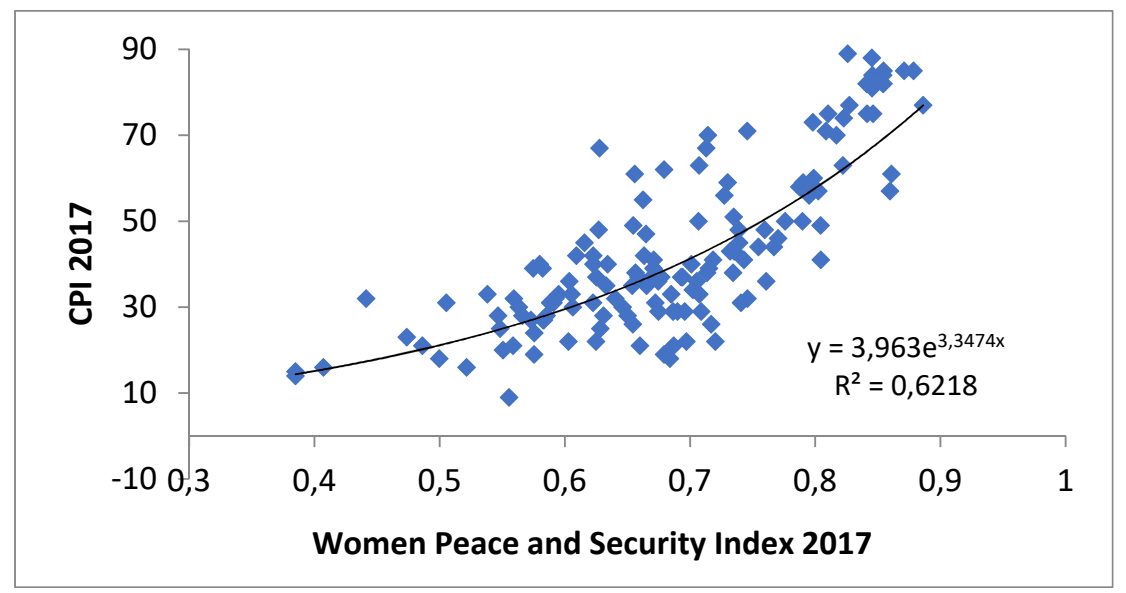

Source Transparency International (2017) and GIWPS and PRIO (2017) 


\subsection{Corruption's implicit assumptions}

Scholarly debate has included a continuous discussion aimed at finding the most appropriate definition of corruption. Indeed, "[c]lassical conceptions focusing on the moral vitality of whole societies have given way to modern 'behavior classification' definitions in which specific actions are measured against a variety of standards" (Johnston, 1996, p. 321) The latter are however still disputed and vary in multiple ways. Early definitions of corruption focused exclusively on government corruption. Nye (1967) for example proposed that "[c]orruption is the behavior that deviates from the formal duties of a public role because of privateregarding, pecuniary or status gain" (p. 419). In recent years, the definition has been broadened to capture the variety of actors and types of gains involved: for example, many European development agencies use the definition of corruption as "the abuse of entrusted authority for illicit gain"(Disch, Vigeland, \& Sundet, 2008). The most widely used definition of corruption is the one promoted by Transparency International: "The abuse of entrusted power for private gain" (Transparency International, n.d., para. 1). ${ }^{17}$ Keeping definitions short and comprehensible surely has many advantages, yet it also means that discussions using these definitions frequently contain a set of implicit assumptions.

Some of these implicit assumptions have been thoroughly discussed. The first question is about 'private gain'. Many agree that the concept here has to be understood broader also to include "activities undertaken in the interests of one's political party, ethnic group or familial network" (Philp, 2008, p. 31). A second implicit assumption is that in their simplest form all definitions consider corruption a deviation from "an ideal state or natural condition" (Lancaster \& Montinola, 2001, p. 6) and therefore corruption is a highly political phenomenon. Stephenson (2014) identifies three possibilities of this deviation from the standard: law (whenever legal statutes are being violated), public opinion (when the public feels that power is being abused) and public interest (when actions conducted are not in the public interest). Especially when discussing corruption in non-Western societies, the question then might become whose standards and morals apply to determine this ideal state.

This is the third, often implicit, discussion, i.e., the assumption that there is a consensus on what the duties of public office entail. Yet, as Philp (2008) discusses, this consensus is not always existent in local populations, and by not defining

\footnotetext{
${ }^{17}$ For a detailed overview of the development of definitions of corruption see for example Kurer (2005).
} 
clearer what 'abuse' or 'misuse' entails, definitions face the danger of being "culturally relativistic" (Rothstein \& Teorell, 2008, p. 171). Alternative definitions have been coined to take this into consideration. Kurer (2005, p. 230) for example argues that "corruption involves a holder of public office violating the impartiality principle ${ }^{18}$ in order to achieve private gain." He argues that this focus depends less on a Western interpretation of "abuse or misuse", as impartiality is a more universally understood concept (Rothstein \& Teorell, 2008, p. 171) ${ }^{19}$. One major advantage of this definition as argued by Rothstein and Teorell (2008) is that it looks at the 'exercise of public power'(i.e., the way in which authority is exercised) rather than the access to a public authority (i.e., the determination of policy content). The authors argue that this is beneficial for several reasons, for one, the content of policies is not only difficult to judge but also very context specific. Even more importantly, they argue that including policy contents in general into the discussion of corruption or quality of government would essentially lead to international organizations (e.g., the World Bank) deciding on the content of the policies rather than the democratic process in the countries itself. While at first sight, this seems to untangle one of the implicit assumptions it explicitly ignores another: the question of access to power. As this chapter will argue, omitting the question of who actually has access to the power that is abused in a corrupt act leads to ignoring the highly gendered character of the corrupt act itself.

Focusing on the gendered nature not only of the consequences or causes of corruption but the act itself should help reshape and broaden the definition of corruption and generally lead to a more inclusive conceptualization, which will also assist in describing women's substantially different experiences of corruption (which will be seen in chapter 6). As this chapter will discuss, this requires a major conceptual shift from the classic understanding of corruption as merely an economic or material exchange, to a new understanding in which it can also involve a sexual and emotional exchange, as expressed by an interview partner ${ }^{20}$ : "The most common is a male-centric definition of corruption. It is capital-based. But, if we take another approach, a gendered approach, we are able to see the role of reproductive labor" (Expert Interview).

\footnotetext{
18 The principle where "a state ought to treat equally those who deserve equally" (Kurer, 2005, p. 223).

19 For a detailed discussion of the benefits and criticisms of using the impartiality principle see Rothstein and Teorell (2008, p. 173ff).

${ }^{20}$ Interviews were conducted in the context of a project on the experiences of corruption during migration. For more details on the methodology and the ethical review please see chapter 6.
} 


\subsection{Corruption and power structures - a black box}

Although no matter which definition one looks at the notion of abuse of power is a core component of corruption, most studies tend to overlook the fundamental question of power structures in place in corrupt contexts. While there is an extensive body of literature on the measurement of corruption (Sampford, 2006; Urra, 2007), its impact on the quality of institutions (McMillan \& Zoido, 2004) or on economic growth and development (Bardhan, 1997; Campos et al., 2010; Mauro, 1995; Ugur, 2011), this chapter finds that the issue of power ${ }^{21}$ is often ignored or made implicit in introductory assumptions. Even if discussions touch on the issue of power -such as in Rothstein and Teorell (2008)- since they are assumed as a fixed and legitimate, the power structures in corruption are rendered invisible. As pointed out by experts in gender and migration, the issue of power and powerholders is absolutely crucial to understand the dynamics of corruption. As one expert noted: "[Corruption] happens when there is illicit gain, using and abusing from authority, always involves this notion of power over someone. It's about the power to coerce and corrupt someone."

Power here does not always refer only to the highest levels, but different types of power are exerted by different high and low-level positions (Expert Interview). Nonetheless, the omission or misrecognition of power relations is generally common, particularly when it comes to power systems build upon male domination and female subordination, that is, patriarchal systems (Hunnicutt, 2009). Indeed, patriarchy is "a system of social structures and practices in which men dominate, oppress and exploit women" (Walby, 1989, p. 214). Recent definitions would nuance the one-directionality of domination and violence from men towards women and point at the fact that powerful men systematically oppress men of inferior status, just as powerful women tend to do with other women. Indeed, Hunnicutt (2009) expresses the need for a theory on the varieties of patriarchy that can also explain male-on-male or female-on-female violence and oppression. The fact that patriarchy is not only perpetuated by both men and women but also is a system that easily adapts itself make it especially difficult and important to study (Enloe, 2017).

\footnotetext{
${ }^{21}$ Power itself is a complex concept; it has been defined in a large variety of ways depending of the discipline from which it is studied. In the context of this research, power will be defined as the "relative capacity to modify others' states by providing or withholding resources or administering punishment" (Keltner, Gruenfeld, \& Anderson, 2003, p. 265).
} 
Even though patriarchy distinctly appears as a system of abuse of power, studies linking any kind of corruption to patriarchy are almost inexistent (with the exception of Pepinsky, 1992). While, the unbalanced gender relation that structures patriarchy is precisely one of the most persistent patterns in power relations across times and societies, most corruption research observes the abuse of power without considering the broader power structures in which it is embedded. This is an important lacuna in most corruption scholarship, which has too often neglected the identification of power structures and dynamics at work, resulting in the invisibility of relevant power struggles and contributing to the consolidation of hierarchies.

3.3.1.Power, patriarchy, and corruption, bridging the gaps in the literature

As confirmed by several interviewees throughout this research, there are strong reasons to believe that corruption varies substantially across genders. The forms as well as the intensity of corruption appear to be substantially different in the experiences of migrant men and women. As one male migrant described it:

It's all corruption and violence. For men, if you don't have money then its torture, for women it's sexual violence. They tell to the women 'you want to cross? Then come with me' (...) Us, men, we give them money, but for women, it's this double price. They always have to pay this price, it's an enormous suffering you see?

While, as discussed, reflections on power structures in these corrupt dynamics are most often left out of corruption studies, it is relevant to note that a few recent studies have indeed looked at corruption by considering the role that attitudes and power relations might play in it. As previously discussed, Rothstein and Teorell (2008) define corruption as the case when 'the exercise of power' is not done impartial, however, explicitly decide to neglect the question of how the power holder has gained power and how the policy was designed. Wang and Sun (2016), in a set of three studies, investigate how different individual attitudes towards power lead to different types of power and hence varying levels of corrupt behaviors and tolerance to corruption. As others have discussed attitudes towards power can vary largely across different cultures, for instance when comparing Scandinavian to South-European power systems and their respective corruption levels (Papakostas, 2001). Wang and Sun's studies show that personalized power, aimed at reaching self-centered goals, is found to increase corrupt behavior and 
tolerance towards the corrupt practices of others, especially towards high-position others. Other forms of power on the other hand, such as socialized power, aimed at achieving pro-social goals appear to decrease tolerance to corruption. There are several important weak points regarding their approach to power. First, the chapter contrasts two opposed conceptions of power, conceptualizing it as a binary rather than as a multi-faceted and multi-layered concept. In practice, there is a wide range of power configurations that do not necessarily oppose each other. By looking only at the two extremes of this power-spectrum, the authors rely too much on the naïve concept of "socialized power". However, this type of power aimed at helping others might be used only to serve a specific ethnic/gender/age group, in which case corruption is not used within this group but used instead to gain benefits from "the other", i.e., outsider groups. The main weak point of the argument, however, is that while they have looked at how different individual positions of power may yield different levels of corruption, one can argue that the authors have also not observed the sources of power and the attributes based on which power is distributed. This legitimizes the position of the power holders and their variable attitudes towards corruption.

Additionally, earlier works have looked at the power relations in corruption within specific fields such as organized crime or education. Van Duyne (1996) argues that the merchant power of organized crime groups is partly gained and maintained through corruption. Corruption, to him, is not a threat from criminal groups but rather a weakness of all others in society who are corruptible (p. 234). While the author raises an interesting point on the agency and responsibility of the participants of a corrupt act, the study again does not identify the source of power which would be in this case the ability to exert violence. On the other hand, in the higher education sector, Waite \& Allen (2003) argue that the highly bureaucratic and hierarchic systems in universities favor corruption. High-ranking academics have often abused their power through these hierarchical structures, to different degrees, and for different purposes. However, only in the conclusion do the authors briefly mention the inequality systems (racism, classism, sexism) on which these solid power structures rest and through which the abuse of power is justified (p.294). Therefore, both studies provide interesting insights into the ways in which power is linked to corruption. However, both of them discuss certain power distributions without looking at the sources and structures of power, hence contributing to a certain extent to a legitimation of these power systems. Moreover, by not choosing to recognize one or several power systems, they fail to provide 
more comprehensive insights into the forms and effects of corruption in each field and how to potentially prevent it.

Importantly, a few studies have looked at corruption from the intersection of gender and power relations. For instance, Esarey \& Chirillo (2013) try to break the stereotype on women naturally seen as the "fairer sex" by arguing that the cultural and the institutional power contexts are in fact the determining factors of women's attitudes and behaviors concerning corruption. By reviewing several cross-country experiments, the authors found that there are no significant gender differences in corruption within countries, but rather across countries, along the axis of autocratic to democratic institutional arrangements. Indeed, in democratic-leaning states, every $10 \%$ increase in female participation in parliament is associated with a 0.515 significant increase in the Control of Corruption score, while this no variation is registered in autocratic-leaning states. In settings where corruption is stigmatized and punished, mainly in functional democratic regimes where the electorate punishes corruption in competitive elections, one can expect gender differences in attitudes towards corruption. This, according to Esarey \& Chirillo (2013), is due to the fact that "women are more powerfully subject to social norms because discrimination makes their position more tenuous. Insomuch that sex discrimination means holding women to a different (higher) standard than men for the same reward, it is riskier for them to flout the formal and informal rules of political culture because transgressions are more likely to invite retaliation" (p.365) (this will be discussed further in chapter 5). Indeed, social expectations on what the role of women should be concerning corruption will determine their will and ability to participate in corruption, while not conforming to these expectations results in disproportionate punishment. This chapter takes their argument further by arguing that it is in fact power structures that shape expectations and gender roles and hence determine who is powerful and who is allowed to participate in corruption. In this case, patriarchal power structures result in low levels of corruption among women as compared to men because they do not have the same access and amount of power.

Along the same lines, Echazu (2010) argues that the relationship between female participation in institutions and lower levels of corruption is not due to the popular idea of innate moral values, but rather to gender differences in the costs for corrupt behavior. She bases her argument on the standard crime and corruption model, to which she adds a gender empathy (gender bias) component. Similar to Esarey \& Chirillo (2013), she finds that the gender differentials in the social punishment for corruption raise the costs of corruption for women, hence 
resulting in lower levels of tolerance to corruption for women. Indeed, where one group is dominant, the other group will be much more intolerant of this group's misbehavior. Here again, women in powerful positions are mostly constrained by stereotypes on their natural sense of integrity and justice. However, it is now proven that the idea of naturally docile and incorruptible women corresponds more to a stereotype rather than a reality and is, as chapter 5 will show, often used to exclude women from certain offices. Group hierarchies and norms rather determine attitude to corruption. Hence, without changing the system, simply increasing the number of women, reversing the gender balance, might, therefore, have the opposite effect and lead to equal or more corruption (Merkle, Reinold, \& Siegel, 2017a).

Both studies also raise a very important point about how the institutional contexts and gendered power structures shape corruption. By doing so, they begin to fill an important gap in corruption literature. These papers hint at the fact that gender regimes within each institutional context and their broader social environment shape both female participation and corruption simultaneously. In fact, Esarey \& Chirillo (2013) hint at this in their conclusion: "We believe that it would be helpful for future research to focus on a finer grained picture of the environment beyond broad institutional context. For example, examining the pathway through which women enter politics could help us understand how they behave once entrenched in government" (p.386). This chapter aims at taking this point further by emphasizing that power structures and their subsequent gender regimes need to be better understood. Identifying and understanding the power systems within which corruption takes place will allow for a more solid understanding of corruption patterns and dynamics. Undoubtedly, the larger power structures at play need to be brought at the fore-front in corruption research.

\subsubsection{Misrecognition reinforces power structures}

Since corruption is an abuse of power, all corrupt acts display a particular power hierarchy; implying necessarily that one agent is powerful while the other is less so (Koester, 2015). In turn, as pointed out by Bourdieu (1979), misrecognition of power relations is precisely what reinforces and preserves power imbalances in societies. One of Bourdieu's main contribution has been to point at the fact that "symbolic domination" entails a certain degree of complicity of the subordinated agents (Mottier, 2002, p. 349). Indeed, as long as the subordinated agents are complicit, power structures are legitimized and reproduced. As Koester (2015) explains, the most pervasive exercise of power operates less visibly "by shaping 
people's sense of themselves and their world, thus keeping issues not only off the agenda but off people's minds" (p.2). By rendering power invisible, the powerful effectively ensure the continuation of their power status to their own benefit. Therefore, talking about power matters, especially also in research on corruption.

The 'making invisible' of power structures also functions through the language employed to characterize corruption; the meaning of power as domination is diluted in the expressions "entrusted authority" (Disch et al., 2008, p. 11), "public role" (Nye, 1967, p. 419), or "public office" (Goel \& Nelson, 1998, p. 109). These terms imply that the agents engaging in corruption need to have a certain level of discretion and power that will allow them to engage in corruption. However, while the expressions cited are connected to the notion of power, they are not equivalents. Indeed, the term "authority" implies consent, morality, and autonomy, which are very distinct notions to those of force, constraint and subordination which are embodied in the concept of power (Hoffman \& Graham, 2006). The use of the term authority gives a sense of social and moral legitimacy rather than domination or imposition. Subordination works when the subordinated agents make assumptions on the legitimacy of power and fail to recognize its exacts sources and holders. However, as put by Pepinsky (1992): "There is no logical starting point for a patriarchal approach to freeing people from corruption" (p.25). When studying corruption, its forms, its magnitude, and its impact, one ought to ask first some essential questions concerning the specific power configuration within the type of corruption in focus: Whose power? Over whom? What form does this power take? And last but not least, what is the source of this particular power?

Naturally, this chapter does not imply that all those who hold power automatically abuse it. Instead, it argues that investigations on the abuse of power need to consider which individuals or groups hold power and what interests leads them to abuse their office. Such identifications are sometimes far from being obvious, as power divisions are in no way binary and fixed over time. As pointed out by Hunnicutt (2009), power systems are based on "labyrinths of power dynamics". These can be envisioned as different "terrains of power", in which different actors are assigned "varying amounts of social value, privilege, and power (p.558). For instance, within the same system of domination, the power relations in corruption between a customs agent and a low-educated migrant woman is different to that of a university professor and her boss. A range of variables that determine the assigned amount of power is at play in every act of corruption. This is due to the 
intersection of various axis of discrimination and the way in which these shape power allocations, as developed in the next section.

Moreover, it is not only important to recognize the power relations in a given situation of corruption between two individuals or groups, but also to recognize the broader power dynamics in which it takes place. Power is often individualized, and difficult to identify outside of individual acts within a structure of power and a set of social relations. However, as pointed out by Connell (1987), actions such as corruption in this case "are not intelligible without the structure"(p. 107). Power is intrinsically asymmetrical and reflects a certain inequality structure organized along one or several axes of inequality such as gender, race, age, sexual orientation, income level, professional status, reproductive status, and others. There are various structures or systems of power that have been theorized and are propitious to corruption in various magnitudes. Most systems of power overlap and are mutually supportive. In the case cited, Connell is referring to the power structures within the gender order of patriarchy (Hunnicutt, 2009). Other systems of power based on subordination of a specific population include classism, colonialism, heterosexism, among others. Overall hierarchical structures of social inequality such as these provide the opportunity for abuse of power, that is, for corruption. Hence, to understand and study corruption from its roots, it is crucial to reveal the power relations in place and the structural inequalities that these reflect.

\subsection{Gender as a power system}

This chapter argues that one of the most common power systems in place at the global level and relevant to the discussion on corruption is that of patriarchy; a power hierarchy exclusively based on the gender divide. As mentioned, gender is defined as the set of roles, behaviors, and attitudes that are assigned to men and women in society (Prince, 2005). This gender divide in social roles and value is, in fact, the most persistent pattern in power distribution across societies. Inequalities in power are sustained by assigned gender roles which create the gendered division of labor, which in turn shapes the distribution of power at all levels, from the household to the highest levels of the political sphere. Besides an uneven distribution of power, patriarchy is also characterized by the way in which such power is exerted. While Follett proposed in 1924 "power-with" or "power to" as paradigms that see power as collective and relational and lead to alternative social organizations, as she acknowledged, global patriarchy is rather characterized by the "power-over" paradigm exerted through polarity and coercion (Melé \& Rosanas, 2003). "Power-over" is perhaps the most observed configuration of power 
in our societies, in which the group in power has the capacity to influence all other's states by providing or withholding resource, mainly through coercion and the monopoly of violence. Gender roles are thus power relations within the prevalent "power-over" paradigm, in which men of all ranks systematically exert power over women (Koester, 2015). Gender-based power hierarchies can be identified in every aspect of society. In the context of this research, gendered power relations quickly became apparent when discussing migrant women's journeys. As one health worker stated: "Women victims of trafficking have no power over their sexual and reproductive rights. If the networks want them to abort they abort, if it wants them to have it they have it. Its total and absolute dependency." And another expert described her experience: "99\% of women arrive through human trafficking networks controlled by men. It is absolutely impossible for women to do this journey on their own." Dependency on males in all aspects of the migration journey is a determining factor in shaping the journey (see chapter 6 for more detail).

With this in mind, it is relevant to note that the ways in which gender and power interact are multi-directional. Indeed, gender is not solely a cause but also a result of power relations. The power system itself serves to reinforce gender roles. A prime example of this dynamic can be seen with sextortion, whereby demanding sexual acts from women, men are reinforcing the assumption that their bodies is their most valuable possession and their role is mainly sexual and reproductive. Patriarchal power relations have an intrinsically gendered impact on individuals of all genders. At the same time, the gender divide serves as an instrument to reassert and legitimize the power distribution in patriarchy. As put by Koester (2015): "Gender is a key mechanism through which power not only constrains but constitutes individuals and is perhaps the most persistent form of 'invisible power' in our world." (p. 3). Here again, the societal assumptions on gender roles and their corresponding power allocations contribute to the misrecognition of power and its holders, which in turn perpetuates inequalities. In that sense, power systems have self-sustaining dynamics that ought to be identified if these are to be changed.

Along with gender, other axes of inequality come into play in every system of power. Different forms of discrimination are often combined or overlapped. Indeed, as initially pointed out by Crenshaw, a woman's "value" is not determined by gender alone but also by race, age, class, reproductive status, sexual orientation, among many others. The term "intersectionality" is also useful to understand how different oppressive institutions (racism, sexism, able-ism, etc.) are interconnected 
and cannot be observed or fought separately (Crenshaw, 1991; Samuels \& RossSheriff, 2008). In that sense, patriarchy is very often intertwined with classism, racism, and heteronormativity, among others. Intersectionality allows us to observe how the different attributes of an individual or group come together to determine his or her social location on a "matrix of domination", and the resulting power allocations (Hunnicutt, 2009). One of the experts interviewed illustrated this idea by pointing at the condition of certain categories of migrant women: "So vulnerability is even bigger when she's a woman, also poor and also black. For instance, in Spain we studied discrimination; the most discriminated are those who are black, poor and are trapped in prostitution networks (...) Police was telling there were bitches, all they say are lies, all they want are papers to stay. This is the answer of the state!"

It is important to also point out that corruption seems to be more intense as well as for those who are the most disadvantaged, in that sense it seems there is a cumulative aspect to corruption that only reinforces inequalities, as pointed out by several interviewees:

Indirect corruption is very prevalent; many victims tell us they don't want or can't return to the origin country because as poor women without economic capacity they are not going to receive any kind of attention from their authorities. There is so much corruption in these countries that the authorities won't protect unless there is money involved. They don't have economic capacity to cover this extortion. This makes them more vulnerable. (Expert Interview)

Additionally, those gender roles provide the ground for abuse of power does not only mean that high-status men may abuse of women, but also that higher-ranking men may abuse of lower-status men, which is generally the majority of corruption cases (Boehm, 2015). As proposed by feminist scholars, there is a gender hierarchy with the gender category of men as well. For Connell (1987), this hierarchy involves hegemonic masculinity, conservative masculinity, and subordinated masculinity. Indeed, a few powerful hegemons in patriarchy do not only oppress women but also the great majority of men. According to Connell (1987), hegemonic masculinity is the core of power in the gender order: "if authority is defined as legitimate power, then we can say that the main axis of the power structure of gender is the general connection of authority with masculinity" (p.109). The general assumption that a certain kind of masculinity equates authority is the very 
basis and legitimizing factor of patriarchy. Hegemonic masculinity is a widespread form of domination that translates into practices characterized by coercion, force, and violence. Men who are in positions of power within a given institution due to their gender, age, income level, academic achievements or level of responsibility have usually embodied hegemonic masculinity. The latter then relies on two pillars or sources of power: the subordination of women and the hierarchy of male dominance.

\subsection{Institutions' gender regimes}

Moreover, power systems transcend multiple aspects and levels of social life in which power is implied. Feminists scholars have identified different structures of power on which patriarchy relies. For instance, Walby (1989) points at the patriarchal structures of paid work, household production, culture, sexuality, violence, and the state. The division of the public and private sphere has indeed been a key component for the assertion of patriarchy, by creating two different spheres of power relations and confining women to the "less valuable" domestic sphere (Federici, 1975). Each sphere reproduces the power structure of patriarchy as they are organized according to well-defined gender roles. According to these well-defined gender roles, women are caring and do not seek for self-benefit within these structures, which nurtures the stereotype on their falsely positive moral integrity and incorruptibility.

Power hierarchies transcend all spheres of society -all of the structures mentioned above- and notably public institutions. It appears clearly that institutions are not neutral; scholars have emphasized that institutional actors and processes are inevitably gendered (Acker, 1992; Connell, 2006; Kenny, 2007; Lovenduski \& Norris, 2003). Institutions rely on gender roles for their functioning, that way shaping and reinforcing the current distribution of power. Gender imbalances of power in public and private institutions create the potential for corruption (Echazu, 2010). Connell (1987, p. 109) advances that hegemonic masculinity as a power core has four main components, the first of which refers to the work-forces of institutionalized violence such as the military, paramilitary, police and prison systems, among others. These are precisely institutions that are typically associated with corrupt or non-transparent practices. Corruption is not only prevalent in male-dominated public justice and security institutions but also in a whole range of private institutions from multinational firms to international and local NonGovernmental Organizations (Anand, Ashforth, \& Joshi, 2005). 
Power relations and gender relations are hence embedded in public institutions. As proposed by Connell (1987), a gender regime refers to the pattern of gender relations within a particular institution, while the ensemble of gender regimes across the whole range of institutions is known as the gender order. Connell's framework is particularly relevant to analyses the role played by corruption in patriarchy. Following this framework, this chapter argues that there is a circular relationship between the gender order, institutions, and corruption. Indeed, corruption is a result of institutions' own gender regime but also comes as a main instrument of subordination for the assertion of the broader gender order. Through gender regimes, corruption is generated while in turn, corruption reinforces the gender order by abusing the powerless. As mentioned earlier, corruption takes place between mostly powerful male agents and power-destitute agents such as women and men of lower status. Every institution embodies a set of power relations and consequently displays the corresponding levels of corruption. As suggested by a variety of studies on the matter, institutions such as parliaments, governments and public bureaucracies with more balanced gender relations usually display lower levels of corruption (Echazu, 2010; Esarey \& Chirillo, 2013). However, the hypothesis driving the research by Dollar et al. (2001) is based on the assumption that women, given their gender role, are intrinsically "more trustworthy and public-spirited than men" (p.423). This is also one of the main hypothesis underlying the study by Swamy et al. (2001), although the authors are here more nuanced and briefly hint at possible reverse causality.

Considering the circular relationship of patriarchy and its self-sustaining effect on corruption, this analysis suggests that high corruption levels in non-genderbalanced institutions are rather due to highly hierarchical patriarchal power structures that provide the ground for the abuse of power and simultaneously keep the powerless out of such institutions. While the studies mentioned previously may have been positive in bringing new arguments for the participation of women in the public and political arena, they can also be dangerous in the sense that they reinforce the stereotype on the irrevocable and uniform nature of women, hence comforting the gender regime (for a detailed discussion on how this can occur see chapter 5). The myth of inherently less corrupt women leads to the reinforcement of gender stereotypes (N. Hossain, Nyami Musembi, \& Hughes, 2010), where "[t]he very traits that traditionally branded women as deficient in moral development, their concern to help and to please, are now seen as a functional for good governance reforms in developing and transitional societies" (Goetz, 2007, S. 91). Hazarika (2016) continues this 
argument and notes that "traits ascribed to women once viewed as making for moral weakness are now seen as cornerstones of moral strength, that is, the definition of morality has changed. It may make little sense to consider women morally superior if notions of morality are mutable. Perhaps it is more useful to speak of honesty than morality" (p.8). Women are not innately the "fairer sex", they simply do not have access to opportunities for corrupt behavior in such gendered systems of power (Bjarnegård, 2013; Goetz, 2007). This is very much in line with the findings of Echazu (2010) and Esarey \& Chirillo (2013) that were detailed in section 3.2. The verdict is still out on the role women that can and should play in anti-corruption; however, it is clear that this discussion has deflected attention from the big question of gendered impacts of corruption (Goetz, 2007; UNDP, 2012). However, looking at the impact of corruption is fundamental since it can have great consequences for individual victims and societies as a whole. In the context of patriarchy, corruption is one of the main instruments of hegemonic masculinity and can be expressed through coercion and different forms of violence. Corruption takes places in a variety of ways; bribery is often referred to as its main expression, however, corruption can take many other forms, some of which are non-monetary, such as nepotism, patronage, fraud and some of which are particularly gendered such as sexual extortion or "sextortion" (IAWJ, 2012; Merkle et al., 2017a, p. 11).

As will be developed in the next section, sextortion as a form of corruption clearly reflects the power hierarchies at play in a wide range of institutions and the violence that results from it. As one of the most violent expressions of corruption, sextortion is the embodiment of the corruptions' own gender regime.

\subsection{Sextortion as a gendered form of corruption}

At the intersection of corruption and sexual violence, sextortion is defined as the abuse of power to obtain sexual benefit or advantage (IAWJ, 2012). Although the practice is not new, the term "sextortion" was coined only recently by the International Association of Women Judges (IAWJ), who saw the need to provide a legal frame for this specific form of corruption. Extortion is a form of corruption in which an agent uses his/her position to make threats and thereby obtain private gain (Fjeldstad, Amundsen, Søreide, \& Andvig, Jens Chr, 2001). Cases where the payment is in forced sexual services shall be referred to as sextortion. Earlier works have also pointed at the necessity of the recognition of the term, notably to replace the jargon term "quid pro quo harassment". As Baker (1995) puts it: "Quid pro quo sexual harassment is sexual extortion. By threatening to deny or withdraw benefits 
from a victim, the harasser attempts to induce her to comply with his sexual demands." (p. 240). In addition to the sexual component, three distinct features need to be present for the corruption component in sextortion: "abuse of authority; a quid pro quo exchange; and psychological coercion rather than physical force" (IAWJ, 2012, p.9). On the latter, the sexual component in sextortion does not have to involve sexual intercourse but can also be acts like exposing private body parts or posing for sexual photographs (ibid.). These three elements are important in that they allow professionals to recognize when sexual abuse is also sextortion.

The International Association of Women Judges also lists the numerous configurations that this type of corruption can have (Merkle et al., 2017a, p. 34). For instance, sextortion can happen when a judge requests sexual favors in order to grant asylum to a refugee. Another example of sextortion is when a teacher asks for sexual services to pass a student. In fact, education is one of the most studied fields for cases of sextortion. In primary and secondary education, sextortion exposes pupils to sexual and gender-based violence at very early ages. Sextortion is carried by higher authorities such as teachers or staff, particularly male teachers. In Zimbabwe, South-Africa, Uganda as well as Australia, male teachers have reportedly requested sexual services in exchange of good grades and materials to young girls, or simply against reprisals (Nhundu \& Shumba, 2001; Prinsloo, 2006; Thomson Reuters Foundation, International Association of Women Judges, \& Marval, O'Farrell, Mairal, 2015). This has grave consequences for girls' schooling attendance rates and education levels (Leach \& Sitaram, 2007). There is also a large number of studies on the prevalence of sexual harassment, including sextortion, in higher education (e.g., Eyre, 2000; Gelfand, Fitzgerald, \& Drasgow, 1995). Power relations and strongly hierarchical systems in academia help the discourse on the legitimation of sexual harassment and has contributed to hiding the issue for decades (Eyre, 2000).

Lastly, recent studies on gendered experiences of migration and corruption have found that sextortion is a prevalent and common form of corruption during irregular migration journeys as well as in forced migration. Indeed, sextortion has reportedly happened in refugee and internally displaced persons (IDP) camps for food or documents, and even for being able to enter and exit the camp. As reported by an asylum and protection specialist "From the testimonies we have, they tell us there is corruption for the food, for exit authorizations...many things [...] in the case of women, they pay with sex" (Expert Interview). Sextortion is prevalent in the transit phase of migration, particularly at borders, such as reported in the case of Spanish-Moroccan border around the enclaves of Ceuta and Melilla. The quotes 
from experts and migrants below illustrate the reality of sextortion in the context of migration in that area.

"As women struggle, run out of money during the migration process, well ultimately a woman has her body. Through survival sex, we've seen that women achieve to get on boats and things like that." (Expert Interview)

"Women... They take for instance a full convoy. They stop the pick-up. Take the keys of the driver. Then they take the women, and when they come back, they put the keys back in. In other places, we've seen official, military, they go, and they choose the most beautiful women. And sometimes to be nice, they give them passports, that they had seized from other people in exchange of sexual favors" (Male Migrant)

"We had this yearly party in the center. One girl, E., she did a play in which she represented her migration journey from her country. There was something about the policeman taking her. Well she did not say it explicitly, but she showed it in the play" (Expert Interview)

Despite a few legal studies, sextortion is a form of corruption that up to now has clearly been understudied both from the gender and corruption studies' perspectives. In gender studies, sextortion has often been dissolved in the categories of sexual abuse and/or sexual harassment, in which the corruption element hasn't been observed at all. Because of the controversy on the notion "sexual favors", which implies that coerced sex can be understood as a favor, sextortion was never privileged to describe such type of situations. However, this chapter argues that introducing the term sextortion would by no means belittle the experience of victims. On the contrary, sextortion is by definition a sexual abuse of power. The "corruption aspect" does not weaken the understanding of the longterm effects of sexual violence on women, rather, it helps explain the complex experiences of women and may even include behavior that would not otherwise be criminalized (Thomson Reuters Foundation et al., 2015). Furthermore, the term sextortion can bring back the notion of agency in women's experiences of corruption. As the degree of agency in the corrupt act can vary substantially across situations, so do the experiences and the feelings associated with it. While the traditional terms automatically categorize women as victims, sextortion allows observing nuances of agency, through its "quid pro quo" component. Overall, 
sextortion seems to be more effective in capturing the wide variety and nuances in women's corruption experiences. With this, putting sextortion in the corruption agenda is essential; it uncovers an important field of evidence that was previously hidden, by recognizing women's experiences of corruption. Ultimately, acknowledging sextortion would make anti-corruption initiatives more inclusive and hence very likely more effective.

\subsubsection{Sextortion is the expression of gender and power relations}

Abusive power relations along gendered lines are a central element of corruption and particularly of sextortion. In fact, the notion of sextortion is the paradigmatic example of how gender relations and power relations are intertwined within corruption. Sextortion as a form of corruption is the direct result of a patriarchal configuration of power in institutions, where power is systematically held by male hegemons and exerted principally against women and non-masculine men. The gender regime of corruption results in women being disproportionally affected by the phenomenon since they are targeted by the most violent forms of corruption. Because sextortion is at the intersection of corruption and violence against women, the concept can reflect both unequal gender relations and unequal power relations in societies, which makes the term particularly useful to observe and recognize women and men's experiences of corruption.

Indeed, these experiences of corruption are very much shaped by gender dynamics, it is important to broaden the classical, male-centric, vision of corruption focusing on the exchange of money and goods and acknowledge gendered forms and effects of corruption, in which female bodies are in many cases the currency of the bribe (Merkle et al., 2017a, p. 33). Ultimately, as an expert on gender and migration phrases it, "Women's experiences [of corruption] are shaped by the fact that, if they have nothing, they still have their female bodies" (Expert Interview). In patriarchy, as women are dispossessed of power, women's bodies can be commodified, merely considered as objects, through corruption, among a variety of other patriarchal dynamics.

\subsubsection{Women as subjects and objects in sextortion}

In fact, in certain cases of sextortion, both the currency and the objects of exchange are women's bodies and sexualities. Not only are women coerced into sex in exchange for something they themselves needed, but women's bodies are also gifted to the corrupt authorities by other men as the very object of the bribe. Bribes are no longer one-time sexual favors by a participant in the corrupt exchange, but 
women themselves become the currency. In these situations, the patriarchal mechanic is double; women are owned and can be gifted as any other object and women are then the subject of abuse by other relatively powerful men. In these cases, the agency of the victims in the corrupt act is non-existent as they are reduced to objects of exchange rather than subjects in the exchange. Indeed, the agency of women in a highly corrupt environment is extremely reduced. This type of sextortion has been studied recently in the case of irregular migration. In the West and Central African migration route, for instance, it is not uncommon that traffickers and even smugglers pay the bribe for passage by gifting women to the corrupt agents (Merkle et al., 2017a). It has been reported that migrant groups would transport women only to be able to offer them to border guards, police officers or mafias in transit so that they "turn a blind eye". Indeed, the term "means of exchange" when referring to these practices at the borders was recurrent, as shown in the following testimonies of migrant experiences. As an expert stated: "They [women] are often used by the traffickers as "moneda cambio" [currency of exchange], this sexual favor can be a mean of exchange. (...) I would say for sure is that traffickers offer sexual services to authorities or officers." And a male migrant recounted the use of women as currency for an entire group of migrants:

We always travel in pick-up, and there always has to be at least two women in each pickup, when there are women in a connection, there are more chances to cross. A Tamanrasset in Algeria, the police come and take the women and leave with them, it's often policemen. And this does not only happen with policemen, but also with the migrant groups.

The commodification of women's and girl's bodies is then perpetuated throughout the migration process, in origin, in transit and in destination where migrant women are the main population in the sexual exploitation market (Merkle et al., 2017a) (see chapter 6 for further discussion). Migrant women, situated at the bottom in the "matrix of power and domination" are hence among the first victims of this recurrent and violent form of corruption. In consequence, they are caught in long-term situations of sexual abuse and dependency. 


\subsubsection{Violence against women as a product of hegemonic masculinity}

Sextortion is, ultimately, one type of violence against women. A major consequence of the gender order of patriarchal relations across all societies and their institutions is widespread violence against women and minorities. It has been estimated that in 2010, globally, $7.2 \%$ of women aged over 15 were victims of nonpartner sexual violence (Abrahams et al., 2014). Violence against women is the product of structural power and gender arrangements in which men monopolize power and violence. Similarly, sextortion is a form of corruption that is intrinsically gendered; it embodies patriarchy in that it is an abuse of power that systematically falls upon women as the disenfranchised gender. The immense majority of perpetrators of sextortion are men while, unlike other forms corruption, most victims are women and girls (Thomson Reuters Foundation et al., 2015).

Because I saw women experience lots of violence, when they arrive in one place they don't have anywhere to sleep and are exposed to a lot of violence (...) But the women who had children, they were taken by the bandits in Oujda, they told me they weren't sure if one day they could speak about it. All the terrible things women have to suffer, you wouldn't imagine. (Male Migrant)

To understand the roots of violence, it is also necessary to reveal and comprehend how men are situated in their own scheme of domination upon women and relative to other males (K. L. Anderson \& Umberson, 2001; Connell, 1987; Hunnicutt, 2009). Men who perpetrate sextortion abuse of their power towards women, but they might themselves be in a position of powerlessness relative to other men within the patriarchal hierarchy. This might trigger violence towards those in an inferior position. As put by Mellon (2013): "men's quid pro quo sexual harassment may be motivated by the social punishment of their own failures to conform to masculine gender role expectations" (p.2287). Research on migrant experiences also revealed that men are greatly exposed to violence in irregular migration, showing that hegemonic masculinity is harmful to all genders. Such violence is coming from peers but mainly from institutional authorities such as police. Male on male violence has reportedly happened at the Spanish-Moroccan border for instance:

I know a case here in Ceuta, a military force...well they were patrolling with a car by night and some obliged migrant boys to 
come in the car, to the boys! A security force from here, from Ceuta...And the boys do not report, they tell 'we are nothing, no one is going to believe us'.... (Male Migrant)

Overall, sextortion, among other forms of corruption, might be used as a tool to reassert power and gender hierarchies. Hegemonic masculinity and dominance are embodied in the act and consequences of sextortion, in which physical or psychological violence is exerted towards women and results in further silencing and subordination of women to authorities. Patriarchal power systems, through the reproduction of hegemonic masculinity, are enshrined into most, if not all, aspects of life in society. Hence, abuses of power such as sextortion are repeated and reproduced across each of these. As pointed out by the Thomson Reuters Foundation et al. (2015), sextortion takes place in virtually all regions of the world, from least developed to developed states. However, the subject has been largely understudied. Few studies in the legal, educational, employment or migration field have shed light on the phenomenon. Indeed, power distributions in education, the workplace or migration have organized very rigid hierarchies that may set the ground for the abuse of power: between student and professor, between employee and employer, between migrant and administration agent. Most of these sectors use the terms sexual favors, sexual harassment, quid pro quo harassment or transactional sex. This chapter argues that in all the examples proposed across these studies, the use of the term sextortion would have been more appropriate. Sextortion, as a pervasive phenomenon in the workplace, has often been referred to as "quid pro quo harassment". The phenomenon results in profound job related, psychological and physical health outcomes (Fitzgerald, 1993; O'Connell \& Korabik, 2000; Willness, Steel, \& Lee, 2007). Sextortion in the workplace is associated with negative outcomes such as decreased job satisfaction, lower organizational commitment, withdrawing from work, ill physical and mental health, and even symptoms of post-traumatic stress disorder (Willness et al., 2007). There again, patriarchal divisions are self-sustaining, as male-dominated workplaces create hostile environments for female professionals to develop their career and achieve more gender-balanced private as well as public institutions.

Additionally, the research for this chapter found that sextortion has gained more attention recently in migration studies, as cases have been reported in several refugee camps. In an extensive field report, experts have detected the prevalence of sexual violence including but not limited to early and forced marriage, transactional sex, sexual harassment and physical assault in the country of origin and on the journey (United Nations Refugee Agency, United Nations Population 
Fund, \& Women's Refugee Commission, 2016). In high-risk migration, it is common that migrant women end-up in a highly exploitative situation where they are coerced into sexual services to cover their most basic needs (Zimmermann, MCAlpine, \& Kiss, 2016). In a recent study, Merkle et al. (2017a) have identified the prevalence of sextortion for migrant women at all stages of their journey, and more particularly in transit. In that context, it appears clearly how female bodies are the currency of the bribe. Sextortion happens for a variety of motives, from crossing borders to obtaining travel documents, accessing transportation or only to avoid reporting. Additionally, smugglers abuse of their position as protectors and the urgency of the situation at borders to demand sex from migrant women. As mentioned, in irregular migration, women are not only subjects of sextortion, they are the very means of exchange in the corrupt act. It appears from all these examples that sextortion is a gendered form of corruption present in a wide variety of institution in different regions. A global approach to tackling sextortion requires acknowledgment and recognition, as well as the international and national legal frames to prosecute it.

\subsection{Language as a reinforcement of stereotypes}

However, as mentioned above, the first few studies on sextortion have approached it with different lexica such as sexual harassment, survival sex, transactional sex, etc. From quid pro quo harassment to transactional sex, a wide variety of terms are used across cultural and legal systems to describe the same phenomenon. This chapter argues that the term "sextortion" allows to uniformly and unequivocally name this reality at the intersection of corruption and sexual violence. The first attempt to criminalize sextortion are found with "quid pro quo harassment" in the workplace. As presented by Baker (1995) "In the workplace, quid pro quo sexual harassment occurs when submission to sexual conduct is made a term or condition of an individual's employment or when an individual's submission to or rejection of such conduct is used as the basis for employment decisions affecting that individual" (p.213). Even if it is recognized by certain scholars, jurisprudence has shown that the concept "quid pro quo harassment" remains unclear. Dickinson (1995) argues that courts aren't recognizing a quid pro quo course of action since it does not involve typically tangible or economic harm. The complexity of the term has led others to call for the excision of the term "with Occam's razor", with the argument that it is complex prove, redundant of sex discrimination and hence the latter loses strength as an argument in the justice process (Scalia, 1997, p. 325). 
The approach of quid pro quo harassment is insufficient for various reasons. First, the term "quid pro quo harassment" seems quite inaccessible and euphemistic, as it minimizes the victim's experience of extortion and sexual violence. In fact, the term seems to emphasize the exchange itself and how women get something in return by highlight the "this for that" aspect instead of recognizing extortion. Second, "quid pro quo harassment" has only be referred to in the context of the workplace. Sextortion, instead, can apply not only to workplace harassment, but to a broader range of social spheres, as shown with migration, but also in many other sectors such as healthcare, politics or sports, among many others.

In humanitarian settings, sextortion is referred to as transactional sex or survival sex. In contexts where women are particularly resource-less, they depend on men to cover their most basic needs. Some argue that the term "transactional sex" allows us to consider the agency of women, a concept that was previously left out, as women engage in rational, economically-driven exchange (Stoebenau, Heise, Wamoyi, \& Bobrova, 2016; Weissman et al., 2006). While it is true that focusing mainly on vulnerability can be detrimental to gender empowerment, the notion of rational and economically driven sex fails to recognize the broader power system of patriarchy in which women are systematically coerced into sex. For instance, in the context of migration, it has been reported that women are asked for sexual favors in exchange for basic protection or even to avoid being reported. This can be interpreted as an exchange, but more properly as coercion. This is a paradigmatic example to show the pertinence of the term sextortion rather than transactional sex, in context's were women's agency is very reduced.

What is also interesting to point out is how the different terms are employed in different regions. While terms such as "harassment" or "sexual assault" are used in developed countries, more drastic expressions such as transactional or survival sex are used very often for least developed countries and are often used in development works. However, as detailed earlier, sexual violence against women happens worldwide at relatively similar levels, with grave consequences for women globally. The fact that the term employed for developed countries is much softer and euphemistic, while the term employed in poorer contexts -transactional sex- is cruder reflects yet another dynamic of power at play; the North-South power imbalances. Wealthy states would not use the terms transactional or survival sex when referring to the corruption experiences of women in the North but rather to point at a violent reality that is supposedly proper of underdeveloped, southern countries. However, sextortion is a reality, often a violent one, not only in contexts of economic deprivation but also in advanced economies. 
Indeed, what matters in sextortion is not the absolute but the relative deprivation of power of women in each region. Even across the North-South power imbalances, the gender order of patriarchy remains and systematically leads to abuses of power.

Overall, the terms used up until now to identify sextortion seems sex seem euphemistic. In that sense, the language used to refer to sextortion is also part of the process of making the power system and its oppressive institutions invisible. Once again, the misrecognition process has been successful in achieving the implicit legitimation of the patriarchal order. As happens with general sexual violence, the category of the powerful is left out of the conversation, and the dynamics of power are rendered invisible. For instance, when discussing sexual and gender-based violence, the discussion quickly focuses almost exclusively on "battered women", referring to women in passive voice, rather than "male violent perpetrators", in active voice (Katz, 2012). This is a perverse phenomenon in that it moves the attention away from the root of the problem, power imbalances and abuses of power against women, to focus only on the result - the injured woman. This is again an example of how patriarchal dynamics are self-sustaining and successful in obscuring abusive power relations. Once again, power dynamics are reflected in the language and the way such events are spoken and thought about.

Hence, this chapter encourages the use of the term sextortion as a way to unveil patriarchal dynamics and bring to light how the violent gender and power relations are embodied in corruption. The term "sextortion" makes the crime more recognizable by revealing grave abuses of power that were previously legitimized or made implicit, hence contributing to justice for the victims at the individual level and elimination of sextortion at the collective level. The recognition of sextortion as a form of corruption opens a field of study in corruption research, where women's experiences of corruption had until now been widely underreported.

\subsection{Conclusion}

This chapter has started to draw attention to the identification of power structures at play in corruption dynamics. Corruption and gender scholarship has too often neglected the identification of power systems and dynamics at work in corruption, to the extent that these are rendered invisible and hence allowing for their continuity. In particular, patriarchy as a power system plays a fundamental role in shaping corruption practices and experiences. For that matter, this chapter presents 
sextortion as a paradigmatic example of the intertwining of gender relations and power relations in corruption. Sextortion is a form of corruption at the intersection of corruption and violence against women and hence embodies the coalition of patriarchal dynamics. Drawing on previous research, this chapter suggests that sextortion is frequent across regions yet largely understudied. Sextortion has nonetheless been reported in fields such as education, the workplace or migration. However, the lack of consensus on the ideal term to identify it has resulted in general omission. This chapter advocates for the use of the term "sextortion" as a mean to recognize and prosecute these grave abuses of power. Moreover, by reflecting upon the underlying dynamics of corruption, it aims at encouraging the adoption of a solid theoretical framework on the relationship between gender and corruption that would guide further research on the matter. 

It is all about power - corruption, patriarchy and the political participation of women

That focal point is women's status and sexuality. We will elicit much through the lens of gender, not just about women as such, but about attitudes toward civic tolerance and governance more broadly.

$\overline{\text { Jacobson, 2012, p.198 }}$

\subsection{Introduction ${ }^{22}$}

With the 1995 Beijing Declaration and Platform for Action, the Millennium Development Goals (goal 3) and the Sustainable Development Goals (SDGs) (goal 5), more attention has been paid to gender equality in the international arena. One fundamental aspect of achieving this equality is increasing the level of political participation of women. Within this discourse two seminal studies, Dollar et al. (2001) and Swamy et al. (2001) bring about a new focus: the potential of women in politics as an anti-corruption force. They argue that, on average, women are less likely to engage in corruption than men and that achieving higher rates of political participation of women will decrease levels of corruption in society. This argument, also known as the "fairer-sex hypothesis", was quickly picked up by the World Bank, which identified gender equality as an important tool to curb corruption (E. M. King \& Mason, 2001). Since then there have been heated debates about the nexus of corruption and gender. One of the most prominent criticisms is that the focus on latent gender differences oversimplifies a complicated relationship and is counterproductive for the fight against corruption and in efforts aimed at increasing women's political participation. However, research that analyzes this relationship is limited. This chapter asserts that most of the existing

\footnotetext{
${ }_{22}$ This chapter is based on the forthcoming chapter: Merkle, O. and Wong, P.; It is all about powercorruption, patriarchy and the political participation of women in Sub-Saharan Africa. In: Konte, M and Tirivayi, N. Women and Sustainable Human Development - Empowering Women in Africa. Palgrave Macmillan.
} 
research on corruption and gender simplifies the understanding of gender by focusing solely on women and only in rare instances on gender, namely socially constructed roles, activities, attributes, behaviors, personality traits, relationships, power and influence that a society conceptually attributes to men and women (Prince, 2005) and gender dynamics.

Gender is an institutionalized "multilevel system of differences and disadvantages that includes socioeconomic arrangements and widely held cultural beliefs at the macro level, ways of behaving in relation to others at the interactional level, and acquired traits and identities at the individual level" (Ridgeway, 1997, p. 219). Yet, the discussion on corruption typically treats gender as a one-dimensional variable and neglects the role of underlying dynamics. This chapter addresses this gap by arguing that, in order to understand how corruption (i.e. the abuse of power) works one must have a better understanding of how power is distributed within a society. Therefore, this chapter argues that rather than being a question of inherent gender differences both the question of acceptance of corruption and women's political participation are linked to an underlying patriarchal system. Using a gender-centered theory, such as patriarchy, will deepen the understanding of "the complex ways that gender interacts with other social conditions and processes" (Hunnicutt, 2009, p. 556).

This study investigates the correlation between attitudes toward female political leadership and the acceptance of corruption. The study hypothesizes that both corruption and women's political participation are essentially questions of how power is distributed within society and therefore influenced by patriarchic structures. It finds that men and women who agree that men are better political leaders than women, are more likely to condone corruption. This suggests that underlying patriarchal norms influence attitudes towards corruption. These findings provide new insights on the relationship between higher political participation of women (SDG target 5.5.) and lower corruption levels (SDG target 16.5). The chapter is organized as follows; section two discusses the theoretical argument while section three introduces the data and methodology. A discussion of the findings is presented in section four and section five concludes the chapter by providing policy recommendations. 


\subsection{Corruption and patriarchy as asymmetric power relations}

According to Rothstein \& Teorell (2008), a political process can be divided into an input side (access to power) and an output side (exercise of power). Corruption takes place in the exercise of power, as reflected in the majority of corruption definitions, e.g. Transparency International (para. 1 n.d.) defines corruption as "the abuse of entrusted power for private gain". Hence, in the corruption literature, the exercise of political power is frequently scrutinized. Surprisingly, even though most definitions refer to corruption as an abuse of power, the existing literature is usually completely detached from the aspect of access to power and discussions about the dysfunction of the governing process routinely neglect questions about the distribution of power. Some researchers, even explicitly exclude these questions. Rothstein (2011) and Rothstein \& Teorell (2008), for example, discuss the concept of 'quality of government' as the opposite of corruption in terms of impartiality. In their view, the principle of impartiality is upheld when "government officials shall not take into consideration anything about the citizen/case that is not beforehand stipulated in the policy or the law" (Rothstein \& Teorell, 2008, p. 170). This definition focuses on the question of how authority is exercised without looking at who exercises this authority. While in the ideal case of a perfectly functioning government this can be logical, the definition gets problematic in the instances where officials violate this ideal state.

As feminist research has shown, the argument that one can look at exercise of power independently is a gross oversimplification, and for good reason the question of who has access to the political system and how access is granted are fundamental debates in political science. Most researchers agree that the underlying principle of how a state should be governed is that of political equality, i.e. equal access to political powers for all groups within the state, which is not synonymous with democracy. While democracy certainly does provide the best opportunity for political equality, it is not, by default a guarantee that all groups are included. For women, democracy has been shown to have a positive effect but it is not by itself sufficient for equality (i.a. Elisabeth Friedman, 2000; Goetz \& Hassim, 2003; Matland \& Montgomery, 2003; Waylen, 2003).

A state can only have legitimacy if all groups are included in the political process, hence the political participation of women is a building block of state legitimacy (Thomas, 2005). In democracies, both men and women perceive the government to be more legitimate if a sufficient number of women is represented, since the proper representation of disadvantaged groups indicates that the majority can trust that 
their interests are properly heard (Schwindt-Bayer \& Mishler, 2005). In 1861 John Stuart Mill argued that "in the absence of its natural defenders, the interest of the excluded is always in danger of being overlooked; and when looked at, is seen with very different eyes from those of the persons who it directly concerns" (Mill, 2015, p. 216 [1861]). Importantly, although few women can already achieve positive outcomes for women, a "critical mass" of female politicians seems to be needed to achieve lasting societal impact (Bratton \& Ray, 2002; Schwindt-Bayer \& Mishler, 2005, p. 424). This is one of the rationales behind gender quotas, which have become increasingly important to ensure a faster increase in the number of women in parliament (Bauer \& Burnet, 2013). Yet, this is only useful if attention is also paid to the question of which women actually are joining the political sphere, as power structures within society often grant different access to women with different ethnic, religious, economic and political backgrounds.

Despite the established positive impacts of women's political participation, there are many roadblocks that affect how small the window is for women to be politically engaged. For instance, a woman's decision to seek political office often includes more deliberations about family-related obligations than a man's. Yet Fulton et al. (2006) argue that women are more aware of the benefits that holding elected office provides and have a deeper sense of responsibility once they do hold the job. Political institutions and culture also can act as obstacles. Many researchers find that electoral systems have an impact on the political participation of women (Matland \& Brown, 1992; Norris, 1985; Rule, 1994), as do party size and orientation (Kittilson, 2006). The political culture also has a direct effect on how individuals see their representatives and what qualifications and characteristics they expect. Fox and Lawles (2004) point out that the socialization of politics is still biased towards allowing more men to participate in the process and the paradigm that men are more suited for holding public office remains in place. This paradigmatic thinking not only has an impact on parties' candidate selection but also on potential female candidates who often feel less qualified for public office than men with similar experience and education.

The reasons that women do not (yet) participate enough are centered firmly around sexist stereotypes. While sexism is often understood as hostility against women, many of these sexist stereotypes are not at first sight understood as negative and are much subtler. In a seminal study, Glick \& Fiske (1996) distinguish two types of sexism: hostile and benevolent (for a more detailed discussion see chapter 5). Hostile sexism is prejudice. By contrast, benevolent sexism is associated with positive feelings, which tend to elicit prosocial behaviors such as helping. 
However, benevolent sexism evokes traditional stereotypes and can be equally damaging; for example, it usually projects the image of the man as the provider and a woman as his dependent, being nice but incompetent at many important tasks (Glick \& Fiske, 1996). Therefore, both hostile and benevolent sexism are driven by a patriarchal structure, which places women in a subordinate position and creates dependency to consolidate men's structural power and violates the principle of equality. Consequently, patriarchy is not a simplistic concept of "bad" men having power over "poor" women. On the contrary, patriarchy can be understood as a complex system of power relationships where "both men and women wield varying types and amounts of power" (Hunnicutt, 2009, p. 565). Patriarchy should also not be seen as a static system, rather it is a continuously evolving web of ideas and relationships (Enloe, 2017, p. 16).

In short, ignoring the power access problem and neglecting the power structure in politics will prevent a deeper understanding of how corruption is embedded in society. Hence, this chapter hypothesizes that both the idea of the importance of equal participation of women and the view on the acceptability of corruption speak to the question of how patriarchy is embedded in the structure of society. Therefore, unlike what the fairer-sex hypothesis suggests, gender differences - be they inclination to sacrifice personal gains or disparity in self-control - do not explain tolerance towards corruption. Rather, it is underlying patriarchal norms that matter for the persistence of corruption. This chapter is looking at views on women as a representation of the underlying patriarchal structure and tests the following hypothesis: People who agree that men are better politicians than women are more likely to condone corruption.

\subsection{Data and methodology}

Data for this chapter come from the latest wave of the World Values Survey (20102014). The World Values Survey database consists of nationally representative surveys conducted in about 100 countries using a common questionnaire. This study only includes the surveys for Sub-Saharan Africa countries. Countries for which surveys are available are Ghana, Nigeria, Rwanda, South Africa and Zimbabwe. The analytical sample used for the analysis contains 9,827 observations from these countries.

Gender Equality (SDG5) is a multifaceted issue. In terms of political participation of women countries in Sub-Saharan Africa vary widely. While Rwanda has the highest number of women in Parliament worldwide with 61.3\% in 2018, Nigeria 
currently only has $5.6 \%$ of female members of parliament (Inter-Parliamentary Union, 2018b). Similar variation can be seen in corruption levels, where Botswana ranks 34 in the corruption perception index, while Somalia ranks 180 and therefore the last worldwide (Transparency International, 2018). The countries selected for this study also show a wide scale of women's participation in formal politics and corruption levels (see Table 3 for 2018 ranks). Therefore, country cases from the region can be considered as paradigmatic cases with interesting variation in levels of women's participation and corruption. If we do not find supportive evidence from these cases, we would therefore have a higher level of confidence to reject a theory.

Table 3 Participation of women and corruption

\begin{tabular}{l|l|l}
\hline \hline Country & $\begin{array}{l}\text { World classification - women in } \\
\text { national Parliament (rank) 2014 }\end{array}$ & $\begin{array}{l}\text { Ranking Corruption Perception } \\
\text { Index 2014 }\end{array}$ \\
\hline Rwanda & 1 & 55 \\
South Africa & 11 & 67 \\
Zimbabwe & 29 & 159 \\
Ghana & 118 & 61 \\
Nigeria & 133 & 136 \\
\hline \hline
\end{tabular}

Sources: rank as of December 2014: Inter-Parliamentary Union (2014); Transparency International (2014).

This study investigates the correlation between attitudes toward women's political leadership and attitudes toward corruption. It does not claim causality and only uses regression analysis to identify a pattern, while accounting for various factors. The empirical analysis pools individual responses across the five Sub-Saharan Africa countries and includes dummy variables for each country to account for country heterogeneity. The dependent variable is the attitude towards corruption. Respondents were asked to indicate whether they think "Someone accepting a bribe in the course of their duties" is justifiable. Responses are reported on a 10point Likert scale, where 1 indicates "Never justifiable" and 10 "Always justifiable". Given the number of possible responses, the variable is treated as an ordered response since about 80 per cent of the responses take an extreme value (i.e. scales 1 and 2).

The key independent variable denotes the attitudes toward women's political leadership. The measure is derived from a question, which asks respondents to indicate whether they agree with the following statement: "On the whole, men make better political leaders than women do". Responses are reported on a 4-point 
Likert scale, where 1 indicates "Strongly agree" and 4 "Strongly Disagree". Given the small number of possible responses, treating the variable as continuous imposes a strong linearity assumption on the relationship between the dependent and independent variables; that is, the effect of a one-point increase from 'Strongly agree' to 'Agree' is the same as the one from 'Agree' to Disagree'. The assumption is likely to be untrue. Therefore, five dummy variables are created and used to avoid making this bold assumption. Each dummy variable corresponds to a scale point, plus an additional one that pools 'missing' and 'do not know' together. The baseline is 'Agree' and is omitted in regression models to avoid perfect multicollinearity.

Several control variables are also included in the analysis. The gender of the respondent is controlled for since women and men may respond differently, according to the fairer-sex hypothesis (Dollar et al., 2001). The other control variables include age, marital status, religiosity and employment status (i.e. employed, unemployed, inactive). People who are the chief wage earner of a household and work in a certain sector may have a higher exposure to corruption in their workplace. To account for the potential differences in responses, both variables are included in the regression. Moreover, since the income level of the respondent was not captured in the survey, self-reported class levels are used to proxy the economic well-being of the respondents. Possible responses are 'upper class', 'upper middle', 'upper lower', 'working class' and 'lower class. The baseline is 'lower class. Education can be a powerful policy tool to combat corruption (Eicher, García-Peñalosa, \& Ypersele, 2009). To control for the effect of education, the variable is included as well. The original survey response has nine categories, ranging from 1 (no formal education) to 9 (university-level education, with degree). Finally, people who thought that "having a strong leader who does not have to bother with parliament and elections" is a good (or bad) way of governing the country may have a stronger opinion about corruption. A set of five variables is created to control for this effect (very good, fairly good, fairly bad, very bad, don't know). The baseline is 'very bad'.

Due to the ordinal nature of the dependent variable, an ordered logit model is used in the analysis. Furthermore, a multilevel logistic regression is utilized as a robustness check to accommodate the hierarchical structure of the data. More specifically, in the context of survey data analysis, individuals are usually found to be influenced by a common set of contextual factors; for example, people living in one region are subjected to the same policy. This feature of the data makes responses from the same region correlated. If the correlation is particularly strong, 
the usual ordered logit model will lead to smaller standard errors and hence inaccurate hypothesis testing results (Steenbergen \& Jones, 2002). Under this circumstance, a multilevel model might be superior to the usual ordered logit model as it can explicitly model this kind of dependency and, at the same time, account for unobserved heterogeneity. The model looks similar to the usual ordered logit model, but with a constant containing a random component, which is allowed to vary across region $j$ in which respondent $i$ lived. This random component is assumed to have zero mean and its variance is estimated explicitly.

\subsection{Judging women and corruption - shared norms}

Estimation results are reported in Table 1 . Model 1 includes only the key independent variables and country dummies as covariates. It shows that people who strongly disagreed that men are better political leaders are also less likely to think that corruption is justifiable than those who agree. The estimate is statistically significant at the $1 \%$ level. The findings lend support to the hypothesis that perceptions of corruption and attitudes toward women's political leadership are related to underlying norms, i.e. patriarchy. The coefficient of the dummy variable "disagree" is negative but not statistically different from that for the baseline, "agree", at the 5\% significant level. Another interesting finding is that people in Rwanda and South Africa are more likely to condone corruption than people in Zimbabwe. As discussed in previous chapters Rwanda and South Africa are among the world leaders in terms of shares of women in parliament, yet, they still have relatively high levels of corruption, further contradicting the simplistic view that increasing the number of women in parliament will lead to lower corruption levels or more critical attitudes toward corruption.

Table 4 Relationship between attitude towards women as political leaders and corruption

Men Better (don't know)

Men Better (strongly agree)
(1)

Ordered

Logit

(2)

(3)

\section{Ordered}

Logit

$-0.761^{* *+*}$

$-0.208$

(0.119)

$-0.171$

(0.126) 
Men Better (agree)

Men Better (disagree)

Men Better (strongly disagree) baseline

$-0.385$

$(0.215)$

$-0.630^{* *}$

$(0.238)$

Female

Age

Incomplete primary school

Complete primary school

Incomplete secondary school:

technical/ vocational type

Complete secondary school:

technical/ vocational type

Incomplete secondary school:

university-preparatory type

Complete secondary school:

university-preparatory type

University-level education

without degree

University- level education with

degree

No formal education

Religious (yes $=1$ ) baseline

baseline

$-0.366^{*}$

$-0.373^{* * *}$

(0.171)

(0.050)

$-0.500^{*}$

$-0.468^{* * *}$

(0.207)

(0.070)

$\begin{array}{ll}0.030 & 0.037 \\ (0.052) & (0.040) \\ -0.007^{* * * *} & -0.006^{* * *} \\ (0.001) & (0.002)\end{array}$

$-0.002$

$-0.007$

(0.028)

0.016

$-0.018$

(0.062)

(0.105)

$-0.109^{*}$

$-0.168$

(0.048)

(0.106)

0.050

$-0.008$

(0.118)

(0.108)

$-0.208^{*}$

$-0.216^{*}$

(0.121)

(0.108)

$-0.134$

$-0.211^{*}$

(0.107)

(0.104)

$-0.005$

$-0.06$

(0.101)

(0.122)

$-0.298^{*}$

$-0.348^{* *}$

(0.178)

(0.126)

baseline

baseline

$-0.053$

$-0.132^{*}$

(0.056)

(0.066) 
4 It is all about power - corruption, patriarchy and the political participation of women

\begin{tabular}{|c|c|c|}
\hline \multirow[t]{2}{*}{ Married } & $-0.166^{* * *}$ & $-0.147^{* * *}$ \\
\hline & $(0.042)$ & $(0.043)$ \\
\hline \multirow[t]{2}{*}{ Chief Wage Earner $($ yes $=1$ ) } & 0.043 & 0.069 \\
\hline & $(0.058)$ & $(0.047)$ \\
\hline Work (not working) & baseline & baseline \\
\hline \multirow[t]{2}{*}{ Work (government) } & 0.106 & 0.112 \\
\hline & $(0.156)$ & $(0.084)$ \\
\hline \multirow[t]{2}{*}{ Work (private sector) } & 0.015 & -0.006 \\
\hline & $(0.204)$ & $(0.067)$ \\
\hline \multirow[t]{2}{*}{ Work (non-profit) } & 0.126 & 0.106 \\
\hline & $(0.255)$ & $(0.082)$ \\
\hline \multirow[t]{2}{*}{ Employed } & 0.101 & 0.046 \\
\hline & $(0.064)$ & $(0.064)$ \\
\hline \multirow[t]{2}{*}{ Unemployed } & 0.008 & -0.010 \\
\hline & $(0.062)$ & $(0.058)$ \\
\hline Inactive & baseline & baseline \\
\hline \multirow[t]{2}{*}{ Strong leader (don't know) } & $-0.461^{*}$ & -0.235 \\
\hline & $(0.279)$ & $(0.150)$ \\
\hline \multirow[t]{2}{*}{ Strong leader (very good) } & $0.673^{* * *}$ & $0.605^{* * *}$ \\
\hline & $(0.159)$ & $(0.061)$ \\
\hline \multirow[t]{2}{*}{ Strong leader (good) } & $0.756^{* * *}$ & $0.702^{* * *}$ \\
\hline & $(0.192)$ & $(0.055)$ \\
\hline \multirow[t]{2}{*}{ Strong leader (bad) } & $0.430^{* *}$ & $0.367^{* * *}$ \\
\hline & $(0.133)$ & $(0.053)$ \\
\hline Strong leader (very bad) & baseline & baseline \\
\hline \multirow[t]{2}{*}{ Upper class } & $0.839^{* *}$ & $0.832^{* *}$ \\
\hline & $(0.109)$ & $(0.158)$ \\
\hline
\end{tabular}




\begin{tabular}{|c|c|c|c|}
\hline \multirow[t]{2}{*}{ Upper middle } & & $0.317^{* *}$ & $0.374^{* *}$ \\
\hline & & $(0.112)$ & $(0.128)$ \\
\hline \multirow[t]{2}{*}{ Lower middle } & & $0.204^{*}$ & $0.265^{* * *}$ \\
\hline & & (0.119) & $(0.067)$ \\
\hline \multirow[t]{2}{*}{ Working class } & & -0.077 & -0.057 \\
\hline & & $(0.069)$ & $(0.055)$ \\
\hline \multicolumn{2}{|l|}{ Lower class } & baseline & baseline \\
\hline \multirow[t]{2}{*}{ Ghana } & $-0.605^{* * *}$ & $-0.627^{* * * *}$ & \\
\hline & $(0.046)$ & $(0.603)$ & \\
\hline \multirow[t]{2}{*}{ Nigeria } & -0.028 & $-0.211^{* * * *}$ & \\
\hline & $(0.040)$ & $(0.034)$ & \\
\hline \multirow[t]{2}{*}{ Rwanda } & $0.386^{* * *}$ & $0.339^{*}$ & \\
\hline & $(0.038)$ & $(0.131)$ & \\
\hline \multirow[t]{2}{*}{ South Africa } & $1.349^{* * *}$ & $1.250^{* * *}$ & \\
\hline & $(0.164)$ & $(0.156)$ & \\
\hline \multicolumn{2}{|l|}{ Zimbabwe } & baseline & baseline \\
\hline \multirow[t]{2}{*}{$\operatorname{var}\left(\mu_{\mathrm{j}}\right)$} & & & $0.738^{* * *}$ \\
\hline & & & $(0.173)$ \\
\hline$N$ & 9,827 & 9,776 & 9,776 \\
\hline No. of regions & - & - & 39 \\
\hline Log Likelihood & $-16,736$ & $-16,407$ & $-16,141$ \\
\hline LR test ( $p$-value) & 0.000 & 0.000 & 0.000 \\
\hline
\end{tabular}

\footnotetext{
Notes: The dependent variable is the justifiability of accepting a bribe. The variable is on a 10-point Likert scale, where 1 means never justifiable and 10 always justifiable. Robust clustered standard errors in parentheses in Models (1) and (2); ${ }^{*} p<0.05,{ }^{* *} p<0.01,{ }^{* * *} p<$ 0.001 .
} 
Results from Model (2), which adds further controls to the estimation, are consistent with previous findings. The coefficients of interests, "disagree" and "strongly disagree", have the expected negative sign are statistically significant at the $5 \%$ level.

In a further analysis, the average marginal effects are obtained. The marginal effect is negative when the "justifiability" level (scale of dependent variable) is at two or above-recalling that one means always justified and ten always unjustified. Based on the marginal effects, respondents who strongly disagreed that men are better politicians than women are about $1.3 \%$ more likely (baseline $=4 \%$ ) to disapprove corruption than those who agree with the statement.

To improve statistical inference, model (3) includes a region-level mixed-effect in the regression model. The log-likelihood of the model improves, suggesting that the model is superior to the one without the mixed-effects. Results from the likelihood ratio test also suggests that the model is better than the one without the multilevel feature. Results are very similar to those obtained from model (2). The estimates are also more precise and statistically significant at the $0.1 \%$ level. The previous findings are robust to unobserved heterogeneity.

Interestingly, results from both models (2) and (3) suggest that women are equally likely as men to condone corruption, a finding that contradicts the fairer-sex hypothesis proposed by Dollar et al. (2001). This is in line with the previous research by Alhassan-Alolo (2007), who finds that women in public positions in Ghana do not have different ethical principles than their male counterparts and that both sexes are equally likely to act unethically when societal constructs call for it. Similarly, McCabe et al. (2006) show that in the U.S. "expressive traits and egalitarian gender-role attitudes contribute to both men's and women's propensity to perceive unethical workplace behavior as unethical" (p.101) rather than gender alone. Goetz (2007) further argues that in a "female-dominant working environment, or where women professionals are dealing with women clients or with a socially inferior class, women professionals are not averse to extorting unofficial 'payments' for services that ought to be provided as a right" (p.101). Additionally, results from the present study suggest that people who agree that men are better political leaders than women are more likely to condone corruption, regardless of gender. This is in line with an essential aspect of patriarchy, a system that can only exist as long as it is reinforced by men and women alike (Enloe, 2017). Previous research on the relationship between corruption and political participation, which criticizes the overly naive view by authors such as Dollar et al. 
(2001), argued that the relationship between gender and corruption is rooted in the fairness of the system (Sung, 2003), in opportunity (Alhassan-Alolo, 2007; Bjarnegård, 2013), and not in gender differences. And while a fairer, more equal system and access to opportunities for all are essential in fighting corruption, the findings in this chapter suggest that in order to change views on corruption, a fairer system, that gives opportunities for participation to women (such as in Rwanda) is not enough when underlying power dynamics, i.e. patriarchy, are not addressed.

Other authors also hint at the role underlying gender norms might play in the relationship of corruption and gender. Esarey \& Chirillo (2013) argue that women's behavior is marked by societal rules more than by their gender and therefore women are much more aware and reluctant to commit acts of corruption, when it is systematically seen as immoral. However, if corruption is the modus operandi in the system, they are less likely to abstain from the practice. Echazu (2010) posits that women's behavior is more honest and reliable probably because they are a minority. This minority bias makes them more aware and sensitive to breaking the rules. So rather than intrinsically being more prone to honesty, it is their current situation that makes them act less corrupt. Alatas et al. (2009) conducted surveys and find that gender differences regarding corruption are not equally present in all societies. They argue that this could be due to "the differing social roles of women across cultures (Alatas et al., 2009, p. 678). They state that "in relatively more patriarchal societies where women do not play as active a role in the public domain, women's views on social issues may be influenced to a greater extent by men's views. In such societies, one would expect to see less of a gender difference in behavior toward corruption in comparison with societies where women feel more comfortable in voicing their own opinions" (Alatas et al., 2009, p. 678). This view is supported by the present study's findings showing that men's and women's attitudes on corruption and the participation of women are very similar.

Attitudes are not static and are heavily influenced by other factors such as education, which has been included as a categorical control variable. As expected, education in gender has a negative effect on attitudes towards corruption in Model (3), consistent with findings from Eicher et al. (2009), although the statistical significance and size of the factor is weaker than what previous research suggested (e.g. Truex, 2011). However, the effect varies among different categories. Having some kind of university preparatory school or a finished university degree has a significant negative effect on attitudes towards corruption compared to having no formal education. Patriarchy is not a static system and explicitly does not only 
focus on the domination of men over women but shows a complicated web of power relationships, where "[d]ifferent resources of protection and resistance are available to men and women in different social positions. For women of privilege, class confers power on subordinated women. For more disadvantaged women, subordinated status creates opportunities for resistance" (Hunnicutt, 2009, p. 565). Hence, one cannot look at the role of patriarchy without also analyzing economic class as an additional layer in this analysis. One may think that a wealthier person may be more likely to benefit from corruption as they have access to corruption networks or, as Lui (1985) argues, have higher time costs which makes them more willing to pay a bribe to economize time on the queue. Consistent with the idea that class does shape attitudes towards power, the results show that the negative relationship between class and the acceptance of corruption is weaker among individuals in the upper classes than among individuals in the lower classes. Interestingly, the attitudes towards corruption of respondents working in the government or public institutes are not significantly different from those of people working in non-profit organization. This result is in contrast to what Bardhan (2006) proposes but is consistent with the argument that attitudes towards corruption and participation of women are based on underlying societal norms rather than the workplace.

\subsection{Conclusion}

This study's findings strongly suggest that patriarchal structures can be linked to views on corruption. While previous research already linked stereotypes about female political candidates and the perception of government corruption (Barnes \& Beaulieu, 2014; Esarey \& Schwindt-Bayer, 2017) this study takes it further by connecting attitudes towards women's political leadership with attitudes on corruption. Showing how patriarchy and corruption is connected will help in "exposing ways patriarchal systems are being perpetuated today [and] will enable us to more effectively challenge and dismantle them (Enloe, 2017, p. 17). While corruption, gender equality and women's political participation in particular are all issues worth addressing in their own right, this study shows that changing attitudes towards women in politics, and therefore challenging patriarchal structures can also change attitudes towards corruption and therefore is expected to have a multilayered positive effect on development. Findings from the analysis clearly support the hypothesis that patriarchal norms play a role in how one judges corruption. 
Findings from this chapter therefore have several implications. Firstly, they suggest that a more bottom-up policy approach is important to successfully change attitudes towards corruption. Rather than relying on the (few) female politicians to break the old boys' network and to fight against corruption, policymakers should also promote the changing of gender norms at the grass-root level and change the climate of corruption through a large-scale socialization process. While the traditional top-down approach has the drawback of relying on the minority in a network to induce changes, which has proven to be difficult, the proposed bottomup approach tries to transform the social perception from within and avoids counting only on the few. This is more likely to produce a more durable outcome by reducing the risk of reversal due to a sudden drop in the percentage of female politicians in the national parliament or disappointment with women participating in the same corrupt networks.

Secondly, this chapter argues that changing attitudes towards participation of women in all spheres of society will also help change attitudes towards corruption. There is a second benefit to thinking about both issues as a question of patriarchal norms rather than inherent gender differences. Making anti-corruption the standard-bearer of the need for women to join the political sphere can backfire (Alhassan-Alolo, 2007). Since women are not necessarily less corrupt, this might not only hurt anti-corruption efforts but also the goal to involve women in politics. Instead, the main argument could be that women diversify the thinking of government and play a decisive role in the creation of multi-dimensional politics, which benefits society as a whole (Sung, 2006). All in all, women are equally corrupt as men given the opportunity and power structure. To successfully fight against corruption and improve the political participation of women, underlying structures need to be addressed. 



\section{Dainty women - dirty politics: the role of sexism in political participation in Georgia}

Institutional sexism may be a precondition of modern politics. The spread of public organizations was predicated on the existence of male power over women (and some men) in private life and private organizations. Political institutions such as governments, legislatures and political parties were part of the process in which men in organizations set rules of the game that ensured that the qualifications most likely to be held by some men were better valued and led more reliably to power and rewards.

$\overline{\text { (Lovenduski, 2005, p. 53) }}$

\subsection{Introduction}

Across democracies the widespread problem persists that not all citizens are participating equally in the political sphere (Brady, Verba, \& Schlozman, 1995; Broockman, 2014; Griffin \& Newman, 2005; Lijphart, 1997). This democratic deficit not only can bias the policy agenda but also frequently reinforces existing inequalities (Isaksson, Kotsadam, \& Nerman, 2014). One of the groups that is still consistently underrepresented is women. Therefore, the question "Where are the women?" has been a central point in the study of women and politics (Beckwith, 2005). While it is true that the position of women has improved significantly over the last decades the gender gap, especially regarding economic and political participation continues to be an issue and in recent years has often even increased (Hausmann, Tyson, Bekhouche, \& Zahidi, 2014). Many different approaches have been taken to explain the underlying gendered dynamics, such as attitudes, experiences, (socio-economic) resources and political socialization that lead to the gender gap in political participation (e.g. Bernstein, 2005; Burns, Schlozman, \& Verba, 2001; Coffé \& Bolzendahl, 2010; Fox \& Lawless, 2004, 2014; Sartori, Tuorto, \& Ghigi, 2017). 
Even the potential solution of implementing gender quotas have not been an easy fix. ${ }^{23}$ Not only do quotas "fast-track" the inclusion of women in formal politics (Dahlerup \& Freidenvall, 2005), it has also been shown that quotas can be a signal for a wider societal change of attitudes (Franceschet, Krook, \& Piscopo, 2012). However, the positive effects of gender quotas are not uniform. Beauregard (2017) finds that gender quotas decrease gender gaps in some political activities within countries but at the same time she shows that countries with quotas still have larger gender gaps in political participation than those without. Much of the success, however, amongst other things depends on the question if the party elites actually implement and enforce those quotas (Dahlerup \& Freidenvall, 2005). Additionally, even with quotes, political careers are still fundamentally shaped by gender and high status political offices are often reserved for men (Franceschet \& Piscopo, 2014). This shows that in order to increase the political participation of women it is not enough to know how women are disadvantaged in the system but it is important to understand how male dominance in politics is maintained (Bjarnegård, 2013).

Therefore, when one asks the question "Where are the women?" a logical next question has to be how potential political candidates are selected. Political parties are considered to be gatekeepers for female politicians (Norris, 1993) and party structures play an important role in deciding women's chances for office (Caul, 1999; Wängnerud, 2009). Kunovich and Paxton (2005) argue that women have to pass two filters to become public officials, first they must be selected to run by the parties and then they must be favored by the electorate. It has been widely discussed that for the latter, cultural norms on the role of women can be a severe hindrance (Norris \& Inglehart, 2001; Paxton \& Kunovich, 2003). The former has often been described as a "secret garden of politics" (Gallagher \& Marsh, 1988), that takes place behind closed doors and is regulated by informal practices and internal party rules and needs to be explored further.

This chapter adds to studies analyzing other parts of the world (e.g. Bjarnegård, 2013 on Thailand; Franceschet \& Piscopo, 2014) discussing how corruption effectively hinders women from entering formal politics. Bjarnegård (2013) argues that "whereas democracy has often been viewed as enabling participation, clientelism is here seen as constraining genuine political participation for the majority of people"(p.8). Much of the initial literature assessing the relationship of

23 For a detailed overview of arguments for and against gender quotas see for example Dahlerup and Freidenvall (2010). 
gender and corruption is focused on the question of women in politics and their role as potential anti-corruption force (e.g. Dollar et al., 2001; Frank et al., 2011; Swamy et al., 2001). It is important to study in more detail what makes "corruption systems prone to inclusion of already corrupt men while effectively excluding outsiders such as women"(Bjarnegård, 2018, p. 257). While chapter 4 analyzed how views on corruption and patriarchal views on the participation of women are related, this chapter looks at the relationship of corruption and political representation of women from a different angle. Adding to the discussion of chapter 3 it shows that in fact patriarchal structures that shape expectations and gender roles and hence determine who is powerful and who is allowed to participate in corruption. In this case, patriarchal power structures result in low levels of corruption among women as compared to men because they do not have the same access and amount of power. Therefore, this chapter discusses how patriarchal norms are used to exclude women from clientelistic networks. Therefore, feminist institutionalism is used in this chapter to show how informal rules are enforced through sexist rhetoric and therefore prevent women from joining clientelistic networks.

This chapter takes a closer look at the role of sexism to get a deeper understanding of how patriarchal structures are shaping these informal institutions and are therefore excluding (most) women from clientelistic networks and therefore participation in formal politics. Research has long shown that patriarchy shapes societal relationships (see chapter 3 for detailed discussion) and theories discussing prejudice have long discussed that there is a close relationship between status differences between groups and the use of hostile stereotypes to justify restricting a group to a lower status and exploiting such groups (e.g. Abad-Merino, Dovidio, Tabernero, \& González, 2018; Allport, 1954; Tajfel, 1969). Previous research shows that benevolent or patronizing treatment are often used towards others who are perceived to have a lower status because the more powerful feels more comfortable in expressing affection towards lower-status individuals (Hebl, King, Glick, Singletary, \& Kazama, 2007, p. 1509). Glick and Fiske (1996) argue that patriarchal structures lead to the control of social, political and economic institutions by men, which results in hostility towards women who are attempting to challenge this control. At the same time, men depend on women for procreation and as (sexual) partners, which leads to idealization of women in traditional gender role. ${ }^{24}$ ${ }^{24}$ This has also been discusses as the 'pedestal-gutter syndrome' and 'Madonna-whore dichotomy'
(Glick \& Fiske, 1996; Tavris \& Wade, 1984). 
This chapter looks at the Republic of Georgia as a case study. Georgia gained independence from the Soviet Union in 1991 and the following years were "marked by fervent nationalism and rapid structural change" (Chkheidze, 2017, p. 79) and dominated by nationalist political groups (Jones, 2013). ${ }^{25}$ And while Georgia has seen a number of democratic openings (elections since 2008 have been considered free and fair $^{26}$ (Gilbreath \& Balasanyan, 2017)) over the decades it still has not truly been able to consolidate its democratic institutions (Pokleba, 2016, p. 235). The political sphere of Georgia has and continues to be largely dominated by elite politics and clientelism.

In the context of corruption and gender Georgia presents an especially interesting case study. While much of the discussion in the field has been centered around the role women play in decreasing levels of corruption (Dollar et al., 2001; Rothstein, 2016; Swamy et al., 2001) this chapter adds to the small emerging body of research studying how clientelist networks exclude women from the political sphere. Georgia lends itself for this analysis as the number of women in formal politics is still very low and despite successes in fighting low level corruption, clientelism still plays a fundamental role.

Historically, while women played an important role in the transition process and took on many different roles, they remained largely excluded from political power (Chkheidze, 2017). At the same time economic hardships after the collapse of the Soviet Union pushed many women into the informal sector and employment far below their qualifications (Sabedashvili, 2007; Sumbadze, 2017). Under Saakashvili, the new neoliberal economic, political and social order brought further increased the divide where large parts of the population where excluded from the post 2003 economic growth. The harsh economic conditions during the transition for many women went hand in hand with being "subjugated to rehabilitated cultural and religious traditionalism" (Javakhadze, 2006, p. 68). These changes also impacted the gender norms in the country, where many demanded social and political change that transforms women's lives (Waterston, 2017, p. 7). However, gender inequality in Georgia is still high. In 2014 the country ranked 70 out of 188 on the Human Development Index (HDI). One of the measures included in the HDI is the Gender Inequality Index (GII) ${ }^{27}$. It measures three dimensions, namely

\footnotetext{
${ }^{25}$ For a detailed history of Georgia and its political development see Jones (2013).

${ }^{26}$ With minor problems the elections were considered free and fair by the OSCE/ODIHR Election observer missions (OSCE ODIHR, 2008a, 2008b, 2012, 2014, 2017, 2018).

${ }^{27}$ Available at http://hdr.undp.org/en/countries/profiles/GEO
} 
reproductive health, empowerment (the proportion of parliament seats held by women) and the economic status of women and has a value between 0 and 1 , where higher values signify higher levels of inequality. Georgia in 2014 had a GII of 382 .

While surveys in Georgia show public opinion is in favor of including more women in formal politics and a general agreement that women are an important part of political life (Thornton \& Turmanidze, 2014, 2017), there seem to be obstacles that prevent women from being fully included. And despite relatively constant support for adopting gender quotas of around 50\% (Thornton \& Turmanidze, 2017, p. 28ff) the parliament voted against implementing quotas that would have required parties to have at least $50 \%$ Women in their candidate lists, in March 2018 (OC MEDIA, 2017, 2018). Therefore, this chapter sets out to get a better understanding of the underlying structures hindering participation of women. While initial existing research reveals that family obligations still can hinder participation of women (Duban, 2010) and that stereotypes and myths play a role (Urchukhishvili, 2017) more detailed research is still needed. This chapter explores how patriarchal structures, such as sexism, prevent women from joining the male clientelistic networks currently at the top of formal politics in Georgia.

\subsection{Georgia - clientelism is alive and well}

The recent history of Georgia is dominated by tightknit political elites. In the years following independence corruption and organized crime were rampant (Kukhianidze, 2009) and the government of President Shevardnadze (1992-2003) was filled with old party elites and closely linked to corruption and the criminal world (Jones, 2013). And while space for civic and political freedoms had been established but the conditions for true political competition and participation did not exist (Nodia \& Scholtbach, 2006, pp. 5-21). Anger about corruption, professional crime groups and the accusation of falsifications in the elections brought about major protests in 2003, the so-called Rose- Revolution (Kukhianidze, 2009). Created as a splinter group of Shevardnadze's Citizen's Union of Georgia and lead by Mikheil Saakashvili, the former minister of justice under president Shevardnadze the United National Movement (UNM) took over power in a peaceful transition (Chiaberashvili \& Tevzadze, 2005). Yet, this revolution was also closely linked to political elites. Not only were many old elites among the main drivers of regime change, Kupatadze (2017) argues that the inability of President Shevardnadze to include elites and interest groups to their political and economic advantage throughout his governing time was one major reason for the revolution. 
Saakashvili's consolidation of power in the parliamentary and presidential elections of 2004 and the municipal elections of 2006 lead to a sweeping and largely successful administrative and anti-corruption reform (Aphrasidze \& Siroky, 2010; The World Bank, 2012) eliminating street level corruption and increasing transparency.28 These Saakashvili area reforms are often considered the most successful and comprehensive anti-corruption reforms seen in the world to date (Mungiu-Pippidi, 2016). Yet, these reforms were once again only possible due to two major elite factors: a "radical break with the past [and its elites] and elite cohesiveness"(Kupatadze, 2017, p. 203). The Rose Revolution lead to a break with the old Soviet, corrupt and clientelistic structures, and a breaking up of "collusive links between the state and the business" (Kupatadze, 2017, p. 192). This allowed for sweeping anti-corruption reforms on the bureaucratic level without considering old elite interests. At the same time, the kind of drastic reforms enacted in Georgia, were only possible with a homogenous, tightknit and unified new elite (Kupatadze, 2017) and were therefore accompanied by elite group decision making with little transparency (Gallina, 2010) and the diminishing of other political groups (Siroky \& Aprasidze, 2011). The latest with the constitutional amendments of 2004 power was shifted to the executive which resulted in a grass imbalance of power between the governmental branches - weakening the parliament and strengthen the presidency (Caryl, 2012; Pokleba, 2016; Tatum, 2009). Saakashvili and his team were of the opinion that "necessary reforms are best promoted by the decisive actions of the chief executive rather than by sharing power"(Hale, 2006) and therefore other political forces were in large parts excluded from the system, by the new institutional design (Lanskoy \& Areshidze, 2008; Wertsch, 2006). Much of this shift in power was also accompanied by "abuses of state resources and changes in electoral system to the advantage of the ruling party" (Cianciara, 2016, p. 397). One academic interviewed for this project summarized it: "From this point of view Saakashvili fought corruption on low and medium level but political corruption was flourishing. He was fighting the political corruption of the previous government but brought his people to office and then used the administration to stay in power e.g. he used the reformed police, court system et cetera to maintain his presidency."

The exclusive nature of the governing process was further increased by a sharp focus on economic growth and international rankings (Schueth, 2011) as well as enforcement capacity (L. Rekhviashvili \& Polese, 2017). Additionally, governance

\footnotetext{
${ }^{28}$ For an overview of the reforms see World Bank (2012) and for a critical overview Kupatadze (2016).
} 
during this time was highly informal, as Rekhviashvili and Polese (2017) argue, precisely because of the official liberal reform course which lacked coping mechanisms for the social costs of marketisation and political-economic crisis. Interestingly enough, the Saakashvili government largely relied on informal practices while at the same time setting the reduction of informality as a major policy goal (L. Rekhviashvili \& Polese, 2017). This resulted in the further exclusion of large parts of the population in the post 2003 economic growth (Baumann, 2012; De Waal, 2011; Gugushvili, 2017).

The nation building process during this time was torn between multiple issues, question of inclusion of ethnic minorities, a focus on the Georgian Orthodox Church and Westernization. Inclusion of ethnic minorities have often been neglected by the political parties, except UNM which had an more active strategy to inclusion early on (George, 2014). Yet, this was often contradicted by the focus on Georgian Orthodox traditions in the nation building project under president Saakashvili (Metreveli, 2016) Throughout his government, the importance of the church is cemented in "practices of clientelism" towards the Georgian Orthodox Church (Metreveli, 2016, p. 709). This focus on the Georgian Orthodox Church also impacts the standing of women in society, which are expected to adhere to traditional gender roles. At the same time Westernization and Europeanization became an important raison d'être for some ruling elites, especially the UNM, and simultaneously has been used as a domestic policy tool in the "national identity construction process"(Metreveli, 2016; Ó Beacháin \& Coene, 2014, p. 923) as well as a tool to claim national and international legitimacy (Cianciara, 2016). This focus has also guaranteed a large inflow of funds for the democratization project (Mitchell, 2006) as Georgia was considered a successful example of democratization. Therefore the time after the Rose Revolution was also marked by an unprecedented influx of Western aid which increased again after the RussoGeorgian war in 2008 (Metreveli, 2016). Western institutions have often been perceived as supporters of the Saakashvili government which was viewed critically by many more conservative actors, in for example the Georgian Orthodox church (Metreveli, 2016) and has increased the divide between elites. The focus on the West and Europe also shows how difficult it is to identify clear ideologies in the political parties. While the opposition uses their pro-European stance to increase their domestic legitimacy "and to de-legitimize ruling parties internationally as antidemocratic and guilty of 'selective justice'. [...] pro-Russian ruling parties concentrated on international legitimization as pragmatic players and moderate pro-Europeans." (Cianciara, 2016, p. 407) 
The Russo-Georgian war and the presidential election of 2008 marked another critical point in Georgian political history. The latest by this point the new elite developed and maintained new corrupt, clientelistic structures. "'New' corruption ran more along the lines of clientelism and patrimonialism, with the state's power to distribute resources being used to benefit specific groups and individuals. The 'tell' here was the number of big contributors to the UNM who also owned companies that received large government contracts. " (Kupatadze, 2016, p. 114)

In 2011, after rising discontent about the current government a new party platform, the Georgian Dream (GD), was established by Bidzina Ivanishvili, attempting to unite opposition forces (Cianciara, 2016, p. 398). The parliamentary elections in 2012, marked an important milestone in the history of Georgia, the GD won and the country saw an orderly, peaceful and constitutional transfer of power (Pokleba, 2016, p. 236) Georgia is still categorized a transitional or hybrid regime (Freedom House, 2013, 2018; Levitsky \& Way, 2010).

Kinship ties have always been influential in Georgian society, especially during difficult times and the political system has been and still is largely centered around political elites and personalities (Nodia \& Scholtbach, 2006) and nepotism and patronage play an important role. As Sichinava (2018) found "to a significant extent, cleavage politics in the post-Communist polities is still alive and well"(p. 15). This includes both lower level bureaucracy as well as high level politics. As one female interview partner from an NGO stated:

[High level corruption] that is still a problem. My husband for example is looking for a job but he cannot fine it because the positions are only put online for show. Really the positions are already filled. And there are so many unexperienced people put on really important positions. For example, the minister of internal affairs was put in power because he was the son of someone.

While more cases of citizen's activism are sprouting up, civil society ${ }^{29}$ in Georgia is still rather weak (Pokleba, 2016) and their role limited. Overall, the Georgian population is largely disconnected from civil society organizations and limits political participation to elections and at times protests (Pokleba, 2016; Sumbadze, 2003). The interviews however, revealed an interesting dichotomy. Civil society

\footnotetext{
${ }^{29}$ Civil Society is not limited to Non-Governmental Organizations (NGO) but encompasses a large number of associations, including but not limited to, educational, peace, environmental human rights, political, church and religious and watchdog organizations, labor unions etc., (Howard, 2002, 2003).
} 
was often presented as weak at the same time it also has significant influence in politics. As one interviewee said: "They expect me to do things that the ministry should do. They tell me: write this policy. And I tell them this is something you need to do. It is not my role". Discussing with the interviewees NGOs are considered a good employment opportunity and a jumping board for other careers and only in rare cases have a strong base of volunteers, which has also been confirmed by other research (Pokleba, 2016). Along the same lines, NGOs are important service providers and agenda setters, but play only a small role in encouraging citizen's engagement. In line with Pokleba's (2016) research, interview partners did see their main role in being a watchdog for the government and actively driving the policy agenda. For the big NGOs it was normal to be strongly involved with day to day government business and a revolving door between civil society and government is common. This definitely is another example of how tight-not the elites are and how limited the group of people who are involved in policy making.

Table 5 Percentage of women in parliament since independence

\begin{tabular}{l|l}
\hline \hline Year Parliamentary Elections & Percentage of Women in Parliament \\
\hline 1992 & $6.22 \%$ \\
1995 & $6.64 \%$ \\
1999 & $7.17 \%$ \\
2004 & $9.33 \%$ \\
2008 & $6 \%$ \\
2012 & $12 \%$ \\
2016 & $16 \%$ \\
\hline \hline
\end{tabular}

Source: Inter-Parliamentary Union (2018a)

The role of women in formal politics is still minor. While in 2014 about 57\% of women were active in the labor force (77\% of men) (National Statistics Office of Georgia, 2015, p. 39), women typically work in less profitable sectors (horizontal segregation) and work in lower paying positions than men even when they work in the same sector (UNDP Georgia, 2018, p. 22) The participation of women in public life shows an interesting contrast. While civil society is largely dominated by women, ever since Georgia's independence, women only held a small percentage of the seats in Parliament (see Table 5 and Table 6). 
5 Dainty women - dirty politics: the role of sexism in political participation in Georgia

Table 6 Members of the parliament of Georgia by factions 2014

\begin{tabular}{l|ll}
\hline \hline Party & Women & Men \\
\hline Georgian Dream & 8 & 37 \\
Georgian Dream - Free Democrats & 1 & 7 \\
Georgian Dream- Republicans & 1 & 8 \\
Georgian Dream - Conservatives & - & 6 \\
Georgian Dream- Entrepreneurs & - & 6 \\
Georgian Dream - National Forum & 1 & 5 \\
Independent Majoritarians-for Powerful Regions & 1 & 5 \\
Non-Partian, Independent Majoritarians & - & 6 \\
United National Movement & 5 & 34 \\
National Movement-Majoritarians & - & 6 \\
United National Movement - regions & - & 6 \\
Out of Faction & - & 6 \\
Total & $\mathbf{1 7}$ & $\mathbf{1 3 2}$ \\
\hline \hline
\end{tabular}

Source: National Statistics Office of Georgia (2015, p. 63)

Table 7 Composition of the government of Georgia December 2014

\begin{tabular}{l|l|l}
\hline \hline & Women & Men \\
\hline $\begin{array}{l}\text { Ministers of Georgia } \\
\text { (including State Ministers) }\end{array}$ & 3 & 16 \\
Deputy Ministers & 10 & 56 \\
\hline \hline
\end{tabular}

Source: National Statistics Office of Georgia (2015, p. 64) 


\subsection{Methodology}

The research for this chapter took place during the government of Georgian Dream Coalition in 2014 and 2015, at a time where discussions about gender equality jumped to the national agenda, sparked by outcries over domestic violence cases ${ }^{30}$. A preparation trip in July 2014 was followed by three primary data collection trips in September 2014 and January and March 2015. As civil society and political elites are almost entirely based in the capital (Sichinava, 2015), the interviews were conducted in Tbilisi.

The target population of the interviews were civil society actors and political representatives from a wide spectrum of believes. To reach a wide variety of actors and cover different political believes, a mix of purposive and snowball sampling has been used (Blaikie, 2009). The number of registered Non-Governmental Organizations (NGO) in Georgia is incredibly large but only few are actually active, hence many initial contacts did not lead to results. A Council of Europe report (2017) found for example that over 200 NGOs could be identified to work on women's issue but only a small number was actually active (p.29). For the preparation trip, NGOs working on issues of corruption, transparency, accountability, gender and participation with English websites, international development organizations and INGOs were identified. The contacts established through this initial round were then used in snowball sampling to refer other potential interview partners. Many additional contacts dependent on personal networks of interviewees and could have not been reached without. This is especially true for political actors and government agencies.

For the initial trip, a translator was hired, yet it became quickly apparent that due to the almost tribal distinction between 'good and evil' in political believes and harsh political distrust interview partners were less trustful with a third, Georgian, person in the room. Therefore, all interviews were conducted in English. Enough time was scheduled to ensure time for repetition and questions. Four of the interview partners opted to bring a translator from within their own organizations.

Semi-structured interviews were conducted with all interview partners. The interviews and questions were targeted towards the role and expertise of each interviewee and left room for participants "to answer more in their own terms than the standardized interview permits, but still provide a greater structured for

\footnotetext{
${ }^{30}$ Especially the murder of Prof. Maka Tsivsivadze by her ex-husband in 2014 created a wider movement.
} 
comparability over that of the focused or unstructured interview" (May, 2011, p. 135). This method also left room for the researcher to probe and ask for elaborations, which was especially important to get more information on the underlying believes.

The research takes a constructivist approach, "which examines the ways in which events, realities, meanings, experiences and so on are the effects of a range of discourses operating within society"(Braun \& Clarke, 2006, p. 81). The data was analyzed using thematic analysis (Braun \& Clarke, 2006). The interviews and field notes were transcribed and coded in multiple cycles (Saldaña, 2016) and themes were identified. Overall 57 interviews were conducted with 54 people. 8 interviewees were interviewed twice at two different points in time.

Table 8 Interview break-up by gender

\begin{tabular}{l|l}
\hline \hline Gender of respondent & \\
\hline Male & 22 \\
Female & 32 \\
Total & $\mathbf{5 4}$ \\
\hline \hline
\end{tabular}

Interview partners can fit multiple categories, e.g. a number of interview partners are former government but now in the opposition movement and active in civil society and similarly some are currently in the government or have since the interview switched into government. Many of the NGOs interviewed also included members of the previous government or current members of parliament. Additionally, many interview partners had dual roles - e.g. university and NGO, Government and NGOs. For organizations that work on many different issues the expertise of the interview partner has been chosen as the main work area. 
Figure 12 Number and type of organizations

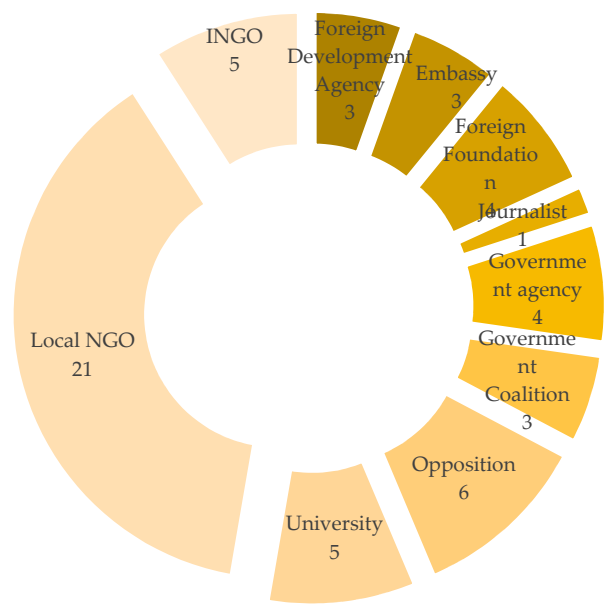

Figure 13 Focus area of NGOs and INGOs

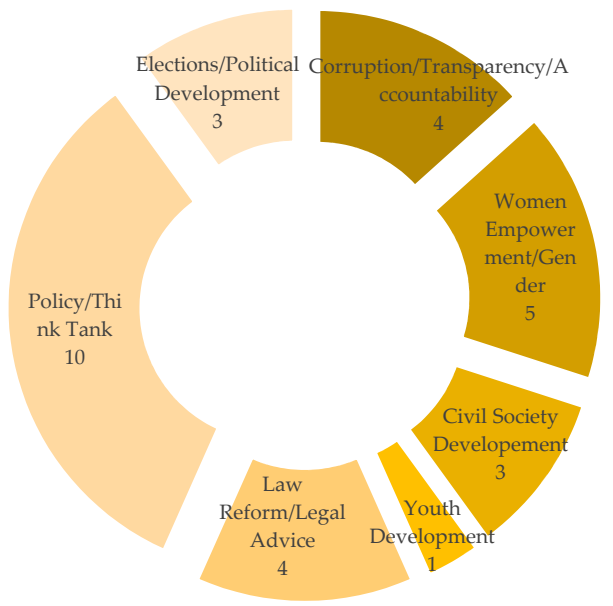

Figure 12 gives an overview of the types of organizations interviewed and Figure 13 shows the topics covered by NGOs and INGOs that were interviewed.

Researcher positionality plays an important role in this research. As a young, Western female, researching corruption and the political participation of women, certain questions can provoke a certain degree of social desirability response bias (Bernardi, 2006; Furnham, 1986). For example, all respondents for this study agreed that it is desirable to have more women in formal politics. This is not in line with survey findings which in the same year determined that $34 \%$ of the respondents argued that there are enough women in parliament and 3\% found it too many. The discrepancy can be explained by both the fact, that all respondents are active in politics and civil society and therefore more aware of the issue or by social desirability response bias. By using different probing questions and triangulating the findings with existing research of Georgian researchers the study tries to overcome this potential bias as much as possible. 


\subsection{Informal institutions and sexism}

Politics essentially is about power and gender fundamentally shapes who has this power within political institutions, which were built around the understanding that men are the norm and the powerful both in public and private life (Lovenduski, 2005). This understanding still persists and strongly shaped our understanding of how institutions should function. Oftentimes, it is women who are at a disadvantage "in the power play over which ideas matter and who accumulates institutional resources"(Mackay, Kenny, \& Chappell, 2010, p. 582). Feminist institutionalism, therefore, has worked on understanding this phenomenon better by focusing on the importance of analyzing 'the rules of the game', both formal and informal, in political institutions and how these rules are gendered (Krook \& Mackay, 2011, p. 1). Informal rules here are defined as "socially shared rules, usually unwritten, that are created, communicated and enforced outside of officially sanctioned channels"(Helmke \& Levitsky, 2004, p. 727). In this context, it is essential to note that "not only are gendered relations seen to be 'institutional', these relations are 'institutionalized', embedded in particular political institutions and constraining and shaping social interaction" (Mackay, Monro, \& Waylen, 2009, p. 580).

Initially much of the discussion focused on the question of how institutions can bring about positive gendered change but increasingly has also been utilized to understand how positive change is obstructed and resisted within institutions (Thomson, 2018, p. 178; Waylen, 2014). Therefore, feminist institutionalist research has shown that institutions can foster and hinder the participation of women (Kenny, 2013). This is true for both new and long existing institutions. New institutions have the advantage that they can be created with a clear effort to promote gender equality (Chappell, 2014; Waylen, 2006). And while often new institutions can be more likely to adopt positive gender policies (e.g. Chappell, 2002; Mackay \& Mcallister, 2012), they also easily regress into old norms (Mackay, 2014). Therefore, Mackay's (2014) research shows how important it is to understand "institutional legacies and ongoing dynamics, including gender regimes that can open and foreclose opportunities for embedding of innovations and opportunities for new paths"(p. 567) in order to implement successful gendered changes in new institutions. This research focuses on the informal institutions within political parties.

Looking at the impact of political parties on women's candidate recruitment Norris (1993) adds a second layer. She distinguishes not only between the level of 
institutionalization (formal vs informal) but also considers if control in the party is centralized or localized. Her analysis shows that in systems that are formal and localized, women can often recruit support easier at the local level but at the same time know that formal rules will be followed and through this can become candidates despite potential hostility of the party leaders. In a system that is formal and centralized the party leader has to be interested in gender equity to increase the number of female candidates (Norris, 1993, p. 326). The most problematic system for women to be able to run for political office is one where the rules are informal and the decision making is centralized, which usually means decisions are based on (male) patronage networks (Norris, 1993, p. 323). This chapter explores in more detail how these informal institutions within the political parties are preventing women's participation in formal politics and are therefore used to protect clientelistic male networks. In order to see how these informal rules are enforced this chapter looks at the role of sexist rhetoric in the debate on the participation of women.

Sexism is a complex phenomenon, which initially it is most frequently thought of as hostility and antipathy towards women (Allport, 1954), i.e. hostile sexism. It has been widely discussed that this form of sexism can undermine equality policies (Harrison, Kravitz, Mayer, Leslie, \& Lev-Arey, 2006; Jost \& Kay, 2005; Konrad \& Hartmann, 2001; Son Hing et al., 2011) and can prevent women from achieving in the work place or being able to enter certain positions. Masser and Abrams (2004) show that hostile sexism leads to negative evaluations of female candidates for managerial positions and higher recommendations for the hiring of male candidates. Yet, often times, stereotypes also contain positive traits about women. However, since they focus mostly on social-emotional abilities than women's agency they often characterize females as nice people but incompetent at tasks such as analytical thinking (Glick \& Fiske, 1996, p. 492). This is especially true when focusing on traditional gender roles, which interestingly enough can simultaneously encompass both very negative and very positive evaluations of women (Glick \& Fiske, 1997). Therefore, Glick and Fiske $(1996,1997)$ argue in their ambivalent sexism theory that sexism can be hostile as well as benevolent. Benevolent sexism here is defined by "subjectively positive attitudes toward women characterized by a sense of protection, idealization, and affection for women" (Hideg \& Ferris, 2016, p. 707). Benevolent sexism has three fundamental components: "protective paternalism (e.g. the belief that women should be protected by men), complementary gender differentiation (e.g. the belief that women have - typically domestic - qualities that few men possess), and 
heterosexual intimacy (e.g. the belief that women fulfill men's romantic needs) (Barreto \& Ellemers, 2005a, p. 643). Importantly, benevolent here is referring to the subjectively positive tone, and does not imply that the recipient of the sexist comment does see it as something positive ${ }^{31}$ (Glick \& Fiske, 1996, p. 491). An example of how close benevolence and hostility can lie together is the research by Hebl, King, Glick, Sincletary and Kazama (2007), who show that pregnant women are exposed to benevolent sexism when they are within feminine roles, e.g. as a customer, but are faced with hostile sexism when they "engage in nontraditional or gender-incongruent behaviors"(p.1499) such as seeking employment while pregnant.

Like politics itself, stereotypes are essentially a question of power. As men have the structural power they will react differently to women who challenge this power than to those who enforce the status quo. Thus, women face stereotypes not as a single category "women" but depending on the way that they potentially threaten or sustain men's power. Research shows that there are in general three consistent, but not exclusive, subgroups: career woman, housewife, and sex object around which these stereotypes are then centered (Altermatt, DeWall, \& Leskinen, 2003). While women who fulfill traditional roles such as the housewife and mother enforce existing power-relations will be met with benevolence, fostered by. "men's interdependence with women (because of sexual reproduction, heterosexuality, and kinship relations)" (Hebl et al., 2007, p. 1500f) women who are challenging these structures ('career women') are likely to face hostile sexist reactions (Glick, Diebold, Bailey-Werner, \& Zhu, 1997). Women as 'sex object' can elicit both hostile and benevolent reactions depending if the woman's sexuality is considered "good" or "bad", i.e. a way to manipulate men's power (seductress, tease) (Glick et al., 1997). The following sections will first analyze political parties and their informal rules and then discuss the role of sexism as a tool to enforce these rules.

\footnotetext{
31 That benevolent sexism can have detrimental effects has been widely shown in the literature, e.g. it has been linked to attitudes that tend to legitimize domestic violence (Glick, Sakalli-Ugurlu, Ferreira, \& Souza, 2002; Sakall, 2001). Vescio et al (2005) show that patronizing feedback diminishes women's task performance and King et al (2012) analyze how benevolent sexism, leads to women getting less challenging assignments and hence limits their presentation in the highest levels of the organizations they are working in. They explicitly also find that there is no difference between men or women in the desire to receive challenging assignments.
} 


\subsection{Political parties in Georgia - informal rules}

Political parties in Georgia are still unstable and often only serve small group interests rather than larger social groups. "In periods between elections, they tend to create coalitions, change partners, and individual politicians move from one party to another" (Pokleba, 2016, p. 240). Ideology still plays a small role in the Georgian political party landscape. Citizens mostly do not link political parties to specific ideologies Nodia and Scholtbach (2006) and the interviews for this research confirmed that ideology still plays a much smaller role, even though some party members do try to emphasize on more ideological differences, however, they mostly revolve around a Pro-European versus a Pro Russian stance. As a taxi driver told me on the way to one of the party headquarters: "who cares about the party - one day he is in that party the other in that, it does not matter. It's all about where he gets something" This is in line with the account of a young male political activist who told me that while he originally was in another party, he decided to switch parties as he just saw more opportunity for development there even though the political ideology was not necessarily clear or the same. And a female NGO respondent summarized: "When things started changing [in 2003] those thinking in democratic terms who did not want Saakashvili founded their own parties. Then you had the disappointment by Saakashvili because they did not get the right party job and therefore they found new parties. That is how parties get started here".

Even the division between current opposition and government is in large parts not based on ideology. "There is no ideological goal in the parties", an NGO worker stated, "the ideas of the parties are all pretty similar and the biggest coalition at the moment is only based on hatred of the UNM". It is an important factor for understanding the access for women to public offices that parties are still largely structured around personalities rather than ideological differences, decisions are made by a few powerful rather than the rules and parties are strongly centralized. This makes clientelistic networks even more important for access to power within the organization.

The inclusion of women still does not play a major role, while many of the political parties have some focus on gender sensitivity in their party statues ${ }^{32}$, none of them have committed to active promotion of gender equality among political candidates. While parties often have many female members (about $40 \%$ in 2012

\footnotetext{
${ }^{32}$ For an overview see Bagratia and Badashvili (2012).
} 
(Bagratia \& Badashvili, 2012)) this does not translate into political offices. The women are also frequently tasked with lower rank tasks such as managing volunteers and election campaigns (Bagratia \& Badashvili, 2012, p. 13) which has also been confirmed in the interviews. Women are essential for the functioning of the party but are frequently not rising up the ladder.

Exploring the informal rules, one such rule emerged immediately from the interviews. When interview partners were asked about their political career (current or previous), a clear pattern was visible. While for all, personal connections were the main factor for getting involved in a specific party or even switching parties, rather than deliberations about ideological preferences, all women referred to a moment of invitation by a powerful male member of the network: "I got a call and [... he] told me that I would be good for the job and so I said yes." The narrative of men was entirely different, they focused on their choice for a specific party and how and why they were the ideal candidate to join that party. Women on the other hand always connected their qualifications to what the inviting male had highlighted as their qualification. Hence, a clear informal rule in the political parties is that women have to be invited for higher office by a powerful male network member.

The existence of formal and informal rules is not in itself a bad thing. Informal rules can have a positive effect on change in guaranteeing that formal rules are followed or they can override formal rules or "exist alongside formal arrangements." (Bjarnegård \& Kenny, 2015, p. 751).

As Georgian party politics is still largely organized around informal rules rather than formal party statutes and as interviewees pointed out, becoming a candidate is less determined by official intra-party rules than by personal contacts. The gatekeepers to these networks and any potential candidacy are almost entirely powerful men. Additionally, studies in 2012 and 2016 showed that the formal rules within parties are still largely gender insensitive (Bagratia \& Badashvili, 2012; Urchukhishvili, 2017, p. 12f) ${ }^{33}$ and if they exist, they at first sight seem gender neutral.

Yet, to understand why male power continues to dominate the political sphere one must also understand the "gendered expectations implicitly inherent in different formal rules" (Bjarnegård \& Kenny, 2015, p. 750) as well as the informal rules that

\footnotetext{
${ }^{33}$ None of the parties has enacted gender quotas. The Republican Party has declared support for party gender quotas, but it is not clear yet how they will be enforced (Council of Europe, 2017, p. 39).
} 
shape political recruitment. The formal rules of the electoral system can determine who a party might find to be an appropriate candidate (Ljungholm, 2017). And indeed, as Urchukhishvili (2017) shows for Georgia, the partially majoritarian election system gives man a chance to exclude women by arguing that they are not 'made for' the type of election campaign that is necessary, i.e. door to door canvassing and direct argumentation with voters and opponents (p.37). This also shows that even ostensibly gender neutral rules often also have a gendered dimension, where such institutional norms proscribe and prescribe " 'acceptable' masculine and feminine forms of behavior, rules, and values for men and women within institutions" (Chappell, 2006, p. 226). As an example how seemingly neutral rules can be gendered, Chappell (2006), discussing norms in the public sector, points out that often times, norms that seem neutral are actually masculine. As Stivers (1993) argues the expectation that public servants act with "dispassionate objectivity" shows that masculine characteristics are valued as the norm, while more feminine characteristics are considered biased (p.40f.). This point carried through the discussions in the Georgian context. Political activity was discussed to require assertiveness, willingness to get dirty etc. Women on the other hand were identified with those traits that were also attributed to civil society such as caring, nurturing and conciliatory. Therefore, it is important to further investigate the informal rules, which are used to exclude women from clientelistic networks and how these rules are mostly enforced through shared sexist rhetoric.

\subsection{Women are just not made for this - the role of sexism in Georgian politics}

At first all interviewees for this study agreed that more women should join formal politics and especially the parliament. This is in line with population surveys in 2014 that showed that 55\% of Georgians ${ }^{34}$ think that there are too few women in Parliament (Thornton \& Turmanidze, 2014). Yet the discussions quickly took a different turn when men were asked if they would encourage their female relatives to join and non-politically active women were asked if they would consider running for office. The answer was the same for all: "politics is too dirty. It is a job for men". One needs to dig deeper into this rhetoric to expose the underlying informal rules implied by this statement.

A classic patriarchal ideology often still shapes the discourse around women's role in society that construes women as "keeper of the family" and men as the "builder 
of the state". Where state formation itself has historically been associated with "physical strength, violence, and war" (Lovenduski, 2005, p. 53), attributes, which are associated with masculine behavior continue to be our reference for political actors. In addition as Lovenduski (2005) points out, "an idealized separation of state and society parallels and supports a division of labour in which the contribution of women has been rendered unimportant or invisible. In short, institutional sexism pervades political life." (p. 53).

Overall, gender roles in Georgia are still highly traditional. Javakhadze (2006) describes the norm that women have to conform by as "that of a gentle, beautiful, tender, loving, and passive woman who is fully dependent on someone (family, male, relatives, husband), i.e. a helpless female" (p.67) and power still lies mostly with men (Sumbadze, 2017). The gender division within the family is also mostly traditional where the mother is considered the family caretaker and has a subordinate role while the men are the breadwinners (Duban, 2010; Sumbadze \& Tarkhan-Mouravi, 2012). Motherhood plays a fundamental role in Georgian identity and is "women's real mission on earth" (A. Rekhviashvili, 2010, p. 22), where the mother is revered but only as long as she fulfills the role that has been assigned by society (Javakhadze, 2006; Nogaideli, 2012; Vanore, 2015). This link between national identity and the traditional role of women is so intertwined it is still shaping much of the space women are given in society, as will be discussed later.

Much of the discussion of what are the necessary traits to engage in formal politics is centered around these gender stereotypes. Where men are assumed to be suitable for public office because of their "masculine traits - such as aggression and competition" which are widely considered necessary for succeeding in the political sphere (Franceschet \& Piscopo, 2014, p. 87). Feminine traits, such as nurturing and softness on the other hand are ascribed for women and they are considered to be mostly concerned with people's welfare and are more ethical and honest (Barnes \& Beaulieu, 2014, p. 367). This stereotype that women are 'better, softer and nurturing', is frequently discussed also in the Georgian context. As one male NGO advocate said, when explaining why women should be more involved in formal politics: "women just know more about childcare and disabilities and such things. Us men don't care about these things enough, but women do" and one will often hear similar statements as the reasons as to why more women should be in the parliament. This argument is in line with existing research, which shows that women in formal politics often do bring different topics to the table (e.g. Bhalotra, Clots-Figueras, \& Iyer, 2017; Halim, Yount, Cunningham, \& Pande, 2016; Hicks, 
Hicks, \& Maldonado, 2016). However, this chapter argues that sexist stereotypes and the way they are employed also serve another purpose: keeping women out of clientelistic networks. Informal rules around candidate selection in the political parties in Georgia are centered around sexist notions on who is fit to run for political office and a reinforced through constant repetition.

The discussion regarding the participation of women in formal politics in Georgia clearly centers around all three stereotypes identified by Altermatt et al. (2003), career woman, housewife and sex object. The focus on traditional roles and motherhood in the national narrative exposes women who focus on careers to criticism because they are considered to not fulfill their main duty for the family. Still, where roughly one third of households is female headed (National Statistics Office of Georgia, 2015, p. 36) and many families depend on women's earnings, it is common for women to participate in the labor market as long as they are not considered as 'career women'. Civil Society is in many aspects different from the rest of the labor market, not only are the lower level positions dominated by women, a significant number of NGOs are also headed by women. This is in line with the rhetoric about the caring and nurturing women. Many of the respondents agreed that civil society is a better fit for women because they can do what women are best at: care for others. An interesting difference appeared when asked why so many are active in the NGO sector but not in formal politics. One male interviewee stated: "Many women prefer to work for NGOs it is just not so competitive". Women on the other hand reiterated different reasons for their preference for the civil society sector. For one the pay is relatively higher to other sectors, work is interesting and most importantly women appreciated that NGOs frequently have a more meritocratic hiring system: "Working for an NGO is all about merit - if you are good you can get a good job and be successful." The rhetoric around civil society clearly shows that women's involvement is not perceived as a threat to male institutional power as it is considered a 'feminine' sphere. Hence, a career in NGOs for women often is not considered a "career" in the classical sense. The picture in political hiring is fundamentally different.

Women's sexuality, not surprisingly does also play an important role, even though it is often discussed more implicitly. Urchukhishvili (2017) finds that in some instances sexist discussions about women's sexuality are used to define which women might be an acceptable candidate, where being considered "sexy" (i.e. a seductress or tease, as Glick et al (1997) define it) is seen as equivalent to incompetent. As a male mid-level party manager stated: 


\begin{abstract}
"A female politician should have no sexuality. Sexuality has to be taken outside the party. Being sexy is not advantageous for this job, because it means she cannot be loyal and focused. This is my view. This type of a woman has other functions. If I were a man saw a beautiful woman with big breasts etc. who wanted to join the party, I would think that I don't need this woman for a serious job, I would rather see a loyal, determined person in the party." (Urchukhishvili, 2017, p. 36)
\end{abstract}

However, not always is this connection made so clearly. Throughout the interviews for this research, it became apparent that for the most part, the rhetoric used is more-subtly discussing women's sexuality and is often seemingly benevolent. As previously discussed the idealization of motherhood plays an important role in the Georgian narrative - this glorification is also closely linked to the importance of virginity before marriage where women's sexuality is reduced to importance of motherhood (Nogaideli, 2012, p. 20; A. Rekhviashvili, 2010). Defining women as chaste and sexually moral is an essential narrative of the national identity (Nogaideli, 2012), hence women who are deviating from this norm in any way are considered amoral or dirty. "Politics are dirty" was a central argument in the discussion of why women are not yet and should not be involved in formal politics. While at first glance the statement that women are too clean for politics seems to stem from a paternalistic, protectoral view, it is also a clear signal for women who want to challenge this notion - if they do indeed join the political arena, without having been invited by a man, they will risk to become dirty and sexually deviant, i.e. unlike what a Georgian woman should be like, and are hence free to being chastised. This idealization of women in traditional gender roles and the disparagement of those who do not fulfill this role has also been discussed as the 'pedestal-gutter syndrome' and 'Madonna-whore dichotomy' (Glick \& Fiske, 1996; Tavris \& Wade, 1984), which plays an essential role as an informal rule in party recruitment. Where benevolent sexism, "women are too clean for politics", is used to send a clear message: women are only allowed to enter formal politics once they have been invited by a powerful man, if this informal rule is challenged and women push for their own seat, they will fall into the gutter/whore category and are open to aggressive hostile sexist behavior. The use of benevolent sexism to reinforce this informal rule shows that in many instances benevolent sexism might be even more harmful than hostile sexism as it leads to the acceptance of prejudicial attitudes (Barreto \& Ellemers, 2005a, p. 640) and receives less opposition than openly hostile behavior. 
In Georgia, women's dependence on an 'invitation' to join formal politics continues to give the gatekeeper power to men and does not allow all women to join depending on merit. It is also a tool to limit access to political networks to 'trusted women', i.e. those that do not threaten the clientelistic networks, and therefore can be used to further reinforce patriarchal structures. Previous studies in other countries have shown similar patterns (Chathukulam \& John, 2000; Kudva, 2003; Waylen, 2000) Therefore, without addressing this underlying informal rules, changing the formal rules by, e.g. establishing gender quotas might not lead to durable change. As Goetz (2002) discussed in the case of Uganda, quotas often are used to control women in politics, rather than a tool of empowerment. If the control remains in the hands of a male-elite-network, the quotas might also be simply a measure to ensure that 'malleable' women are hand-picked (Goetz \& Hassim, 2003; Krook, 2007, p. 371) A tendency to belittle and diminish women in politics because they were 'only invited' can already be seen in Georgia. As Urchukhishvili (2017) found in a more recent study, the fact that women were invited is also used as a way to belittle women by highlighting that they are not in formal politics because they are competent but they were promoted by men. This oftentimes goes hand in hand with insinuations about sexual relations as "she must be someone's mistress"'(Urchukhishvili, 2017, p. 47). In these cases, the reality that informal rules limit women to join on their merit alone is simultaneously turned into hostile sexist rhetoric that these women are incapable of joining on merit alone. Interestingly enough for men the invitation by a powerful member of the party was throughout the interviews presented as a sign for the proven competence of the invited partner.

This research shows that a mix of benevolent and hostile sexism is a very effective measure to exclude women from clientelistic networks. It is effectively used to discourage women from joining formal politics, yet as some women are included and national and international pressure is rising to expand those numbers, it is important to see the effects of this sexism beyond restricting access to power.

5.7. Stick with what you know - limited space for participation of women

Informal institutions determine who has access to power and despite the informal rules largely excluding women from high level politics in Georgia, some women were still granted this access. In 201417 out of 132 members of parliament were women (from 6 different parties) and three ministers and 10 deputy ministers were female (Table 6 and Table 7). International and national pressure is rising for 
Georgia to increase the number of women in parliament significantly and informal rules excluding women might no longer be the most adequate way of protecting clientelistic networks. Hence, it is interesting to take a closer look at the ongoing discussion regarding potential quotas and the question which role women should and could play in the political field.

It has been well established that the mere presence of women in parliament does not automatically translate into an actual voice for women. As Pitkin (1967) discussed in her seminal work on representation, there is a fundamental difference between 'standing for' (being female) and 'acting for' (substantive representation) women. As has been widely discussed in the literature, the number of women by itself, does not guarantee that women's issues are represented (for an overview Celis \& Childs, 2008). While quotas have been a good measure to increase the number of women on the political stage, they also have not guaranteed substantive representation of women. "Quotas did not put an end to resistance to women within the party or to associated fears that only "tame" women loyal to malecontrolled factions would ever benefit " (Sawer, 2000, p. 371) and parties are likely to continue to promote women who are either reliable allies or inexperienced (e.g. Chathukulam \& John, 2000; A. Ghosh, 2003; Waylen, 2000). Goetz (2002) shows how in the case of Uganda quotas were rather used as a way to "control women in politics"(p. 573) and how elites can use quotas to select compliant women to political office that are unlikely to challenge the male dominant status quo (Goetz \& Hassim, 2003). Additionally women elected through quotas in some countries have been shown to be more dependent on party lines and less able to vote independently, due to the nature of how women were selected into the quota systems (Chathukulam \& John, 2000; Cowley \& Childs, 2003; A. Ghosh, 2003; Goetz, 2003). As Nistotskaya and Stensöta (2018) show for the case of Russia, "women are 'boxed in' to roles that suit the needs of the regime and tightly controlled in their 'boxes' by their male patrons " (p. 160). And Devlin and Elgie (2008) show that in the case of Rwanda, "increased women's representation has had little effect on policy outputs"(p. 237). Therefore, it is important to understand how women are selected pre-quota to see which issues need to be addressed with and without quota to ensure women's holistic participation.

As discussed, all women referred to an invitation by a male patron, which is conforming to previously discussed research showing that only women who are "in line" with the clientelistic goals are actually let into the "boys club". The women who already are active in the political sphere all agreed that there should be more women in the parliament, but when asked if they would be willing to 
work with women in other parties to address this issue all of them referred to the large political division and the importance of party over issue. They also did not identify as representatives of women, but rather saw themselves fundamentally different from other women not involved in politics. This is in line with discussions by Barreto and Ellemers (2005a, p. 640) that show that in a patriarchal society women who are different from the traditional gender norms, by e.g. having a successful career, often see themselves and are seen by others as different (the so called queen bee effect). Indeed, the majority of politically active women are part of Tbilisi elite male networks long before joining the pollical sphere and have therefore little connection to issues faced by other women, e.g. in rural settings. As one female civil society interviewee stated: “[current] female politicians don't really have women's issues on the agenda. They just don't serve as a model for girls or women to stand up for themselves. Think about it, how did the women in parliament get there? It is not the regular women who get there."

Until now the space for women, who had been invited into official politics, to be politically active is clearly defined and limited by sexist rhetoric as an informal rule of recruitment. However, with internal and external pressure rising to include more women in formal politics, a new informal rule is emerging. In addition to choosing women who are opportune and not dangerous to the clientelistic network women are pushed into feminine aspects of politics and more masculine fields are reserved for 'the real politician'- men.

As Bergqvist et al (2016) discuss informal institutions do not only influence the question of who has access to power but also, how this power can be executed. They argue that women face a two-dimensional mandate, where women face "both external expectations on female politicians to act on behalf of women (i.e., the external mandate) and an internalization of these expectations, so that female politicians also feel a greater responsibility to act for women than male politicians do (i.e., internal mandate)"(Bergqvist et al., 2016, p. 4).

Formal mandates, i.e. "the ascribed mandate in terms of exceptions from other so to support certain issues and groups [...] are communicated in day-to-day interactions with others active in the political sphere (i.e., party officials, group leaders, representatives of interest organizations) and there re informal sanctions for deviating from the expected behavior or from not assuming the expected area of responsibility"(Bergqvist et al., 2016, p. 3). Men at the same time are not or less affected by these constraints (Bergqvist et al., 2016). While this has not been much of an issue yet, as women in politics were seen less as representatives for women 
and more as a mere extension of male networks, this is likely to change with more women entering politics under the current push for more women's involvement or even a potential quota.

The question of why more women should be entering the political system was answered almost unanimously both in civil society and within political parties: "they bring different issues to the table. They care more about children and elderly. They just are more caring" (young, female NGO) This assumption is important and in line with existing research that shows that there is a relationship between descriptive representation (being a female representative) and substantive representation (representing women's issues, interests and needs) (Celis, 2009; Pitkin, 1967) and that women and men often have different policy priorities (e.g. McEvoy, 2016). Female politicians are more likely to discuss and prioritize gender related issues in parliament (e.g. Bäck, Debus, \& Müller, 2014; Debus \& Hansen, 2014; Franceschet \& Piscopo, 2008; Swers \& Larson, 2005; Wängnerud, 2000) and focus more on issues such as child education and health (Bhalotra et al., 2017; Halim et al., 2016; Hicks et al., 2016) Based on their different experiences women are more likely to bring women's issues to the table (e.g. Wängnerud, 2000) yet this does not mean that all women will be represented just because some women are included.

For one there are no universal women's interests (Chattopadhyay \& Duflo, 2004), as issues that are most important to women can vary widely depending on different factors. In Georgia this came up frequently in terms of the rural urban divide, where women in the rural areas face different challenges and often have different priorities than those in urban settings (Chankseliani, 2013; Habibov, 2012). However, the majority of women in formal politics in Georgia comes from urban settings and therefore often do not represent rural women's issues any more than men would. Additionally, women often feel obliged to push for gender related issues once they have entered formal politics (Anzia \& Berry, 2011; Franceschet \& Piscopo, 2008; Swers \& Larson, 2005) this puts an extra burden on female politicians that men do not have to take care of "women's issues", as Bergqvist et al (2016) discuss : "Male politicians have more leeway and can make strategic decisions and further their political careers without always taking into account a potential dissonance between the party line on the one hand and the gender mandate on the other" (p.14).

Even beyond this caveat this answer needs to be examined further. For one, this is the socially desired answer, which has been discussed frequently by activists and 
international organizations and hence is easily repeated. But there is more behind this at first glance positive view on the participation of women. It represents the view of women in large parts of Georgia as the 'caretaker and nurturer' - and reiterates the same sexism that is until now used to keep women out of politics entirely. The focus on this is problematic as it "reflects the understanding of male politicians as the norm, and that the way in which they act as politicians is 'politics as normal' and goes unproblematized"(Bjarnegård, 2018, p. 258). Additionally, concentrating on this aspect of political participation limits women to participate in areas that are seen as masculine and do not threaten male structural power. This is in line with previous research on employment where Hideg and Ferris (2016) discuss that benevolent sexism can support the success of gender based employment equity policies as long as those lead to more women being hired in feminine positions and not in more masculine ones (p.722). The areas included in this discussion such as health care, children, disability and elderly, is by many seen as a mere extension of the realm of civil society and therefore does not threaten "real, masculine politics" The rhetoric has shifted from focusing on the importance of equal access to power and gender equality to the question of how women can fulfill their patriarchal role even better. "We need female politicians to take care of issues of children and elderly and people with disabilities [this list could be expanded as desired with other vulnerable populations and female topics]" one male interviewee said. Statements like these almost seemed an attempt to excuse the participation of women, arguing, that we need them in politics because only if some women are active can they fulfill their duty of caring for the vulnerable. While at first sight this argumentation allows women a small step into the sphere of formal politics, it at the same time forces them to stay entirely within the realm of their gender roles - the nurturer. This shows another problematic consequence of benevolent sexism. Benevolent sexism here would support gender equality as long as women are working in traditional feminine work places, which can make it even more difficult to detect how sexism is excluding women. Additionally, while hostile sexism can be addressed by the legal system, benevolent sexist behavior is more subtle and interpersonal and can less easily be addressed by antidiscrimination legislation (Hebl et al., 2007). Furthermore benevolent sexism is less likely to be noticed as prejudice and therefore is more difficult to fight (Barreto \& Ellemers, 2005a, 2005b). 


\subsection{Conclusions}

After discussing the important role of patriarchy in corruption (chapter 3) and the relationship between views on corruption and views on the political participation of women (chapter 4), this chapter adds another layer of discussion. Looking at the case of Georgia which has achieved impressive results in anti-corruption reform but lags behind in levels of participation of women, the study discusses how patriarchal norms are used to enforce informal rules that exclude women from the clientelistic networks dominating the Georgian political landscape.

The three fundamental components of benevolent sexism identified by Barreto and Ellemers (2005a) can be found in the rhetoric that is used to prevent women from entering male networks. Women need to be protected from the dirty business of politics, especially those that fulfill the expectation of a 'good women' ("protective paternalism"). Additionally, the focus is put on the seemingly positive attributes that make women different from men, such as being more caring, nurturing and less aggressive ("complementary gender differentiation") which is not only used to push women out of formal politics and into civil society but also to limit the space for those women who are able to enter formal politics on their own. Last but not least, the glorification of motherhood and the role of women in the family ("heterosexual intimacy") is used both in benevolent and hostile sexism, contingent on if the woman adheres to or challenges traditional gender roles. For those who challenge such roles, sexuality is not only used as a way to demean potential candidates but also to question their competence and portray them as a "bad Georgian woman".

That some women are active in formal politics does not change the importance of these informal rules. The women who are part of the system support the patriarchal structures and are not willing to invest in women's empowerment against their parties. While political active women in the interviews all recognized the importance of inter-party coalition building to push for gender equality issues, all admitted that the current political climate and the intense political cleavages make such efforts implausible. As one politician said: "it is important [to join efforts with other women], but I would not go against the rest of my party. They would have to agree to it."

Another issue that was highlighted in the discussion is the debate of what actually constitutes "women's issues" is ongoing. As Celis and Childs (2012) argue, researchers "often subjectively define women's issues as either those traditionally associated with women (such as childcare and the family), or those with a 'feminist 
accent' (such as abortion or domestic violence)" (p.213), however, also more conservative views can be representation for women. And while this discussion on what constitutes women's issues in Georgia should be left for another time, the important issue was that throughout the interviews the rhetoric in Georgia was very uniform in identifying certain issues such as childcare, family, disability and violence against women as women's issues and explicitly excluding things like security and the economy. This rhetoric interestingly enough was seen throughout not only the political sphere but also among civil society focusing on women's empowerment This severely limits the actual substantive representation of women that is possible in parliament. This way of including women in politics does not uproot the patriarchal system. Clearly limiting the space, they are allowed to engage in does simply mean that the patriarchal system has been changed. As Walby (1990) discusses "is a dynamic system in which men usually give up an activity only when they no longer wish to undertake it" (p.173). This can be seen in the case of Georgia, while international and national pressure is increasing and will eventually lead to more women being included into the political field, men are redefining what areas constitute real and masculine politics and are restricting access for women to this area.

Overall, this chapter yields two important findings. For one, true participation of women can only be achieved through combating hostile and benevolent sexism within the parties and society at large and is likely not going to be solved by quotas alone. For another, for the understanding of the relationship of corruption and gender, it adds to the important discussion that the focus on women as an anti-corruption force neglects an important aspect, namely how much effort is put into excluding women form clientelistic networks. 



\title{
How female migrants pay a heavy toll: experiences of corruption
}

\begin{abstract}
Morocco, Libya and Turkey are a catastrophe. It is pure violence and women hardly talk about it. It must be appalling experiences that they cannot talk about. They can talk about their forced prostitution in Italy, Spain and Greece, but about their experiences in Libya and Morocco they say 'it was not good'. They tell you about 29 rapes on their journey from [their country of origin] to Morocco, but what happened in Morocco 'was not good'.
\end{abstract}

$\overline{(\text { Expert Interview })}$

\subsection{Introduction ${ }^{35}$}

A common understanding in research is that women are often affected differently by corruption than men (e.g. Chêne et al., 2010; Ellis et al., 2006; Justesen \& Bjørnskov, 2014; Leach et al., 2014), yet, surprisingly little research has set out to study in more detail how experiences of corruption are gendered. Surveys have been used to investigate if women are less frequently targeted for bribes than men, yet the analysis have produced mixed results (e.g. Breen, Gillanders, Mcnulty, \& Suzuki, 2017; W.-S. Lee \& Guven, 2013; Mocan Naci, 2008; Seligson, 2006). Notably, only few studies use a qualitative approach to try to investigate further if women and men are experiencing corruption differently, and if so, how (e.g. Ellis et al., 2006; N. Hossain et al., 2010). This chapter adds to this discussion by taking a gender lens to the experiences of corruption of migrants. Research on this topic is interesting for several reasons: (1) it complements the small body of literature on gendered experiences of corruption, (2) it furthers the discussion how gender norms are related to corruption, (3) it adds to the emerging literature on corruption and migration. This chapter brings the dissertation full circle by focusing on the gendered experiences of corruption of one of the most vulnerable groups -

\footnotetext{
35 This chapter is based on research for the report: Merkle, O., Reinold, J., \& Siegel, M. (2017a). A Gender Perspective on Corruption Encountered During Forced and Irregular Migration. Maastricht: GIZ AntiCorruption and Integrity Programme; and Merkle, O., Reinold, J., \& Siegel, M. (2018). Corruption, Gender and Migration, OECD Global Anti-Corruption and Integrity Forum.
} 
irregular migrants. Having discussed on a more theoretical level how patriarchal structures shape corruption (chapter 3) and are linked to views of corruption (chapter 4), chapter 5 took a look at some of the most privileged in a society, i.e. politicians, this chapter now looks at a group that is much less powerful as a whole and analyzes how their experiences of corruption are gendered. This chapter shows that corruption affects both low status men and women, which is in line with the knowledge about patriarchy where not only women are oppressed by men but also lower status men are oppressed by those men with a higher status. This chapter at the same time however shows that even though men and women both are in precarious situations during the migration journey, their experiences of corruption still differ fundamentally, also because patriarchal structures play a role for both, but in different ways.

The relationship of corruption with other social phenomenon has been widely studied, yet surprisingly, the complex relationship between migration and corruption has only recently started to receive increased attention. While initial research focused mostly on corruption as a facilitator of migration (e.g. Bales, 2007; Richards, 2004; UNODC, 2013) an increasing body of literature also explores the role of corruption as a push factor for migration (e.g. Ariu \& Squicciarini, 2013; Dimant, Krieger, \& Redlin, 2015; Merkle, Reinold, \& Siegel, 2017b) and the impact of migration on corruption in the country of origin (e.g. Batista \& Vicente, 2010; Beine \& Sekkat, 2014; Ivlevs \& King, 2017).Yet, the emerging discussion on this multifaceted relationship is still lacking nuance. Even though research that has been conducted in both fields separately suggest experiences of men and women are fundamentally different there has been no research on how the link between corruption and migration is gendered and potentially impacted by gender norms.

Slightly fewer than half of international migrants worldwide are female (UN DESA, 2017) and the gendered experiences of migration have received increasing attention (for an overview see Fleury, 2016; Jolly, Reeves, \& Piper, 2005). While initially female migration was mainly considered in the context of the migration of husbands or households, as increasing numbers of women are migrating independently (Oishi, 2002; Pedraza, 1991) the focus of migration research also changes. These studies show that women and men can be affected very differently by migration and that the effects vary widely. Women might experience social stigma when migrating without a partner or husband (Malkin, 2004). At the same time, migration can also serve as a chance to become economically independent and has been linked to women's empowerment and changing gender roles(Lodigiani \& Salomone, 2015; Lopez-Ekra, Aghazarm, Kötter, \& Mollard, 
2011). And while increased economic independence through migration has been shown to help women to escape abusive relationships (Taylor, Moran-Taylor, \& Ruiz, 2006); women often end up in abuse and precarious work environments in host communities, such as bars and domestic work. ${ }^{36}$

This further increases their vulnerability to exploitation (Tacoli \& Mabala, 2010). Female labor migrants overall often work in positions traditionally performed by women, including domestic work and sex work (Farah, 2006; Fleury, 2016). Domestic work in most cases implies low social standing, lack of proper contractual arrangements, and highly personalized relationships with employers (Kofman, Phizacklea, Raghuram, \& Sales, 2000; Piper, 2005). In turn, this often leads to poor working conditions and a high prevalence of physical, psychological, and sexual abuse (Piper, 2005). Sex workers often face additional discrimination and receive little support from receiving societies, especially when the dominant culture in the country is patriarchal. Zhidkova and Demir (2016) report on patriarchal attitudes to sexuality in Turkey, whereby sex workers are socially stigmatized, and where the focus is on public health and morality rather than protection of migrant women. In the case of victims of trafficking, female migrants will often find themselves criminalized and without appropriate help from authorities - because of a combination of the low societal status of women, and low-salaried officials taking bribes (Boyd, 2006). Although females are rarely the subject of targeted immigration policies, they of course can also be found in more skilled positions such as the health sector (Fleury, 2016; J. Ghosh, 2009; Piper, 2005). ${ }^{37}$

Upon arrival in the destination country, female migrants are more likely to be unemployed or underemployed compared to male migrants and the female native population (Fleury, 2016; J. Ghosh, 2009). Possible explanations for this are issues with the recognition of qualifications and professional experience, language barriers, and double discrimination. Double discrimination here implies that all women are subject to gender-specific stereotypes, which can affect their employment situation. Employers, for instance, may not regard women as primary breadwinners and assume that they only want to work temporarily before starting a family (Castles, De Haas, \& Miller, 2013). In the case of migrant women this is

\footnotetext{
${ }^{36}$ For a discussion on domestic and care work see for instance Anderson (2000, 2007) and Cox (2006); for discussions focused specifically on Asia see Huang, Yeoh \& Rahman (2005) and Huang, Thang \& Toyota (2012).

${ }^{37}$ In this context more research has been done on the migration of nurses, for instance (for an overview of the literature Moyce, Lash, \& de Leon Siantz, 2016).
} 
combined with stereotypes against migrants, ethnic and racial groups, and a weak legal standing (Castles et al., 2013; J. Ghosh, 2009; Piper, 2005). As a consequence, female migrants often have the worst paying jobs and are at risk of "isolation, abuse, or sexual violence" (J. Ghosh, 2009, p. 24).

At the same time, how easy it is to migrate is also highly gendered. For women, the question if migration is acceptable without a husband or family is highly dependent on the societal norms in the home country. A more patriarchal society makes individual migration more difficult or impossible as decision making power rests solely with the male household members (Boyd, 2006; Massey, Fischer, \& Capoferro, 2006). However, research shows that while gender discrimination can make migration more difficult it can also be a reason for women to choose to migrate (e.g. Baudassé \& Bazillier, 2014; Black, Hilker, \& Pooley, 2004; Ruyssen \& Salomone, 2018; Zachariah, Mathew, \& Rajan, 2001).

While research on gendered experiences of corruption is more scarce, it also shows that corruption experience differ widely for men and women (e.g. Boehm \& Sierra, 2015). These differences are often directly linked to gendered power imbalances within the society and the resulting gender roles. Several areas have been identified where corruption impacts women differently. Corruption disproportionately affects the poor, by taking up a larger share of their income (Hunt \& Laszlo, 2012; Justesen \& Bjørnskov, 2014). Gender plays a large role in poverty, where "[l]ower proportions of women than men have their own cash income from labour as a result of the unequal division of paid and unpaid work" and women, especially when they have dependent children and no partners are more likely to be poor than men (United Nations, 2015, p. xiv). Access to basic public services is an area where women are affected differently. Control over household resources lies with men, so women in developing countries often do not have the financial resources to pay for bribes and so are frequently denied services (Nyami Musembi, 2007). As women spend more time in the health care system, during pregnancy and child care, they are also more exposed to corruption in this sector than men (Chêne et al., 2010). Ellis et al. (2006) for example show that women are targeted more frequently by corruption, even though significantly more men work in the private sector in Uganda. Unfortunately, there is little data available on the question why women are often more vulnerable to corruption than men as this goes beyond the question of exposure to corruption (Boehm \& Sierra, 2015). 
For this reason, experiences of corruption during the migration process are also expected to vary for male and female migrants, as well as different migrant groups (e.g. forced and voluntary, regular and irregular migrants). Therefore, this chapter investigates the gendered experiences of corruption of irregular and forced migrants. ${ }^{38}$ This is an exploratory study focusing on the experiences of migrants on route to Europe via the Central or Western Mediterranean route in the country of origin and transit.

This chapter adds to the literature on gender and corruption in three ways. First, it furthers the knowledge of gendered experiences of corruption, focusing on experiences during migration, which are still understudied by investigating for the first time in a comprehensive manner how women and men are affected by different forms of corruption throughout their migration journey. In doing so, it focuses especially on experiences made while leaving the country of origin as well as on experiences made during transit. Second, it adds to the small body of literature discussing gendered forms of corruption, such as sextortion (illustrating discussions from chapter 3). Lastly, after having discussed the connection between gender norms and views of corruption (chapter 4) as well as the connection between sexism and the access to corruption networks (chapter 5), this chapter illustrates the role of gender norms in shaping experiences of corruption.

\subsection{Methodology}

Previous studies have shown that academic literature on the migration-corruption nexus is scarce (see for instance Merkle et al., 2017b), and usually does not apply a gender perspective. This chapter is therefore largely exploratory in nature and follows a qualitative research approach. It is based on desk research and 67 semistructured interviews with experts and male and female migrants, which were conducted between November 2016 and May 2017.

\footnotetext{
${ }^{38}$ Irregular migration - also known as undocumented or unauthorized migration - refers to mobility outside countries' rules and regulations and can come in various forms such as entering a country without authorization or required travel documents or staying in a country after visa or travel documents have expired (IOM, 2011).Forced migration, in contrast to voluntary migration, is defined as a "movement in which an element of coercion exists, including threats to life and livelihoods, whether arising from natural or man-made causes" (IOM, 2011). Yet, the distinction between forced and voluntary migration is not always clear-cut.
} 
Table 9 Gender and country of origin of migrants interviewed

\begin{tabular}{ll}
\hline \hline Migrant Gender & Country of Origin \\
\hline Female & Mexico \\
Female & Nigeria \\
Female & Nigeria \\
Female & Nigeria \\
Female & Nigeria \\
Female & Nigeria \\
Female & Ukraine \\
Male & Nigeria \\
Male & Democratic Republic of the Congo \\
\hline \hline
\end{tabular}

Interview guides were developed based on a review of key academic literature on migration, corruption and gender. Two rounds of interviews with experts were conducted. The first round ( $\mathrm{n}=24)$ focused on the role of corruption as a push factor for migration, while the second round $(n=43)$ focused on gendered experiences of corruption during the migration process. Experts interviewed included policymakers, representatives of local, national and supranational government organizations, international organizations, non-governmental organizations, practitioners in the field of migration, corruption and/or gender and academia (see Table 14 in the appendix). Interviews with experts were conducted in person or through skype or telephone to ensure geographic diversity. All interviews have been anonymized to ensure the anonymity of those who asked for it and references to interviews throughout the chapter have been randomly assigned.

Where possible both female and male migrants were interviewed to gain first-hand knowledge about gendered corruption experiences during the migration process. Between March and May 2017, eight migrants were interviewed. Due to the sensitivity of the topic, all migrant interviews were anonymized and conducted in person. Interview data was analyzed with NVivo through thematic coding, which allows to work towards the identification of a number of themes that provide an accurate description of the data (Flick, 2009; Howitt, 2010).

This research is ethically sensitive for several reasons: (1) corruption frequently involves a criminal act (2) migrants upon arrival in Europe are especially vulnerable due to their often delicate political and legal position (e.g. lack of legal status, ongoing asylum proceedings etc.). (3) the research touches on inherently 
sensitive topics, i.e. the personal migration experiences which have often been traumatic and characterized by (sexual) violence. Therefore, the research has been approved by the Ethical Review Committee of the Inner City and strict guidelines regarding interviews, consent, anonymity and data storage were followed. ${ }^{39}$ To mitigate the risks for migrants, the interview partners were contacted exclusively through reputable organizations working with migrant as they are aware of the risks migrants and refugees face and have strict guidelines on ensuring confidentiality and anonymity. They need to ensure the (female) migrants' and refugees' anonymity to be able to provide services especially for those whose legal status is unclear. They also are aware of the difficult experiences many of the migrants and refugees had along their journey and often directly provide counseling and medical services or are well connected with other organizations that do. These organizations for their daily work rely on their ability to protect (female) migrants and refugees from any harm - this includes any possibility that information about the experiences, legal statuses etc. is brought to the attention of any unauthorized persons or organizations. They also rely on the (female) migrants and refugees trusting that all their information will be kept confidential. Only with this trust are they able to reach (female) migrants and refugees with their services. Therefore, we considered them reliable partners for our research, and will also require the organizations to sign a confidentiality form.

\subsection{Experiences of corruption during migration}

The following sections analyze the experiences of corruption throughout the journey, separating the migration journey into country of origin, transit (and arrival). It is important to remember that the separation between origin and transit countries is not always clear cut as "all countries can be categorized as either. In the case of Nigeria, it's an origin country for trafficking to Europe but a destination country for many West Africans" (Expert Interview 16). While keeping this in mind, it is still helpful to use these broad distinctions for the purpose of the analysis because migrants' experiences differ significantly once they have left their country of origin. Therefore, distinguishing between origin and transit countries contributes to a better understanding of migrants' experiences during different stages of the migration process. The analysis for this chapter is limited to the country of origin and transit for mainly two reasons. For one, all interviewees agreed that most corrupt encounters occurred during these two stages. For

\footnotetext{
39 The research has been examined and approved by Maastricht University's Ethical Review Committee Inner City Faculties (ERCIC) approval 7 June 2017 reference number: ERCIC_035_05_04_2017.
} 
another, while some hints were given by the interviewed migrants of corruption in the destination countries, often these seem to have been of different nature and based on a general mistrust in and fear of public officials, especially the police, rather than actual corrupt experiences. Throughout our research it was therefore often not possible to distinguish between this general distrust and actual corrupt experiences. Hence, more research is needed in this area to give an accurate account of the situation at a later point. Lastly, many incidents of corruption that the interview partners referred to in the country of arrival in Europe referred to private persons, such as landlords overcharging for apartments. While these abuses of power call for more detailed research, they do not fall into the broad concept of corruption and therefore will be excluded for now.

A special focus is put on the role that patriarchy plays in shaping experiences of corruption. The corruption experiences are not all equal and the form of corruption that a migrant is exposed to is fundamentally shaped by gender. Typical forms of corruption discussed as enabling migration include bribery, coercion, extortion and fraud (OECD, 2015), these mirror a classic understanding of corruption focusing on a male centric view of the exchange of money and goods. As one of the male migrants interviewed for this research shared his experience: "They [the border guards] always tell you 'we're going to help you'. What they mean is that if you give them money maybe they help you" (Expert Interview 18). Analyzing the corruption experiences during migration show an important flaw in this common understanding of corruption - it is not just money or goods, in many cases it is also female bodies which are the currency. This intersection of corruption and sexual violence has been coined 'sextortion' 40 and while some attention has recently been given to this gendered form of corruption (IAWJ, 2012), most research sill focuses on a classic -monetary understanding. (for a detailed discussion see chapter 3) Women in these cases of corruption are not just the participant in the corrupt exchange, but at the same time also the means. Gendered power relations fundamentally shape the experiences of migrants throughout their journey as they do not only determine the form of corruption but also experience of corruption. Why is it important to understand gender norms in this context? the answer is simple. Focusing the discussion on women alone, leaves out an important part of the puzzle: "men and masculinity as locations of power" (Turner, 2016, p. 195).

Importantly, the research acknowledges that gender does not exist in isolation but intersects with other categories of oppression, such as race and class (Burman,

${ }^{40}$ Sextortion is "the abuse of power to obtain a sexual favour" (IAWJ, 2012). 


\subsubsection{Shaping the migration path-corruption in the home country}

2003; Crenshaw, 1991; K. Davis, 2008) where possible the following sections will highlight these as well.

\subsubsection{Shaping the migration path- corruption in the home country}

This section examines corruption experiences of (potential) migrants, both male and female, in the country of origin and their effects. As previously discussed corruption can directly and indirectly affect individuals. An example of a direct effect is when individuals participate in corrupt acts, for example paying a bribe to access certain services. In contrast, indirect effects refer to cases where individuals are affected by the corrupt acts of others (Boehm \& Sierra, 2015). Examples for indirect effects are the embezzlement of development aid that was supposed to benefit a certain population and taxpayers' money flowing into grand corruption.

In the context of the origin country, it is important to distinguish between three different kinds of direct and indirect effects: On the one hand, experiences of corruption in the country of origin can lead to migration aspirations. On the other hand, it can impede or facilitate migration.

For one corruption can enable regular and irregular migration in and from the country of origin. In the context of regular migration, corruption can be a way to speed up administrative processes, for instance, when issuing travel documents. Where options for regular migration are limited, corruption is crucial in facilitating irregular migration such as obtaining fake travel documents (through middlemen) (OECD, 2015 and Expert Interviews 11,35,21,26,41) and bribing border officials when leaving the country (OECD, 2015). In addition, migrants oftentimes need the help of smugglers who know the route out of the country and smuggling is facilitated through corruption (Expert Interviews 11; 35).

Corruption can enable female migration in and from countries where it is prohibited and thereby help to overcome involuntary immobility (Ferrant \& Tuccio, 2015; Fleury, 2016) . In many prominent countries of origin, women seem to be more dependent on middlemen such as smuggling networks due to their disadvantaged position in societies limiting their access to information, financial and social capital. This dependency increases their risk of exploitation and vulnerability to becoming victims of human trafficking (Fleury, 2016; Gosh, 2009; Kawar, 2016). Hence, women's vulnerability to corruption and associated risks like becoming victims of trafficking can be attributed to patriarchal structures in their home countries which assign different roles to men and women. 
Corruption does not only enable international migration but can also facilitate internal migration in countries with high levels of corruption. It has been reported that internally displaced persons (IDPs) and families in Syria rely on smuggling networks for their own protection and access to basic goods and services. In this context, IDPs are vulnerable to typical forms of corruption like bribery and extortion as well as atypical forms of corruption such as sextortion, forced marriages and boys having to join armed groups (Expert Interview 31).

For another, corruption can directly and indirectly shape migration aspirations in the country of origin. Interviewees agree that high levels of corruption within a country can affect (democratic) institutions and social protection systems leading to unequal opportunities for citizens. Resulting imbalances in terms of access to power and resources can encourage individuals especially of disadvantaged populations to seek opportunities abroad (Barbieri \& Carr, 2005 and Expert Interviews 29, 4). Merkle, Reinold and Siegel (2017b) developed a theoretical framework explaining the various ways in which different forms of corruption can directly and indirectly impair the seven dimensions of human security.

Last but not least, corruption can impede (regular) migration in and from the country of origin. High levels of corruption in countries of origin can increase the costs of migration and consequently make (regular) migration less affordable, for instance when high bribes are required to obtain regular travel documents. This can ultimately lead to involuntary immobility. This concept refers to a situation in which an individual wants to migrate but is not able to do so (Carling, 2002). In some countries, women can be disproportionately affected by involuntary immobility due to patriarchal structures. Where the access of women and girls to economic and social capital is restricted, or women are not allowed to travel or leave the country without the consent of a male relative or household member, their options for migration are limited.

Patriarchal structures in the home country also can make women less likely to ask for help or protection, as one of the experts stated: "They come from patriarchal societies where their vulnerability is emphasized as part of the culture and it goes beyond issues like physical strength, it goes on issues that a person will have been born into, nurtured and brought up in a culture that makes them subservient to men"(Expert Interview 36). 


\subsubsection{Facilitator and hindrance - corruption throughout the migration journey}

Once migrants leave their countries of origin with or without corruption, transit for most of them is filled with corrupt encounters. For the purpose of this article, transit migration is defined as a situation between emigration and settlement. It is assumed that migrants do not have the intention to remain living in transit countries. Interviewees agree that migrants experience the most intense forms of corruption during this time.

[Transit often is] a period where opportunist use corruption, where you have corrupt officials, corrupt systems. They see opportunities in migrating populations, and they're quick to jump and exploit those opportunities whereas perhaps in the source countries it's more deliberate, more planned, more structured. During transit it's more opportunistic perhaps, particularly with migration flows that are going now. (Expert Interview 36)

The question of why migrants are more vulnerable to corruption during transit is often simply a case of lack of connections and the necessity to use corrupt exchanges for things that would usually be achieved by a social network. Hence, the idea of vulnerability is a difficult concept which covers many different areas and combines a lot of factors; "It can be about a lack of networks and a lack of social capital and of course the more you move from your country of origin, along that transit route to your destination country, the further and further you move away from your social network, from family, from things you're familiar from, you become by virtue of being a stranger, you become vulnerable." (Expert Interview 36)

Just as in the home country, corruption can enable migration during transit and migrants' experiences of corruption during transit continue to be manifold and seem to occur at any stage. Interviews revealed that bribes are expected, for instance, for sharing information with migrants, for letting migrants continue their journey, for officials to ignore fake travel documents and to prevent denunciation (OECD, 2015). This applies to transit countries in various parts of the world including West African countries, Turkey, Bulgaria and Mexico to name only a few examples from the interviews for this chapter. Migrants are especially vulnerable to corruption and abuse during transit since they depend on middlemen like smugglers. Deprived of legal migration channels to get out of Turkey for example, migrants "need to contact smugglers and sometimes they require having sex with 
one of the daughters in order to agree to facilitate the migration. It can also happen on route. They already started travelling and the smuggler says that in order to continue then we require sexual services affecting both women and children" (Expert Interview 24). Crossing the Sahara Desert without smugglers is also a task that the interviewees determined impossible. The harsh environmental conditions and the presence of bandits in the region would almost certainly lead to death (Expert Interviews 11; 6). One Nigerian migrant described her encounter with these bandits: "They [the armed groups say] come, if you don't have sex with me I will kill you, with a gun or a knife, all those things. So many girls were afraid. They had no choice" (Female Migrant).

In particular, when crossing borders migrants experience corruption in various forms. Border officials have been reported to only let migrants pass in return for bribes whether they are travelling through regular means or not (Female Migrant). In addition to monetary forms of corruption, it has been reported that middlemen, including smugglers and traffickers, pay border officials with female migrants (Expert Interviews 26; 31; 7; 4; 6; 13), implying that each vehicle transporting migrants always has to carry female migrants for payment (Expert Interview 6). The same is true for checkpoints guarded by soldiers along the route (Expert Interview 13, Migrants). This showed two important findings that need to be explored further in research of corruption. For one it showed a nuance regarding experiences of sextortion. Women's bodies are frequently used as a means of exchange not only for herself but for an entire group. A male migrant recounts: "The border guards see that there are women in your convoy, they stop the pickup and take the women. You can wait three or four days, sometimes one week, you never know how long, until the time they can satisfy all their desires [pause] and they come back" (Expert Interview 18). The second point is that the experiences in the desert also show that smugglers and traffickers seem to work together with officials (Expert Interviews 6, 17, 21), which makes it almost impossible for migrants to distinguish between state and non-state actors. While the official definition of corruption only refers to state actors with entrusted power, the distinction is blurred during transit.

Besides experiencing corruption as a means to organize the journey, it is also sometimes experienced as the only way for (irregular) migrants and refugees to get access to basic services like (reproductive) health care (Expert Interview 16) or humanitarian aid (OCCRP, 2014). Displaced women also can experience different forms of corruption in the context of humanitarian assistance or when living in refugee camps. Countries affected by emergencies such as natural disasters and 
conflict are often poor and face high levels of corruption (Chêne, 2009). In this context inflows of aid resources can actually increase corrupt practices, which then negatively impact the quality and quantity of humanitarian assistance. Women are assumed to be most affected by such emergencies - not least because they often lack information regarding their rights. Hence, they are also most affected by corruption in the context of humanitarian aid. It has been reported that Syrian refugees in Lebanon had to pay bribes for humanitarian aid (OCCRP, 2014). Furthermore, limited financial resources make them vulnerable to sexual exploitation, in particular because of patriarchal attitudes, gender discrimination, and the fact that it is oftentimes men who deliver basic services (e.g. shelter, food distribution, health services, and education (Amnesty International, 2016; Chêne, 2009; Gosh, 2009; UNHCR \& Save the Children, 2002).Single and widowed women are most vulnerable to sexual exploitation for aid because they are not protected by male household members (Chêne, 2009). Having male household members, however, does not necessarily protect women from exploitation. UNHCR and Save the Children (2002) report cases of men having to offer their female (under aged) family members to humanitarian aid workers in exchange for access to aid.

Corruption and sexual exploitation curtail women's and girl's access to basic services and can lead to severe physiological, psychological and social consequences for them (Chêne, 2009). Other possible forms of violence include sexual assault, rape, forced marriage, sterilization, forced prostitution, military sexual slavery, and human trafficking (J. Ghosh, 2009). In a study on the Calais refugee camp, researchers found that the presence of smugglers within the camp leads to fears of sexual exploitation, with roughly 73 per cent of women saying they felt unsafe in the camp (Hangul, Paton, Stanton, \& Welander, 2016).

Much of the vulnerability and the power imbalances migrants face throughout the journey are due to the lack of legal channels of migration. "Legal status" has to be considered as an integral intersectional category, not only in the destination country but also throughout the journey. In migration research this has been well documented. Research on the United States has shown how race not only is a major determinant of legal status of immigrants (e.g. Ngai, 2004) but also, that individuals experience their lack of legal status as a similar distinction as distinctions based on race, class or gender (Dreby, 2015; Menjívar, 2006). Herrera (2016) continues by arguing that "illegality must be seen as a coterminous with other forms of difference that produces new modes of discrimination not solely reducible to legal status" (p. 320) and coins the concept of 'racializing illegality'. García (2017) advances this discussion by showing how racializing illegality is 
"further complicated by other social locations such as gender and class". García (2017) shows how in the context of migration from Mexico to the U.S. the question of legal status and racialization is connected inseparably, as "[p]ortraying Mexicans with 'illegal' immigration was part of an emergent Mexican 'race' problem". (García, 2017, p. 476). Surprisingly little has been done however, on questions of legal status as an intersecting category of oppression during the migration journey.

The research for this chapter shows that in many instances, where legal channels are not available, corruption is a necessity to enable the migration process. As migrants are moving further from their social networks, they rely on corruption to create connections to navigate their journey and to allow them to cross borders. Corruption in these cases can often be considered a means to overcome the limitations of the lack of legal status and are therefore seen as not necessarily negative. As one expert stated:

"If you made a conscious decision to migrate and a conscious decision to use an illegal route then the degree of agency, cooperation, acceptance, indeed the degree of welcoming corruption can be vastly different. There will be people who say I want to migrate from A to B, legal systems don't allow me to do it. So, I will use illegal systems and I am very grateful that there are corrupt officials that can help me." (Expert Interview 36)

Yet, the irregular status during transit makes people most vulnerable to corruption and exploitation. "In Lebanon for example, we have some reports of people forced to have sex in order to have their legal status recognized or in order to cross the borders. This is really a key issue. In a legal situation, most of these risks are gone because corruption arises from contacts with smugglers and so on. This is kind of a repeated pattern, not context specific, that we see everywhere" (Expert Interview 31).

Corruption can impede onwards migration during transit. One interviewee reported that she was stranded in Libya, one of the main transit countries for migration from Africa to Europe, for almost one year until she had enough money to pay corrupt border officials to migrate onwards (Female Migrant). This concept of involuntary immobility in Libya is also receiving more attention as a consequence of the European Union's and Italy's deal with the Libyan government (Dalhuisen, 2017; Times of Malta, 2017). In the 2017 Malta Declaration, the European Council in accordance with a prior European Commission Communication (European Commission, 2017) decided to expand collaboration 
with Libya as the "main country of departure" beyond Operation SOPHIA in order to "significantly reduce migratory flows along the Central Mediterranean route and break the business model of smugglers" (European Council, 2017). Consequently, thousands of migrants are stranded in Libyan detention centers under inhumane conditions, which was confirmed by our interviews with migrants and experts. This is underlined especially by migrants being reluctant to talk about their experiences in Libya. While for instance migrant women share their experiences with sexual violence and forced prostitution in other transit countries, they hardly talk about experiences in Libya. As one interviewee puts it: "It is pure violence and women hardly talk about it. It must be appalling experiences that they cannot talk about. They can talk about their forced prostitution in Italy, Spain and Greece but about their experiences in Libya [...] they say 'it was no good'" (Expert Interview 10). Female migrants in Libyan prisons have also been reported to be forced into transactional sex for basic goods and services (Expert Interview 23). Corruption has also been reported to facilitate exploitation of women and girls during transit. As one expert explained, corruption enables a form of temporary marriages in Syria's neighbor countries. "You have religious figures and official authorities facilitating these kinds of marriages even though they are illegal. So, if you take Lebanon or Jordan, there were Syrian girls subject to these kinds of marriages. So, that Jordanian or Lebanese or also sex tourists could come, have the marriage for a few days or weeks, sexually abuse them and then leave" (Expert Interview 31).

The amounts of bribes migrants report can vary extensively: It has been reported for instance that Turkish officials let migrants continue their journey towards Europe for very small fees. In contrast, migrants in the ECOWAS region often arrive at their destination without having any money left due to the high amounts and high frequency of corruption throughout the journey (Expert Interviews 11;1). Latin American women have been reported to work in prostitution to be able to afford their journey through Mexico where it is required to bribe police officers as well as cartels (Expert Interview 27). As already pointed out where enormous bribes are expected this can lead to involuntary immobility until the migrant receives or earns the required sums. Migrants also reported severe punishments for the inability to pay for corruption. "There was a lot of police. When you get to the border they say stop. You bring money for them and then if you didn't give them money they would beat you, they will tell you to sit down in the sun. You will be there until you find something on you or beg someone to just give me some money. [...] They will make sure that they will beat you as nastily as possible. Oh 
God I hated it" (Female Migrant). This is also where a gendered difference because visible. While men who could not comply with demands for bribes were severely beaten, women faced sexual violence and abuse (Bruni \& Merkle, 2018).

Men have described facing extreme violence throughout their journey and our interviewees reported of severe beatings for men by corrupt officials, yet in the context of corruption their experience is significantly different: while men pay with money, "women's experiences [of corruption] are shaped by the fact that, if they have nothing, they still have female bodies" (Expert Interview 2). This form of corruption in itself, as discussed in chapter 3 is fundamentally a manifestation of patriarchal power structures.

This does not remain the only role that patriarchy plays in determining the lived experiences of corruption throughout the journey. As many of our expert interviews recounted, the availability of funds for corruption in both the home country and throughout the journey is often determined by gender norms in the home country. While families in patriarchal societies often collect money to send a male relative on the migration journey, women travelling alone frequently leave against the will of their family and hence without the family's financial and emotional support. This leaves them not only more vulnerable to sextortion, as the only available means of payment is their body, but also increases their risk to be caught up in trafficking networks.

The central moment is in the country of origin. Very often corruption impacts on the reasons to migrate in a first place because women are often convinced by trusted people with the deception of a better future. Instead, men are more aware of the difficulties of the journey. Women are often convinced to migrate by relatives or friends in the country of origin, so since the first connection with the smuggler or trafficker corruption is crucial, because a trusted person mediates the process. (Expert Interview)

Patriarchal structures in the country of origin and transit also determine who is considered an easy and viable target for corruption and violence. Often this make women easier targets, especially when they are travelling without male relatives and are far from their family:

With a lot of culture, the abuse of a woman is less likely to bring retribution than the abuse of a man. An example, if you're [...] mistreating a man, there's always the chance, as a corrupt official, that you might upset someone, that might be related to someone important, they might be 
related to this and so on. Women are, in a lot of places, seen much more as a commodity or a good, or something that's fair game. You know, and once women have left their country of origin, they're in that transit space, there are less powerful factors about the honor of the women or the family will protect them - these things are gone and have fallen away during the transit journey. (Expert Interview)

Interviewees agree that women travelling alone are especially vulnerable to abuse and exploitation during transit. They are more likely to be pressured into corruption, especially sextortion and as previously discussed usually have less resources available. It has been reported several times that women might have to engage in transactional sex for protection with men (Interviews 27; 11; 23). They pretend to be couples during transit and/or upon arrival to be less vulnerable to violence from other migrants or groups they meet along the way and to increase their chances of being accepted or granted asylum in the destination country (Interview 8). Another example of this is female migrants in Libyan prisons having to engage in sexual acts for food, water and health services (Interview 23). This also applies to housing needs, especially in Algeria and Morocco, where abusive landlords often claim sexual services as a form of complementing a low rent (Interview 6). It is also reported that sextortion, or as one interviewee preferred to call it "survival sex", is common in refugee camps such as the former so-called "Calais Jungle", where one respondent highlighted that single mothers in the camp were particularly vulnerable to transactional sexual relationships built around protection (Interview 12). Yet, travelling with male family members does not automatically guarantee protection. Where women do not have a say over what will happen to them male family members frequently use females as a pawn to get ahead in the migration journey (Expert Interview 29) and evidence suggests that migrant women are forced to "pay down [their] husband's debt to smugglers by making [themselves] available for sex along the way" (Bennhold, 2017).

Interviews with former sex workers who were trafficked from Nigeria to Italy highlighted that women were especially and overwhelmingly sexually abused by corrupt officials whilst in transit in Libya (Interview female migrant). Whilst most of the migrants interviewed for this report were reluctant to talk about Libya and their journey, the few words that they used to describe it are enough to understand the situation. In fact, they described their life in Libya as "terrible", "hell", "lots of suffering", "no freedom". Respondents explained that women would be told that they would have to go with the men, and if they refused they would be beaten or whipped (Female Migrant). It was also clear that the impact of being in a transit 
country where the women had no command of the language, contributed to feelings of insecurity and a loss of autonomy (migrant woman, Europe). One girl pointed out that she was stuck in Libya for more than 10 months because they were waiting for the money needed to pay corrupt border police in order to gain safe passage (Female Migrant). The abuse in these countries often has long-lasting impacts on the women, beyond the abuse itself.

In Libya is very bad, they sleep with you. Many of them do not use condoms because men... you don't know the sickness they have or anything, you can take it from them. So, when you get to Italy you can be sick, they can be pregnant, lots of them they don't know the father, the father is in another country. So that is very bad. But there are girls [inaudible] there is a lot of pain, maybe man came and slept with you in that condition and you get pregnant and you can't say that you don't want to... I can't explain this... as in very risky. I can't invest any hope my friends or relatives as in come to Libya, or pass through that route, it's very risky. (Female Migrant)

One can expect that the oversexualization of the black female body in some parts of Europe does not only support trafficking of women but also limits access to help and leads to having allegations of sexual misconduct being taken less seriously. Which is a phenomenon that needs to be researched in more detail.

Last but definitely not least, especially for trafficking victims, disabilities and lack of education was identified as a major source of vulnerability.

what we tend to see in trafficked individuals is an underlying vulnerability. [...] I can see what their vulnerability was that the traffickers saw and exploited. And so, you do tend to see a much higher incidence of mental health, learning disabilities, poor schooling, history of abuse as a child, than you would in the normal population. The other thing that you see overrepresented are minority groups. [...] you can kind of say to yourself, I can see why you were preyed upon, why you were selected by the traffickers, you know because there is an underlying vulnerability. And that's one of the reasons why women are overrepresented is because they tend to be in some countries of origin, les empowered less educated, less able to speak languages, less aware of the correct procedures, and less likely to challenge corrupt officials. You know simply have less power than men. (Expert Interview) 
Education also plays a role: "The poorer people are educated the more they have to pay. Those that knew e.g. that the borders were opened to Germany, they did not have to pay, because they knew that they could go there and they were well organized." (Expert Interview)

\subsection{Conclusion}

Migrants experience corruption at various occasions in the country of origin as well as during transit. Corruption can lead to migration aspirations, enable migration or impede it (i.e. involuntary immobility). This chapter finds that corruption comes into play whenever legal options for migration are limited and is a constant throughout all stages of the migration process for many migrants. Despite being exploratory in nature, this research provides some crucial insights into the gendered experiences and forms of corruption during migration. While both men and women routinely encounter corruption during different stages of the migration process, this chapter finds that women are especially vulnerable to atypical forms of corruption such as sextortion in addition to more typical forms of corruption that are also experienced by men. Women travelling alone are also especially exposed to corruption and sexual exploitation along the way. Furthermore, we find that underlying gender norms play a crucial role in shaping the experiences of corruption both in the home country and during the journey. For example, we find that women from highly patriarchal societies frequently travel with little financial resources and are therefore often more vulnerable to sextortion and abuse. The research also discovered another layer in the relationship between gender and corruption. Frequently, women are not only participants in the corrupt exchanges but are commodified as the means of exchange for groups of migrants when crossing borders. While official definitions of corruption mostly refer to state actors with entrusted power, the distinction between state and non-state actors asking for payments is blurred in many transit countries. These experiences with corruption and severe violence by state and uniformed non-state actors also partly explain why many migrants are scared of authorities upon arrival in Europe. Lastly, experiences with corruption and consequences of non-payment have serious consequences for male and female migrants' short- medium- and long-term physical and mental health.

The research presented in this chapter is only a starting point in analyzing migrants' experiences with corruption and due to its explorative nature, this chapter does not claim that be able to include all aspects that play a role in the analysis These experiences do not happen in isolation and are not shaped by 
gender alone but, as hinted at in the analysis for this research intersects with many other factors of oppression such as race, class, ability and other. Future research on experiences of corruption, and especially in the context of migration, should therefore take an intersectional approach to better understand the nuances of the phenomenon. For one, the role of different power systems, such as capitalism and colonialism in causing conflict and negatively impacting economic opportunities and therefore the shaping of migration aspirations is acknowledged but cannot be discussed in this chapter. Additionally, the link of patriarchy and colonialism should be understood but could not be included at this moment. Future research also needs to pay more attention to the role of race in the experiences of corruption. This dissertation explicitly is a starting point and recognizes that further research is necessary to explore more nuanced relationships including historical analysis of colonialism and non-Eurocentric feminism to fully understand the complex social context of corruption. 


\section{Conclusion}

Paying feminist attention, asking feminist questions, conducting feminist investigations, crafting gender-revealing concepts, creating diversely welcoming broad alliances, and acting with care and creativity - patriarchy doesn't stand a chance.

(Enloe, 2017, p. 167)

\subsection{The myth of gender-neutral power - what did we learn?}

While the importance of looking at the relationship between gender and corruption is not debated, questions about underlying power structures have largely been excluded from the discussion. As a first step to filling this gap in the academic debate, this dissertation, therefore, has taken a closer look at the relationship between patriarchal power structures and corruption. Using interview data from fieldwork in Georgia and experts on migration, corruption, and gender across Europe and survey data for six Sub-Saharan African countries the four stand-alone empirical chapters in this dissertation think about this relationship from different angles. This dissertation deliberately has used the sometimes-contested concept of patriarchy, to show that neither power nor its abuse is gender neutral but rather highly gendered phenomena. As is shown in the four empirical chapters learning from what feminist literature has long discussed about gendered power imbalances in society can assist in understanding better how corruption persists and functions within society and therefore can help in identifying new routes in anti-corruption measures. This last chapter now reflects on the main findings of this dissertation, discusses how they fit within the ongoing research on corruption and could shape future research agendas and proposes preliminary policy recommendations.

Following the introduction in chapter 1, chapter 2 gave a detailed overview of the current academic debate on corruption and gender, centered around the three main questions asked in this field until now: a) are women less corrupt b) are women the new anti-corruption force c) do women experience corruption differently from men. Most importantly this chapter highlighted the vast number 


\section{Conclusion}

of ways in which corruption can affect an individual's life and shows how these relationships can be gendered. This overview can be seen as a roadmap for research, showcasing how little is known about a question researchers and policymakers should have a vested interest in, i.e., how do experiences of corruption differ for men and women. The dissertation returns to this question in chapter 6 to explore the experiences of a specific group - irregular migrants.

Chapter 3, the first of the empirical chapters, focuses on a relatively newly discussed form of corruption, i.e., sextortion, to show how patriarchal structures and corruption are linked. Focusing on what is known in the feminist literature on sexual and gender-based violence, this chapter argues that both corruption and SGBV are the results of the same underlying power system, i.e., patriarchy. Sextortion, in particular, shows that power is not gender neutral and that without tackling the underlying gendered power structures the issue cannot be tackled. This chapter sets the scene by showing how one of the grimmest forms of corruption is embedded within the patriarchic system. As the other chapters will show, this relationship is not limited to sextortion.

Chapter 4 takes survey data from the World Values Survey's $6^{\text {th }}$ wave and considers how perceptions of corruption and views on the role of women are related. Sub-Saharan Africa which includes countries with the highest rate of female participation in the world as well as the lowest and most widely varying levels of corruption provided a good case study for this research. As perceptions of corruption are an important measure in corruption research, it is interesting to see if these can also be linked to patriarchal views, continuing the argument that the two are connected. This chapter's findings strongly suggest that such a connection exists. This adds to the existing research that already linked stereotypes about female political candidates and the perception of government corruption (Barnes \& Beaulieu, 2014; Esarey \& Schwindt-Bayer, 2017); but this study takes it further by connecting attitudes towards women's political leadership with attitudes on corruption. Showing how patriarchy and corruption are connected will help in "exposing ways patriarchal systems are being perpetuated today [, and] will enable us to more effectively challenge and dismantle them (Enloe, 2017, p. 17).

Chapter 5 continues to look at the political participation of women, but unlike a majority of research it does not look at the question of how female politicians can have a positive effect on anti-corruption efforts. Focusing on the case of Georgia, a country with an impressive anti-corruption record but the low participation rate of women; this chapter instead outlines how patriarchy is used to exclude the 
majority of women from clientelistic networks and only allows those that are in line with the "old boys' network" to join. Therefore, patriarchal power structures are not only detrimental to gender equality but, as this chapter shows, also play a substantial role in upholding corrupt structures. Efforts to protect clientelistic networks and the monetary and political benefits related to them be a reason to further exclude women from political activities.

Chapter 6, the final empirical chapter, then shifts the focus to the experiences of corruption, which as chapter 2 has pointed out is still one of the most understudied areas of corruption research. Focusing on a very vulnerable group, irregular migrants, this chapter discusses the gendered experiences and forms of corruption encountered during the migration process. For both men and women corruption is a constant throughout the migration journey, yet, they experience it very differently. While men pay with money and goods, women pay with sexual services, i.e., sextortion. That both men and women experience corruption does not negate the role of patriarchy, on the contrary, patriarchy also includes the oppression of lower status men (in this case irregular migrants) by higher status men (e.g., border officials). While both experience corruption, how they experience it and which form they experience is fundamentally different and shaped by patriarchal structures in the home and transit countries.

\subsection{Corruption researchers - we need to talk patriarchy}

The \#metoo movement has brought to international attention what feminists have been advocating for decades: power is highly gendered and understanding this is fundamental in analyzing how society functions. Who has access to power and how power is exercised are both necessarily gendered questions. However, surprisingly, discussions about the abuse of power, i.e., corruption, are largely disconnected not only from discussions about the gendered nature of power but also from questions of access to power in general. This dissertation is a first step in filling this gap by taking a closer look at the underlying power system that shapes acts, experiences, and perceptions of corruption - patriarchy. It argues that one cannot discuss the exercise of power, and its abuse without also discussing access to power and the system that gives power to one group over others.

Therefore, one of the main findings of the research presented in this dissertation is that discussions on corruption must learn from the feminist discourse to truly get a thorough understanding of how corruption and gender are related in several areas. Corruption researchers must stop treating gender as a one-dimensional variable 


\section{Conclusion}

and expand their understanding to research that has already been conducted in other fields.

Firstly, as this dissertation has shown, more attention needs to be paid to how access to power is granted and structured to truly understand its abuse. Therefore, more nuanced research is needed on the role of patriarchy in shaping forms and experiences of corruption. This needs a more rigorous feminist discourse of corruption which until now is only in its infancy. This approach is important not only to understand experiences of women but also those of men, as less powerful men are also oppressed through the patriarchic system, just as powerful women often are the oppressor of less powerful women. The question of how corruption persists is a fundamental one that cannot be understood without understanding how access to power is gained. Surprisingly, this discussion has largely been excluded from current research which limits our understanding of the phenomenon and therefore, anti-corruption efforts.

As discussed patriarchy is not a simplistic concept of "bad" men having power over "poor" women, on the contrary, it is a complex system of power relationships where "both men and women wield varying types and amounts of power" (Hunnicutt, 2009, p. 565). This is an important finding for corruption research for several reasons. For one, it challenges the idea that women and men are homogenous categories. As the research in this dissertation shows, particularly chapter 4 and 5, women are complicit both in maintaining the patriarchal system and in oppressing the less powerful. Women who become beneficiaries of the corrupt system have the same incentive to maintain the corrupt order than the men who are complicit. Hence, further research on corruption needs a more nuanced view of the different groups and how these are affected by the underlying system. Furthermore, patriarchy focuses on social arrangements, and social systems that reinforce domination and rather than looking at individual men's motivation to dominate takes a look at societal structures (Hunnicutt, 2009). This is also helpful in corruption research, where, while important to understand, it is not enough to look at an individual's propensity to be corrupt, but research needs a better understanding of the structural factors allowing for corruption to occur, in this case: gendered power dynamics.

Secondly, and in line with the call to a more feminist approach of corruption another important pathway forward that has been touched upon in chapter 6 but needs to be studied in much more detail is intersectionality. Having established that male and female migrants are frequently vulnerable to different forms of 
corruption, it is essential to acknowledge where these differences originate. To fully understand gendered experiences, we must accept that inequalities do not arise solely through one system of oppression. Many different forms of oppression are interlinked and feed into one another to form an individual's experiences (Bastia, 2014). First developed by Crenshaw (1990), the concept of intersectionality argues that race, class, and ethnicity are interconnected, and interdependent categories of disadvantages rather than separate notions (Burman, 2003; Valentine, 2007) and the sum of these intersecting oppressions is frequently larger than the sum of their parts (Crenshaw, 1990). Importantly, trying to discuss these categories only separately omits an important aspect, as "there is no meaning to the notion of 'black', for instance, which is not gendered and classed, no meaning to notion of 'women' which is not ethnocided and classed, etc. " (Yuval-Davis, 2007, p. 565). Intersectionality also shows the importance of including men in the analysis. "An integral facet of intersectionality is that it highlights that black men are not simply victimized by race and privileged by patriarchy, but occupy a different social location where they do not receive privileges supplied by patriarchy." (Yakubi \& Merkle, 2018, p. 35)

Intersectionality has for the most part been ignored in research on corruption. Some advancement has been made on questions of gendered forms of corruption, for example, some discussions have focused on gender corruption and poverty (e.g., Seppänen \& Virtanen, 2008) but overall the understanding that other categories intersect with gender has been ignored in most corruption research. Chapter 6 hints at the importance of race, class, ability and other categories of oppression that need to be taken into consideration to get a true understanding on how corruption is experienced.

Additionally, the majority of research on gender and corruption still focuses on the impact of (powerful) women on decreasing corruption. Even though Goetz (2007) and others have debunked the myth of women as the easy 'anti-corruption force' long ago and also clearly showed the danger of perpetuating such a myth, it still persists. Not only does the 'add women and stir' approach oversimplify the relationship and lead to unrealistic anti-corruption expectations, it also harms the efforts of increasing political participation of women as it is no longer discussed as a question of human rights or democratic justice but now is expected to have an "efficiency payoff" (Goetz, 2007, p. 87f). While this dissertation does not negate the importance of women in fighting corruption, it also argues that more nuance is needed. One needs to understand not only which women are joining the political sphere and which groups they do or do not represent but it also has to be 


\section{Conclusion}

understood how women are kept out of politics by men trying to protect clientelistic networks. Interestingly it is both men and women who participate in upholding the patriarchic structures that make this possible.

The discussion in chapter 5 of this dissertation shows how ill-informed the focus on the seemingly 'better' qualities of women as a reason for increasing the number of women in politics can be. It explores how benevolent sexism is used to exclude women from clientelistic networks and large policy areas and how only women who are "liked" by the men's networks will be allowed to enter the political field. This brings a double burden on women who do not fall into the category. For one, they would have to fight a tight-knit network of corruption men, which by itself is already a big task. However, at the same time, they have to fight the patriarchal structures that are used to not only exclude them but also work on 'dishonoring' them when they are attempting to challenge male power. And lastly, as previous research has indicated, the failure to deliver on the anti-corruption promise could have detrimental effects on the participation of women.

Chapter 3 and 6 show the importance of widening our understanding of corruption and moving away from a male-centric view of corruption, focusing on the exchange of money and goods towards a gender-sensitive understanding that also includes the female body as the currency of the corrupt exchange. Research on sextortion is relevant in all areas of life and affects women everywhere. The little research that has been conducted shows that it is a prevalent form of corruption not only during migration but in the education sector and employment and likely can be expected in other areas as well. To get a truly holistic understanding of the relationship between gender and corruption it is not enough to focus on the role of women in politics, we also need to understand the different forms of corruption that women experience. More research on the occurrence of sextortion is needed just as much as more discussions on the definitions and the underlying causes of sextortion.

An important discussion in regards to sextortion also needs to be the question to what extent men also experience sextortion. Sexual violence, often as an act of dominance, by men towards other men, has been reported frequently in conflict settings (e.g., Carpenter, 2006; Sivakumaran, 2007, 2010) and one can expect that men are also affected by this phenomenon, especially those who are in lower status situations. Therefore, more research is needed into the experiences of sextortion of men to see where they occur and which factors shape those experiences. As research on sexual violence against men in other fields has shown, this is not an 
easy but important task that corruption researchers also need to tackle. Once again, much can be learned from other feminist discussions on how to research sexual violence.

In line with the quest to better understand gendered forms, effects, and causes of corruption, researchers do not only need different, more feminist discussions, it also requires more gender-sensitive data. So far hardly any large-scale gendersensitive data is available. Important and widely used data sets such as Transparency International's Corruption Perception Index or the World Bank's Worldwide Governance Indicators do not include any gender component. So far there seems to be no publicly available data on corruption perceptions that is sex aggregated, and no data sets include information on gendered forms of corruption such as sextortion. Hence, a rigorous discussion needs to start on how to best integrate gender into corruption data. It is not enough to collect the gender of the respondent, even though that is an important start, but data must include information on gendered experiences but also gender-specific forms of corruption such as sextortion. This is a challenge that can only succeed if researchers and anticorruption organizations significantly broaden their dialog on the gendered aspect of corruption.

Last but not least, the role of corruption in creating migration aspirations and determining the migration journey as well as the arrival in the destination country need more research. As chapter 6 shows, the research on the issue is still in its infancy, but the connection between the two areas are manifold. Hence, corruption and migration researchers should be encouraged to work together to determine how corruption shapes migrants' experiences.

For researchers the implications are clear. It is not enough to look at the connection between corruption and gender, but we need to further disentangle the underlying mechanisms making corruption persist. One should not be blinded by apparent successes in anti-corruption or gender equality but must continue to ask the important question of "who is in power?" "who benefits?" "who is excluded?" and lastly, "what underlying structures are in place?"

\subsection{Policy Implications}

The findings of this research suggest that much can be achieved by combining the efforts of anti-corruption and gender-equality initiatives. Policymakers and civil society have tirelessly worked on the fight against corruption and gender inequality, achieving many positive results. Yet, until now, the efforts have been 


\section{Conclusion}

largely disconnected from each other. One of the main recommendations from this dissertation is that synergies can be developed. As the discussion in this dissertation has shown, fighting patriarchal structures will also fight the structures that help corruption to persist. While corruption, gender equality and women's political participation, in particular, are all issues worth addressing in their own right, this study shows that changing attitudes towards women in politics and in general, and therefore challenging patriarchal structures can also change attitudes towards corruption and therefore is expected to have a multilayered positive effect on development. Findings from the analysis clearly support the hypothesis that patriarchal norms play a role in how one judges corruption (chapter 4). At the same time as chapter 5 shows, gender equality is hindered by corrupt networks using patriarchal norms. In addition, forms of corruption are designed by patriarchal structures, in particular, sextortion (chapter 3), and experiences of corruption are shaped by patriarchy as chapter 6 shows. Hence, while more research on this relationship will be beneficial, joint efforts between actors working on both issues need to be encouraged when structural changes in both gender equality and anti-corruption want to be achieved. Therefore, it is advisable for organizations working on anti-corruption and those striving for gender equality to work closer together. As feminists have long argued, gender-neutral power is a myth - it is time corruption initiatives learn from organizations working on gender equality on how to address this. If one wants to fight gender inequality and stop abuses of power, this is only possible when the systems allowing for both to persists can be dismantled.

This dissertation also makes another point very clear: Sextortion needs to be included much more prominently in anti-corruption efforts. While organizations such as Transparency International have started to look at this form of corruption more closely, it still takes the back seat in most discussions. Yet, this means that the experiences of corruption which disproportionally affect women are entirely excluded from the discussion. Therefore, the understanding that the female body is frequently the means of exchange needs to be publicized and discussed. Two important areas need to be highlighted here. For one, as discussed above, more information is needed on the experience of sextortion of men. While not much information is available yet the discussion should include these considerations to create a holistic picture. Secondly, there seems to be a certain resistance within civil society organizations and activists working on gender issues to the term sextortion. As the interviews for chapter 3 and 6 have shown, many of these organizations voiced a fear that including this form of sexual violence under the umbrella of 
corruption might take away from the gravity of the crime. As discussed in chapter 3 this dissertation argues that it will rather give an additional entry point to fight this form of violence and raise awareness of the issue. Yet, it is highly recommended that anti-corruption initiatives take these concerns seriously and enter into a dialogue with organizations working on sexual and gender-based violence to not only learn from them but to also make sure that the framework created for tackling sextortion complements the existing frameworks on sexual and gender-based violence rather than contradicting them.

Since 2001, despite multiple critical studies having been published, the focus on women in politics as an anti-corruption force has continued to be a dominant narrative in policy and civil society work. As this dissertation shows, focusing on women in politics to fight corruption is not enough. The discussion in chapter 5 of this dissertation shows how ill-informed the focus on the seemingly 'better' qualities of women as a reason for increasing the number of women in politics can be. It explores how benevolent sexism is used to exclude women from clientelistic networks and large policy areas and how only women who are "liked" by the men's networks will be allowed to enter the political field. This brings a double burden on women who do not fall into the category. For one, they would have to fight a tight-knit network of corruption men, which by itself is already a big task. However, at the same time, they have to fight the patriarchal structures that are used to not only exclude them but also work on 'dishonoring' them when they are attempting to challenge male power. And lastly, as previous research has indicated, the failure to deliver on the anti-corruption promise could have detrimental effects on the participation of women. While this does not mean that women in politics should not be encouraged to participate in the fight against corruption, but it advises caution that expectations of what women alone and in small numbers can achieve must be realistic. The focus should instead be on the underlying structures that perpetuate gender inequality as well as corruption and the efforts to change these structures.

Chapter 3 and 5 show another important point that is often underestimated. The importance of language used to push a policy issue forward. At first sight, a large body of research has been dedicated to this, by fighting over definitions and nuances. However, this is only true for certain aspects of the anti-corruption agenda. While the feminist agenda has in general been more aware of the importance of language the push for female political participation in Georgia shows how easy gender stereotypes are perpetuated and patriarchal structures reinforced through the focus on certain "qualities" of women. Therefore, activists 


\section{Conclusion}

should be encouraged to continuously research and question their narratives to ensure that they do not proof counterproductive in the long run.

For anti-corruption initiatives the same is true. But for them, language has an additional role to play. The language on sextortion needs to be unified and applied and as discussed above, mainstreamed with organizations working on genderbased and sexual violence. Too frequently until now, terminology is used that makes the act appear less harmful or shifts the attention away from the perpetrator ( $\mathrm{X}$ extorted $\mathrm{Y}$ for sex) to the victim, eliminating the perpetrator ( $\mathrm{Y}$ has been involved in a quid pro quo exchange). The importance of language and the messages it sends, especially in regards to gender issues should take a more prominent role in anti-corruption initiatives if they want to be successful.

In gender, civil society, policymakers and researchers must carefully consider how their narratives might perpetuate the underlying gender structures, shaping both gender inequality and corruption. More training and discussions across policy areas are needed to contribute to this dialog.

Corruption and migration, as chapter 6 has discussed, have a complicated relationship that still needs significantly more research. Yet, one finding became very clear, where no legal channels for migration exist, corruption plays a fundamental role during the migration process and often times irregular migrants are exposed to especially violent forms of corruption and repercussions for not being able to pay the bribe. More legal channels for migration help not only make people less vulnerable but also create fewer opportunities for corruption. The precarious legal status of irregular migrants can make the fight against corruption at borders even more difficult. Therefore civil society organizations should be involved to monitor this situation and serve as a privacy shield for irregular migrants.

Last but definitely not least, we all, men and women must continue to ask ourselves what we do to maintain the patriarchic system, which while morphing continues to exist; and perhaps more importantly what we can do to change it. Exposing the system and our own role in it will be the foundation for sustainable change towards a more just society, since: "patriarchy made transparent is patriarchy made vulnerable" (Enloe, 2017, p. 167). 


\section{Bibliography}

Abad-Merino, S., Dovidio, J. F., Tabernero, C., \& González, I. (2018). The systematic study of how subtle forms of bias related to prosocial behavior operate in racial and gender relations. Theory $\mathcal{E}$ Psychology, 28(1), 104-121. https://doi.org/10.1177/0959354317745588

Abrahams, N., Devries, K., Watts, C., Pallitto, C., Petzold, M., Shamu, S., \& GarcíaMoreno, C. (2014). Worldwide prevalence of non-partner sexual violence: a systematic review. The Lancet, 383(9929), 1648-1654. https://doi.org/10.1016/S0140-6736(13)62243-6

Acker, J. (1992). From Sex Roles to Gendered Institutions. Contemporary Sociology, 21(5), 565-569. https://doi.org/10.2307/2075528

Agénor, P.-R., \& Canuto, O. (2015). Gender equality and economic growth in Brazil: A long-run analysis. Journal of Macroeconomics, 43, 155-172. https://doi.org/10.1016/j.jmacro.2014.10.004

Alatas, V., Cameron, L., Chaudhuri, A., Erkal, N., \& Gangadharan, L. (2009). Gender, Culture, and Corruption: Insights from an Experimental Analysis. Southern Economic Journal, 75(3), 663-680.

Alesina, A., \& Perotti, R. (1996). Income distribution, political instability, and investment. European Economic Review, 40(6), 1203-1228. https://doi.org/10.1016/0014-2921(95)00030-5

Alhassan-Alolo, N. (2007). Gender and corruption: testing the new consensus. Public Administration and Development, 27(3), 227-237. https://doi.org/10.1002/pad.455

Allport, G. W. (1954). The nature of prejudice. Oxford: Addison Wesley.

Altermatt, T. W., DeWall, C. N., \& Leskinen, E. (2003). Agency and Virtue: Dimensions Underlying Subgroups of Women. Sex Roles, 49(11-12), 631641. https://doi.org/10.1023/B:SERS.0000003133.90488.71

Amnesty International. (2016, January 18). Female refugees face physical assault, exploitation and sexual harassment on their journey through Europe. Retrieved February 15, 2018, from https://www.amnesty.org/en/latest/news/2016/01/female-refugees-facephysical-assault-exploitation-and-sexual-harassment-on-their-journeythrough-europe/ 
Anand, V., Ashforth, B. E., \& Joshi, M. (2005). Business as usual: The acceptance and perpetuation of corruption in organizations. Academy of Management Perspectives, 19(4), 9-23. https://doi.org/10.5465/ame.2005.19417904

Anderson, B. (2000). Doing the Dirty Work?: The Global Politics of Domestic Labour. Palgrave Macmillan.

Anderson, B. (2007). A Very Private Business: Exploring the Demand for Migrant Domestic Workers. European Journal of Women's Studies, 14(3), 247-264. https://doi.org/10.1177/1350506807079013

Anderson, K. L., \& Umberson, D. (2001). Gendering Violence: Masculinity and Power in Men's Accounts of Domestic Violence. Gender and Society, 15(3), 358-380.

Anderson, L. (2011). Demystifying the Arab Spring: Parsing the Differences between Tunisia, Egypt, and Libya. Foreign Affairs, 90(3), 2-7.

Andvig, J. C., Fjeldstad, O., Amundsen, I., Søreide, T., \& Sissener. (2000). Research on Corruption A policy oriented survey. Chr. Michelsen Institute (CMI) \& Norwegian Institute of International Affairs (NUPI).

Andvig, J. C., \& Fjeldstad, O.-H. (2008). Crime, Poverty and Police Corruption in Developing Countries. CMI Working Paper, WP 2008: 7. Retrieved from http://www.cmi.no/publications/publication/?3076=crime-poverty-policecorruption-in-developing

Andvig, J. C., Fjeldstad, O.-H., Amundsen, I., Sissener, T., \& Søreide, T. (2001). Corruption. A Review of Contemporary Research (CMI Report No. 2001:7). Chr. Michelsen Institute (CMI).

Anzia, S. F., \& Berry, C. R. (2011). The Jackie (and Jill) Robinson Effect: Why Do Congresswomen Outperform Congressmen? American Journal of Political Science, 55(3), 478-493. https://doi.org/10.1111/j.1540-5907.2011.00512.x

Apergis, N., Dincer, O. C., \& Payne, J. E. (2009). The relationship between corruption and income inequality in U.S. states: evidence from a panel cointegration and error correction model. Public Choice, 145(1-2), 125-135. https://doi.org/10.1007/s11127-009-9557-1

Aphrasidze, D., \& Siroky, D. (2010). Frozen Transitions and Unfrozen Conflicts, or What went Wrong in Georgia Spotlight on Security. Yale Journal of International Affairs, 5, 121-136.

Ariu, A., \& Squicciarini, P. (2013). The Balance of Brains: Corruption and High Skilled Migration (Discussion Papers (IRES - Institut de Recherches Economiques et Sociales) No. 2013010). Université catholique de Louvain, Institut de 
Recherches Economiques et Sociales (IRES). Retrieved from https://ideas.repec.org/p/ctl/louvir/2013010.html

Audit Service Sierra Leone. (2014). Report on the Audit of the Management of the Ebola Funds. Retrieved from http://www.auditservice.gov.sl/report/assl-reporton-ebola-funds-management-may-oct-2014.pdf

Bäck, H., Debus, M., \& Müller, J. (2014). Who Takes the Parliamentary Floor? The Role of Gender in Speech-making in the Swedish Riksdag. Political Research Quarterly, 67(3), 504-518. https://doi.org/10.1177/1065912914525861

Bagratia, T., \& Badashvili, M. (2012). Developing intra-party democracy from a gender perspective (Policy Paper) (pp. 7-37). Tbilisi: Netherlands Institute of Multiparty Democracy.

Bailey, S. (2008). Perceptions of corruption in humanitarian assistance among Internally Displaced Persons in Northern Uganda. Humanitarian Policy Group (HPG).

Bain, L. E., Awah, P. K., Geraldine, N., Kindong, N. P., Siga, Y., Bernard, N., \& Tanjeko, A. T. (2013). Malnutrition in Sub - Saharan Africa: burden, causes and prospects. Pan African Medical Journal, 15(1). https://doi.org/10.11604/pamj.2013.15.120.2535

Baker, C. N. (1995). Sexual Extortion: Criminalizing Quid Pro Quo Sexual Harassment. Law \& Inequality: A Journal of Theory and Practice, 13(1), 213251.

Bales, K. (2007). What Predicts Human Trafficking? International Journal of Comparative and Applied Criminal Justice, 31(2), 269-279. https://doi.org/10.1080/01924036.2007.9678771

Barbieri, A. F., \& Carr, D. L. (2005). Gender-specific out-migration, deforestation and urbanization in the Ecuadorian Amazon. Global and Planetary Change, 47(2), 99-110.

Bardhan, P. (1997). Corruption and Development: A Review of Issues. Journal of Economic Literature, 35(3), 1320-1346.

Bardhan, P. (2006). The economist's approach to the problem of corruption. World Development, 34(2), 341-348. https://doi.org/10.1016/j.worlddev.2005.03.011

Barnes, T. D., \& Beaulieu, E. (2014). Gender Stereotypes and Corruption: How Candidates Affect Perceptions of Election Fraud. Politics \& Gender, 10(03), 365-391. https://doi.org/10.1017/S1743923X14000221 
Barreto, M., \& Ellemers, N. (2005a). The burden of benevolent sexism: how it contributes to the maintenance of gender inequalities. European Journal of Social Psychology, 35(5), 633-642. https://doi.org/10.1002/ejsp.270

Barreto, M., \& Ellemers, N. (2005b). The Perils of Political Correctness: Men's and Women's Responses to Old-Fashioned and Modern Sexist Views. Social Psychology $\quad$ Quarterly, 68(1), 75-88. https://doi.org/10.1177/019027250506800106

Bastia, T. (2014). Intersectionality, migration and development. Progress in Development Studies, 14(3), 237-248. https://doi.org/10.1177/1464993414521330

Batista, C., \& Vicente, P. C. (2010). Do Migrants Improve Governance at Home? Evidence from a Voting Experiement. IZA Discussion Paper, (4688).

Baudassé, T., \& Bazillier, R. (2014). Gender inequality and emigration: Push factor or selection process? International Economics, 139, 19-47. https://doi.org/10.1016/j.inteco.2014.03.004

Bauer, G., \& Burnet, J. E. (2013). Gender quotas, democracy, and women's representation in Africa: Some insights from democratic Botswana and autocratic Rwanda. Women's Studies International Forum, 41, Part 2, 103-112. https://doi.org/10.1016/j.wsif.2013.05.012

Baumann, E. (2012). Post-Soviet Georgia : it's a long, long way to "Modern" social protection. Économies et Sociétés, 46(2), 259-285.

Bayley, D. H. (1966). The Effects of Corruption in a Developing Nation. The Western Political Quarterly, 19(4), 719-732. https://doi.org/10.2307/445147

Beauregard, K. (2017). Quotas and Gender Gaps in Political Participation among Established Industrial European Democracies: Distinguishing Within- and Across-Country Effects. Political Research Quarterly, 70(3), 657-672. https://doi.org/10.1177/1065912917710116

Beauvoir, S. de. (2010). The Second Sex. London: Vintage.

Beckwith, K. (2005). A Common Language of Gender? Politics E Gender, 1(1), 128 137. https://doi.org/10.1017/S1743923X05211017

Beine, M., \& Sekkat, K. (2014). Emigration and origin country's institutions: does the destination country matter? Middle East Development Journal, 6(1), 20 44. https://doi.org/10.1080/17938120.2014.898411

Bennhold, K. (2017, December 21). On Perilous Migrant Trail, Women Often Become Prey to Sexual Abuse. The New York Times. Retrieved from 
https://www.nytimes.com/2016/01/03/world/europe/on-perilous-migranttrail-women-often-become-prey-to-sexual-abuse.html

Bergqvist, C., Bjarnegård, E., \& Zetterberg, P. (2016). The gendered leeway: male privilege, internal and external mandates, and gender-equality policy change. Politics, Groups, and Identities, 0(0), 1-17. https://doi.org/10.1080/21565503.2016.1229627

Berko, A., \& Erez, E. (2007). Gender, Palestinian Women, and Terrorism: Women's Liberation or Oppression? Studies in Conflict \& Terrorism, 30(6), 493-519. https://doi.org/10.1080/10576100701329550

Bernardi, R. A. (2006). Associations between Hofstede's Cultural Constructs and Social Desirability Response Bias. Journal of Business Ethics, 65(1), 43-53. https://doi.org/10.1007/s10551-005-5353-0

Bernstein, A. G. (2005). Gendered Characteristics of Political Engagement in College Students. Sex Roles, 52(5-6), 299-310. https://doi.org/10.1007/s11199-005-2674-5

Bhalotra, S., Clots-Figueras, I., \& Iyer, L. (2017). Pathbreakers? Women's Electoral Success and Future Political Participation. The Economic Journal, n/a-n/a. https://doi.org/10.1111/ecoj.12492

Bjarnegård, E. (2013). Gender, informal institutions and political recruitment: explaining male dominance in parliamentary representation. Palgrave Macmillan.

Bjarnegård, E. (2018). Focusing on Masculinity and Male-Dominated Networks in Corruption. In H. Stensöta \& L. Wängnerud (Eds.), Gender and Corruption Historical Roots and New Avenues for Research (pp. 257-273). UK: Palgrave Macmillan. Retrieved from //www.palgrave.com/gp/book/9783319709284

Bjarnegård, E., \& Kenny, M. (2015). Revealing the "Secret Garden": The Informal Dimensions of Political Recruitment. Politics Eamp; Gender, 11(4), 748-753. https://doi.org/10.1017/S1743923X15000471

Black, R., Hilker, L. M., \& Pooley, C. (2004). Migration and Pro-Poor Policy in East Africa (Working Paper No. C7) (p. 53). Sussex: Sussex Centre for Migration Research.

Blackburn, K., Bose, N., \& Haque, M. E. (2010). Endogenous corruption in economic development. Journal of Economic Studies, 37(1), 4-25. https://doi.org/10.1108/01443581011012234

Blackden, C. M., \& Wodon, Q. (2006). Gender, Time Use, and Poverty in Sub-Saharan Africa. World Bank Publications. 
Blaikie, N. (2009). Designing Social Research (2 edition). Cambridge, UK; Malden, MA: Polity.

Boehm, F., \& Sierra, E. (2015). The gendered impact of corruption: Who suffers more men or women? (U4 Brief 2015 No. 9). Chr. Michelsen Institute. Retrieved from http:/www.u4.no/publications/the-gendered-impact-of-corruptionwho-suffers-more-men-or-women/downloadasset/3882

Bohara, A. K., Mitchell, N. J., Nepal, M., \& Raheem, N. (2008). Human Rights Violations, Corruption, and the Policy of Repression. Policy Studies Journal, 36(1), 1-18. https://doi.org/10.1111/j.1541-0072.2007.00250.x

Bourdieu, P. (1979). Symbolic Power. Critique of Anthropology, 4(13-14), 77-85. https://doi.org/10.1177/0308275X7900401307

Boyd, M. (2006). Push Factors Resulting in the Decision for Women to Migrate. In UNFPA-IOM (Ed.), Female Migrants: Bridging the Gaps Throughout the Life Cycle (pp. 29-38). New York. Retrieved from https://www.unfpa.org/sites/default/files/resource-pdf/bridging_gap.pdf

Brady, H. E., Verba, S., \& Schlozman, K. L. (1995). Beyond SES: A Resource Model of Political Participation. American Political Science Review, 89(02), 271-294. https://doi.org/10.2307/2082425

Bratton, K. A., \& Ray, L. P. (2002). Descriptive Representation, Policy Outcomes, and Municipal Day-Care Coverage in Norway. American Journal of Political Science, 46(2), 428-437. https://doi.org/10.2307/3088386

Braun, V., \& Clarke, V. (2006). Using thematic analysis in psychology. Qualitative Research in Psychology, 3(2), 77-101. https://doi.org/10.1191/1478088706qp063oa

Breen, M., Gillanders, R., Mcnulty, G., \& Suzuki, A. (2017). Gender and Corruption in Business. The Journal of Development Studies, 53(9), 1486-1501. https://doi.org/10.1080/00220388.2016.1234036

Broockman, D. E. (2014). Distorted Communication, Unequal Representation: Constituents Communicate Less to Representatives Not of Their Race. American Journal of Political Science, 58(2), 307-321. https://doi.org/10.1111/ajps.12068

Bruni, V., \& Merkle, O. (2018). Gendered Effects of Corruption on the Central Mediterranean Route. ECDPM Great Insights, 7(1 (Winter 2018)). Retrieved from http:/ecdpm.org/great-insights/migration-moving-backwardmoving-forward/gendered-corruption-central-mediterranean/ 
Bryson, V. (1999). 'Patriarchy': A concept too useful to lose. Contemporary Politics, 5(4), 311-324. https://doi.org/10.1080/13569779908450014

Burman, E. (2003). From difference to intersectionality: challenges and resources. European Journal of Psychotherapy $\mathcal{E}$ Counselling, 6(4), 293-308. https://doi.org/10.1080/3642530410001665904

Burns, N., Schlozman, K. L., \& Verba, S. (2001). The private roots of public action. Harvard University Press.

Byrne, B. (1995). Gender, conflict and development, Volume I: Overview (BRIDGE Report No. 34).

Byrne, B. (1996). Towards a Gendered Understanding of Conflict. IDS Bulletin, 27(3), 31-40. https://doi.org/10.1111/j.1759-5436.1996.mp27003004.x

Byrnes, J. P., Miller, D. C., \& Schafer, W. D. (1999). Gender differences in risk taking: A meta-analysis. Psychological Bulletin, 125(3), 367-383. https://doi.org/10.1037/0033-2909.125.3.367

Cahn, N. R. (2005). Women in Post-Conflict Reconstruction: Dilemmas and Directions. William E Mary Journal of Women and the Law, 12, 335.

Campos, N., Dimova, R., \& Saleh, A. (2010). Whither corruption? A Quantitative Survey of the Literature on Corruption and Growth (IZA Discussion Paper No. 5334). Bonn: Institute for the Study of Labor (IZA).

Capraro, C., \& Rhodes, F. (2016, April 7). Why the Panama Papers are a feminist issue. Retrieved June 23, 2018, from https://www.opendemocracy.net/5050/chiara-capraro-francescarhodes/why-panama-papers-are-feminist-issue

Caprioli, M. (2000). Gendered Conflict. Journal of Peace Research, 37(1), 51-68. https://doi.org/10.1177/0022343300037001003

Caprioli, M. (2005). Primed for Violence: The Role of Gender Inequality in Predicting Internal Conflict. International Studies Quarterly, 49(2), 161-178. https://doi.org/10.1111/j.0020-8833.2005.00340.x

Caprioli, M., \& Boyer, M. A. (2001). Gender, Violence, and International Crisis. Journal of Conflict Resolution, 45(4), 503-518. https://doi.org/10.1177/0022002701045004005

Carling, J. (2002). Migration in the age of involuntary immobility: Theoretical reflections and Cape Verdean experiences. Journal of Ethnic and Migration Studies, 28(1), 5-42. https://doi.org/10.1080/13691830120103912 
Carpenter, R. C. (2006). Recognizing Gender-Based Violence Against Civilian Men and Boys in Conflict Situations. Security Dialogue, 37(1), 83-103. https://doi.org/10.1177/0967010606064139

Caryl, C. (2012, January 31). The Georgian Paradox. Retrieved May 20, 2018, from https://foreignpolicy.com/2012/01/31/the-georgian-paradox/

Caspary, G. (2007). The Impacts of Development- induced Displacement on Human Security. Human Security Journal, 4 Summer 2007, 70-81.

Casson, A., \& Obidzinski, K. (2002). From New Order to Regional Autonomy: Shifting Dynamics of "Illegal" Logging in Kalimantan, Indonesia. World Development, $\quad 30(12), \quad 2133-2151 . \quad$ https://doi.org/10.1016/S0305750X(02)00125-0

Castles, S., De Haas, H., \& Miller, M. J. (2013). The Age of Migration: International Population Movements in the Modern World (5th ed. 2014). Basingstoke: Palgrave.

Caul, M. (1999). Women's Representation in Parliament The Role of Political $\begin{array}{llll}\text { Parties. Party } & \text { Politics, }\end{array}$ https://doi.org/10.1177/1354068899005001005

CDC. (2014). Case Counts - 2014-2016 Ebola Outbreak West Africa. Atlanta: Center of Disease Control and Prevention. Retrieved from https://www.cdc.gov/vhf/ebola/history/2014-2016-outbreak/casecounts.html

Celis, K. (2009). Substantive Representation of Women (and Improving it): What it is and should be About? Comparative European Politics, 7(1), 95-113. https://doi.org/10.1057/cep.2008.35

Celis, K., \& Childs, S. (2008). Introduction: The Descriptive and Substantive Representation of Women: New Directions. Parliamentary Affairs, 61(3), 419-425. https://doi.org/10.1093/pa/gsn006

Celis, K., \& Childs, S. (2012). The Substantive Representation of Women: What to Do with Conservative Claims? Political Studies, 60(1), 213-225. https://doi.org/10.1111/j.1467-9248.2011.00904.x

Chankseliani, M. (2013). The financial burden of attending university in Georgia: Implications for rural students. PROSPECTS, 43(3), 311-328. https://doi.org/10.1007/s11125-013-9274-x

Chappell, L. (2002). Gendering Government: Feminist Engagement with the State in Australia and Canada. Vancouver: UBC Press. 
Chappell, L. (2006). Comparing Political Institutions: Revealing the Gendered "Logic of Appropriateness." Politics Eamp; Gender, 2(2), 223-235. https://doi.org/10.1017/S1743923X06221044

Chappell, L. (2014). "New," “Old," and "Nested" Institutions and Gender Justice Outcomes: A View from the International Criminal Court. Politics Eamp; Gender, 10(4), 572-594. https://doi.org/10.1017/S1743923X14000427

Charron, N. (2009). The Impact of Socio-Political Integration and Press Freedom on Corruption. The Journal of Development Studies, 45(9), 1472-1493. https://doi.org/10.1080/00220380902890243

Chathukulam, J., \& John, M. S. (2000). Empowerment of Women Panchayat Members: Learning from Kerala (India). Asian Journal of Women's Studies, 6(4), 66-101. https://doi.org/10.1080/12259276.2000.11665894

Chattopadhyay, R., \& Duflo, E. (2004). Women as Policy Makers: Evidence from a Randomized Policy Experiment in India. Econometrica, 72(5), 1409-1443. https://doi.org/10.1111/j.1468-0262.2004.00539.x

Chen, M. A. (2001). Women and Informality: A Global Picture, the Global Movement. SAIS Review, 21(1), 71-82. https://doi.org/10.1353/sais.2001.0007

Chêne, M. (2009). Gender and corruption in humanitarian assistance (U4 Expert Answer No. 223). Bergen: Chr. Michelsen Institute (CMI). Retrieved from https://www.u4.no/publications/gender-and-corruption-in-humanitarianassistance/

Chêne, M., Clench, B., \& Fagan, C. (2010). Corruption and Gender in Service Delivery: The Unequal Impacts. Transparency International Working Paper, (02/2010).

Cheng, C. S., \& Zaum, D. (2008). Introduction-Key Themes in Peacebuilding and Corruption. International Peacekeeping, 15(3), 301-309. https://doi.org/10.1080/13533310802058752

Chiaberashvili, Z., \& Tevzadze, G. (2005). Power Elites in Georgia: Old and New. In P. H. Fluri \& E. Cole (Eds.), From Revolution to Reform: Georgia's struggle with democratic institution building and security sector reform (pp. 187-207). Vienna and Geneva: Bureau for Security Policy at the Austrian Ministry of Defense.

Chkheidze, K. (2017). Women's Political Representation in Post-Soviet Georgia. In M. Barkaia \& A. Waterston (Eds.), Gender in Georgia: Feminist Perspectives on Culture, Nation, and History in the South Caucasus (1 edition, pp. 78-94). New York, NY Oxford: Berghahn Books. 
Bibliography

Cianciara, A. K. (2016). 'Europeanization' as a legitimation strategy of political parties: the cases of Ukraine and Georgia. Southeast European and Black Sea Studies, 16(3), 391-411. https://doi.org/10.1080/14683857.2016.1201984

Clausen, B., Kraay, A., \& Nyiri, Z. (2011). Corruption and Confidence in Public Institutions: Evidence from a Global Survey. The World Bank Economic Review, 25(2), 212-249.

Cockburn, C. (1991). In the Way of Women: Men's Resistance to Sex Equality in Organizations (1 edition). Ithaca, N.Y: ILR Press.

Coffé, H., \& Bolzendahl, C. (2010). Same Game, Different Rules? Gender Differences in Political Participation. Sex Roles, 62(5-6), 318-333. https://doi.org/10.1007/s11199-009-9729-y

Connell, R. (1987). Gender and Power: Society, the Person, and Sexual Politics. Bulletin of Science, Technology $\mathcal{E}$ Society, 8(4), 445-445. https://doi.org/10.1177/027046768800800490

Connell, R. (2006). Glass Ceilings or Gendered Institutions? Mapping the Gender Regimes of Public Sector Worksites. Public Administration Review, 66(6), 837-849. https://doi.org/10.1111/j.1540-6210.2006.00652.x

Council of Europe. (2017). Regional Study on Women's Political Representation in the Eastern Partnership Countries (Council of Europe handbook for civil society organisations). Strasbourg: Council of Europe. Retrieved from https://rm.coe.int/regional-study-on-women-s-political-representation-inthe-eastern-part/168070b6a4

Cowley, P., \& Childs, S. (2003). Too Spineless to Rebel? New Labour's Women MPs. British Journal of Political Science, 33(3), 345-365. https://doi.org/10.1017/S0007123403000164

Cox, R. (2006). The Servant Problem: Domestic Employment in a Global Economy (Annotated edition). London; New York : New York: I B Tauris.

Crenshaw, K. (1989). Demarginalizing the Intersection of Race and Sex: A Black Feminist Critique of Antidiscrimination Doctrine, Feminist Theory and Antiracist Politics. University of Chicago Legal Forum, 1989(1). Retrieved from http://chicagounbound.uchicago.edu/uclf/vol1989/iss1/8

Crenshaw, K. (1990). Mapping the Margins: Intersectionality, Identity Politics, and Violence against Women of Color. Stanford Law Review, 43, 1241-1300.

Crenshaw, K. (1991). Mapping the Margins: Intersectionality, Identity Politics, and Violence against Women of Color. Stanford Law Review, 43(6), 1241. https://doi.org/10.2307/1229039 
Creswell, J. W. (2007). Qualitative Inquiry and Research Design (2nd ed.). Thousand Oaks: Sage Publications.

Croix, D. de la, \& Delavallade, C. (2008). Growth, public investment and corruption with failing institutions. Economics of Governance, 10(3), 187. https://doi.org/10.1007/s10101-008-0057-4

d'Agostino, G., Dunne, J. P., \& Pieroni, L. (2016). Government Spending, Corruption and Economic Growth. World Development, 84, 190-205. https://doi.org/10.1016/j.worlddev.2016.03.011

Dahlerup, D., \& Freidenvall, L. (2005). Quotas as a 'fast track' to equal representation for women. International Feminist Journal of Politics, 7(1), 2648. https://doi.org/10.1080/1461674042000324673

Dahlerup, D., \& Freidenvall, L. (2010). Judging gender quotas: predictions and results. Policy $\mathcal{E}$ Politics, 38(3), 407-425.

Dahlström, C., Lapuente, V., \& Teorell, J. (2011). The Merit of Meritocratization: Politics, Bureaucracy, and the Institutional Deterrents of Corruption. Political Research Quarterly, 1065912911408109. https://doi.org/10.1177/1065912911408109

Dakolias, M., \& Thachuk, K. (2000). Attacking Corruption in the Judiciary: A Critical Process in Judicial Reform. Wisconsin International Law Journal, 18, 353-406.

Dalhuisen, J. (2017, December 12). Libya's wretched web of collusion [Online News]. Retrieved February 15, 2018, from http://www.aljazeera.com/indepth/opinion/eu-complicity-refugee-abuselibya-171212072937704.html

Damania, R. (2002). Environmental controls with corrupt bureaucrats. Environment and Development Economics, 7(3), 407-427. https://doi.org/10.1017/S1355770X02000256

Damania, R., Fredriksson, P. G., \& List, J. A. (2003). Trade liberalization, corruption, and environmental policy formation: theory and evidence. Journal of Environmental Economics and Management, 46(3), 490-512. https://doi.org/10.1016/S0095-0696(03)00025-1

Davis, J. (2004). Corruption in Public Service Delivery: Experience from South Asia's Water and Sanitation Sector. World Development, 32(1), 53-71. https://doi.org/10.1016/j.worlddev.2003.07.003 
Davis, K. (2008). Intersectionality as buzzword: A sociology of science perspective on what makes a feminist theory successful. Feminist Theory, 9(1), 67-85. https://doi.org/10.1177/1464700108086364

de Vaal, A., \& Ebben, W. (2011). Institutions and the Relation between Corruption and Economic Growth. Review of Development Economics, 15(1), 108-123. https://doi.org/10.1111/j.1467-9361.2010.00596.x

De Waal, T. (2011). Georgia's Choices: Charting a Future in Uncertain Times. Washington D.C: Carnegie Endowment for International Peace.

Debus, M., \& Hansen, M. E. (2014). Representation of Women in the Parliament of the Weimar Republic: Evidence from Roll Call Votes. Politics Eamp; Gender, 10(3), 341-364. https://doi.org/10.1017/S1743923X1400021X

Delavallade, C. (2006). Corruption and distribution of public spending in developing countries. Journal of Economics and Finance, 30(2), 222-239. https://doi.org/10.1007/BF02761488

Devlin, C., \& Elgie, R. (2008). The Effect of Increased Women's Representation in Parliament: The Case of Rwanda. Parliamentary Affairs, 61(2), 237-254. https://doi.org/10.1093/pa/gsn007

DFID. (2008). Growth - Building Jobs and Prosperity in Developing Countries. Great Britain: Department of International Development.

Dickinson, L. T. (1995). Quid Pro Quo Sexual Harassment: A New Standard Note. William \& Mary Journal of Women and the Law, 2, 107-124.

DiJohn, J. (2010). The Concept, Causes and Consequences of Failed States: A Critical Review of the Literature and Agenda for Research with Specific Reference to Sub-Saharan Africa. European Journal of Development Research, 22(1), 10-30.

Dimant, E., Krieger, T., \& Redlin, M. (2015). A Crook is a Crook ... But is He Still a Crook Abroad? On the Effect of Immigration on Destination-Country Corruption. German Economic Review, 16(4), 464-489. https://doi.org/10.1111/geer.12064

Dimant, E., \& Tosato, G. (2018). Causes and Effects of Corruption: What Has Past Decade's Empirical Research Taught Us? A Survey. Journal of Economic Surveys, 32(2), 335-356. https://doi.org/10.1111/joes.12198

Disch, A., Vigeland, E., \& Sundet, G. (2008). Anti-Corruption Approaches: A Literature Review (No. Study 2/2008). Oslo: NORAD. Retrieved from https://www.sida.se/contentassets/3f5c8afd51a6414d9f6c8f8425fb935b/anticorruption-approaches-a-literature-review_3153.pdf 
Dix, S., Hussmann, K., \& Walton, G. (2012). Risk of Corruption to State Legitimacy and Stability in Fragile Situations (U4 Issue No. No 3). Chr. Michelsen Institute (CMI) \& Norwegian Institute (CMI).

Dollar, D., Fisman, R., \& Gatti, R. (2001). Are women really the "fairer" sex? Corruption and women in government. Journal of Economic Behavior $\mathcal{E}$ Organization, 46(4), 423-429. https://doi.org/10.1016/S0167-2681(01)00169-X

Donato, K. M., Gabaccia, D., Holdaway, J., Manalansan, M., \& Pessar, P. R. (2006). A Glass Half Full? Gender in Migration Studies. International Migration Review, 40(1), 3-26. https://doi.org/10.1111/j.1747-7379.2006.00001.x

Dreby, J. (2015). Everyday Illegal: When Policies Undermine Immigrant Families. Oakland, California: University of California Press.

Duban, E. (2010). Gender Assessment, USAID/Georgia (p. 59). Tbilisi: USAID/Georgia. $\quad$ Retrieved from https://pdf.usaid.gov/pdf_docs/Pnads884.pdf

Dupuy, K., \& Divjak, B. (2015). Ebola and corruption: Overcoming critical governance challenges in a crisis situation. U4 Brief. Retrieved from //www.cmi.no/publications/5522-ebola-and-corruption

Durojaye, E. (2010). Corruption as a Threat to Human Security in Africa. In A. Abass, Protecting human security in Africa (pp. 217-243). Oxford University Press.

Dutta, N., Kar, S., \& Roy, S. (2011). Informal sector and Corruption: An Empirical Investigation for India (IZA Discussion Paper No. 5579). Institute for the Study of Labor (IZA).

Echazu, L. (2010). Corruption and the Balance of Gender Power. Review of Law $\mathcal{E}$ Economics, 6(1), 59-74. https://doi.org/10.2202/1555-5879.1397

Eckel, C. C., \& Füllbrunn, S. C. (2015). Thar SHE Blows? Gender, Competition, and Bubbles in Experimental Asset Markets. American Economic Review, 105(2), 906-920. https://doi.org/10.1257/aer.20130683

Eicher, T., García-Peñalosa, C., \& Ypersele, T. van. (2009). Education, corruption, and the distribution of income. Journal of Economic Growth, 14(3), 205-231. https://doi.org/10.1007/s10887-009-9043-0

Ellis, A., Manuel, C., \& Blackden, M. C. (2006). Gender and economic growth in Uganda: Unleashing the power of women (Directions in Development). Washington D.C.: World Bank. 
Enloe, C. (2017). The Big Push: Exposing and Challenging the Persistence of Patriarchy. University of California Press.

Esarey, J., \& Chirillo, G. (2013). "Fairer Sex" or Purity Myth? Corruption, Gender, and Institutional Context. Politics \& Gender, 9(04), 361-389. https://doi.org/10.1017/S1743923X13000378

Esarey, J., \& Schwindt-Bayer, L. A. (2017). Women's Representation, Accountability and Corruption in Democracies. British Journal of Political Science, 1-32. https://doi.org/10.1017/S0007123416000478

European Commission. (2017). Managing migration along the Central Mediterranean Route - Commission contributes to Malta discussion (European CommissionPress release No. IP/17/134). Retrieved from http://europa.eu/rapid/pressrelease_IP-17-134_en.htm

European Council. (2017). Malta Declaration by the members of the European Council on the external aspects of migration: addressing the Central Mediterranean route Consilium (Press Release No. 43/17). European Council. Retrieved from http://www.consilium.europa.eu/en/press/press-releases/2017/02/03/maltadeclaration/

Ewins, P., Harvey, P., Savage, K., \& Jacobs, A. (2006). Mapping the risks of corruption in humanitarian action.

Eyre, L. (2000). The Discursive Framing of Sexual Harassment in a University Community. Gender and Education, 12(3), 293-307. https://doi.org/10.1080/713668301

Farah, F. (2006). An Expert Group Meeting on Female Migrants: What is so special abou it? In UNFPA-IOM (Ed.), Female Migrants: Bridging the Gaps Throughout the Life Cycle (pp. 23-26). New York. Retrieved from https://www.unfpa.org/sites/default/files/resource-pdf/bridging_gap.pdf

Farzanegan, M. R., \& Witthuhn, S. (2016). Corruption and Political Stability: Does the Youth Bulge Matter? (CESifo Working Paper No. 5890). CES ifo. Retrieved from https://papers.ssrn.com/abstract=2791977

Federici, S. (1975). Wages against housework. Falling Wall Press Bristol.

Ferrant, G., Pesando, L. M., \& Nowacka, K. (2014). Unpaid Care Work: The missing link in the analysis of gender gaps in labour outcomes. Issues Paper, OECD Development Centre, Www.Oecd.Org/Dev/Developmentgender/Unpaid_care_work.Pdf (Accessed 12 October 2017). 
Ferrant, G., \& Tuccio, M. (2015). How do female migration and gender discrimination in social institutions mutually influence each other? (OECD Development Centre Working Papers No. 326). Paris: OECD.

Feuerstein, L., Gronemeier, K., Müller, S., Nordmann, D., Rumohr, J., \& Schnabel, S. (2013). Stopping the Drain on Resources: Fighting Corruption in the Water Sector; Discussion Paper - Services on Water and Sanitation (SOWAS) Working Group Water Governance. GIZ/BMZ.

Fiorino, N., Galli, E., \& Petrarca, I. (2012). Corruption and Growth: Evidence from the Italian regions. European Journal of Government and Economics, 1(2), 126144.

Fisman, R. (2001). Estimating the Value of Political Connections. The American Economic Review, 91(4), 1095-1102.

Fitzgerald, L. F. (1993). Sexual harassment: Violence against women in the workplace. American Psychologist, 48(10), 1070.

Fjeldstad, O.-H., Amundsen, I., Søreide, T. S. and T., \& Andvig, Jens Chr. (2001). Corruption: A review of contemporary research. CMI Report, R 2001:7. Retrieved from https://www.cmi.no/publications/861-corruption-a-reviewof-contemporary-research

Fleury, A. (2016). Understanding women and migration: A literature review. Global Knowledge Partnership on Migration and Development Working Paper, 8.

Flick, U. (2009). An Introduction to Qualitative Research. SAGE.

Foellmi, R., \& Oechslin, M. (2007). Who gains from non-collusive corruption? Journal of Development Economics, 82(1).

Fox, R. L., \& Lawless, J. L. (2004). Entering the Arena? Gender and the Decision to Run for Office. American Journal of Political Science, 48(2), 264-280. https://doi.org/10.2307/1519882

Fox, R. L., \& Lawless, J. L. (2014). Uncovering the Origins of the Gender Gap in Political Ambition. American Political Science Review, 108(03), 499-519. https://doi.org/10.1017/S0003055414000227

Franceschet, S., Krook, M. L., \& Piscopo, J. M. (Eds.). (2012). The Impact of Gender Quotas (1 edition). Oxford: Oxford University Press.

Franceschet, S., \& Piscopo, J. M. (2008). Gender Quotas and Women's Substantive Representation: Lessons from Argentina. Politics \& Gender, 4(03). https://doi.org/10.1017/S1743923X08000342 
Franceschet, S., \& Piscopo, J. M. (2014). Sustaining Gendered Practices? Power, Parties, and Elite Political Networks in Argentina. Comparative Political Studies, 47(1), 85-110. https://doi.org/10.1177/0010414013489379

Frank, B., Lambsdorff, J. G., \& Boehm, F. (2011). Gender and Corruption: Lessons from Laboratory Corruption Experiments. European Journal of Development Research, 23(1), 59-71. https://doi.org/10.1057/ejdr.2010.47

Freedom House. (2013). Nations in Transit 2013-Georgia (Country Profile). Washington D.C: Freedom House. Retrieved from https://freedomhouse.org/sites/default/files/NIT13_Georgia_2ndProof.pdf

Freedom House. (2018). Nations in Transit 2018 - Georgia (Country Profile). Washington D.C.: Freedom House. Retrieved from https://freedomhouse.org/sites/default/files/NiT2018_Georgia_final.pdf

Friedman, Elisabeth. (2000). Unfinished Transitions: Women and the Gendered Development of Democracy in Venezuela, 1936-1996. University Park, PA: The Pennsylvania State University Press. Retrieved from http://www.psupress.org/books/titles/0-271-02023-7.html

Friedman, Eric, Johnson, S., Kaufmann, D., \& Zoido-Lobaton, P. (2000). Dodging the grabbing hand: the determinants of unofficial activity in 69 countries. Journal of Public Economics, 76(3), 459-493. https://doi.org/10.1016/S00472727(99)00093-6

Fulton, S. A., Maestas, C. D., Maisel, L. S., \& Stone, W. J. (2006). The Sense of a Woman: Gender, Ambition, and the Decision to Run for Congress. Political Research Quarterly, 59(2), 235-248.

Furnham, A. (1986). Response bias, social desirability and dissimulation. Personality and Individual Differences, 7(3), 385-400. https://doi.org/10.1016/0191-8869(86)90014-0

Gallagher, M., \& Marsh, M. (Eds.). (1988). Candidate selection in Comparative Perspective: the Secret Garden of Politics. Sage Publications.

Gallina, N. (2010). Puzzles of state transformation: the cases of Armenia and Georgia. Caucasian Review of International Affairs, 4, 2--34.

Galtung, F., \& Tisné, M. (2009). A New Approach to Postwar Reconstruction. Journal of Democracy, 20(4), 93-107.

García, S. J. (2017). Racializing "Illegality": An Intersectional Approach to Understanding How Mexican-origin Women Navigate an Anti-immigrant Climate. Sociology of Race and Ethnicity, 3(4), 474-490. https://doi.org/10.1177/2332649217713315 
Gassebner, M., Jong-A-Pin, R., \& Mierau, J. O. (2008). Terrorism and electoral accountability: One strike, you're out! Economics Letters, 100(1), 126-129. https://doi.org/10.1016/j.econlet.2007.12.011

Gathii, J. T. (2009). Defining the Relationship between Human Rights and Corruption. University of Pennsylvania Journal of International Law, 31, 125202.

Gelfand, M. J., Fitzgerald, L. F., \& Drasgow, F. (1995). The Structure of Sexual Harassment: A Confirmatory Analysis across Cultures and Settings. Journal of Vocational Behavior, 47(2), 164-177. https://doi.org/10.1006/jvbe.1995.1033

George, J. A. (2014). Can hybrid regimes foster constituencies? Ethnic minorities in Georgian elections, 1992-2012. Electoral Studies, 35, 328-345. https://doi.org/10.1016/j.electstud.2014.02.007

Ghosh, A. (2003). Women's Reservations and Electoral Politics in Urban Local Bodies: An Analysis of Chennai Municipal Corporation Elections, 2001. Indian Journal of Gender Studies, 10(1), 117-141. https://doi.org/10.1177/097152150301000106

Ghosh, J. (2009). Migration and gender empowerment: Recent trends and emerging issues.

Gilbreath, D., \& Balasanyan, S. (2017). Elections and election fraud in Georgia and Armenia. Caucasus Survey, 5(3), 238-258. https://doi.org/10.1080/23761199.2017.1378856

Gilinskiy, Y. (2011). Torture by the Russian police: an empirical study. Police Practice and Research, 12(2), 163-171. https://doi.org/10.1080/15614263.2010.512138

GIWPS and PRIO. (2017). Women, Peace, and Security Index. Washington D.C.: Georgetown Institute for Women, Peace and Security. Retrieved from https://giwps.georgetown.edu/the-index/

Glick, P., Diebold, J., Bailey-Werner, B., \& Zhu, L. (1997). The Two Faces of Adam: Ambivalent Sexism and Polarized Attitudes Toward Women. Personality and Social Psychology Bulletin, 23(12), 1323-1334. https://doi.org/10.1177/01461672972312009

Glick, P., \& Fiske, S. T. (1996). The Ambivalent Sexism Inventory: Differentiating hostile and benevolent sexism. Journal of Personality and Social Psychology, 70(3), 491-512. https://doi.org/10.1037/0022-3514.70.3.491 
Bibliography

Glick, P., \& Fiske, S. T. (1997). Hostile and Benevolent Sexism: Measuring Ambivalent Sexist Attitudes Toward Women. Psychology of Women Quarterly, 21(1), 119-135. https://doi.org/10.1111/j.1471-6402.1997.tb00104.x

Glick, P., Sakalli-Ugurlu, N., Ferreira, M. C., \& Souza, M. A. de. (2002). Ambivalent Sexism and Attitudes Toward Wife Abuse in Turkey and Brazil. Psychology of Women Quarterly, 26(4), 292-297. https://doi.org/10.1111/1471-6402.t01-100068

Glover, S. H., Bumpus, M. A., Logan, J. E., \& Ciesla, J. R. (1997). Re-examining the Influence of Individual Values on Ethical Decision Making. In M. Fleckenstein, M. Maury, L. Pincus, \& P. Primeaux (Eds.), From the Universities to the Marketplace: The Business Ethics Journey (pp. 109-119). Springer Netherlands. https://doi.org/10.1007/978-94-009-1475-9_10

Goel, R. K., \& Nelson, M. A. (1998). Corruption and government size: A disaggregated analysis. Public Choice, 97(1-2), 107-120. https://doi.org/10.1023/A:1004900603583

Goetz, A.-M. (2002). No shortcuts to power: constraints on women's political effectiveness in Uganda. The Journal of Modern African Studies, 40(04), 549575. https://doi.org/10.1017/S0022278X02004032

Goetz, A.-M. (2003). Women's Political Effectiveness: A Conceptual Framework. In A.-M. Goetz \& S. Hassim (Eds.), No Shortcuts to Power: African Women in Politics and Policy Making (pp. 29-80). Zed Books.

Goetz, A.-M. (2007). Political Cleaners: Women as the New Anti-Corruption Force? Development and Change, 38(1), 87-105. https://doi.org/10.1111/j.14677660.2007.00404.x

Goetz, A.-M., \& Hassim, S. (Eds.). (2003). No Shortcuts to Power: African Women in Politics and Policy Making. Zed Books.

Gosh, J. (2009). Migration and gender empowerment: Recent trends and emerging issues (Human Development Research Paper (HDRP) Series No. 2009/4). UNDP.

Griffin, J. D., \& Newman, B. (2005). Are Voters Better Represented? The Journal of Politics, 67(04), 1206-1227. https://doi.org/10.1111/j.1468-2508.2005.00357.x

Grindle, M. S. (2011). Good Enough Governance Revisited. Development Policy Review, 29, s199-s221. https://doi.org/10.1111/j.1467-7679.2011.00526.x

Gubler, J. R., \& Selway, J. S. (2012). Horizontal Inequality, Crosscutting Cleavages, and Civil War. Journal of Conflict Resolution, 56(2), 206-232. https://doi.org/10.1177/0022002711431416 
Gugushvili, D. (2017). Lessons from Georgia's neoliberal experiment: A rising tide does not necessarily lift all boats. Communist and Post-Communist Studies, 50(1), 1-14. https://doi.org/10.1016/j.postcomstud.2016.11.001

Günther, I., \& Launov, A. (2012). Informal employment in developing countries: Opportunity or last resort? Journal of Development Economics, 97(1), 88-98. https://doi.org/10.1016/j.jdeveco.2011.01.001

Gupta, S., Davoodi, H., \& Alonso-Terme, R. (2002). Does Corruption Affect Income Inequality and Poverty? Economics of Governance, 3(1), 23-45. https://doi.org/10.1007/s101010100039

Gupta, S., Davoodi, H. R., \& Tiongson, E. (2000). Corruption and the provision of health care and education services (IMF Working Paper No. WP/00/116). Washington D.C.: International Monetary Fund.

Gupta, S., \& Ogada, C. (2016). Corruption: Costs and Mitigating Strategies (IMF Staff Discussion Note No. SDN/16/05). International Monetary Fund.

Habibov, N. (2012). Income inequality and its driving forces in transitional countries: evidence from Armenia, Azerbaijan and Georgia. Journal of Comparative Social Welfare, 28(3), 209-221. https://doi.org/10.1080/17486831.2012.749504

Haggard, S., \& Tiede, L. (2011). The Rule of Law and Economic Growth: Where are We? World Development, 39(5), 673-685. https://doi.org/10.1016/j.worlddev.2010.10.007

Hale, H. E. (2006). Democracy or autocracy on the march? The colored revolutions as normal dynamics of patronal presidentialism. Communist and PostCommunist Studies, 39(3), 305-329. https://doi.org/10.1016/j.postcomstud.2006.06.006

Halim, N., Yount, K. M., Cunningham, S. A., \& Pande, R. P. (2016). Women's Political Empowerment and Investments in Primary Schooling in India. Social Indicators Research, 125(3), 813-851. https://doi.org/10.1007/s11205015-0870-4

Hameed, S., \& Magpile, J. (2014). The Costs of Corruption: Strategies for Ending a Tac on Private-sector-led Growth. Washington D.C.: Center for Strategic \& International Studies (CSIS).

Hangul, Ö., Paton, E., Stanton, N., \& Welander, M. (2016). Unsafe Borderlands Filling Data Gaps Relating to Women in the Calais Camp. London: Refugee Rights Data Project. Retrieved from http://refugeerights.org.uk/wpcontent/uploads/2016/06/RRDP_UnsafeBorderlands.pdf 
Hapke, H. M. (2013). Theorizing Patriarchy: Development Paradoxes and the Geography of Gender in South Asia. Gender, Technology and Development, 17(1), 1-29. https://doi.org/10.1177/0971852412472121

Harris, C. R., Jenkins, M., \& Glaser, D. (2006). Gender differences in risk assessment: Why do women take fewer risks than men. Judgment and Decision Making, 1(1), 48-63.

Harrison, D. A., Kravitz, D. A., Mayer, D. M., Leslie, L. M., \& Lev-Arey, D. (2006). Understanding attitudes toward affirmative action programs in employment: summary and meta-analysis of 35 years of research. The Journal of Applied Psychology, 91(5), 1013-1036. https://doi.org/10.1037/00219010.91.5.1013

Hausmann, R., Tyson, L. D., Bekhouche, Y., \& Zahidi, S. (2014). The Global Gender Gap Report 2014. Switzerland: World Economic Forum. Retrieved from http://www.weforum.org/reports/global-gender-gap-report-2014

Hazarika, G. (2016). The Plough, Gender Roles, and Corruption (SSRN Scholarly Paper No. ID 2889672). Rochester, NY: Social Science Research Network. Retrieved from https://papers.ssrn.com/abstract $=2889672$

Hebl, M. R., King, E. B., Glick, P., Singletary, S. L., \& Kazama, S. (2007). Hostile and benevolent reactions toward pregnant women: Complementary interpersonal punishments and rewards that maintain traditional roles. Journal of Applied Psychology, 92(6), 1499-1511. https://doi.org/10.1037/00219010.92.6.1499

Helmke, G., \& Levitsky, S. (2004). Informal Institutions and Comparative Politics: A Research Agenda. Perspectives on Politics, 2(4), 725-740.

Herrera, J. (2016). Racialized illegality: The regulation of informal labor and space. Latino Studies, 14(3), 320-343. https://doi.org/10.1057/s41276-016-0007-1

Heyneman, S. P. (2011). The concern with corruption in higher education. Creating the Ethical Academy: A Systems Approach to Understanding Misconduct and Empowering Change in Higher Education. Routledge, Taylor E Francis Group.

Heyneman, S. P., Anderson, K. H., \& Nuraliyeva, N. (2008). The Cost of Corruption in Higher Education. Comparative Education Review, 52(1), 1-25. https://doi.org/10.1086/524367

Hicks, D. L., Hicks, J. H., \& Maldonado, B. (2016). Women as policy makers and donors: Female legislators and foreign aid. European Journal of Political Economy, 41, 46-60. https://doi.org/10.1016/j.ejpoleco.2015.10.007 
Hideg, I., \& Ferris, D. L. (2016). The compassionate sexist? How benevolent sexism promotes and undermines gender equality in the workplace. Journal of Personality and Social Psychology, 111(5), 706-727. https://doi.org/10.1037/pspi0000072

Hill, K. Q. (2003). Democratization and Corruption Systematic Evidence from the American States. American Politics Research, 31(6), 613-631. https://doi.org/10.1177/1532673X03255178

Hoffman, J., \& Graham, P. (2006). Introduction to political concepts. Pearson Education.

Holmberg, S., \& Rothstein, B. (2011). Dying of corruption. Health Economics, Policy and Law, 6(4), 529-547. https://doi.org/10.1017/S174413311000023X

Holmes, L. (2010). Conclusions: quadruple victimisation. In L. Holmes (Ed.), Trafficking and Human Rights: European and Asia-Pacific Perspectives (pp. 175205). Edward Elgar Publishing.

Hossain, M., Zimmerman, C., Kiss, L., Kone, D., Bakayoko-Topolska, M., A, D. M. K., ... Watts, C. (2014). Men's and women's experiences of violence and traumatic events in rural Côte d'Ivoire before, during and after a period of armed conflict. BMJ Open, 4(2), e003644. https://doi.org/10.1136/bmjopen2013-003644

Hossain, N., Nyami Musembi, C., \& Hughes, J. (2010). Corruption, Accountability and Gender: Understanding the Connection. UNDP and UNIFEM.

Howard, M. M. (2002). Postcommunist civil society in comparative perspective. Demokratizatsiya, 10(3), 285-305.

Howard, M. M. (2003). The weakness of civil society in post-communist Europe. Cambridge University Press.

Howitt, D. D. (2010). Introduction to Qualitative Methods in Psychology (1 edition). México: Prentice Hall.

Huang, S., Thang, L. L., \& Toyota, M. (2012). Transnational mobilities for care: rethinking the dynamics of care in Asia. Global Networks, 12(2), 129-134. https://doi.org/10.1111/j.1471-0374.2012.00343.x

Huang, S., Yeoh, B. S. A., \& Rahman, N. A. (2005). Asian Women as Transnational Domestic Workers. Marshall Cavendish Academic.

Humphreys, M. (2005). Natural Resources, Conflict, and Conflict Resolution Uncovering the Mechanisms. Journal of Conflict Resolution, 49(4), 508-537. https://doi.org/10.1177/0022002705277545 
Hunnicutt, G. (2009). Varieties of Patriarchy and Violence Against Women Resurrecting "Patriarchy" as a Theoretical Tool. Violence Against Women, 15(5), 553-573. https://doi.org/10.1177/1077801208331246

Hunt, J., \& Laszlo, S. (2012). Is Bribery Really Regressive? Bribery's Costs, Benefits, and Mechanisms. World Development, 40(2), 355-372. https://doi.org/10.1016/j.worlddev.2011.06.001

Huntington, S. P. (1968). Political Order in Changing Societies. New Haven, CT: Yale University Press.

Hussmanns, R. (2004). Defining and measuring informal employment. Bureau of Statistics Paper, ILO, Geneva, February (Http://Www.Ilo.Org/Public/English/Bureau/Stat/Download/Papers/Meas. Pdf).

IAWJ. (2012). Stopping the abuse of power though sexual exploitation: Naming, Shaming and Ending Sextortion. International Association of Woman Judges. Retrieved. $\quad$ Retrieved from http://www.iawj.org/iawj_international_toolkit_final.pdf

Inter-Parliamentary Union. (2014, December). Women in Parliaments: World Classification 2014. Retrieved June 11, 2018, from http://archive.ipu.org/wmn-e/arc/classif011214.htm

Inter-Parliamentary Union. (2018a). Georgia Sakartvelos Parlamenti (Parliament). Retrieved June 10, 2018, from http://archive.ipu.org/parlinee/reports/2119_arc.htm

Inter-Parliamentary Union. (2018b, January). Women in Parliaments: World Classification. Retrieved June 11, 2018, from http://archive.ipu.org/wmne/arc/classif010118.htm

IOM. (2011). Glossary on Migration. International Migration Law, 25, 114.

Isaksson, A.-S., Kotsadam, A., \& Nerman, M. (2014). The Gender Gap in African Political Participation: Testing Theories of Individual and Contextual Determinants. The Journal of Development Studies, 50(2), 302-318. https://doi.org/10.1080/00220388.2013.833321

Ivlevs, A., \& King, R. M. (2017). Does emigration reduce corruption? Public Choice, 171(3-4), 389-408. https://doi.org/10.1007/s11127-017-0442-z

Jacobson, D. (2012). Of Virgins and Martyrs: Women and Sexuality in Global Conflict. JHU Press.

Javakhadze, K. (2006). Gender Balance and Women in the Board of Trustees Programme in Georgia. In E. Saurer, M. Lanzinger, \& E. Frysak (Eds.), 
Women's Movements: Networks and Debates in Post-communist Countries in the 19th and 20th Centuries. Böhlau Verlag Köln Weimar.

Johnsøn, J., \& Mason, P. (2013). The Proxy Challenge: Why bespoke proxy indicators can help solve the anti-corruption measurement problem (U4 Brief 2013 No. 2) (p. 6). Bergen: Chr Michelsen Institute. Retrieved from http://www.u4.no/publications/the-proxy-challenge-why-bespoke-proxyindicators-can-help-solve-the-anti-corruption-measurement-problem/

Johnson, S., Kaufmann, D., \& Zoido-Lobatón, P. (1998). Regulatory Discretion and the Unofficial Economy. The American Economic Review, 88(2), 387-392.

Johnston, M. (1996). The search for definitions: the vitality of politics and the issue of corruption. International Social Science Journal, 48(149), 321-335. https://doi.org/10.1111/1468-2451.00035

Johnston, M. (2005). Syndromes of Corruption: Wealth, Power, and Democracy. Cambridge University Press.

Johnston, M. (2010). First, Do No Harm - Then, Build Trust: Anti-Corruption Strategies in Fragile Situations (Background Paper). World Bank. Retrieved from http://siteresources.worldbank.org/EXTWDR2011/Resources/64060821283882418764/WDR_Background_Paper_Johnston.pdf

Jolly, S., Reeves, H., \& Piper, N. (2005). Gender and migration: Overview report (Cutting Edge Pack Series). Brighton: BRIDGE-IDS. Retrieved from http://www.bdigital.unal.edu.co/39697/

Jones, S. F. (2013). Georgia: A Political History since Independence. London: I.B.Tauris.

Jost, J. T., \& Kay, A. C. (2005). Exposure to benevolent sexism and complementary gender stereotypes: consequences for specific and diffuse forms of system justification. Journal of Personality and Social Psychology, 88(3), 498-509. https://doi.org/10.1037/0022-3514.88.3.498

Jury, W. A., \& Vaux Jr., H. J. (2007). The Emerging Global Water Crisis: Managing Scarcity and Conflict Between Water Users. In B.-A. in Agronomy (Ed.) (Vol. 95, pp. 1-76). Academic Press. Retrieved from http://www.sciencedirect.com/science/article/pii/S0065211307950014

Justesen, M. K., \& Bjørnskov, C. (2014). Exploiting the Poor: Bureaucratic Corruption and Poverty in Africa. World Development, 58, 106-115. https://doi.org/10.1016/j.worlddev.2014.01.002

Jütting, J., \& de Laiglesia, J. (2009). Employment, Poverty Reduction and Development: What's New? In J. Jütting \& J. de Laiglesia (Eds.), Is Informal 
Normal?: Towards More and Better Jobs in Developing Countries (pp. 17-26). Paris: OECD Publishing.

Kabeer, N., \& Natali, L. (2013). Gender Equality and Economic Growth: Is there a Win-Win? IDS Working Papers, 2013(417), 1-58. https://doi.org/10.1111/j.2040-0209.2013.00417.x

Kahn, M. E. (2005). The Death Toll from Natural Disasters: The Role of Income, Geography, and Institutions. Review of Economics and Statistics, 87(2), 271284. https://doi.org/10.1162/0034653053970339

Katz, J. (2012). Violence against women -- it's a men's issue. Retrieved from https://www.ted.com/talks/jackson_katz_violence_against_women_it_s_a_ men_s_issue

Kawar, M. (2016). Gender and Migration: Why are Women more Vulnerable? In F. Reysoo \& C. Verschuur (Eds.), Femmes en mouvement: Genre, migrations et nouvelle division internationale $d u$ travail (pp. 71-87). Genève: Graduate Institute Publications. Retrieved from http://books.openedition.org/iheid/6256

Keefer, P. (2007). Clientelism, Credibility, and the Policy Choices of Young Democracies. American Journal of Political Science, 51(4), 804-821. https://doi.org/10.1111/j.1540-5907.2007.00282.x

Keltner, D., Gruenfeld, D. H., \& Anderson, C. (2003). Power, approach, and inhibition. Psychological Review, 110(2), 265-284. https://doi.org/10.1037/0033-295X.110.2.265

Kenny, M. (2007). Gender, Institutions and Power: A Critical Review. Politics, 27(2), 91-100. https://doi.org/10.1111/j.1467-9256.2007.00284.x

Kenny, M. (2013). Gender, Institutions and Political Recruitment. In Gender and Political Recruitment (pp. 13-33). Palgrave Macmillan, London. https://doi.org/10.1057/9781137271945_2

King, E. B., Botsford, W., Hebl, M. R., Kazama, S., Dawson, J. F., \& Perkins, A. (2012). Benevolent Sexism at Work: Gender Differences in the Distribution of Challenging Developmental Experiences. Journal of Management, 38(6), 1835-1866. https://doi.org/10.1177/0149206310365902

King, E. M., \& Mason, A. D. (2001). Engendering development through gender equality in rights, resources, and voice (No. 21776) (pp. 1-388). The World Bank. Retrieved from http://documents.worldbank.org/curated/en/2001/01/891686/engenderingdevelopment-through-gender-equality-rights-resources-voice 
Kis-Katos, K., \& Schulze, G. G. (2013). Corruption in Southeast Asia: a survey of recent research. Asian-Pacific Economic Literature, 27(1), 79-109. https://doi.org/10.1111/apel.12004

Kittilson, M. C. (2006). Challenging Parties, Changing Parliaments: Women and Elected Office in Contemporary Western Europe. Ohio State University Press.

Kleinig, J. (1996). The ethics of policing. Cambridge University Press.

Klitgaard, R. (1986). Elitism and Meritocracy in Developing Countries: Selection Policies for Higher Education. Baltimore: The Johns Hopkins University Press.

Koester, D. (2015). Gender \& Power (DLP Concept Brief No. 04). Birmingham: Developmental Leadership Program.

Kofman, E., Phizacklea, A., Raghuram, P., \& Sales, R. (2000). Gender and international migration in Europe: employment, welfare, and politics. Psychology Press.

Konrad, A. M., \& Hartmann, L. (2001). Gender Differences in Attitudes Toward Affirmative Action Programs in Australia: Effects of Beliefs, Interests, and Attitudes Toward Women. Sex Roles, 45(5-6), 415-432. https://doi.org/10.1023/A:1014317800293

Koubi, V., \& Böhmelt, T. (2014). Grievances, economic wealth, and civil conflict. Journal of Peace Research, 51(1), 19-33. https://doi.org/10.1177/0022343313500501

Krook, M. L. (2007). Candidate gender quotas: A framework for analysis. European Journal of Political Research, 46(3), 367-394. https://doi.org/10.1111/j.14756765.2007.00704.x

Krook, M. L., \& Mackay, F. (2011). Introduction: Gender, Politics, and Institutions. In M. L. Krook \& F. Mackay (Eds.), Gender, Politics and Institutions: Towards a Feminist Institutionalism (pp. 1-20). London: Palgrave Macmillan UK. https://doi.org/10.1057/9780230303911_1

Kudva, N. (2003). Engineering Elections: The Experiences of Women in $<$ Emphasis Type="Italic">Panchayati Raj</Emphasis $>$ in Karnataka, India. International Journal of Politics, Culture, and Society, 16(3), 445-463. https://doi.org/10.1023/A:1022312613488

Kukhianidze, A. (2009). Corruption and organized crime in Georgia before and after the 'Rose Revolution.' Central Asian Survey, 28(2), 215-234. https://doi.org/10.1080/02634930903043709 
Kumar, C. R. (2005). Corruption, Human Rights, and Development: Sovereignty and State Capacity to Promote Good Governance. Proceedings of the Annual Meeting (American Society of International Law), 99, 416-419.

Kunovich, S., \& Paxton, P. (2005). Pathways to Power: The Role of Political Parties in Women's National Political Representation. American Journal of Sociology, 111(2), 505-552. https://doi.org/10.1086/444445

Kupatadze, A. (2016). Georgia's Break with the Past. Journal of Democracy, 27(1), 110-123. https://doi.org/10.1353/jod.2016.0003

Kupatadze, A. (2017). Accounting for diverging paths in most similar cases: corruption in Baltics and Caucasus. Crime, Law and Social Change, 67(2), 187-208. https://doi.org/10.1007/s10611-016-9658-y

Kurer, O. (2005). Corruption: An Alternative Approach to Its Definition and Measurement. Political Studies, 53(1), 222-239. https://doi.org/10.1111/j.1467-9248.2005.00525.x

Kutnjak Ivkovic, S. (2005). Fallen Blue Knights: Controlling Police Corruption (1st ed.). Oxford ; New York: Oxford University Press.

Lalountas, D. A., Manolas, G. A., \& Vavouras, I. S. (2011). Corruption, globalization and development: How are these three phenomena related? Journal of Policy Modeling, 33(4), 636-648.

Lambsdorff, J. G., \& Schulze, G. G. (2015). What Can We Know About Corruption? Jahrbücher Für Nationalökonomie Und Statistik, 235(2), 100-114.

Lancaster, T. D., \& Montinola, G. R. (2001). Comparative Political Corruption: Issues of Operationalization and Measurement. Studies in Comparative International Development, 36(3), 3-28. https://doi.org/10.1007/BF02686202

Lanskoy, M., \& Areshidze, G. (2008). Poverty, Inequality, and Democracy. Journal of Democracy, 19(4), 154-168.

Le Billon, P. (2008). Corrupting Peace? Peacebuilding and Post-conflict Corruption. International Peacekeeping, 344-361. https://doi.org/10.1080/13533310802058851

Leach, F., Dunne, M., \& Salvi, F. (2014). School-Related Gender Based Violence (Background Research Paper for UNESCO).

Leach, F., \& Sitaram, S. (2007). sexual harassment and abuse of adolescent schoolgirls in South India. Education, Citizenship and Social Justice, 2(3), 257277. https://doi.org/10.1177/1746197907081262 
Leaning, J. (2001). Ethics of research in refugee populations. The Lancet, 357(9266), 1432-1433. https://doi.org/10.1016/S0140-6736(00)04572-4

Lee, H. (2004). Fasting for Food: Ethiopia's Years of Famine. Harvard International Review, 26(2), 14.

Lee, W.-S., \& Guven, C. (2013). Engaging in corruption: The influence of cultural values and contagion effects at the microlevel. Journal of Economic Psychology, 39, 287-300. https://doi.org/10.1016/j.joep.2013.09.006

Leff, N. H. (1964). Economic Development Through Bureaucratic Corruption. American Behavioral Scientist, 8(3), 8-14. https://doi.org/10.1177/000276426400800303

Levitsky, S., \& Way, L. A. (2010). Competitive Authoritarianism: Hybrid Regimes after the Cold War (1 edition). Cambridge: Cambridge University Press.

Leys, C. (1965). What is the Problem about Corruption? The Journal of Modern African Studies, 3(2), 215-230.

Lijphart, A. (1997). Unequal Participation: Democracy's Unresolved Dilemma. The American Political Science Review, 91(1), 1-14. https://doi.org/10.2307/2952255

Ljungholm, D. P. (2017). Feminist Institutionalism Revisited: The Gendered Features of the Norms, Rules, and Routines Operating within Institutions. Journal of Research in Gender Studies, 7, 248-254.

Locatelli, G., Mariani, G., Sainati, T., \& Greco, M. (2017). Corruption in public projects and megaprojects: There is an elephant in the room! International Journal of Project Management, 35(3), 252-268. https://doi.org/10.1016/j.ijproman.2016.09.010

Lodigiani, E., \& Salomone, S. (2015). Migration-Induced Transfers of Norms. The Case of Female Political Empowerment (SSRN Scholarly Paper No. ID 2622394). Rochester, NY: Social Science Research Network. Retrieved from https://papers.ssrn.com/abstract $=2622394$

López, R., \& Mitra, S. (2000). Corruption, Pollution, and the Kuznets Environment Curve. Journal of Environmental Economics and Management, 40(2), 137-150. https://doi.org/10.1006/jeem.1999.1107

Lopez-Ekra, S., Aghazarm, C., Kötter, H., \& Mollard, B. (2011). The impact of remittances on gender roles and opportunities for children in recipient families: research from the International Organization for Migration. $\begin{array}{llll}\text { Gender } & \& & \text { Development, } & \text { 69-80. }\end{array}$ https://doi.org/10.1080/13552074.2011.554025 
Bibliography

Lovei, L., \& McKechnie, A. (2000). The Costs of Corruption for the Poor-The Energy Sector. World Bank Viewpoint Note No, 207.

Lovenduski, J. (2005). Feminizing Politics. Polity.

Lovenduski, J., \& Norris, P. (2003). Westminster Women: The Politics of Presence. Political Studies, 51(1), 84-102. https://doi.org/10.1111/1467-9248.00414

Lui, F. T. (1985). An Equilibrium Queuing Model of Bribery. Journal of Political Economy, 93(4), 760-781.

Lutterbeck, D. (2013). Arab Uprisings, Armed Forces, and Civil-Military Relations. $\begin{array}{llll}\text { Armed Forces } & \text { \& } & \text { Society, } & \text { 39(1), }\end{array}$ https://doi.org/10.1177/0095327X12442768

Lynch, J. F. (2004). The age of welfare: Patronage, citizenship, and generational justice in social policy. Minda de Gunzburg Center for European Studies, Harvard University.

Mackay, F. (2014). Nested Newness, Institutional Innovation, and the Gendered Limits of Change. Politics and Gender, 10(4), 549-571. https://doi.org/10.1017/S1743923X14000415

Mackay, F., Kenny, M., \& Chappell, L. (2010). New Institutionalism Through a Gender Lens: Towards a Feminist Institutionalism? International Political Science Review, 31(5), 573-588. https://doi.org/10.1177/0192512110388788

Mackay, F., \& Mcallister, L. (2012). Feminising British Politics: Six Lessons from Devolution in Scotland and Wales. The Political Quarterly, 83(4), 730-734. https://doi.org/10.1111/j.1467-923X.2012.02365.x

Mackay, F., Monro, S., \& Waylen, G. (2009). The Feminist Potential of Sociological Institutionalism. Politics Eamp; Gender, 5(2), 253-262. https://doi.org/10.1017/S1743923X09000208

Mackenzie, C., McDowell, C., \& Pittaway, E. (2007). Beyond 'Do No Harm': The Challenge of Constructing Ethical Relationships in Refugee Research. Journal of Refugee Studies, 20(2), 299-319. https://doi.org/10.1093/jrs/fem008

MacKenzie, M. (2009). Securitization and Desecuritization: Female Soldiers and the Reconstruction of Women in Post-Conflict Sierra Leone. Security Studies, 18(2), 241-261. https://doi.org/10.1080/09636410902900061

Malkin, V. (2004). "We go to Get Ahead": Gender and Status in Two Mexican Migrant Communities. Latin American Perspectives, 31(5), 75-99. https://doi.org/10.1177/0094582X04268402 
Marenin, O. (1996). Policing Change, Changing Police: Some Thematic Questions. In O. Marenin (Ed.), Policing Change, Changing Police: International Perspectives (pp. 3-22). New York: Routledge.

Masser, B. M., \& Abrams, D. (2004). Reinforcing the Glass Ceiling: The Consequences of Hostile Sexism for Female Managerial Candidates. Sex Roles, 51(9-10), 609-615. https://doi.org/10.1007/s11199-004-5470-8

Massey, D. S., Fischer, M. J., \& Capoferro, C. (2006). International Migration and Gender in Latin America: A Comparative Analysis. International Migration, 44(5), 63-91. https://doi.org/10.1111/j.1468-2435.2006.00387.x

Matland, R. E., \& Brown, D. D. (1992). District Magnitude's Effect on Female Representation in U. S. State Legislatures. Legislative Studies Quarterly, 17(4), 469-492. https://doi.org/10.2307/439862

Matland, R. E., \& Montgomery, K. A. (2003). Women's access to political power in postcommunist Europe. Oxford University Press.

Mauro, P. (1995). Corruption and Growth. The Quarterly Journal of Economics, 110(3), 681-712.

Maxwell, D., Walker, P., Church, C., Harvey, P., Savage, K., Bailey, S., ... Ahlendorf, M.-L. (2008). Preventing Corruption in Humanitarian Assistance. Berlin: Transparency International/Feinstein International Center Research Report.

May, T. (2011). Social Research. McGraw-Hill Education (UK).

McCabe, A. C., Ingram, R., \& Dato-on, M. C. (2006). 'The Business of Ethics and Gender.' Journal of Business Ethics, 64(2), 101-116. https://doi.org/10.1007/s10551-005-3327-x

McEvoy, C. (2016). Does the Descriptive Representation of Women Matter? A Comparison of Gendered Differences in Political Attitudes between Voters and Representatives in the European Parliament. Politics E Gender, 12(4), 754-780. https://doi.org/10.1017/S1743923X16000118

McKay, S. (1998). The Effects of Armed Conflict on Girls and Women. Peace and Conflict: Journal of Peace Psychology, 4(4), 381-392. https://doi.org/10.1207/s15327949pac0404_6

McMillan, J., \& Zoido, P. (2004). How to Subvert Democracy: Montesinos in Peru. Journal of Economic Perspectives, 18(4), 69-92. https://doi.org/10.1257/0895330042632690 
Melander, E. (2005). Political Gender Equality and State Human Rights Abuse. Journal of Peace Research, 42(2), 149-166. https://doi.org/10.1177/0022343305050688

Melé, D., \& Rosanas, J. M. (2003). Power, Freedom and Authority in Management: Mary Parker Follett's 'Power-With.' Philosophy of Management, 3(2), 35-46. https://doi.org/10.5840/pom20033221

Mellon, R. C. (2013). On the motivation of quid pro quo sexual harassment in men: relation to masculine gender role stress. Journal of Applied Social Psychology, 43(11), 2287-2296. https://doi.org/10.1111/jasp.12178

Menjívar, C. (2006). Liminal Legality: Salvadoran and Guatemalan Immigrants' Lives in the United States. American Journal of Sociology, 111(4), 999-1037. https://doi.org/10.1086/499509

Méon, P.-G., \& Sekkat, K. (2005). Does corruption grease or sand the wheels of growth? Public Choice, 122(1-2), 69-97. https://doi.org/10.1007/s11127-0053988-0

Méon, P.-G., \& Weill, L. (2010). Is Corruption an Efficient Grease? World Development, 38(3), 244-259. https://doi.org/10.1016/j.worlddev.2009.06.004

Merkle, O., Reinold, J., \& Siegel, M. (2017a). A Gender Perspective on Corruption Encountered During Forced and Irregular Migration. Maastricht: GIZ AntiCorruption and Integrity Programme. Retrieved from https://i.unu.edu/media/migration.unu.edu/attachment/4665/A-GenderPerspective-on-Corruption-Encountered-during-Forced-and-IrregularMigration.pdf

Merkle, O., Reinold, J., \& Siegel, M. (2017b). A Study on the Link between Corruption and the Causes of Migration and Forced Displacement. Maastricht: GIZ AntiCorruption and Integrity Programme. Retrieved from https://i.unu.edu/media/migration.unu.edu/publication/4597/A-Study-onthe-Link-between-Corruption-and-the-Causes-of-Migration-and-ForcedDisplacement.pdf

Merkle, O., Reinold, J., \& Siegel, M. (2018). Corruption, gender and migration. In Planet Integrity: Building a Fairer Society. Paris.

Metreveli, T. (2016). An undisclosed story of roses: church, state, and nation in contemporary Georgia. Nationalities Papers, 44(5), $694-712$. https://doi.org/10.1080/00905992.2016.1200021

Mill, J. S. (2015). On Liberty, Utilitarianism and Other Essays. (M. Philp \& F. Rosen, Eds.) (Second Edition). Oxford, New York: Oxford University Press. 
Mishra, A., \& Ray, R. (2010). Informality, Corruption, and Inequality (Department of Economics Working Paper). University of Bath, Department of Economics. Retrieved from http://econpapers.repec.org/paper/eidwpaper/22127.htm

Mitchell, L. A. (2006). Democracy in Georgia Since the Rose Revolution. Orbis, 50(4), 669-676. https://doi.org/10.1016/j.orbis.2006.07.007

Mo, P. H. (2001). Corruption and Economic Growth. Journal of Comparative Economics, 29(1), 66-79. https://doi.org/10.1006/jcec.2000.1703

Mocan Naci. (2008). What determines corruption? international evidence from microdata. Economic Inquiry, 46(4), 493-510. https://doi.org/10.1111/j.14657295.2007.00107.x

Montgomery, M. A., \& Elimelech, M. (2007). Water And Sanitation in Developing Countries: Including Health in the Equation. Environmental Science $\mathcal{E}$ Technology, 41(1), 17-24. https://doi.org/10.1021/es072435t

Morano Foadi, S. (2006). Key Issues and Causes of the Italian Brain Drain. Innovation: The European Journal of Social Science Research, 19(2), 209-223. https://doi.org/10.1080/13511610600804315

Morris, S. D. (2008). Disaggregating Corruption: A Comparison of Participation and Perceptions in Latin America with a Focus on Mexico1. Bulletin of Latin American Research, 27(3), 388-409. https://doi.org/10.1111/j.14709856.2008.00276.x

Moser, S. (2008). Personality: A New Positionality? Area, 40(3), 383-392.

Mottier, V. (2002). Masculine domination: Gender and power in Bourdieu's writings. Feminist Theory, 3(3), 345-359. https://doi.org/10.1177/146470002762492042

Moyce, S., Lash, R., \& de Leon Siantz, M. L. (2016). Migration Experiences of Foreign Educated Nurses: A Systematic Review of the Literature. Journal of Transcultural Nursing, 27(2), 181-188. https://doi.org/10.1177/1043659615569538

Mulgan, R. (2000). Comparing Accountability in the Public and Private Sectors. Australian Journal of Public Administration, 59(1), 87-97. https://doi.org/10.1111/1467-8500.00142

Mungiu-Pippidi, A. (2016). Learning from Virtuous Circles. Journal of Democracy, 27(1), 95-109. https://doi.org/10.1353/jod.2016.0000

National Statistics Office of Georgia. (2015). Women and Men in Georgia (Statistical Publication). Tbilisi: National Statistics Office Georgia. 
Neudorfer, N. S., \& Theuerkauf, U. G. (2014). Buying War Not Peace The Influence of Corruption on the Risk of Ethnic War. Comparative Political Studies, 0010414013516919. https://doi.org/10.1177/0010414013516919

Newburn, T. (2015). Literature review-Police integrity and corruption. HMIC. Retrieved from https://www.justiceinspectorates.gov.uk/hmic/wpcontent/uploads/pic-literature-review.pdf

Ngai, M. M. (2004). Impossible subjects : illegal aliens and the making of modern America. Princeton, N.J.: Princeton University Press,. Retrieved from ACLS Humanities E-Book http://hdl.handle.net/2027/heb.06691

Nhundu, T. J., \& Shumba, A. (2001). The nature and frequency of reported cases of teacher perpetrated child sexual abuse in rural primary schools in Zimbabwe. Child Abuse $\mathcal{E}$ Neglect, 25(11), 1517-1534. https://doi.org/10.1016/S0145-2134(01)00288-5

Nistotskaya, M., \& Stensöta, H. (2018). Is Women's Political Representation Beneficial to Women's Interests in Autocracies? Theory and Evidence from Post-Soviet Russia. In H. Stensöta \& L. Wängnerud (Eds.), Gender and Corruption - Historical Roots and New Avenues for Research (pp. 145-167). UK: Palgrave Macmillan.

Nodia, G., \& Scholtbach, A. P. (Eds.). (2006). The Political Landscape of Georgia. Delft: Eburon Publishers.

Nogaideli, E. (2012). Single Mothers - Un-Respectable "Others" of Georgian Nationalism: Production of Subjectivities through "Nesting Respectability" (Masters Thesis). Central European University, Budapest. Retrieved from http://www.etd.ceu.hu/2012/nogaideli_eter.pdf

Norad. (2012). Results Report 2011: Aid and Conflict. Retrieved from http://www.norad.no/en/tools-and-

publications/publications/publication?key=392469

Norris, P. (1985). Women's legislative participation in western Europe. West European Politics, 8(4), 90-101. https://doi.org/10.1080/01402388508424556

Norris, P. (1993). Conclusions: Comparing Legislative Recruitment. In J. Lovenduski \& P. Norris (Eds.), Gender and Party Politics (pp. 309-330). London: SAGE Publications Ltd.

Norris, P., \& Inglehart, R. (2001). Cultural Obstacles to Equal Representation. Journal of Democracy, 12(3), 126-140. https://doi.org/10.1353/jod.2001.0054

Nyami Musembi, C. (2007). Gender and corruption in the administration of justice. In Global Corruption Report 2007: Corruption and Judicial Systems (pp. 121- 
128). Berlin: Transparency International. Retrieved from http://www.transparency.org/whatwedo/publication/global_corruption_re port_2007_corruption_and_judicial_systems

Nye, J. S. (1967). Corruption and Political Development: A Cost-Benefit Analysis. The American Political Science Review, 61(2), 417-427. https://doi.org/10.2307/1953254

Ó Beacháin, D., \& Coene, F. (2014). Go West: Georgia's European identity and its role in domestic politics and foreign policy objectives. Nationalities Papers, 42(6), 923-941. https://doi.org/10.1080/00905992.2014.953466

OC MEDIA. (2017, June 13). Rights groups submit Women's quota law to parliament. Retrieved May 15, 2018, from http://oc-media.org/rightsgroups-submit-womens-quota-law-to-parliament/

OC MEDIA. (2018, March 23). Georgian parliament rejects gender quota bill. Retrieved May 15, 2018, from http://oc-media.org/georgian-parliamentrejects-gender-quota-bill/

O'Carroll, L. (2015, February 16). A third of Sierra Leone's Ebola budget unaccounted for, says report. The Guardian. Retrieved from http://www.theguardian.com/world/2015/feb/16/ebola-sierra-leonebudget-report

OCCRP. (2014, May 19). Syria: Aid Corruption Worsens Plight of Syrian Refugees. Retrieved February 15, 2018, from https://www.occrp.org/en/daily/2452syria-aid-corruption-worsens-plight-of-syrian-refugees

O'Connell, C. E., \& Korabik, K. (2000). Sexual Harassment: The Relationship of Personal Vulnerability, Work Context, Perpetrator Status, and Type of Harassment to Outcomes. Journal of Vocational Behavior, 56(3), 299-329. https://doi.org/10.1006/jvbe.1999.1717

OECD. (2010). The State's Legitimacy in Fragile Situations: Unpacking Complexity (Conflict and Fragility).

OECD. (2015). Responses to the refugee crisis: Corruption and the smuggling of refugees.

OECD. (2016). Terrorism, corruption and the criminal exploitation of natural resources. OECD-DAF.

Oishi, N. (2002). Gender and Migration: An Integrative Approach (Working Paper No. 49). San Diego: The Center of Comparative Immigration Studies. Retrieved from https://ccis.ucsd.edu/_files/wp49.pdf 
Bibliography

Olken, B. A., \& Pande, R. (2012). Corruption in Developing Countries. Annual Review of Economics, 4(1), 479-509. https://doi.org/10.1146/annureveconomics-080511-110917

Ones, D. S., \& Viswesvaran, C. (1998). Gender, age, and race differences on overt integrity tests: Results across four large-scale job applicant datasets. Journal of Applied Psychology, 83(1), 35-42. https://doi.org/10.1037/0021-9010.83.1.35

Orre, A., \& Mathisen, H. W. (2008). Corruption in Fragile States (DIIS Policy Brief: Fragile Situations). Copenhagen, Denmark.

OSCE ODIHR. (2008a). Georgia Extraordinary Presidential Election 5 January 2008 (OSCE/ODIHR Election Observation Mission Final Report). Warsaw. Retrieved from https://www.osce.org/odihr/elections/georgia/30959?download=true

OSCE ODIHR. (2008b). Georgia Parliamentary Elections 21 May 2008 (OSCE/ODIHR Election Observation Mission Final Report). Warsaw. Retrieved from https://www.osce.org/odihr/elections/georgia/33301?download=true

OSCE ODIHR. (2012). Georgia Parliamentary Elections 1 October 2012 (OSCE/ODIHR Election Observation Mission Final Report). Warsaw. Retrieved from https://www.osce.org/odihr/98399?download=true

OSCE ODIHR. (2014). Georgia Presidential Election 27 October 2013 (OSCE/ODIHR Election Observation Mission Final Report). Warsaw. Retrieved from https://www.osce.org/odihr/elections/110301?download=true

OSCE ODIHR. (2017). Georgia Parliamentary Elections 8 and 30 October 2016: (OSCE/ODIHR Election observation Mission Final Report). Warsaw. Retrieved from https://www.osce.org/odihr/elections/georgia/297551?download=true

OSCE ODIHR. (2018). Georgia Local Elections 21 October and 12 November 2017 (OSCE/ODIHR Election Observation Mission Final Report). Warsaw. Retrieved from

https://www.osce.org/odihr/elections/georgia/373600?download=true

OSCE/ODIHR. (2007). Effective Participation and Representation in Democratic Societies. Warsaw: OSCE Office for Democratic Institutions and Human Rights.

OSCE/ODIHR. (2014). Situation Assessment Report on Roma in Ukraine and the Impact of the Current Crisis. Organization for Security and Co-operation in Europe. 
Østby, G. (2008). Polarization, Horizontal Inequalities and Violent Civil Conflict. Journal of Peace Research, 45(2), 143-162. https://doi.org/10.1177/0022343307087169

Otobe, N. (2017). Gender and the Informal Economy: Key Challenges and Policy Response (Employment Working Paper No. 236). Geneva: International Labour Office.

Papakostas, A. (2001). Why is there no Clientelism in Scandinavia? A Comparison of the Swedish and Greek Sequences of Development. In S. Piattoni (Ed.), Clientelism, Interests, and Democratic Representation: The European Experience in Historical and Comparative Perspective (pp. 31-53). Cambridge: Cambridge University Press.

Pateman, C. (1988). The Sexual Contract (1 edition). Stanford, Calif: Stanford University Press.

Paxton, P., \& Kunovich, S. (2003). Women's Political Representation: The Importance of Ideology. Social Forces, 82(1), 87-113. https://doi.org/10.1353/sof.2003.0105

Pedraza, S. (1991). Women and Migration: The Social Consequences of Gender. Annual Review of Sociology, 17(1), 303-325. https://doi.org/10.1146/annurev.so.17.080191.001511

Pellegrini, L., \& Gerlagh, R. (2006). Corruption, Democracy, and Environmental Policy An Empirical Contribution to the Debate. The Journal of Environment E Development, 15(3), 332-354. https://doi.org/10.1177/1070496506290960

Pepinsky, H. E. (1992). Corruption, bribery and patriarchy in Tanzania. Crime, Law and Social Change, 17(1), 25-51. https://doi.org/10.1007/BF00190170

Philp, M. (2008). Peacebuilding and Corruption. International Peacekeeping, 15(3), 310-327. https://doi.org/10.1080/13533310802058786

Philp, M. (2016). Corruption Definition and Measurement. In A. Shacklock \& F. Galtung (Eds.), Measuring Corruption. Routledge.

Piñera, S., \& Selowsky, M. (1981). The optimal ability-education mix and the misallocation of resources within education magnitude for developing countries. Journal of Development Economics, 8(1), 111-131. https://doi.org/10.1016/0304-3878(81)90048-1

Piper, N. (2005). Gender and Migration. Ganeva: Policy Analysis and Research Programme of the Global Commission on International Migration. Retrieved

from 
https://www.iom.int/jahia/webdav/site/myjahiasite/shared/shared/mainsit e/policy_and_research/gcim/tp/TP10.pdf

Pitkin, H. F. (1967). The Concept of Representation. University of California Press.

Pokleba, N. (2016). Civil society in Georgia: expectations versus reality. Southeast European and Black Sea Studies, 16(2), 235-253. https://doi.org/10.1080/14683857.2016.1156344

Poskitt, A., \& Dufranc, M. (2011). Civil Society Organisations in Situations of Conflict. Johannesburg: Open Forum for CSO Developing Effectiveness. Retrieved from http://civicus.org/view/media/cso_conflict_complete_report.pdf

Prince, V. (2005). Sex vs. Gender. International Journal of Transgenderism, 8(4), 29-32. https://doi.org/10.1300/J485v08n04_05

Pring, C. (2015). People and Corruption: Africa Survey 2015 (Global Corruption Barometer). Berlin: Transparency International and Afrobarometer. Retrieved from http://files.transparency.org/content/download/1941/12775/file/2015_GCB_ SubSaharanAfrica_EN.pdf

Pring, C. (2016a). People and Corruption: Middle East $\mathcal{E}$ North Africa Survey 2016 (Global Corruption Barometer). Berlin: Transparency International. Retrieved from http://files.transparency.org/content/download/1995/12992/file/2016_GCB_ MENA_EN.pdf

Pring, C. (2016b). People and Corruption: Europe and Central Asia (Global Corruption Barometer). Berlin: Transparency International.

Prinsloo, S. (2006). Sexual harassment and violence in South African schools. South African Journal of Education, 26(2), 305-318.

Pulfrey, S. (2006). Malnutrition: a silent emergency. Canadian Medical Association Journal, 174(13), 1837-1837. https://doi.org/10.1503/cmaj.060278

Punch, M. (1985). Conduct unbecoming: The social construction of police deviance and control. Tavistock London.

Punch, M. (2009). Police Corruption: Deviance, Accountability and Reform in Policing. Cullompton: Willan Publishing.

Pyman, M., Cohen, J., \& Boardman, M. (2012). Arresting Corruption in the Police: The Global Experience of Police Corruption Reform Efforts. (S. Mustafa, Ed.). Transparency International UK. 
Rauch, J. E., \& Evans, P. B. (2000). Bureaucratic structure and bureaucratic performance in less developed countries. Journal of Public Economics, 75(1), 49-71. https://doi.org/10.1016/S0047-2727(99)00044-4

Ray, A. E. (1996). The Shame of It: Gender-Based Terrorism in the Former Yugoslavia and the Failure of International Human Rights Law to Comprehend the Injuries. American University Law Review, 46, 793.

Rehren, A. (1996). Corruption and local politics in Chile. Crime, Law and Social Change, 25(4), 323-334. https://doi.org/10.1007/BF00572513

Reinikka, R., \& Svensson, J. (2005). Fighting Corruption to Improve Schooling: Evidence from a Newspaper Campaign in Uganda. Journal of the European Economic Association, 3(2-3), 259-267. https://doi.org/10.1162/jeea.2005.3.23.259

Reiss, M. C., \& Mitra, K. (1998). The Effects of Individual Difference Factors on the Acceptability of Ethical and Unethical Workplace Behaviors. Journal of Business Ethics, 17(14), 1581-1593. https://doi.org/10.1023/A:1005742408725

Rekhviashvili, A. (2010). Nationalism and Motherhood in Contemporary Georgia (Masters Thesis). Central European University, Budapest. Retrieved from http://www.etd.ceu.hu/2010/rekhviashvili_ana.pdf

Rekhviashvili, L., \& Polese, A. (2017). Liberalism and shadow interventionism in post-revolutionary Georgia (2003-2012). Caucasus Survey, 5(1), 27-50. https://doi.org/10.1080/23761199.2017.1283471

Richards, K. (2004). The Trafficking of Migrant Workers: What are the Links Between Labour Trafficking and Corruption? International Migration, 42(5), 147-168. https://doi.org/10.1111/j.0020-7985.2004.00305.x

Ridgeway, C. L. (1997). Interaction and conservation of gender inequality: Considering employment. American Sociological Review, 218-235.

Ridgeway, C. L., \& Correll, S. J. (2004). Unpacking the Gender System: A Theoretical Perspective on Gender Beliefs and Social Relations. Gender $\mathcal{E}$ Society, 18(4), 510-531. https://doi.org/10.1177/0891243204265269

Robbins, P. (2000). The rotten institution: corruption in natural resource management. Political Geography, 19(4), 423-443. https://doi.org/10.1016/S0962-6298(99)00087-6

Rodrik, D. (2004). Introduction: what do we learn from Country Narratives. In D. Rodrik (Ed.), In Search of Prosperity: analytical narratives on economic growth (pp. 1-23). 
Rose-Ackerman, S. (1996). The Political Economy of Corruption: Causes and Consequences (Viewpoint Note No. 74). Washington D.C.: The World Bank.

Rose-Ackerman, S., \& Palifka, B. J. (2016). Corruption and Government: Causes, Consequences, and Reform. Cambridge University Press.

Rothstein, B. (2011). The Quality of Government: Corruption, Social Trust, and Inequality in International Perspective. University of Chicago Press.

Rothstein, B. (2016). Corruption, Gender Equality and Feminist Strategies (QoG Working Paper Series No. 2016:09) (p. 31). Gothenburg: Quality of Government Institute, Department of Political Science, University of Gothenburg.

Rothstein, B., \& Teorell, J. (2008). What Is Quality of Government? A Theory of Impartial Government Institutions. Governance, 21(2), 165-190. https://doi.org/10.1111/j.1468-0491.2008.00391.x

Rule, W. (1994). Women's Underrepresentation and Electoral Systems. Political Science and Politics, 27(04), 689-692. https://doi.org/10.2307/420369

Ruyssen, I., \& Salomone, S. (2018). Female migration: A way out of discrimination? Journal of Development Economics, 130(Supplement C), 224-241. https://doi.org/10.1016/j.jdeveco.2017.10.010

Sabedashvili, T. (2007). Gender and Democratization: The Case of Georgia 1991-2006. Tbilisi: Heinrich Böll Foundation. Retrieved from https://ge.boell.org/sites/default/files/gender_and_democratisation_eng.pd $\mathrm{f}$

Sakall, N. (2001). Beliefs About Wife Beating Among Turkish College Students: The Effects of Patriarchy, Sexism, and Sex Differences. Sex Roles, 44(9-10), 599610. https://doi.org/10.1023/A:1012295109711

Saldaña, J. (2016). The coding manual for qualitative researchers (3rd edition). Los Angeles, California ; SAGE,

Sampford, C. (Ed.). (2006). Measuring corruption. Aldershot, Hampshire: Ashgate.

Samuels, G., \& Ross-Sheriff, F. (2008). Identity, Oppression, and Power: Feminisms and Intersectionality Theory (Vol. 23). https://doi.org/10.1177/0886109907310475

Sartori, L., Tuorto, D., \& Ghigi, R. (2017). The Social Roots of the Gender Gap in Political Participation: The Role of Situational and Cultural Constraints in Italy. Social Politics: International Studies in Gender, State E Society, 24(3), 221-247. https://doi.org/10.1093/sp/jxx008 
Savage, K., Delesgues, L., Martin, E., \& Ulfat, G. P. (2007). Corruption perceptions and risks in humanitarian assistance: an Afghanistan case study. London, HDP-ODI, 4, 12-13.

Savedoff, W., \& Hussmann, K. (2006). Why are health systems prone to corruption? In Transparency International, Global Corruption Report 2006: (pp. 4-13). London: Pluto Press.

Sawer, M. (2000). Parliamentary Representation of Women: From Discourses of Justice to Strategies of Accountability. International Political Science Review / Revue Internationale de Science Politique, 21(4), 361-380.

Scalia, E. (1997). The Strange Career of Quid Pro Quo Sexual Harassment. Harvard Journal of Law \& Public Policy, 21, 307-326.

Schneider, F. (2005). Shadow economies around the world: what do we really know? European Journal of Political Economy, 21(3), 598-642. https://doi.org/10.1016/j.ejpoleco.2004.10.002

Schneider, F., \& Enste, D. H. (2013). The Shadow Economy: An International Survey. Cambridge University Press.

Schueth, S. (2011). Assembling International Competitiveness: The Republic of Georgia, USAID, and the Doing Business Project. Economic Geography, 87(1), 51-77. https://doi.org/10.1111/j.1944-8287.2010.01103.x

Schwindt-Bayer, L. A., \& Mishler, W. (2005). An Integrated Model of Women's Representation. Journal of Politics, 67(2), 407-428. https://doi.org/10.1111/j.1468-2508.2005.00323.x

Seawright, J., \& Gerring, J. (2008). Case Selection Techniques in Case Study Research A Menu of Qualitative and Quantitative Options. Political Research Quarterly, 61(2), 294-308. https://doi.org/10.1177/1065912907313077

Seguino, S. (2000). Gender Inequality and Economic Growth: A Cross-Country Analysis. World Development, 28(7), 1211-1230. https://doi.org/10.1016/S0305-750X(00)00018-8

Seguino, S., \& Were, M. (2014). Gendered perspectives on economic growth and development in sub-Saharan Africa (WIDER Working Paper No. 2014/056). Helsinki: UNU WIDER.

Seligson, M. A. (2006). The Measurement and Impact of Corruption Victimization: Survey Evidence from Latin America. World Development, 34(2), 381-404. https://doi.org/10.1016/j.worlddev.2005.03.012 
Sen, A. (2001). Development as freedom. Oxford University Press.

Seppänen, M., \& Virtanen, P. (2008). Corruption, Poverty and Gender: With Case Studies of Nicaragua and Tanzania. Ministry for Foreign Affairs of Finland. Retrieved from http://formin.finland.fi/public/download.aspx?ID=30208\&GUID=\%7B40D A532C-C63F-4A78-A82C-57047A3DCBD0\%7D

Sequeira, S. (2012). Advances in Measuring Corruption. In D. Serra \& L. Wantchekon (Eds.), New advances in experimental research on corruption (pp. 145-175). Bingley, U.K.: Emerald. Retrieved from http://www.emeraldinsight.com/0193-2306/15

Sewpaul, V. (2008). Transforming Gendered Relationships: Rural Women in Africa. Agenda: Empowering Women for Gender Equity, (78), 43-54.

Shelley, L. (2004). The Unholy Trinity: Transnational Crime, Corruption, and Terrorism Illuminating the Shadow Economy. Brown Journal of World Affairs, 11, 101-112.

Shelley, L. (2012). The Relationship of Drug and Human Trafficking: A Global Perspective. European Journal on Criminal Policy and Research, 18(3), 241-253. https://doi.org/10.1007/s10610-012-9175-1

Shleifer, A., \& Vishny, R. W. (1993). Corruption. The Quarterly Journal of Economics, 108(3), 599-617.

Sichinava, D. (2015). Cleavage Theory and the Electoral Geographies of Georgia. In G. Nodia \& C. H. Stefes (Eds.), Security, Democracy and Development (pp. 27-44). Bern: Peter Lang. Retrieved from https://www.peterlang.com/view/9783035199314/chap1.html

Sichinava, D. (2018). Cleavages, electoral geography, and the territorialization of political parties in the Republic of Georgia. Eurasian Geography and Economics, 1-21. https://doi.org/10.1080/15387216.2018.1442734

Siroky, D. S., \& Aprasidze, D. (2011). Guns, roses and democratization: Huntington's secret admirer in the Caucasus. Democratization, 18(6), 12271245. https://doi.org/10.1080/13510347.2011.579514

Sivakumaran, S. (2007). Sexual Violence Against Men in Armed Conflict. European Journal of International Law, 18(2), 253-276. https://doi.org/10.1093/ejil/chm013

Sivakumaran, S. (2010). Lost in translation: UN responses to sexual violence against men and boys in situations of armed conflict. International Review of the Red Cross, 92(877), 259-277. https://doi.org/10.1017/S1816383110000020 
Sjoberg, L., \& Gentry, C. E. (2011). Women, Gender, and Terrorism. University of Georgia Press.

Small Arms Survey. (2010). Small Arms Survey 2010: Gangs, Groups, and Guns. Geneva.

Smith, J., Obidzinski, K., Subarudi, S., \& Suramenggala, I. (2003). Illegal logging, collusive corruption and fragmented governments in Kalimantan, Indonesia. International Forestry Review, 5(3), 293-302. https://doi.org/10.1505/IFOR.5.3.293.19138

Snyder, R., \& Duran-Martinez, A. (2009). Does illegality breed violence? Drug trafficking and state-sponsored protection rackets. Crime, Law and Social Change, 52(3), 253-273. https://doi.org/10.1007/s10611-009-9195-z

Son Hing, L. S., Bobocel, D. R., Zanna, M. P., Garcia, D. M., Gee, S. S., \& Orazietti, K. (2011). The merit of meritocracy. Journal of Personality and Social Psychology, 101(3), 433-450. https://doi.org/10.1037/a0024618

Spector, B. I. (2012). Negotiating Anti-Corruption Reforms in Post-Conflict Societies: The Case of Afghanistan. The Brown Journal of World Affairs, 18(2), $45-56$.

Steenbergen, M. R., \& Jones, B. S. (2002). Modeling Multilevel Data Structures. American Journal of Political Science, 46(1), 218-237. https://doi.org/10.2307/3088424

Stephenson, M. (2014, February 13). On Differing Understandings of "Corruption." Retrieved November 20, 2014, from http://globalanticorruptionblog.com/2014/02/13/on-differingunderstandings-of-corruption/

Stewart, F. (2009). Horizontal Inequality: Two Types of Trap. Journal of Human Development and Capabilities, 10(3), 315-340. https://doi.org/10.1080/19452820903041824

Stivers, C. (1993). Gender Images in Public Administration: Legitimacy and the Administrative State. SAGE Publications.

Stoebenau, K., Heise, L., Wamoyi, J., \& Bobrova, N. (2016). Revisiting the understanding of "transactional sex" in sub-Saharan Africa: A review and synthesis of the literature. Social Science $\mathcal{E}$ Medicine, 168(Supplement C), 186-197. https://doi.org/10.1016/j.socscimed.2016.09.023

Stohl, R. J. (2005). Fighting the Illicit Trafficking of Small Arms. SAIS Review of International Affairs, 25(1), 59-68. https://doi.org/10.1353/sais.2005.0018 
Stokes, S. C. (2007). Political clientelism. In C. Boix \& S. C. Stokes (Eds.), The Oxford handbook of comparative politics (pp. 604-627). Oxford: Oxford University Press.

Sumbadze, N. (2003). Civic Participation in Public and Political Life. In International Institute for Democracy and Electoral Assistance (IDEA) (Ed.), Building Democracy in Georgia: Developing a Democratic Community in Georgia (pp. 29-35). Stockholm. Retrieved from http://georgica.tsu.edu.ge/files/01-Politics/Democratization/IDEA$2003 \% 20(7) \cdot p d f$

Sumbadze, N. (2017). Gender Equality Still a Disputed Value in Georgian Society. In M. Barkaia \& A. Waterston (Eds.), Gender in Georgia: Feminist Perspectives on Culture, Nation, and History in the South Caucasus (1 edition, pp. 172-180). New York, NY Oxford: Berghahn Books.

Sumbadze, N., \& Tarkhan-Mouravi, G. (2012). Transition to adulthood in Georgia: Dynamics of generational and gender roles in post-totalitarian society. Tbilisi: Institute of Policy Studies.

Sung, H.-E. (2003). Fairer Sex or Fairer System? Gender and Corruption Revisited. Social Forces, 82(2), 703-723.

Sung, H.-E. (2006). From Victims to Saviours? Women, Power and Corruption. Current History: A Journal of Contemporary World Affairs, 105, 139-143.

Svensson, J. (2003). Who Must Pay Bribes and How Much? Evidence from a Cross Section of Firms. The Quarterly Journal of Economics, 118(1), 207-230.

Svensson, J. (2005). Eight Questions about Corruption. The Journal of Economic Perspectives, 19(3), 19-42. https://doi.org/10.1257/089533005774357860

Swaine, A. (2015). Beyond Strategic Rape and between the Public and Private: Violence against Women in Armed Conflict. Human Rights Quarterly, 37, 755.

Swamy, A., Knack, S., Lee, Y., \& Azfar, O. (2001). Gender and corruption. Journal of Development Economics, 64(1), 25-55. https://doi.org/10.1016/S03043878(00)00123-1

Swers, M., \& Larson, C. (2005). Women in Congress: Do They Act as Advocates for Women's Issues? In S. Thomas \& C. Wilcox (Eds.), Women and Elective office: Past, Present, and Future (pp. 110-128). New York: Oxford University Press. 
Tacoli, C., \& Mabala, R. (2010). Exploring mobility and migration in the context of rural-urban linkages: why gender and generation matter. Environment and Urbanization, 22(2), 389-395. https://doi.org/10.1177/0956247810379935

Tajfel, H. (1969). Cognitive aspects of prejudice. Journal of Biosocial Science, 1(S1), 173-191. https://doi.org/10.1017/S0021932000023336

Tanzi, V., \& Davoodi, H. (1998). Corruption, Public Investment, and Growth. In H. Shibata \& T. Ihori (Eds.), The Welfare State, Public Investment, and Growth: Selected Papers from the 53rd Congress of the International Institute of Public Finance (pp. 41-60). Tokyo: Springer Japan. https://doi.org/10.1007/978-4431-67939-4_4

Tanzi, V., \& Davoodi, H. R. (2000). Corruption, Growth, and Public Finances (IMF Working Paper No. ID 880260). Washington D.C.: International Monetary Fund. Retrieved from https://papers.ssrn.com/abstract $=880260$

Tarrant, A. (2014). Negotiating Multiple Positionalities in the Interview Setting: Researching Across Gender and Generational Boundaries. The Professional Geographer, 66(3), 493-500. https://doi.org/10.1080/00330124.2013.805621

Tatum, J. D. (2009). Democratic Transition in Georgia: Post-Rose Revolution Internal Pressures on Leadership. Caucasian Review of International Affairs, 3(2), 156-171.

Tavris, C., \& Wade, C. (1984). The longest war: Sex differences in perspective. Harcourt.

Taylor, M. J., Moran-Taylor, M. J., \& Ruiz, D. R. (2006). Land, ethnic, and gender change: Transnational migration and its effects on Guatemalan lives and landscapes. Geoforum, 37(1), 41-61.

Terminski, B. (2012). Development-induced displacement and human security: a very short introduction.

Tessler, M., \& Warriner, I. (1997). Gender, Feminism, and Attitudes toward International Conflict: Exploring Relationships with Survey Data from the Middle East. World Politics, 49(2), 250-281.

The World Bank. (2012). Fighting Corruption in Public Services: chronicling Georgia's Reforms (public sector governance). Washington D.C.: World Bank. Retrieved from http://documents.worldbank.org/curated/en/518301468256183463/pdf/6644 90PUB0EPI0065774B09780821394755.pdf

Thomas, S. (2005). Introduction. In S. Thomas \& C. Wilcox (Eds.), Women and Elective Office: Past, Present, and Future (2nd ed., pp. 3-25). Oxford University Press. 
Bibliography

Thomson, J. (2018). Resisting gendered change: Feminist institutionalism and critical actors. International Political Science Review, 39(2), 178-191. https://doi.org/10.1177/0192512116677844

Thomson Reuters Foundation, International Association of Women Judges, \& Marval, O'Farrell, Mairal. (2015). Combating Sextortion: A Comparative Study of Laws to Prosecute Corruption Involving Sexual Exploitation. Thomson Reuters Foundation. Retrieved from http://www.trust.org/publications/i/?id=588013e6-2f99-4d54-8dd89a65ae2e0802

Thornton, L., \& Turmanidze, K. (2014). Results of October 2014 Public Opinion Poll on Women's Political Participation in Georgia (p. 64). Tbilisi, Georgia: National Democratic Institute (NDI). Retrieved from https://www.ndi.org/node/24026

Thornton, L., \& Turmanidze, K. (2016). Public attitudes in Georgia: results of a November 2016 survey (p. 64). Tbilisi: National Democratic Institute (NDI). Retrieved from https://www.ndi.org/sites/default/files/NDI_November\%202016\%20poll_Is sues_ENG_vf.pdf

Thornton, L., \& Turmanidze, K. (2017). Public attitudes in Georgia - Results of December 2017 survey (p. 58). National Democratic Institute (NDI). Retrieved from https://www.ndi.org/sites/default/files/NDI\%20poll_December_2017_POLI TICAL_ENG_final.pdf

Times of Malta. (2017, November 22). EU-Libya deal on migration may be breaching Geneva Convention - Kofi Annan. Retrieved February 15, 2018, from https://www.timesofmalta.com/articles/view/20171122/world/eulibya-deal-on-migration-may-be-breaching-geneva-convention-kofi.663768

Timofeyev, Y. (2012). The Effects of the Informal Sector on Income of the Poor in Russia. Social Indicators Research, 111(3), 855-866. https://doi.org/10.1007/s11205-012-0037-5

Transparency International. (2011). Corruption in the Land Sector (Working Paper No. 04/2011). Berlin: Transparency International.

Transparency International. (2014). Corruption Perception Index 2014. Retrieved June 11, 2018, from https://www.transparency.org/cpi2014/infographic

Transparency International. (2016a). The Humanitarian Imperative: How Curbing Corruption Can Save Lives (Policy Brief No. 01/2016). Berlin: Transparency International. 
Transparency International. (2016b, July 3). Sextortion: undermining gender equality [Transparency International News Feature]. Retrieved October 10, 2016, from http://www.transparency.org/news/feature/sextortion_undermining_gend er_equality

Transparency International. (2017, January 25). Corruption Perceptions Index 2016. Retrieved June 11, 2018, from https://www.transparency.org/news/feature/corruption_perceptions_index _2016

Transparency International. (2018, February 21). Corruption Perceptions Index 2017. Retrieved June 11, 2018, from https://www.transparency.org/news/feature/corruption_perceptions_index _2017

Transparency International. (n.d.). Transparency International - What is Corruption? Retrieved June 11, 2018, from https://www.transparency.org/what-is-corruption

Treisman, D. (2000). The Causes of Corruption: A Cross-National Study. Journal of Public Economics, 76, 399-457.

Truex, R. (2011). Corruption, Attitudes, and Education: Survey Evidence from Nepal. World Development, 39(7), 1133-1142. https://doi.org/10.1016/j.worlddev.2010.11.003

Turner, J. (2016). Root Causes, Transnational Mobility and Formations of Patriarchy in the Sex Trafficking of Women. In M. Malloch \& P. Rigby (Eds.), Human Trafficking: The Complexities of Exploitation (pp. 194-209). Edinburgh: Edinburgh University Press. Retrieved from http://login.ezproxy.ub.unimaas.nl/login?url=http://search.ebscohost.com/l ogin.aspx?direct=true\&db=nlebk\&AN=1140054\&site=ehost-live\&scope=site

Ugur, M. (2011). Evidence on the economic growth impacts of corruption in lowincome countries and beyond: a systematic review.

Ugur, M. (2014). Corruption's Direct Effects on Per-Capita Income Growth: A Meta-Analysis. Journal of Economic Surveys, 28(3), 472-490. https://doi.org/10.1111/joes.12035

Ugur, M., \& Dasgupta, N. (2011). Evidence on the economic growth impacts of corruption in low-income countries and beyond. London: EPPI-Centre, Social Science Research Unit, Institute of Education, University of London, 2. 
UN DESA. (2017). International Migration Report 2017: Highlights (No. ST/ESA/SER.A/404). United Nations, Department of Economic and Social Affairs, Population Division. Retrieved from http://www.un.org/en/development/desa/population/migration/publicatio ns/migrationreport/docs/MigrationReport2017_Highlights.pdf

UN WOMEN Training Center. (2017, May). Gender Equality Glossary. Retrieved May 5, 2017, from https://trainingcentre.unwomen.org/mod/glossary/view.php?id=36\&mode =letter\&hook=G\&sortkey=\&sortorder=asc

UNDP. (1994). New Dimensions of Human Security (Human Development Report No. 1994). New York: UNited Nations Development Programme (UNDP).

UNDP. (2012). Seeing Beyond the State: Grassroots Women's Perspectives on Corruption and Anti-Corruption. Retrieved from http://www.anticorruption.org/images/themes/Grassroots\%20women\%20and\%20anticorruption.pdf

UNDP. (2016). Human Development Report 2016. New York: United Nations Development Programme (UNDP). Retrieved from http://hdr.undp.org/sites/default/files/2016_human_development_report.p df

UNDP Georgia. (2018). Gender Equality in Georgia: Barriers and Recommendations Volume 2. Tbilisi: UNDP Georgia. Retrieved from http://www.ge.undp.org/content/dam/georgia/docs/publications/DG/UND P_GE_DG_Gender_Equality_in_Georgia_VOL2_ENG.pdf

UNHCR, \& Save the Children. (2002). Sexual violence and exploitation- The experience of refugee children in Guinea, Liberia and Sierra Leone (Programme/project review). Save the Children. Retrieved from https://www.alnap.org/system/files/content/resource/files/main/825.pdf

United Nations. (2015). The World's Women 2015: Trends and Statistics. New York: United Nations, Department of Economic and Social Affairs, Statistics Division.

United Nations Development Program (UNDP). (1994). Human Development Report 1994: New Dimensions of Human Security (Technical report). New York: UNDP.

United Nations Refugee Agency, United Nations Population Fund, \& Women's Refugee Commission. (2016). Initial Assessment Report: Protection Risks for Women and Girls in the European Refugee and Migrant Crisis. Geneva, New York. Retrieved from http://www.unhcr.org/569f8f419.pdf 
UNODC. (2013). Corruption and the Smuggling of Migrants (Issue Paper). Vienna: United Nations Office on Drugs and Crime.

UNODC, \& World Bank. (2007). Stolen Asset Recovery (StAR) Initiative: Challenges, Opportunities, and Action Plan. Retrieved from http://siteresources.worldbank.org/NEWS/Resources/Star-rep-full.pdf

UNSD. (2015). Poverty. In The World's Women 2015 - Trends and Statistics (pp. 179199). New York: United Nations Statistics Division. Retrieved from https://unstats.un.org/unsd/gender/downloads/WorldsWomen2015_chapte r8_t.pdf

Urchukhishvili, G. (2017). Women in the Parties: Deconstructing Myths (p. 83). Tbilisi: Union Sapari. Retrieved from http://sapari.ge/wpcontent/uploads/2017/11/Women-in-politics-UNDP-Sapari-ENG.pdf

Urra, F.-J. (2007). Assessing Corruption An analytical review of Corruption measurement and its problems: Perception, Error and Utility. Edmund A. Walsh School of Foreign Service (May), 1-20.

Uslaner, E. M. (2008). Corruption, inequality, and the rule of law: The bulging pocket makes the easy life. Cambridge University Press.

Valentine, G. (2007). Theorizing and Researching Intersectionality: A Challenge for Feminist Geography. The Professional Geographer, 59(1), 10-21. https://doi.org/10.1111/j.1467-9272.2007.00587.x

Van Duyne, P. C. (1996). Organized crime, corruption and power. Crime, Law and Social Change, 26(3), 201-238. https://doi.org/10.1007/BF00230862

van Stolk, C., \& Tesliuc, E. (2010). Toolkit on Tackling Error, Fraud and Corruption in Social Protection Programs. Social Protection Discussion Paper 1002.

Vanore, M. (2015). Family- Member Migration and the Psychosocial Health Outcomes of Children in Moldova and Georgia (Dissertation Series No.57). Maastricht Graduate School of Governance, Maastricht.

Vescio, T. K., Gervais, S. J., Snyder, M., \& Hoover, A. (2005). Power and the Creation of Patronizing Environments: The Stereotype-Based Behaviors of the Powerful and Their Effects on Female Performance in Masculine Domains. Journal of Personality and Social Psychology, 88(4), 658-672. https://doi.org/10.1037/0022-3514.88.4.658

Vijayalakshmi, V. (2008). Rent-Seeking and Gender in Local Governance. The Journal of Development Studies, 44(9), 1262-1288. https://doi.org/10.1080/00220380802265611 
Vogel, C., \& Smith, J. (2002). The politics of scarcity: conceptualising the current food security crisis in southern Africa: commentary. South African Journal of Science, $98(7 \& 8)$, 315-317.

Waite, D., \& Allen, D. (2003). Corruption and Abuse of Power in Educational Administration. The Urban Review, 35(4), 281-296. https://doi.org/10.1023/B:URRE.0000017531.73129.4f

Walby, S. (1989). Theorising Patriarchy. Sociology, 23(2), 213-234. https://doi.org/10.1177/0038038589023002004

Walby, S. (1990). Theorizing Patriarchy. Oxford, UK; Cambridge, MA, USA: John Wiley \& Sons.

Wang, F., \& Sun, X. (2016). Absolute power leads to absolute corruption? Impact of power on corruption depending on the concepts of power one holds. European Journal of Social Psychology, 46(1), 77-89. https://doi.org/10.1002/ejsp.2134

Wang, S.-Y. (2013). Marriage Networks, Nepotism, and Labor Market Outcomes in China. American Economic Journal: Applied Economics, 5(3), 91-112. https://doi.org/10.1257/app.5.3.91

Wängnerud, L. (2000). Testing the Politics of Presence: Women's Representation in the Swedish Riksdag. Scandinavian Political Studies, 23(1), 67-91. https://doi.org/10.1111/1467-9477.00031

Wängnerud, L. (2009). Women in Parliaments: Descriptive and Substantive Representation. Annual Review of Political Science, 12(1), 51-69. https://doi.org/10.1146/annurev.polisci.11.053106.123839

Wängnerud, L. (2014). Gender and Corruption. In P. M. Heywood (Ed.), Routledge Handbook of Political Corruption (pp. 288-298). Routledge.

Waterston, A. (2017). Contextualizing Gender in Georgia: Nation, Culture, Power, and Politics. In M. Barkaia \& A. Waterston (Eds.), Gender in Georgia: Feminist Perspectives on Culture, Nation, and History in the South Caucasus (1 edition, pp. 2-18). New York, NY Oxford: Berghahn Books.

Waylen, G. (2000). Gender and Democratic Politics: A Comparative Analysis of Consolidation in Argentina and Chile. Journal of Latin American Studies, 32(3), 765-793. https://doi.org/10.1017/S0022216X00005939

Waylen, G. (2003). Gender and Transitions: What do we Know? Democratization, 10(1), 157-178. https://doi.org/10.1080/714000112

Waylen, G. (2006). Constitutional Engineering: What Opportunities for the Enhancement of Gender Rights? Third World Quarterly, 27(7), 1209-1221. 
Waylen, G. (2014). Informal Institutions, Institutional Change, and Gender Equality. Political Research Quarterly, 67(1), 212-223. https://doi.org/10.1177/1065912913510360

Weissman, A., Cocker, J., Sherburne, L., Powers, M. B., Lovich, R., \& Mukaka, M. (2006). Cross-generational relationships: using a 'Continuum of Volition' in HIV prevention work among young people. Gender \& Development, 14(1), 81-94. https://doi.org/10.1080/13552070500518293

Welsch, H. (2004). Corruption, growth, and the environment: a cross-country analysis. Environment and Development Economics, 9(5), 663-693. https://doi.org/10.1017/S1355770X04001500

Wertsch, J. V. (2006). Georgia after the rose revolution. The Caucasus \& Globalization, $1(1), 54-67$.

Willitts-King, B., \& Harvey, P. (2005). Managing the risks of corruption in humanitarian relief operations. A Study for the UK Department for International Development. Overseas Development Institute: Humanitarian Policy Group. Retrieved August, 11, 2007.

Willness, C. R., Steel, P., \& Lee, K. (2007). A Meta-Analysis of the Antecedents and Consequences of Workplace Sexual Harassment. Personnel Psychology, 60(1), 127-162. https://doi.org/10.1111/j.1744-6570.2007.00067.x

Wimmer, A., Cederman, L.-E., \& Min, B. (2009). Ethnic Politics and Armed Conflict: A Configurational Analysis of a New Global Data Set. American Sociological Review, 74(2), 316-337.

World Bank. (2016). Worldwide Governance Indicators. Washington D.C.: The World Bank. Retrieved from www.govindicators.org

Yakubi, H., \& Merkle, O. (2018). The Exploitation and Abuse of Irregular Migrants in the Context of Corruption: An Intersectional Approach. Unpublished Manuscript, Maastricht.

Yuval-Davis, N. (2007). Intersectionality, Citizenship and Contemporary Politics of Belonging. Critical Review of International Social and Political Philosophy, 10(4), 561-574. https://doi.org/10.1080/13698230701660220

Zachariah, K. C., Mathew, E. T., \& Rajan, S. I. (2001). Social, Economic and Demographic Consequences of Migration on Kerala. International Migration, 39(2), 43-71. https://doi.org/10.1111/1468-2435.00149

Zhidkova, T., \& Demir, O. O. (2016). Turkey's Response to Sex Trafficking of Migrant Women: Is It Efficient Enough? International Migration, 54(6), 122 137. https://doi.org/10.1111/imig.12264 
Bibliography

Zimmermann, C., McAlpine, A., \& Kiss, L. (2016). Safer labour migration and community based prevention of exploitation: The state of the evidence for programming. London School of Hygiene \& Tropical Medicine. Retrieved from http://blogs.lshtm.ac.uk/samegroup/files/2016/02/Safer-labourmigration-and-community-based-prevention-of-exploitation-The-state-ofthe-evidence-for-programming-.pdf

Zinnbauer, D., \& Dobson, R. (Eds.). (2008). Global Corruption Report 2008: Corruption in the Water Sector. Berlin: Transparency International.

Zoellick, R. B. (2008). Fragile States: Securing Development. Survival, 50(6), 67-84. https://doi.org/10.1080/00396330802601859

Zuckerman, E., \& Greenberg, M. (2004). The gender dimensions of post-conflict reconstruction: An analytical framework for policymakers. Gender $\mathcal{E}$ Development, 12(3), 70-82. https://doi.org/10.1080/13552070412331332330 


\section{Methodological Annex}

\section{M.A. 1. Chapter 2}

Table 10 Summary Statistics Figure 1

\begin{tabular}{l|l|l|l|l|l}
\hline \hline Variable & $\mathbf{N}$ & Avg. & St.Dev. & Min. & Max. \\
\hline $\begin{array}{l}\text { Control of } \\
\text { corruption }\end{array}$ & 159 & $-0,04109872$ & 0,99414905 & $-1,71167195$ & 2,29126644 \\
\hline $\begin{array}{l}\text { Gender } \\
\text { Inequality }\end{array}$ & 159 & 0,3596286 & 0,1889783 & 0,04025142 & 0,76748947 \\
\hline \hline
\end{tabular}

Source: Gender Inequality Index (GII) 2015 (UNDP, 2016); Control of Corruption 2015 (World Bank, 2016)

\section{M.A. 2. Chapter 3 and 6}

The data for these chapters has in large parts been collected within the project "A gender perspective on corruption encountered during forced and irregular migration" commissioned by the Deutsche Gesellschaft für Internationale Zusammenarbeit (GIZ) GmbH. Data collection took place between April and May 2017. Chapter 3 in addition draws on interviews conducted in Melilla and Ceuta in July 2017. Data was collected by the author of this dissertation and Julia Reinold, both researchers at Maastricht University and 3 student assistants, Clara Alberola, Vittorio Bruni and Harres Yakubi.

The research has been examined and approved by Maastricht University's Ethical Review Committee Inner City Faculties (ERCIC) approval 7 June 2017 reference number: ERCIC_035_05_04_2017.

Background of the project:

Research shows that female migrants in general and female refugees and irregular migrants in particular are especially vulnerable in many stages of the migration process (Gosh, 2009). This research hypothesizes that women are also more likely to be (in)directly victimized through corruption during the migration process. Therefore, this study aims at adding a gender-perspective on different forms of corruption encountered during the migration process, including special forms of corruption such as sexual extortion ('sextortion'). 
This project had three specific objectives:

1. To conduct scientific research on forms and effects of corruption that directly and indirectly affect female migrants as well as current measures to counter them.

2. To carry out interviews with key stakeholders and female migrants to elaborate on the previous findings.

3. To develop recommendations on how the German Development Cooperation can integrate gender aspects into its sectoral anticorruption approaches.

\section{Research Questions:}

To achieve these objectives, the project aims at answering four main research questions, using five country case studies.

1. What are the forms and effects of corruption that women experience during migration, including irregular and involuntary migration?

2. What are the forms and effects of corruption that women experience upon arrival at identified (intermediate/final) destinations?

3. To what extent can sexual extortion experienced by women be seen as a form of corruption? How do these findings contribute to the definition of sextortion as a form of corruption?

4. What measures can the German Development Cooperation take to address the problem of corruption during (ir)regular migration of women?

\section{M.A. 2.1. Methodological Choice}

The study is explorative, investigating for the first time in a comprehensive manner how women are affected by corruption throughout their migration journey. The study focuses on five destination countries as case studies (Germany, The Netherlands, Italy, Spain and the United Kingdom) to cover a broad range of experiences, both from experts and female migrants themselves.

This study followed a qualitative research approach. It is based on a systematic literature, desk research and semi-structured interviews with stakeholders and female migrants to supplement the existing knowledge. An overview of the interviews that were conducted is available in Appendix D.

Interviews were conducted with three groups: experts working directly with (female) migrants, researchers and policymakers working on issues of corruption 
and migration and migrants themselves. The key experts were identified through a mapping of experts working on issues related to corruption and migration and organizations working with migrant populations. A focus was put on organizations working with irregular migrants, especially those providing medical and psychological care and those working with victims of abuse. The interview sample also included migrant organizations (of any origin country outside the European Union) and humanitarian organization. After the initial mapping over 145 organizations were contacted with interview requests. Interviewees were also asked for potential recommendations for further interviews but only very few additional potential interview partners were added to the list through this.

Interviews with experts were conducted in person or via phone/skype, depending on the interviewee's preference. All interviews with migrants were conducted in person.

\section{Ethical considerations for the interviews}

Migrants were only recruited via reputable organizations working with migrants (e.g. organizations, that are certified and are working with migrants and refugees). As these organizations work with refugees and migrants on a daily basis they are aware of the need for confidentiality and anonymity. They need to ensure the (female) migrants' and refugees' anonymity to be able to provide services especially for those whose legal status is unclear. They also are aware of the difficult experiences many of the migrants and refugees had along their journey and often directly provide counseling and medical services, or are well connected with other organizations that do. These organizations for their daily work rely on their ability to protect (female) migrants and refugees from any harm - this includes any possibility that information about the experiences, legal statuses etc. is brought to the attention of any unauthorized persons or organizations. They also rely on the (female) migrants and refugees trusting that all their information will be kept confidential. Only with this trust are they able to reach (female) migrants and refugees with their services. Therefore, we consider them reliable partners for our research, where we can rely on information being kept confidential to protect the interview participants. We also required the organizations to sign a confidentiality form. We ask them to inform the potential participants beforehand about the study and also include a consent form/confidentiality agreement for them (see attached). We also offer that a trusted person from the organization can join the interview with the migrant/refugee if the interview participant wishes to have this support. 
Interviews with migrants were only conducted in person and in an environment that is comfortable for them. Potentially, participants could fear that their experiences will be known to their family, which could lead to problems of shaming and exclusion. Therefore, it is essential that all possibly identifying information will be removed from interview transcripts and the final report (among other things, this includes information about the legal status, migration route/refugee camps/city of residence upon arrival etc.).

Participants will be asked about their experiences with corruption during the migration journey. No explicit question about sexual or physical abuse were included in the questionnaire, to prevent retraumatizing interview participants.

The research team included two male researchers, a decision which was discussed in detail with the ethics board regarding interviews with female migrants. All interviewers are trained and coached on how to deal with participants emotions (mock interviews, interview guidelines, discussions before and after interviews, provisions of literature on research on sensitive topics). Male interviewers did not conduct interviews alone with female migrants/refugees. They always had either a female translator, a female researcher or a female member of the organization present at their interviews. The organizations were informed if the researcher conducting the interviews with their participants was male and were asked to confirm with their participants that they are comfortable with this.

All research assistants were debriefed regularly on:

- How are they finding the process?

- Are they facing any difficulties?

- Is there anything that they don't understand/ require further explanation on?

- Do they face any emotional difficulties?

The debriefs were conducted weekly. When research assistants interviewed migrants, they checked in with one of the principal investigators daily.

\section{Consent:}

All experts in person or via phone were sent consent forms via email beforehand. The consent forms included all background information (also on the involvement of GIZ) and contact information for questions. For expert interviews oral consent was considered sufficient and was included in the recording. 
For migrants a different consent procedure was implemented. The participant group is especially vulnerable, not only due to their often-traumatic past experiences but also due to their often delicate political and legal position (e.g. lack of legal status, ongoing asylum proceedings etc.). Therefore, the research team needs to take extra precautions to ensure that the participation in the study does not impact personal well-being, legal status or endangers the participants in any other way. Additionally, women might be illiterate (in the language of the interview) or not familiar/uncomfortable with legal documents and consent forms. Therefore, they might also be hesitant to sign a consent form. At the same time, the group of (female) migrants and refugees falling within the scope of the research is very diverse in many factors, such as educational level, country of origin, duration of stay in destination country and legal status. Depending on the country of origin, education level and duration of stay in one of the research countries, participants might also be very familiar with consent forms and expect written information and consent. To account for these differences two different informed consents procedures will be offered. For one, a written informed consent form, which will be translated in the appropriate languages (attached). For those who cannot use a written consent form or feel uncomfortable with it an oral consent script has been prepared (attached). This is also in line with the suggestions of the European Commission's Directorate-General for Research and Innovation Guidance note on Research on refugees, asylum seekers \& migrants. ${ }^{41}$

\section{M.A. 2.2. Data Limitations}

Data collection in this exploratory study had several limitations that can affect the quality of the resulting data and its subsequent analysis.

The focus of this research was very much on migrants and refugees who had arrived in Europe, which is only a small fraction of the world's migrant population, this means that only the experience of a subgroup of migrants has been considered in this study. Yet, this is less problematic as the study is exploratory and does not claim to be representative of all experiences of migrants.

A more serious limitation is the small number and limited geographical representation. For one, many organizations were very hesitant to allow access to migrants to be interviewed for two reasons. For one, this research was conducted

\footnotetext{
${ }^{41}$ http://ec.europa.eu/research/participants/data/ref/h2020/other/hi/guide_research-refugeesmigrants_en.pdf
} 
during the height of the so-called "migration crisis" in Europe which saw a large interest by academics and journalists to interview migrants about their experiences, not all of them with good intentions. Hence, many organizations had decided to not pass on interview requests to migrants they were working with to protect them from harm. Additionally, many organizations, especially those working with survivors of abuse were very suspicious of our interest in research on corruption, especially the concept of sextortion. There was a fear that including this form of abuse in corruption research is merely an attempt to 'water down' the experiences of abuse migrants faced during their journey. In the opinion of these organizations this might be not only harmful to theoretical discussions but also could present a challenge for individual's legal chances to be allowed to stay in Europe when the abuse was presented as something that the individual had a benefit from and therefore volunteered. As researchers, we decided that having a thoughtful and detailed discussion on this issue is fundamentally important when entering this new research field, therefore we decided to focus on discussion and interviews with those that were critical to ensure the "do no harm" principle of qualitative interviews. Hence, more detailed interviews with migrants should be conducted after more research has been done with those working on (sexual) abuse to make sure the use of the concept of "sextortion" benefits those that have experienced them and does not revictimize them.

A second reason for the low number of migrant interviews is that the interview design, explicitly did not include probing questions requiring more detail on the corruption experience, especially regarding sextortion. This decision was made, as in our opinion, as this research was largely exploratory, the risk of retraumatizing interview partners was too big. Yet, considering the power imbalance of European researchers interviewing non-European migrants, with often unclear legal status, there was the risk that migrants would feel the need to discuss difficult experiences, even though they felt uncomfortable, because of fears that not answering might affect their legal status negatively [despite the discussions about consent]. After a number of interviews were conducted, the research team decided that at this stage, the interviews with migrants were adding interesting experiences to the analysis but did not necessarily add additional analytical information that could not be obtained via the experts we interviewed who could share stories they had heard over the years that were in large parts identical to the ones we heard from the migrants themselves. Therefore, the research team decided that the costs of retraumatizing interview partners largely outweighed the scientific benefit of conducting these interviews and interviews with migrants were stopped. We 
acknowledge that this means that migrants voices are omitted from the current research in large parts and urge to continue the research with migrants themselves once more nuanced discussions about the concepts have been conducted.

\section{M.A. 2.3. Data Analysis}

The interviews for this research were conducted in English, German, French, Italian and Spanish depending on the preference of the interview partner.

\section{Storage:}

Audio recordings and transcripts are stored on a UNU-MERIT server that only the research team could access. The interviews were transcribed, translated in English and the audio recordings were deleted.

\section{Anonymization:}

Stakeholders could decide to remain anonymous or not. If they decide to be quoted by name the transcripts was stored with names on the server. For those stakeholders who wished to remain anonymous and all interviewed migrants, transcripts were anonymised. No identifying information was included in the interview transcripts. The key to the anonymised interviews will be stored in a locked cupboard at the MGSoG and will be destroyed after the completion of the project. Anonymised transcripts will also be stored in a public repository to comply with the new data management guidelines adopted by UNUMERIT/MGSoG but access will be restricted. The data will be used by the research team for the length of the research process (max. 1 year). In line with VSNU standards, data will be stored for at least ten years.

The transcripts were coded by the research teams. Coding was conducted in multiple cycles as an iterative process and contained both predefined from the literature and theory and inductive, identifying themes that emerged from the data. The codes were then categorized. 
M.A. 2.4. Descriptive Statistics Chapter 3

Table 11 Summary Statistics Figure 11

\begin{tabular}{l|l|l|l|l|l}
\hline \hline Variable & $\mathbf{N}$ & Avg. & St.Dev. & Min. & Max. \\
\hline WPSI & 146 & 0,69 & 0,11 & 0,38488038 & 0,88624785 \\
\hline CPI & 146 & 43,49 & 19,50 & 9 & 89 \\
\hline \hline
\end{tabular}

Source: Corruption Perception Index, Transparency International (2017) and Women Peace and Security Index, GIWPS and PRIO (2017)

\section{M.A. 3. Chapter 4}

Data for this chapter come from the latest wave of the World Values Survey (20102014). The World Values Survey database consists of nationally representative surveys conducted in about 100 countries using a common questionnaire. This study only includes the surveys for Sub-Saharan Africa countries. Countries for which surveys are available are Ghana, Nigeria, Rwanda, South Africa and Zimbabwe. The analytical sample used for the analysis contains 9,827 observations from these countries.

Table 12 Summary Statistics Table 4

\begin{tabular}{l|l|l|l}
\hline \hline $\begin{array}{l}\text { Variable } \\
\text { Name }\end{array}$ & Survey Question & & \\
\hline \multirow{4}{*}{ Men Better } & $\begin{array}{l}\text { On the whole, men make better } \\
\text { political leaders than women do }\end{array}$ & Frequency. & Percent \\
\cline { 2 - 4 } & Don't know & 140 & 1,42 \\
\cline { 2 - 4 } & Agree strongly & 2738 & 27,74 \\
\cline { 2 - 4 } & Agree & 3185 & 32,27 \\
\cline { 2 - 4 } & Disagree & 2677 & 27,13 \\
\cline { 2 - 4 } & Strongly disagree & 1129 & 11,44 \\
\cline { 2 - 4 } & Total & $\mathbf{9 8 6 9}$ & $\mathbf{1 0 0}$ \\
\hline \multirow{4}{*}{ Gender } & Gender & Frequency. & Percent \\
\cline { 2 - 4 } & Male & 4879 & 49,44 \\
\cline { 2 - 4 } & Female & 4990 & 50,56 \\
\cline { 2 - 4 } & Total & $\mathbf{9 8 6 9}$ & $\mathbf{1 0 0}$ \\
\hline & Highest educational level attained & Frequency. & Percent \\
\hline Education & No formal education & $\mathbf{5 3 8}$ & $\mathbf{5 , 4 7}$ \\
\hline & \multicolumn{2}{|l}{} \\
\hline
\end{tabular}




\begin{tabular}{|c|c|c|c|}
\hline & Incomplete primary school & 598 & 6,08 \\
\hline & Complete primary school & 968 & 9,84 \\
\hline & $\begin{array}{l}\text { Incomplete secondary school: } \\
\text { technical/ }\end{array}$ & 1044 & 10,61 \\
\hline & $\begin{array}{l}\text { Complete secondary school: } \\
\text { technical/v }\end{array}$ & 2154 & 21,9 \\
\hline & $\begin{array}{l}\text { Incomplete secondary school: } \\
\text { university }\end{array}$ & 1236 & 12,57 \\
\hline & $\begin{array}{lll}\begin{array}{l}\text { Complete } \\
\text { university-p }\end{array} & \text { secondary } & \text { school: } \\
\end{array}$ & 2089 & 21,24 \\
\hline & $\begin{array}{l}\text { Some university-level education, } \\
\text { without degree }\end{array}$ & 598 & 6,08 \\
\hline & $\begin{array}{l}\text { University - level education, with } \\
\text { degree }\end{array}$ & 611 & 6,21 \\
\hline & Total & 9836 & 100 \\
\hline Religious & Religious person & Frequency. & Percent \\
\hline & Yes & 8837 & 89,54 \\
\hline & $\mathrm{No}^{42}$ & 1032 & 10,46 \\
\hline & Total & 9869 & 100 \\
\hline Married & Marital status & Frequency. & Percent \\
\hline & Yes & 4160 & 42,15 \\
\hline & $\mathrm{No}^{43}$ & 5709 & 57,84 \\
\hline & Total & 9869 & 100 \\
\hline
\end{tabular}

\begin{tabular}{l|l|l|l}
\hline $\begin{array}{l}\text { Chief Wage } \\
\text { Earner }\end{array}$ & $\begin{array}{l}\text { Are you the chief wage earner in } \\
\text { your house }\end{array}$ & Frequency. & Percent \\
\cline { 2 - 4 } & Yes & 3605 & 36,53 \\
\cline { 2 - 4 } & No & 6264 & 63,47 \\
\cline { 2 - 4 } & Total & $\mathbf{9 8 6 9}$ & $\mathbf{1 0 0}$ \\
\hline
\end{tabular}

\begin{tabular}{l|l|l|l}
\hline \multirow{3}{*}{ Working } & Sector of employment & Frequency. & Percent \\
\cline { 2 - 4 } & Government & 1144 & 11,59 \\
\cline { 2 - 4 } & Private Sector & 4442 & 45,01 \\
\cline { 2 - 4 } & Non-profit & 1038 & 10,52 \\
\hline
\end{tabular}

\footnotetext{
42 "No" includes those who answered 'atheist'.

43 “No" combines the answers: 'Living together'; 'Divorced'; 'Separated', 'Widowed', 'Single'.
} 


\begin{tabular}{|c|c|c|c|}
\hline & Not working & 3245 & 32,88 \\
\hline & Total & 9869 & 100 \\
\hline \multirow{5}{*}{$\begin{array}{l}\text { Employed/ } \\
\text { Unemployed }\end{array}$} & Employment status & Frequency. & Percent \\
\hline & Employed ${ }^{44}$ & 5149 & 52,26 \\
\hline & Unemployed & 2244 & 22,78 \\
\hline & Inactive & 2458 & 24,95 \\
\hline & Total & 9851 & 100 \\
\hline \multirow[t]{7}{*}{$\begin{array}{l}\text { Strong } \\
\text { Leader }\end{array}$} & $\begin{array}{l}\text { Political system: Having a strong } \\
\text { leader who does not have to bother } \\
\text { with parliament }\end{array}$ & Frequency. & Percent \\
\hline & Don't know & 242 & 2,45 \\
\hline & Very good & 1599 & 16,2 \\
\hline & Fairly good & 2170 & 21,99 \\
\hline & Bad & 2129 & 21,57 \\
\hline & Very bad & 3729 & 37,78 \\
\hline & Total & 9869 & 100 \\
\hline \multirow[t]{8}{*}{ Class } & Social class (subjective) & Frequency. & Percent \\
\hline & Don't know & 173 & 1,75 \\
\hline & Upper class & 256 & 2,59 \\
\hline & Upper middle class & 1448 & 14,67 \\
\hline & Lower middle class & 2421 & 24,53 \\
\hline & Working class & 2373 & 24,04 \\
\hline & Lower class & 3198 & 32,4 \\
\hline & Total & 9869 & 100 \\
\hline \multirow[t]{7}{*}{ Country } & Country & Frequency. & Percent \\
\hline & Ghana & 1552 & 15,73 \\
\hline & Nigeria & 1759 & 17,82 \\
\hline & Rwanda & 1527 & 15,47 \\
\hline & South Africa & 3531 & 35,78 \\
\hline & Zimbabwe & 1500 & 15,2 \\
\hline & Total & 9869 & 100 \\
\hline
\end{tabular}

44 "Employed" covers those who are full-time, part-time and self-employed. 


\begin{tabular}{l|l|l|l|l|l}
\hline Variable & $\mathbf{N}$ & Avg. & St.Dev. & Min. & Max. \\
\hline Age & 146 & 31,92 & 12,84 & 18 & 75 \\
\hline \hline
\end{tabular}

There is a clear limitation that the concept of "gender" in this data is represented as men and women, and not a more nuanced understanding. However, it is still an important finding for our understanding of the role of patriarchal structures. Most important, the finding that conservative views on the role of women are related to higher tolerance of corruption is true for both male and female respondents. This is in line with discussion on patriarchy that argue that patriarchy is upheld by both men and women in a society (Enloe, 2017).

\section{M.A. 4. Chapter 5}

This chapter is using a qualitative approach, using semi-structured interviews. As the discussion in this chapter is interested in how corruption is hindering the participation of women in Georgia, the use of semi-structured interviews was deemed the best research method. Where possible interviews were recorded and transcribed, yet due to the highly political nature of the topic and the current political climate many interview partners did not consent to recording. For these interviews the researcher took detailed notes which were then transcribed with the fieldwork notes.

Interview partners were identified in different ways. At first, I conducted a mapping of civil society organizations working on corruption, gender and transparency. As it became quickly apparent that the circle of active civil society organizations is very limited the mapping was expanded to all civil society organizations that work on political and economic issues as well as international organizations and development organizations working in Georgia with a mandate covering anti-corruption, transparency and gender as well as justice and institutional reform. Roughly 100 organizations were identified and contacted, yet, many of the local civil society organizations were inactive and only existed as a website [ which was also confirmed by other actors in the country]. Additional snowball sampling was used - all interview partners were asked to share contacts that they deemed to be important to talk to. Interviews with politicians were difficult as the vast majority did not respond to email requests. Two organizations shared cell phone numbers of parliamentarians with me, and the response rate was higher with this method of contact than with email. 
It was important to cover organizations with different political affiliations. Many civil society organizations in Georgia were founded by current or previous political elites, therefore, I checked the resumes of the heads of organizations to identify which elite they belonged to and ensure that all political sides were included. This also allowed for multiple entry points for snowball sampling covering the vast majority of the political spectrum.

M.A. 4.1. Interview respondents (extended information)

\begin{tabular}{|c|c|c|}
\hline Gender & Type of Organization & Topic Area \\
\hline $\mathrm{F}$ & Embassy & \\
\hline M & Embassy & \\
\hline $\mathrm{F}$ & Embassy & \\
\hline $\mathrm{F}$ & Embassy & \\
\hline M & Foreign Foundation & \\
\hline M & Foreign Foundation & \\
\hline $\mathrm{F}$ & Foreign Foundation & \\
\hline F & Foreign Foundation & \\
\hline $\mathrm{F}$ & Government Agency & \\
\hline $\mathrm{F}$ & Government Agency & \\
\hline $\mathrm{F}$ & Government Agency & \\
\hline $\mathrm{F}$ & Government Agency & \\
\hline $\mathrm{F}$ & Government Coalition & \\
\hline M & Government Coalition & \\
\hline M & International CSO, local office & $\begin{array}{l}\text { Corruption/Transparency/Accountability \& } \\
\text { Elections/Political Development }\end{array}$ \\
\hline F & International CSO, local office & Women Empowerment/Gender \\
\hline F & International CSO, local office & Women Empowerment/Gender \\
\hline M & International CSO, local office & Policy/Think Tank \\
\hline $\mathrm{F}$ & International CSO, local office & $\begin{array}{l}\text { Women Empowerment/Gender \& } \\
\text { Elections/Political Development }\end{array}$ \\
\hline F & Journalist & \\
\hline M & Local NGO & Policy/Think Tank \\
\hline $\mathrm{F}$ & Local NGO & Civil Society Development \\
\hline
\end{tabular}




\begin{tabular}{|c|c|c|}
\hline Gender & Type of Organization & Topic Area \\
\hline M & Local NGO & Policy/Think Tank \\
\hline $\mathrm{F}$ & Local NGO & Law Reform/Legal Advice \\
\hline $\mathrm{F}$ & Local NGO & Civil Society Development \\
\hline $\mathrm{M}$ & Local NGO & $\begin{array}{l}\text { Corruption/Transparency/Accountability \& } \\
\text { Law Reform/Legal Advice }\end{array}$ \\
\hline $\mathrm{M}$ & Local NGO & Civil Society Development \\
\hline M & Local NGO & Policy/Think Tank \\
\hline $\mathrm{M}$ & Local NGO & Policy/Think Tank \\
\hline $\mathrm{F}$ & Local NGO & Women Empowerment/Gender \\
\hline $\mathrm{F}$ & Local NGO & $\begin{array}{l}\text { Corruption/Transparency/Accountability \& } \\
\text { Women Empowerment/Gender }\end{array}$ \\
\hline $\mathrm{F}$ & Local NGO & $\begin{array}{l}\text { Corruption/Transparency/Accountability \& } \\
\text { Law Reform/Legal Advice \& Policy/Think } \\
\text { Tank }\end{array}$ \\
\hline M & Local NGO & Elections/Political Development \\
\hline $\mathrm{F}$ & Local NGO & Policy/Think Tank \\
\hline $\mathrm{F}$ & Local NGO & Elections/Political Development \\
\hline $\mathrm{M}$ & Local NGO & Youth Development \\
\hline $\mathrm{M}$ & $\begin{array}{l}\text { Local NGO \& Opposition \& } \\
\text { University }\end{array}$ & Policy/Think Tank \\
\hline $\mathrm{M}$ & Local NGO \& University & \\
\hline $\mathrm{F}$ & Opposition & \\
\hline $\mathrm{F}$ & Opposition & \\
\hline M & Opposition & \\
\hline $\mathrm{M}$ & University & \\
\hline M & University & \\
\hline M & Foreign Development Agency & \\
\hline M & Foreign Development Agency & \\
\hline $\mathrm{F}$ & Foreign Development Agency & \\
\hline $\mathrm{F}$ & Government Coalition & \\
\hline $\mathrm{F}$ & International CSO, local office & Corruption/Transparency \\
\hline
\end{tabular}




\begin{tabular}{cll}
\hline \hline Gender & \multicolumn{1}{c}{ Type of Organization } & \multicolumn{1}{c}{ Topic Area } \\
\hline $\mathrm{F}$ & Local NGO \& Opposition & Policy/Think Tank \\
$\mathrm{M}$ & Local NGO \& Opposition & Law Reform/Legal Advice \\
$\mathrm{M}$ & Local NGO \& University & Policy/Think Tank \\
\hline \hline
\end{tabular}

\section{M.A. 4.2. Data analysis and limitations}

Interviews were recorded when possible, but due to the highly politicized landscape many interview partners did not feel comfortable with recordings. In the interviews that were not recorded, detailed notes were taken. Additionally, I wrote down my observations after each interview to make sure to have as much information as possible. Therefore, only few direct quotes were included in the text. While verbatim transcripts would have been preferable, for the analysis, being faced with a choice between conducting interviews without recording or not conducting them the note taking was the preferred method. The potential interview pool in Georgia was already limited, therefore, excluding interview partners who do not want to be recorded would have limited the sample too much to still be representative of society as a whole.

All interviews were conducted by me and were in English. For the first 4 interviews a translator was present, but once I become aware of her political affiliation and the political tensions within the civil society field, I conducted all interviews alone. One interview partner brought a trusted colleague to translate during the interview. All interviews and notes were transcribed and coded.

The language limitations were a problem with some of the interviews but outweighed the cost of having an interview partner who is hesitant to speak because of the potential political affiliations of the translator.

The number of current politicians interviewed for this dissertation was smaller than I would have hoped for. Reaching out to Parliamentarians was difficult as most did not respond to emails. Additionally, high tensions in the political elites and a general mistrust of research conducted by "outsiders" was observable. However, there is a revolving door between civil society and political office. Many of the civil society members I interviewed have held political office or have joined political office since the interviews were conducted. Therefore, the interviews conducted are still representative of the current atmosphere in the country. 
One major limitation of this data is that it was not collected with the focus of exploring stereotypes and narratives. While the research question guiding the research was focused on the relationship of gender and corruption in Georgia, the theme of stereotypes only emerged in the analysis. It is recommended to include more specific questions in future research to achieve an even more nuanced analysis. 

Appendices

A. Overview over human security dimensions

Table 13 The seven components of human security and its threats as defined by UNDP

\begin{tabular}{|c|c|c|}
\hline \multirow[t]{2}{*}{ Component } & \multirow[t]{2}{*}{ Definition } & \multirow{2}{*}{ Security Dimensions } \\
\hline & & \\
\hline $\begin{array}{l}\text { Economic } \\
\text { Security }\end{array}$ & $\begin{array}{l}\text { "Economic security requires an } \\
\text { assured basic income-usually from } \\
\text { productive and remunerative } \\
\text { work, or in the last resort from } \\
\text { some publicly financed safety net" } \\
\text { (United Nations Development } \\
\text { Program (UNDP), 1994, p. 25). }\end{array}$ & $\begin{array}{l}\text { Unemployment, poverty, } \\
\text { wage inequality, lack of } \\
\text { social security, limited } \\
\text { access to education, poor } \\
\text { educational institutions }\end{array}$ \\
\hline Food Security & $\begin{array}{l}\text { "Food security means that all } \\
\text { people at all times have both } \\
\text { physical and economic access to } \\
\text { basic food" (UNDP, 1994, p.27). }\end{array}$ & $\begin{array}{l}\text { No access to food and } \\
\text { water, poverty, poor } \\
\text { distribution of food }\end{array}$ \\
\hline $\begin{array}{l}\text { Health } \\
\text { Security }\end{array}$ & $\begin{array}{l}\text { "Health security is defined as the } \\
\text { activities required, both proactive } \\
\text { and reactive, to minimize } \\
\text { vulnerability to acute public } \\
\text { health events that endanger the } \\
\text { collective [and individual] health } \\
\text { of populations" (WHO, 2007, } \\
\text { p.IX). }\end{array}$ & $\begin{array}{l}\text { No access to health care } \\
\text { and doctors, diseases, } \\
\text { epidemics and } \\
\text { pandemics, HIV/Aids }\end{array}$ \\
\hline $\begin{array}{l}\text { Environment } \\
\text { Security }\end{array}$ & $\begin{array}{l}\text { Environment security implies that } \\
\text { "human beings live in a healthy } \\
\text { physical environment" (UNDP, } \\
\text { 1994, p.28). }\end{array}$ & $\begin{array}{l}\text { Environmental } \\
\text { degradation, floods, } \\
\text { droughts, hurricanes, } \\
\text { man-made disasters } \\
\text { (pollution, radiology) }\end{array}$ \\
\hline $\begin{array}{l}\text { Personal } \\
\text { Security }\end{array}$ & $\begin{array}{l}\text { Personal security implies that } \\
\text { human beings are secure from } \\
\text { violence (UNDP, 1994). }\end{array}$ & $\begin{array}{l}\text { Physical torture, war, } \\
\text { ethnic tension, crime, } \\
\text { street violence, rape, } \\
\text { domestic violence, child } \\
\text { abuse, threats to self (e.g. } \\
\text { suicide and drugs) }\end{array}$ \\
\hline
\end{tabular}




\begin{tabular}{|c|c|c|}
\hline $\begin{array}{l}\text { Community } \\
\text { Security }\end{array}$ & $\begin{array}{l}\text { Security of communities, } \\
\text { including families, racial and } \\
\text { ethnic groups, includes that } \\
\text { communities are free to live up to } \\
\text { their respective customs and } \\
\text { traditions. This also implies that } \\
\text { their values, customs and } \\
\text { traditions are passed on to } \\
\text { younger generations preventing } \\
\text { that they become extinct (UNDP, } \\
\text { 1994). }\end{array}$ & $\begin{array}{l}\text { Discrimination, } \\
\text { oppression, ethnic } \\
\text { rivalry/conflict, } \\
\text { modernization, } \\
\text { assimilation, } \\
\text { globalization. }\end{array}$ \\
\hline $\begin{array}{l}\text { Political } \\
\text { Security }\end{array}$ & $\begin{array}{l}\text { "People should be able to live in a } \\
\text { society that honours their basic } \\
\text { human rights" (UNDP, 1994, } \\
\text { p.32). }\end{array}$ & $\begin{array}{l}\text { Political repression, } \\
\text { human rights abuses, } \\
\text { limited civic freedoms }\end{array}$ \\
\hline
\end{tabular}

Source: UNDP (1994). 


\section{B. Corruption and economic growth}

Figure 14 Corruption and economic growth

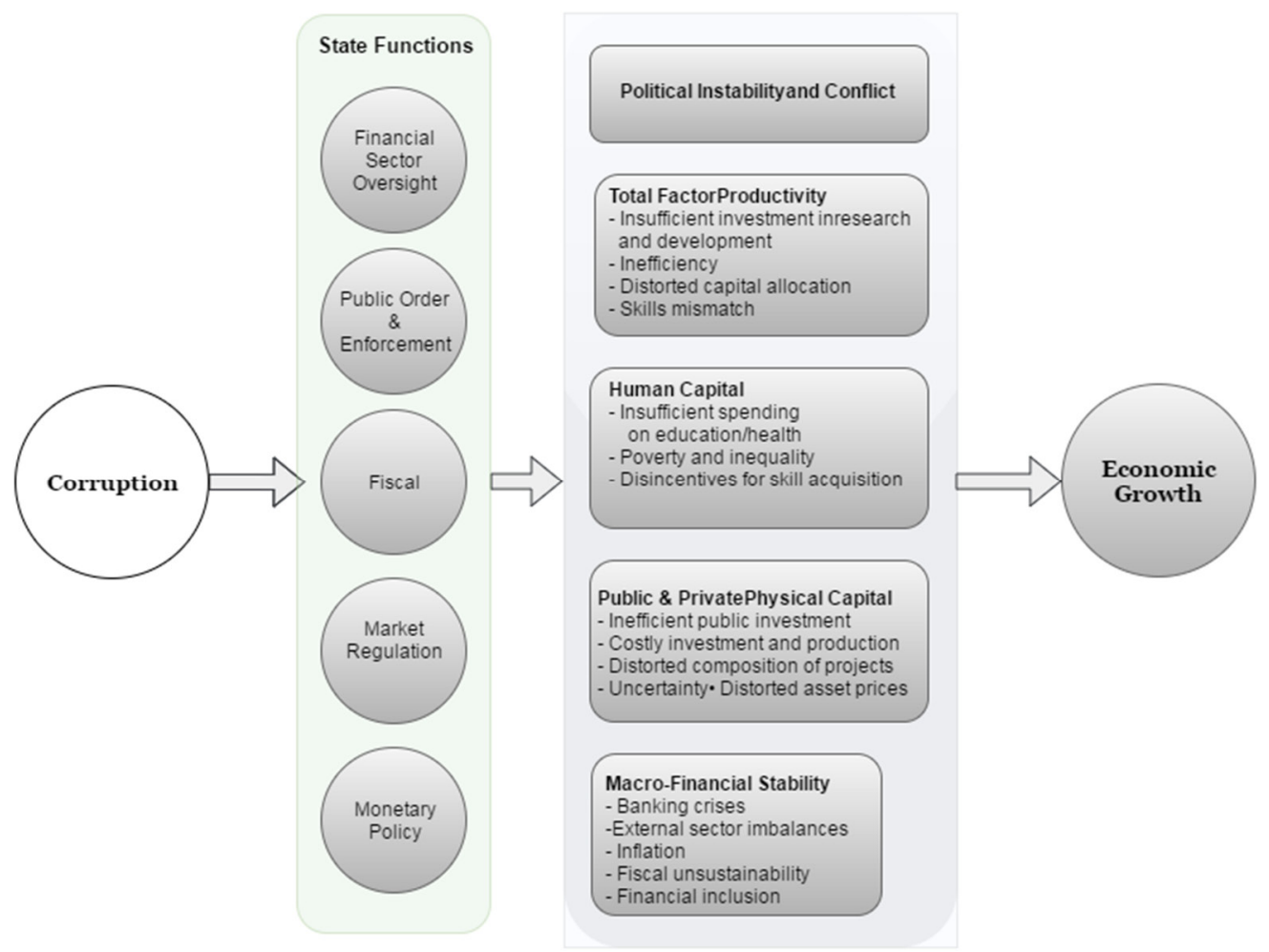

Source: Gupta and Ogada (2016, p. 6). 


\section{Appendices}

\section{Interview guide Georgia}

\section{To Check Before the Start of the Actual interview:}

The data you will disclose in this interview will be used solely for the purpose of this research project. I will ensure the confidentiality of the information given. If, in a later stage, you would like to learn more about the research, have any other additional questions or would like to review the results before submission/publication, you can always contact.

$\checkmark$ Do you agree that I tape this interview? If not, do you agree that I take notes during the interview?

$\checkmark$ Would you like to remain anonymous? (Completely anonymous/mentioned in list of interviewees/ direct citations are ok)

$\checkmark$ Do you have any more questions before we start the interview?

Note: The interview guide was adapted depending on the interview partner. Not all questions were asked to all participants, but depending on their expertise (e.g. civil society activists were not asked about party rules etc.).

\section{Corruption}

1. In your opinion? What is the state of corruption in the country at the moment?

a. low level

b. high level

c. Has it changed in the last years? (with the change of the government?)

d. What sectors do you think still have a problem with corruptions? (judicial, police, health, education...)

2. How do you assess the state of institutions in Georgia overall? Which ones are strong/weak?

3. How do you assess informal institutions?

a. Do they still play a big role?

b. Where?

4. Which anti-corruption reforms were the most successful?

a. How and why were the reforms successful?

5. Is the situation in the regions very different from the capital in terms of corruption?

6. How important is it to know the right people to get a job or other things? 


\section{Political System:}

7. If you look at the current situation in Georgia, how inclusive is the current political system in Georgia?

a. Is there a difference to previous years?

b. What are the dividing lines

8. How do you see the political parties in Georgia?

a. What ideas are the parties based on?

b. Do parties in your opinion have ideologies or are they based on individuals?

c. In your opinion. How do people get appointment into office?

\section{Elites:}

9. In your opinion: who are the elites in Georgia?

a. Are they different from previous elites?

b. How do people become part of this elite?

10. Are political leaders and civil society leaders part of the same elite?

a. What are the similarities/differences between them?

11. Do you think international organizations or the international community plays a role in forming those elites?

\section{Civil Society:}

12. Who do you consider part of civil society in Georgia?

a. Which type of organizations?

b. What is the role of unions, faith-based organizations etc.?

c. Are there dominant organizations?

13. What are the biggest strength and weaknesses of civil society in Georgia?

a. How is the relationship with the population?

b. Funding?

14. What is the relationship of CS and the current government?

a. How is it different from previous governments?

15. Can civil society actively influence policy processes?

a. Do all CS have the same access to policymakers?

b. Who can play a role?

16. What role does the international community play in shaping civil society? 


\section{Political Participation of Women:}

17. What is the current situation like for women in Georgia?

a. Do you feel there is equality? If not, what is the biggest obstacle?

b. Is there a difference between rural and urban women?

c. In your opinion should women have more equal opportunities?

18. What do you think about the political participation of women in Georgia?

a. Should the participation be higher? Why (not)?

b. What effects would you expect if more women were active?

c. Is it an important issue?

19. What are the biggest obstacles for women to run for office?

20. Do you think a quote would make a difference?

21. In civil society women are very active? Why are politics different?

22. What do you think about the women who are currently active? Why are they in a political office?

23. For women who are not in politics: Have you thought about running for political office? Why (not)?

a. Would you encourage your sister/daughter/female friend to run for office?

24. For men: Have you ever encouraged a female member of your family to run for office? Why (not)?

a. What would you say if your wife/daughter/ sister would run for office?

\section{$\underline{\text { For Politicians/Party Members }}$}

1. Can you tell me something about yourself and your political career?

a. How did you become politically active?

b. Why did you decide to become politically active?

c. What did you do before you joined Party [...]

2. Can you tell me something about your party?

a. What are the main ideas?

b. What makes it different from other parties?

c. Why did you decide to join this party?

d. Were you ever a member of another party?

3. In your party, how can you become a candidate for parliament or other offices?

a. What are the formal rules?

b. Are there any unwritten rules? 
4. In your party - do you have a lot of active women?

a. At what level are they active?

b. What do they do?

c. Do you know women who ran for office?

5. Do you think there should be more/less women in politics in general and in your party in particular?

6. Is there a difference between how men and women become candidates?

a. Are the conditions the same for men and women?

7. Do you support a gender quota? Why(not)?

a. What effect would you think it has?

8. For women: Do you think women from all parties should work together to achieve higher participation?

a. Would you work with women from other parties on this issue?

9. For men: Have you ever encouraged a female member of your family to run for office? Why (not)?

a. What would you say if your wife/daughter/ sister would run for office? 


\section{Overview expert interviews}

Table 14 Interview partners

\begin{tabular}{|c|c|}
\hline Name $^{45}$ & Organization Name \\
\hline Sophia Berthuet & Condrobs \\
\hline Veronique Barbelet & Overseas Development Institute \\
\hline Morten Bøås & Norwegian Institute for International Affairs \\
\hline Donald Bowser & UNDP Ukraine \\
\hline Richard Danziger & IOM Regional Office for Western and Central Africa \\
\hline Davide Del Monte & Transparency International Italy \\
\hline $\begin{array}{l}\text { Zsuzsanna Dobos de } \\
\text { Prada }\end{array}$ & MigraMundi e.V \\
\hline Mike Emberson & Medaille Trust \\
\hline Expert & Aid organization \\
\hline Expert & GIZ \\
\hline Expert & GIZ \\
\hline Expert & Norwegian Refugee Council \\
\hline Expert & International Development Organization \\
\hline Expert & Human Rights Organization \\
\hline Marwa Fatafta & Transparency International \\
\hline Teresa Fernández & Women's Link Spain \\
\hline Andriy Garbuza & GIZ Ukraine \\
\hline Marta González & Proyecto Esperanza \\
\hline Igor Gotsyk & European Business Association Ukraine \\
\hline Vanessa Elisa Grotti & European University Institute \\
\hline Liz Hales & Academic and Practitioner in the criminal justice system, retired \\
\hline Claire Healy & ICMPD \\
\hline Marcy Hersh & Women's Refugee Commission \\
\hline Stephanie Hinum & Ärzte der Welt \\
\hline Gabi Höbenreich-Hajek & SOLWODI e.V. \\
\hline Samuel Kaninda & Transparency International West Africa \\
\hline Sadija Klepo & Hilfe von Mensch zu Mensch e.V. \\
\hline Kateryna Kulchytska & Europe without Barriers Civic Initiative Ukraine \\
\hline Oksana Kuziakiv & $\begin{array}{l}\text { The Institute for Economic Research and Policy Consulting } \\
\text { Ukraine }\end{array}$ \\
\hline Theodora Leite Stampfli & Cfd Schweiz \\
\hline Stanislav Liachinskiy & International Renaissance Foundation Ukraine \\
\hline Maria Nella Lippi & Officer Oxfam Italy \\
\hline Philippe Lust-Bianchi & UN WOMEN \\
\hline Emmanuel Mbolela & Refugee and activist \\
\hline
\end{tabular}

\footnotetext{
${ }^{45}$ Interview partners that requested to remain anonymous are indicated as "expert". Organization types are given for those that wanted to remain anonymous.
} 


\begin{tabular}{ll}
\hline \hline Name & Organisation Name \\
\hline Michael McHugh & Refugee Youth Service. \\
Aidan Mcquade, & Anti-Slavery International; Journalist \\
François Menguelé & GIZ Mali \\
Sadhena Moenesar & Vluchtelingenwerk \\
Beshid Najafi & Arbeitsgemeinschaft gegen internationale sexuelle und \\
& rassistische Ausbeutung (Agisra) \\
Esther Nauts & Asielzoekerscentrum Echt \\
Valeska Onken & GIZ \\
Carrie Pemberton Ford & CCHART \\
Serena Perini & Commission for Human Rights and Gender Equality, Solidarity \\
& and International Relations of the city of Florence \\
Abdoulaye Sall & Transparency International Mali \\
Nadia Sebtaoui & France Terre d'Asile \\
Tetiana Shevchuk & Anti-Corruption Action Center Ukraine \\
Oleksandra Slobodian & CEDOS \\
Iryna Solonenko & Deutsche Gesellschaft für Auswärtige Politik e.V. \\
Yegor Stadny & CEDOS Ukraine \\
Oleksii Sydorchuk & Ilko Kucheriv Democratic Initiatives Foundation Ukraine \\
Njoya Tikum & UNDP Regional Bureau for Africa \\
Corina Toledo & Women's rights activist, author, curator frau.kunst.politik \\
Zanobi Tosi & Oxfam Italy \\
Saloum Traoré & Amnesty International Mali \\
Elisa Trossero & ICMPD Trafficking Department \\
Chantal Uwimana & Transparency International \\
Siebrich Visser & Human Security Collective Mali \\
Olga Zhmurko & International Renaissance Foundation Ukraine \\
Anna Zobnina & European Migrant Women Network \\
\hline \hline
\end{tabular}




\section{Appendices}

\section{E. Interview guide corruption as a push factor for migration}

The data you will disclose in this interview will solely be used for the purpose of this research project. We will ensure the confidentiality of the information given. If, in a later stage, you would like to learn more about the research project, have any other additional questions or would like to review the results before submission/publication, you can always contact us.

$\checkmark$ Do you agree that I tape this interview?

$\checkmark$ Would you like to remain anonymous? (Completely anonymous/mentioned in list of interviewees/ direct citations are ok)

$\checkmark$ Do you have any more questions before we start the interview?

1. Could you please introduce yourself briefly and what is your function at the organisation that you currently work for?

2. As an expert of corruption in Mali/Ukraine ${ }^{46}$ - what is the situation of corruption in the country?

a. Which institutions and sectors are most/least affected?

b. Which are the most common forms of corruption in the country?

i. Probe for different kinds of corruption (e.g. bribery, embezzlement, fraud, extortion, favoritism, nepotism)

c. Are there reforms/developments that we should be aware of?

3. In your work how do you encounter corruption?

a. Which kind of corruption do you face?

b. In what circumstances?

4. As an expert of migration in Mali/Ukraine - what is the situation of migration in the country?

a. Regular and irregular migration?

b. Which are the most common reasons for people to migrate?

c. Are there any developments that we should be aware of?

5. We are researching if corruption is a push factor for migration. In your opinion - does corruption make people leave the country?
a. What kind of corruption?
b. In what circumstances?
c. Do you agree that it might be a direct push factor?
d. Do you have examples?

\footnotetext{
46 The case study countries for the research - excluded for general experts.
} 
6. We think that corruption might affect the human security situation of people. Can you give us your insights into the general human security situation in Mali/Ukraine?

e. Economic security

f. Personal security

g. Political security

h. Food/environment/health

7. We think that the connection between corruption and migration might be indirect. We look at the different human security dimensions that can be impacted by corruption and then lead to migration. How do you see these connections in Mali/Ukraine (or your country of expertise)?

a. Economic security

i. Employment

1. Unemployment is a main driver for migration. What is in your opinion the impact of corruption on unemployment?

ii. Income

iii. education

b. Personal security

i. Conflict

ii. Crime

iii. Gender equality

c. Political security

i. Human rights

1. What are in your expert opinion the most severe impacts of corruption on human rights?

ii. Police and judiciary

d. Health

e. Environment

f. Food

8. Are women affected differently? If yes, how?

a. Which spheres in your opinion especially affect women?

b. Which types of corruption affect women especially? 
Appendices

9. To what extent does a lack of human security caused by corruption lead to migration in Mali/Ukraine?

a. Regular and irregular migration?

10. Can you identify best practices for the fight against corruption?

11. Can you identify best practices for the fight against irregular migration?

12. In your view, what needs to be done to address corruption as a cause of (irregular) migration effectively?

13. Is there anything important you would like to add, that I might have missed during this interview regarding this topic? 


\section{F. Interview guide gendered experiences of corruption}

\section{Expert interviews}

\section{To Check Before the Start of the Actual interview:}

The data you will disclose in this interview will solely be used for the purpose of this research project. We will ensure the confidentiality of the information given. If, in a later stage, you would like to learn more about the research project, have any other additional questions or would like to review the results before submission/publication, you can always contact us.

$\checkmark$ Do you agree that I tape this interview?

$\checkmark$ Would you like to remain anonymous? (Completely anonymous/mentioned in list of interviewees/ direct citations are ok)

$\checkmark$ Do you have any more questions before we start the interview?

\section{Questions}

1. Could you please introduce yourself briefly and explain what your current function is at this organization is you currently work for?

a. Do you focus on a specific country?

2. How would you define corruption?

a. For your background: in our study we define corruption as "the abuse of entrusted authority for illicit gain". This includes: bribery, nepotism, extortion, patronage and fraud and considers both political and bureaucratic corruption.

'illicit gain' in the context of corruption does not only mean monetary gain but does also include other benefits for an individual, group or family member or the political party.

3. The migration process can broadly be separated in 3 stages: origin country, transit and destination country. In your opinion what role does corruption play during each of these stages?
a. Origin?
b. Transit?
c. Arrival? 
d. Do you have examples

4. Would you say that men and women experience corruption during the migration process differently? If yes, how?

a. Different forms/types?

i. Extortion and especially sexual extortion

ii. Bribery

iii. Nepotism

b. Different actors/ institutions?

5. When, where and how are female migrants most affected by corruption?

a. Origin (e.g. travel documents; recruitment agencies)?

b. Transit (e.g. border crossing)?

c. Arrival (e.g. work and residence permit)?

i. Refugee camps

ii. Asylum centers

iii. Europe and other countries

6. Can you think of indirect effects of corruption on female migration?

7. How are different types of female migrants affected differently by corruption?

a. Regular female migrants?

b. Irregular female migrants (smuggling \& trafficking)?

c. Forced female migrants (refugees)? (Forced= Disaster, conflict and development induced)

i. Corruption in refugee camps?

ii. Corruption in humanitarian assistance?

8. Are transgender women affected differently by corruption during the migration process? If yes, how? 
9. Which factors make women (or certain groups of women) particularly vulnerable to corruption during the migration process?
a. Individual factors (age, education, financial situation)?
b. Mode of transport (dependency on middlemen)?
c. Access to information?
d. Travelling alone/with male/with children?
e. Specific origin country
f. Specific transit routes

10. Are you aware of programs aimed at mitigating the effects of corruption on female migrants specifically? If yes, could you please give a few examples?
a. Different migrant groups?
b. Different stages in the migration process?

11. In your view, what else needs to be done to successfully mitigate the effects of corruption on female migrants and to prevent victimization?

12. For corruption Experts: In your opinion, should sextortion be considered a separate form of corruption? Why (not)?

13. Is there anything important you would like to add, that I might have missed during this interview regarding this topic? 


\section{Appendices}

\section{Migrant interviews}

To Check Before the Start of the Actual interview:

The data you will disclose in this interview will be used solely for the purpose of this research project. We will ensure the confidentiality of the information given. If, in a later stage, you would like to learn more about the research project, have any other additional questions or would like to review the results before submission/publication, you can always contact us.

$\checkmark$ Do you agree that I tape this interview?

$\checkmark$ Your participation will remain anonymous. We will keep all your personal information confidential. Do you have any questions about this?

$\checkmark$ Do you have any more questions before we start the interview?

$\checkmark$ Remind the interviewee that they do not need to answer all questions if they do not feel comfortable sharing sensitive information. We can always take a break or postpone the interview to later if necessary.

\section{Questions}

1. Can you tell me a little bit about yourself and your migration journey?

a. Where do you come from originally?

b. Why did you leave your home? Did you have a visa for your destination country? (remind people again that this information will not be shared with anyone at any time if they seem unsure)

c. Which countries did you cross during your journey? How long did the journey take?

d. Which mode of transport did you use to get here/where you are now?

e. Did you come through an agency or smuggler? If yes, how was this arranged?

i. Was the contract clear to you?

ii. Did you have to pay in cash?

f. Were you travelling alone? Who did you travel with? (family, friends, strangers?) 
2. How would you define corruption?

a. For the interviewer: We define corruption very broadly, it contains dishonest or illegal behavior especially by powerful people (as government officials or police officers. It can include things like paying a bribe or extortion but also nepotism (where people are given things because they are friends/relatives etc.). It is not always about money, it can also be about positions, sex or other benefits. It might also not always be a benefit for the person themselves but could be for their family member or political party.

3. The migration process can broadly be separated in 3 stages: origin country, transit and destination country. Did you encounter corruption during any of these stages? [give examples: Did you meet public officials that behaved improperly? Did you have to pay to get something that others did not have to pay/paid differently]

a. In your country of origin - did you face corruption when you started your migration journey? (e.g. to obtain identification or travel documents)

i. Could you please give examples?

b. During your Transit - were you faced with corruption? When and where? What type of corruption? (e.g. to cross a border)

i. Could you please give examples?

c. Upon arrival in your current place of residence- did you encounter any corruption? (e.g. to get a residence or work permit)

i. Could you please give examples?

4. Do you have friends, relatives or other acquaintances who encountered corruption during the journey? If yes, how?

a. Where exactly (country and migration stage)?

b. Were they men or women?

c. What kind of corruption? Was it different from your experiences? 
5. As a women/man, would you say your experience of corruption was different from that of men/women? How? Why do you think that is the case?

a. Different forms/types of corruption?

i. Extortion and especially sexual extortion [not to be asked explicitly]

ii. Bribery

iii. Nepotism

b. Different actors/ institutions?

Question 6 and 7 for activists/those that work with networks/ have been very reflective on the journey

6. In your opinion where and how are women most affected by corruption on their journey?

a. Origin (e.g. travel documents; recruitment agencies)?

b. Transit (e.g. border crossing)?

c. Arrival (e.g. work and residence permit)?

i. Refugee camps

ii. Asylum centers

iii. Europe and other countries

7. Which factors make women (or certain groups of women) particularly vulnerable to corruption during the migration process?

a. Individual factors (age, education, financial situation)?

b. Mode of transport (dependency on middlemen)?

c. Access to information?

d. Travelling alone/with male/with children?

e. Specific origin country

f. Specific transit routes 
8. In your view, what needs to be done to make the migration process safer for women?

9. Is there anything important you would like to add, that I might have missed during this interview regarding this topic? 

Ortrun Merkle holds a Master in Economics, a Master in International Relations and a Certificate of Advanced Studies in Security Studies from the Maxwell School of Citizenship and Public Affairs at Syracuse University, NY. Prior to that, she received a B.Sc. in Business Administration and Economics from the University of Passau, Germany and spent an Erasmus year at the Helsinki School of Economics.

Since joining UNU-MERIT, Ortrun has extensively taught at the Bachelor and Master level and supervised numerous Master and Bachelor thesis, focusing on security issues, corruption and gender. She is an academic advisor at the University College Maastricht (UCM) and a Competence Coach for the Premium Master's Honour Programme at Maastricht University. Ortrun is also coorganizing two blog series at UNU-Merit, 'Challenges to Peacekeeping in the 21st Century' and 'Gender Full Spectrum'. During her Ph.D., Ortrun has been a visiting researcher at the Peace Research Institute Oslo (PRIO), the Georgian Foundation for Strategic and International Studies (GFSIS) as well as UNU-GEST in Reykjavik.

Before joining UNU-MERIT, Ortrun worked for the Corporate Compliance Department of Daimler and at Transparency International USA. She has extensive training in mediation and is a certified intercultural trainer. Currently, Ortrun is a Post-Doctoral Researcher at UNU-MERIT/Maastricht Graduate School of Governance focusing on research on corruption, gender and migration. 

In accordance to Article 23 of the regulation governing the attainment for doctoral degree in the Maastricht University, the following section discusses the valorisation opportunities of this doctoral thesis. The aim of this section is to describe how the knowledge gained from this dissertation can be valuable for society and particularly academics and policymakers.

The 2030 Agenda for Sustainable Development has been an important milestone focused on addressing the global challenges humankind is facing. To tackle these challenges and achieve a better and more sustainable future for all by 2030 the UN Sustainable Development Goals (SDGs) were adopted in 2015 as a call for action for all countries. Long negotiations identified 17 goals, each containing multiple sub-targets focusing on inequality, poverty, peace and justice, prosperity and climate and environmental degradation. The achievement of the SDGs is highly ambitious and only possible under two important conditions: a) developing and developed countries must work in close partnership and b) actors must recognize that strategies to achieve the different SDGs have many synergies (e.g. the link between achieving gender equality (SDG 5) and fighting poverty (SDG 1)).

Research over the last decades has shown how moving towards more gender equality is directly related to many positive and sustainable development outcomes. However, interestingly enough, the interconnectedness of gender equality and anti-corruption work (SDG 16.5) and how achieving one can help achieve the other has received little attention from policymakers and academics in the last 15 years. This dissertation adds to the small but growing body of literature examining more critically how corruption and gender (in/equality) are related.

A first major contribution of this Ph.D. dissertation is the, at first glance simple, but important fact that narratives matter. While this is not a new argument within neither the academic nor the policy world, it has often been neglected in discussions around corruption and especially in those around corruption and gender. This dissertation shows, for multiple areas, how important it is to reconsider concepts, discuss language that is being used and reexamine arguments used in anti-corruption initiatives. 
The research in this book is consistently challenging the existing narrative around gender and corruption. Unfortunately, the research on the relationship to this date largely centers around two extreme views of women. On the one hand, the helpless female victims of corruption on the other, in large parts due to two seminal studies published by the World Bank, the myth of women as incorruptible heroes. As this thesis discusses, these views do not only limit our understanding of corruption they are also extremely harmful to any efforts of achieving gender equality, for example by reducing the importance of achieving gender equality in political participation to the potential of women as corruption fighters, rather than a question of equality and human rights.

Previous research (e.g. Goetz, 2007) has discussed that focusing on women as the anti-corruption force might in the long run threaten the political participation of women. If the need for women in parliament is based on their non-corrupt nature, any instance of corruption involving a female parliamentarian can be expected to lead to a large backlash against women in parliament overall. Chapter 5 adds to this discussion by focusing on the narrative that is often used by anti-corruption and women's rights activist. This chapter shows how the seemingly positive argument of "women are the better, cleaner (i.e. less corrupt) sex and should therefore be more involved in politics" is used to limit the space for women who are in politics to supposedly 'feminine' political areas. Simultaneously, the same argumentation is used to exclude women from politics from the onset, as those women who are truly clean, should not get mixed up in "dirty politics". This finding is of fundamental importance for anti-corruption and women's organizations worldwide who need to rethink how the current narrative they use might hurt their goals in the long run.

The research that has been presented in this dissertation argues that women per se are neither saviors nor victims, but rather, men and women are part of an intricate system of gender norms, i.e. patriarchy, that shape opportunities and limitations for both. Importantly, a patriarchal system neither oppresses all women equally nor does it empower all men equally and at all times. While there are women who are "foot soldiers of the patriarchy", i.e. who actively participate in upholding the patriarchal system, and often benefit from it, men also are oppressed by the system. By defining gender roles for both men and women, and determining what is acceptable for either, the space for all is limited. As the discussion in this dissertation shows, to truly understand the relationship between gender and corruption, research and discussions on corruption need to move away from looking only at men or women but rather at gender and underlying gender norms. 
The thesis argues that gender should not merely be a variable that is included in the research or policy agenda but that the prism through which one looks at corruption needs to be changed. Taking a true gender focus does indeed fundamentally alter our understanding of corruption and the societal structures that enable it and forces academics and policymakers to rethink definitions and concepts.

The next critical and innovative argument of this dissertation is the importance of moving away from a male-centric view of corruption as the exchange of money and goods towards a broader understanding of what the currency of a corrupt exchange can entail. As chapter 3 and 6 show for many women the currency of the exchange, especially in the context of migration, is their body. This form of corruption, called sextortion, has so far been largely neglected in research and policy making. This means that current measures of and discussions around corruption exclude a large part of the actual lived experiences of people. Therefore, it is essential for academics to invest more in researching this phenomenon. The finding is also important for anti-corruption organizations and those dealing with (sexual) abuse as they show a facet of abuse that has until now hardly been discussed.

Related to this argument, the dissertation also argues that the narrative about how one speaks about sextortion is important. As chapter 3 shows, the language used to describe sexual extortion varies widely and often minimizes the victim's experiences and reinforces stereotypes. What is even more important, especially in the light of the SDG partnerships, is the fact that the term frequently employed in poorer countries - transactional sex- is cruder compared to "harassment or sexual assault" which is typically used in developed country contexts. This reflects yet another power dynamic at play, i.e. North-South power imbalances. This shows how important it is to have a fundamental discussion about not only the issue itself but also the language used to define and describe it worldwide

The research presented in Chapter 6 is one of the first to take a closer look at the gendered experiences of corruption during migration that goes beyond the human trafficking - corruption nexus. This is not only interesting as an academic exercise but has many real-life implications for governments and civil society. Understanding how corruption endangers migrants throughout their journey is an important aspect of creating successful protection mechanisms in the home countries, during the journey and upon arrival in the destination country. However, these can only be implemented once occurrences of corruption are better understood and mapped. Therefore, the research in this dissertation should be 
seen as a starting point for discussions on how anti-corruption initiatives and the protection of refugees and migrants can complement each other.

Additionally, using different case studies from different areas in the world makes this largely explorative research interesting for policymakers and governments as it shows that the importance of more nuanced analysis of and discussion about the relationship between gender and corruption is not a question of developing or developed countries but is necessary everywhere.

Lastly, the chapters presented in this dissertation highlight the importance of a fruitful exchange between feminist and corruption research as an important new avenue of inquiry. Incorporating feminist research paradigms such as intersectionality or hegemonic masculinity in the research of corruption will lead to a better understanding of the phenomenon, a critical questioning of the concepts and new possibilities to identify different avenues for anti-corruption initiatives.

The research discussed in this dissertation has already been disseminated to both the academic community and policymakers on different occasions. The different chapters were presented at multiple academic conferences such as the International Studies Association Annual Conventions 2014 (Toronto) and 2016 (Atlanta), The Inclusive Peace: Women, Peace and Security Post-2015 Conference at the University of Iceland in 2016, the Human Development and Capability Association (HDCA) 2016 Conference (Japan) and the International Political Science Association 2018 World Congress of Political Science (Australia). Yet, the discussions have not been limited to academia but were also expanded to the policy community. The results of this Ph.D. research have been discussed in international fora with national and international policymakers and government officials, civil society and the news media and have been shared with a wider audience through blogs. The research has also been presented at international high-level meetings, such as the European Development Days 2017, the OECD Global Anti- Corruption \& Integrity Forum 2018 and the 18 $8^{\text {th }}$ International AntiCorruption Conference (IACC) 2018. The presentations at these conferences received considerable positive attention and showed a large interest in the policy community in more research and a better understanding of the relationship between corruption and gender. Additionally, gender and corruption has been highlighted as one of the main areas of focus for the period 2018-2020 at the $18^{\text {th }}$ IACC.

All research presented in this dissertation is to be published in academic journals or books and be further distributed to policymakers through blogs or policy briefs. 
The research in chapter 4 is forthcoming in the book "Women and Sustainable Human Development - Empowering Women in Africa" edited by Konte, M and Tirivayi, N. The research in chapter 3 and 6 has been in parts published as a research report for the German Development Cooperation (GIZ) and as a Youth ResearchEdge Competition Winner working paper at the OECD Global AntiCorruption and Integrity Forum. The next step will be to make the research available to a broader academic audience. Chapter 5 will also be prepared for academic publication, and the results will be shared with interview partners in Georgia in the form of a brief. 



\section{UNU-MERIT/MGSoG Dissertation Series}

2018

\section{Biljana Meshkovska}

Life after Trafficking:

(re)integration processes of women that have been trafficked for the purpose of sexual exploitation in Europe UNU-MERIT/MGSoG Dissertation Series № 214

\section{Vincenzo Vinci}

The Relevance of Institutions and

People's Preferences for Social

Protection

UNU-MERIT/MGSoG Dissertation Series № 213

\section{Silke Heuser}

The Effectiveness of Environmental Policies on Reducing Deforestation in the Brazilian Amazon

UNU-MERIT/MGSoG Dissertation Series № 212

\section{Jennifer Waidler}

Social Assistance and Remittances and Their Role in the Fight Against

Poverty

UNU-MERIT/MGSoG Dissertation Series № 211

\section{Choolwe Muzyamba}

The role of community mobilization in the promotion of maternal health of women living with HIV in Zambia UNU-MERIT/MGSoG Dissertation Series № 210

Juan Carlos A. Castillo Sánchez Assessing the Role of the Export Sector in Mexican Economic

Development,1965-2014

UNU-MERIT/MGSoG Dissertation

Series № 209

\section{Tareq Abuelhaj}

Food Security Policy Impact Analysis: The Econometrics of Cash and Food Assistance Cost Effectiveness

UNU-MERIT/MGSoG Dissertation Series № 208

\section{Marta Férnandez de Arroyabe}

Arranz

Essays on MEAS and Innovation

UNU-MERIT/MGSoG Dissertation

Series № 207

\section{Clotilde Mahé}

Essays on Migration and Occupational Choice

UNU-MERIT/MGSoG Dissertation Series № 206 


\section{Simone Sasso}

Talent on the move. Essays on Human Capital, Graduate Mobility and

Economic Development

UNU-MERIT/MGSoG Dissertation Series № 205

\section{Khaled Walid Rajab}

Strategic Planning under Fragility

UNU-MERIT/MGSoG Dissertation

Series № 204

Mutinta Hambayi Nseluke

A Tall Order: Improving Child Linear Growth

UNU-MERIT/MGSoG Dissertation Series № 203

\section{Elvis Korku Avenyo}

Innovations and Firm Performance

in sub-Saharan Africa: Empirical

Analyses

UNU-MERIT/MGSoG Dissertation

Series № 202

\section{Ni Zhen}

Employment Dynamics, Firm

Performance and Innovation

Persistence in the Context of

Differentiated Innovation Types:

Evidence from Luxembourg

UNU-MERIT/MGSoG Dissertation

Series № 201

\section{Caroline Wehner}

Too Scared to Achieve: The Relation

Between Neuroticism,

Conscientiousness

and Socioeconomic Outcomes

UNU-MERIT/MGSoG Dissertation

Series № 200

\section{Stefania Innocenti}

On Institutional Persistence

UNU-MERIT/MGSoG Dissertation

Series № 199

\section{Hassen Abda Wako}

Economic Globalization, Institutions and Development: Essays on Aid, Foreign Direct Investment and Trade UNU-MERIT/MGSoG Dissertation Series № 198

2017

\section{Hans-Erik Edsand}

Winds of Change

UNU-MERIT/MGSoG Dissertation

Series № 197

\section{Ana Patricia Silva Vara}

Redressing the Gender Gap

UNU-MERIT/MGSoG Dissertation

Series № 196

\section{Andrés Iván Mideros Mora}

Essays on the Economic Effects of Noncontributory Social Protection

UNU-MERIT/MGSoG Dissertation

Series № 195

\section{Tobias Broich}

New Actors in the Global Economy UNU-MERIT/MGSoG Dissertation

Series № 194

\section{Bernard Nikaj}

From No-government to E-government UNU-MERIT/MGSoG Dissertation Series № 193 


\section{Ali Safarnejad}

Prioritizing the HIV Response

UNU-MERIT/MGSoG Dissertation

Series № 192

\section{Clovis Freire}

Diversification and Structural

Economic Dynamics

UNU-MERIT/MGSoG Dissertation

Series № 191

\section{Michael Verba}

Innovation and Knowledge Dynamics:

Essays on the Knowledge Economy

UNU-MERIT/MGSoG Dissertation

Series № 190

\section{Pui Hang Wong}

The Hearts and Minds in Conflict and

Peace: The Economics of

Counterinsurgency and the Psychology of Reconstruction

UNU-MERIT/MGSoG Dissertation Series № 189

\section{Brenda Yamba}

Schooling Despite All Odds: Evidence from Lesotho on Female Child Carers who Stayed in School

UNU-MERIT/MGSoG Dissertation Series № 188

\section{Sheng Zhong}

Moving towards An Energy Efficient

Future: Essays on Energy Efficiency,

Technology and Development

UNU-MERIT/MGSoG Dissertation

Series № 187

\section{Julieta Marotta}

Access to Justice and Legal

Empowerment of Victims of Domestic

Violence through Legal Organizations in the City of Buenos Aires: A

Qualitative Empirical Legal Study

UNU-MERIT/MGSoG Dissertation

Series, № 186

\section{Andrea Franco-Correa}

On the Measurement of

Multidimensional Poverty as a Policy

Tool: Empirical Applications to Chile,

Colombia, Ecuador and Peru

UNU-MERIT/MGSoG Dissertation

Series, № 185

2016

\section{Yesuf Awel}

Insurance for Growth: Empirical

Essays on Insurance Demand and

Impacts in Africa

UNU-MERIT Dissertation Series,

№ 108

\section{Tigist Mekonnen Melesse}

Grow More Food using Fewer

Resources: Agricultural Technology

Adoption and Innovation Practices for

Inclusive and Sustainable

Development

UNU-MERIT Dissertation Series,

№ 107

\section{Eleni Yitbarek}

Getting Ahead or left Behind? Essays on Poverty Dynamics and Social

Mobility in Africa

UNU-MERIT Dissertation Series,

№ 106 


\section{Thuy Dieu Nguyen}

Firm-Level Theory and Evidence of

Corruption

UNU-MERIT Dissertation Series, № 105

\section{Raquel Tsukada Lehman}

Essays on Household Production with

Labor-Saving Technology

UNU-MERIT Dissertation Series, № 104

\section{Eva Barteková}

Multi-Problem Challenges for a

Renewable Future: Empirical Studies on Competitive Disadvantages from

Electricity Price Differentials and

Mineral Supply Risk in an Open

Economy

UNU-MERIT Dissertation Series, № 103

\section{Jocelyn Olivari}

Entrepreneurial Traits and Innovation:

Evidence from Chile

UNU-MERIT Dissertation Series, № 102

\section{Muhammad Shafique}

Essays on the role of knowledge, RED, and Technology-based Firms in the

Evolution of Socio-techno-economic

System

UNU-MERIT Dissertation Series, № 101

\section{Serdar Türkeli}

Governance of Innovation Policy:

Empirical Studies on Applied Political

Economy by Multi-Methods Analysis

UNU-MERIT Dissertation Series,

№ 100

\section{Ayokunu Adedokun}

Pathways to Sustainable Peace

building in Divided Societies: Lessons

and Experiences from Mozambique

MGSoG Dissertation Series, № 75

\section{Luiz Rothier Bautzer}

Organizing Concurrent Engineering

through ICT Platforms

Blueprinting Product Lifecycle

Management Platforms across

Disciplinary Agencies

MGSoG Dissertation Series, № 74

\section{Natalia Popova}

Migration in the Periphery of the

European Union:

Determinants of Successful and

Sustainable Labour Market Integration of Return Migrants in Albania, Egypt, Moldova and Tunisia

MGSoG Dissertations Series, № 73

\section{Richard A. Martina}

Uncertainty and Resource Constraint in the Small Island Developing States: Essays in Entrepreneurial Cognition MGSoG Dissertations Series, № 72 


\section{Cécile Cherrier}

The Expansion of Basic Social

Protection in Low-income Countries:

An Analysis of Foreign Aid Actors'

Role in the Emergence of Social

Transfers in Sub-Saharan Africa

MGSoG Dissertations series, № 71

\section{Paul Caldron}

The Tacit Bargain in Short-Term

Medical Missions: Why U.S.

physicians go and what it costs

MGSoG Dissertation Series, № 70

\section{Mahmut Kobal}

Customs \& Excellence: A Comparative

Approach on Administrative and

Regulatory Compliance Perspectives of

the EU-Turkey Customs Union

MGSoG Dissertation Series, № 69

\section{Craig Loschmann}

Essays on Conflict-related Migration and Development in the Case of

Afghanistan

MGSoG Dissertations Series, № 68

\section{Andrea Milan}

Rural Livelihoods, Location and

Vulnerable Environments: Approaches to Migration in Mountain areas of

Latin America

MGSoG Dissertation Series, № 67

\section{Farida Lada}

On Guarding the Welfare of Clinical

Trial Subjects While Promoting Novel

Drug Innovation

A Game Theoretical Approach

MGSoG Dissertation Series, № 66
2015

\section{Hibret Belete Maemir}

Dissecting Aggregate Productivity:

International Integration and Growth with Heterogeneous Firms

UNU-MERIT Dissertation Series, № 96

\section{Giorgio Triulzi}

Looking for the Right Path: Technology Dynamics, Inventive Strategies and Catching-up in the Semiconductor Industry

UNU-MERIT Dissertation Series, № 95

\section{Abdul Baseer Qazi \\ Knowledge flows and networks in the ICT sector: The case of Pakistan UNU-MERIT Dissertation Series, № 94}

\section{Ajay Thutupalli}

Technology Paradigm Shifts in Agriculture: Drivers of Sustainability and Catch up

UNU-MERIT Dissertation Series, № 93

\section{Eduardo Urias}

Improving access to HIVIAIDS treatment in Brazil: When are Compulsory Licenses effective in Price Negotiations?

UNU-MERIT Dissertation Series, № 92 


\section{Francesca Guadagno}

Why have so few Countries

Industrialised?

UNU-MERIT Dissertation Series, № 91

\section{Daniel Opolot}

The Evolution of Beliefs and Strategic

Behaviour

UNU-MERIT Dissertation Series, № 90

\author{
Alejandro Lavopa \\ Structural Transformation and \\ Economic Development: Can \\ Development Traps be Avoided \\ UNU-MERIT Dissertation Series, \\ № 89
}

\section{Jinjin Zhao}

Urban water management reform: The

Case of China

UNU-MERIT Dissertation Series, № 88

\section{Simona Vezzoli}

Borders, Independence and Postcolonial Ties: the Role of the State in Caribbean Migration

MGSoG Dissertation Series, № 65

\section{Silvia Consuelo Gómez Soler}

Civil Conflict and Education: How

Does Exposure to Civil Conflict Affect

Human Capital Accumulation?

Evidence from Standardized Exit

Exams in Colombia

MGSoG Dissertation Series, № 64

\section{Paula Nagler}

Occupational Choice in the Developing

World

MGSoG Dissertation Series, № 63

\section{Jasmin Kientzel}

Determinants of Professional

Commitment to Environmental

Sustainability

MGSoG Dissertation Series, № 62

\section{Mehmet Güney Celbiş}

Regional Policies: Convergence, Trade, and the Allocation of Public Capital

MGSoG Dissertation Series, № 61

\section{Florian Henning}

Living Up to Standard:

Interoperability Governance and

Standards Adoption in Government

Information Networks

MGSoG Dissertation Series, № 60

\section{Niels P. Groen}

The Never-Ending Project

Understanding E-Government Project

Escalation

MGSoG Dissertation Series, № 59

\section{Derek Copp}

Teacher-Based Reactivity to Provincial

Large-scale Assessment in Canada

MGSoG Dissertation Series, № 58

\section{Michaella Vanore}

Family-Member Migration and the

Psychosocial Health Outcomes of

Children in Moldova and Georgia

MGSoG Dissertation Series, № 57 


\section{Sonja Fransen}

The Economic and Social Effects of Remittances and Return Migration in Conflict-Affected Areas: The Case of Burundi

MGSoG Dissertation Series, № 56

\section{Ibrahim Khalil Conteh}

The Impact of Floods on Primary

School Education in Zambia

MGSoG Dissertation Series, № 55

\section{Richard Bluhm}

Growth Dynamics and Development Essays in Applied Econometrics and Political Economy

MGSoG Dissertation Series, № 54

\section{Nevena P. Zhelyazkova}

Work-Family Reconciliation and Use of Parental Leave in Luxembourg:

Empirical Analysis of Administrative Records

MGSoG Dissertation Series, № 53

\section{4}

\section{Dirk Crass}

The Impact of Brands on Innovation and Firm Performance: Empirical Evidence from Germany UNU-MERIT Dissertation Series, № 87

\section{Samyukta Bhupatiraju}

The Geographic Dimensions of Growth and Development UNU-MERIT Dissertation Series, № 86

\section{François Lafond}

TheEvolution of Knowledge Systems UNU-MERIT Dissertation Series, № 85

\section{Annalisa Primi}

Promoting Innovation in Latin America: What Countries Have Learned (and What They Have Not) in Designing and Implementing Innovation and Intellectual Property Policies

UNU-MERIT Dissertation Series, № 84

\section{Fatoumata Lamarana Diallo}

Evaluation of Meal and Deworming

Programs for Primary Schools in Rural Senegal

UNU-MERIT Dissertation Series, № 83

\section{Sachin Kumar Badkas}

Metachoice and Metadata: Innovating with Environmental Policy Analysis in Europe

MGSoG Dissertation Series, № 52

\section{Irina S. Burlacu}

An Evaluation of Tax-Benefit Systems Impact on the Welfare of Frontier Worker:

The Case of Luxembourg and Belgium MGSoG Dissertation Series, № 51

\section{Özge Bilgili}

Simultaneity in Transnational Migration Research: Links Between Migrants' Host and Home Country Orientation

MGSoG Dissertation Series, № 50 


\section{Yulia Privalova Krieger}

Reshaping the Big Agenda:

Transnational Politics and Domestic

ResistanceFinancial crisis and social

protection reform in Bosnia and

Herzegovina

MGSoG Dissertation Series, № 49

\section{Marieke van Houte}

Moving Back or Moving Forward?

Return migration after Conflict

MGSoG Dissertation Series, № 48

\section{Oxana Slobozhan}

Global Governance in the Management of Natural Resources: The Case of the

Extractive Industries Transparency

Initiative (EITI)

MGSoG Dissertation Series, № 47

\section{Luis Bernardo Mejia Guinand}

The Changing Role of the Central

Planning Offices in Latin America: A

Comparative Historical Analysis

Perspective (1950-2013)

MGSoG Dissertation Series, № 46

\section{Cheng Boon Ong}

Ethnic Segregation in Housing,

Schools and Neighbourhoods in the

Netherlands

MGSoG Dissertation Series, № 45

\section{Luciana V. Cingolani}

Bureaucracies for Development:

Oxymoron or Reality? Studies on State

Capacity in Challenging Governance

Contexts

MGSoG Dissertation Series, № 44

\section{Carlos Cadena Gaitán}

Green Politics in Latin American

Cities - Sustainable Transport Agendas

MGSoG Dissertation Series, № 43

\section{Katie Kuschminder}

Female Return Migration and

Reintegration Strategies in Ethiopia

MGSoG Dissertation Series, № 42

\section{Metka Hercog}

Highly-Skilled Migration and New

Destination Countries

MGSoG Dissertation Series, № 41

\section{Margaret Agaba Rugadya}

Can Remittances Influence the Tenure

and Quality of Housing in Uganda?

MGSoG Dissertation Series, № 40

\section{Ilire Agimi}

New Governance Under Limited

Statehood: The Case of Local

Government Reform in Kosovo

MGSoG Dissertation Series, № 39

\section{3}

\author{
Anant Kamath \\ Information Sharing through Informal \\ Interaction in Low-Tech Clusters \\ UNU-MERIT Dissertation Series, \\ № 82
}




\section{Flavia Pereira de Carvalho}

What we talk about when we talk about

Brazilian Multinationals: An

Investigation on Brazilian FDI,

Economic Structure, Innovation and

the Relationship between them

UNU-MERIT Dissertation Series, № 81

\section{Jun Hou}

Complementarity in Innovation and

Development: A Cross-country

Comparison

UNU-MERIT Dissertation Series, № 80

\section{Rufin Baghana}

Impacts of Government Incentives to $R \mathcal{E D}$, Innovation and Productivity:

A Microeconometric Analysis of the

Québec Case

UNU-MERIT Dissertation Series, № 79

\section{Lilia I. Stubrin}

High-Tech Activities in Emerging

Countries: A Network perspective on

the Argentinean Biotech Activity

UNU-MERIT/MGSoG Dissertation

Series, № 78

\section{Kristine Farla}

Empirical Studies on Institutions,

Policies and Economic Development

MGSoG Dissertation Series, № 38

\section{Marina Petrovic}

Social Assistance and Activation in the Pursuit of Happiness: Shedding New

Light on Old Policy Solutions to Social Exclusion

MGSoG Dissertation Series, № 37

\section{Laura Torvinen}

Assessing Governance Assessments:

The Case of Mozambique: Governance

Assessments in the Context of Aid

Effectiveness Discourse

MGSoG Dissertation Series, № 36

\section{Biniam Egu Bedasso}

Institutional Change in the Long

Shadow of Elite: Essays on

Institutions, Human Capital and

Ethnicity in Developing Countries

MGSoG Dissertation Series, № 35

\section{Sepideh Yousefzadeh Faal}

Deghati

Childhoods Embargoed: Constructing and Reconstructing Multidimensional

Child Poverty in Iran 1984-2009

MGSoG Dissertation Series, № 34

\section{Robert Bauchmüller}

Investing in Early Childhood Care and Education: The Impact of Quality on Inequality

MGSoG Dissertation Series, № 33

\section{Martin Rehm}

Unified Yet Separated: Empirical

Study on the Impact of Hierarchical

Positions within Communities of

Learning

MGSoG Dissertation Series, № 32 


\section{Abdul Waheed}

Innovation Determinants and

Innovation as a Determinant: Evidence

from Developing Countries

UNU-MERIT Dissertation Series,

№ 77

\section{Bilal Mirza}

Energy Poverty and Rural Energy

Markets in Pakistan

UNU-MERIT Dissertation Series, № 76

\section{Benjamin Engelstätter}

Enterprise Software and Video Games:

An Empirical Analysis

UNU-MERIT Dissertation Series, № 75

\section{Fulvia Farinelli}

Natural Resources, Innovation and

Export Growth: The Wine Industry in

Chili and Argentina

UNU-MERIT Dissertation Series

\section{Rodolfo Lauterbach}

Innovation in Manufacturing: From

Product Variety and Labor

Productivity Growth to Economic

Development in Chile

UNU-MERIT Dissertation Series

\section{Kirsten Wiebe}

Quantitative Assessment of

Sustainable Development and Growth

in Sub-Saharan Africa

UNU-MERIT Dissertation Series, № 74
Julio Miguel Rosa

Organizational Strategies, Firms'

Performance and Spatial Spillovers:

The Canadian Case in Research and

Development.

UNU-MERIT Dissertation Series, № 73

Johannes Wilhelmus Marie Boels

Joseph Schumpeter, Honderd Jaar

Economische Ontwikkeling: Een

Historisch-theoretische Beschouwing.

UNU-MERIT Dissertation Series

\section{Dorcas Mbuvi}

Utility Reforms and Performance of the

Urban Water Sector in Africa

MGSoG Dissertation Series, № 31

\section{Lina Salanauskaite}

Distributional Impacts of Public

Policies: Essays in Ex-Ante and Ex-

Post Evaluation

MGSoG Dissertation Series, № 30

\section{Esther Schüring}

To Condition or not - is that the

Question?

An Analysis of the Effectiveness of Ex-

Ante and Ex-Post Conditionality in

Social Cash Transfer Programs

MGSoG Dissertation Series, № 29

\section{Joe Abah}

Strong Organisations in Weak States:

Atypical Public Sector Performance in

Dysfunctional Environments

MGSoG Dissertation Series, № 28 


\section{Zina Samih Nimeh}

Social Citizenship Rights: Inequality and Exclusion

MGSoG Dissertation Series, № 27

2011

\section{Daniel Vertesy}

Interrupted Innovation: Emerging

Economies in the Structure of the

Global Aerospace Industry

UNU-MERIT Dissertation Series, № 72

\section{Tina Saebi}

Successfully Managing Alliance

Portfolios: AnAlliance Capability View UNU-MERIT Dissertation Series, № 71

\section{Nora Engel}

Tuberculosis in India: A Case of

Innovation and Control

UNU-MERIT/MGSoG Dissertation

Series, № 70

\section{Evans Mupela}

Connectivity and growth in Sub-

Saharan Africa: The Role of

Communication Satellites

UNU-MERIT Dissertation Series, № 69

\section{Nantawan Kwanjai}

Cross Cultural Intelligence amid Intricate Cultural Webs: A Tale of the UnDutchables in the Land of 1002 Smiles

UNU-MERIT Dissertation Series, № 68

\section{Lina Sonne}

Innovation in Finance to Finance Innovation: Supporting Pro-poor Entrepreneur-based Innovation UNU-MERIT Dissertation Series, № 67

\section{Lenka Eisenhamerová}

Legitimacy of 'Humanitarian Military Intervention'

MGSoG Dissertation Series, № 26

\section{Sonila Tomini}

Informal Payments for Health Care

Services in Albania

MGSoG Dissertation Series, № 25

\section{Jinjing Li}

Dynamic Microsimulation in Public

Policy Evaluation

MGSoG Dissertation Series, № 24

\section{Aziz Atamanov}

Rural Nonfarm Employment and International Migration as

Alternatives to Agricultural

Employment: The Case of Kyrgyzstan

MGSoG Dissertation Series, № 23

\section{Frieda Vandeninden}

Poverty Alleviation: Aid and Social

Pensions

MGSoG Dissertation Series, № 22

\section{Juliana Nyasha Tirivayi}

The Welfare Effects of Integrating AIDS Treatment with Food Transfers: Evidence from Zambia MGSoG Dissertation Series, № 21 
Agnieska Ewa Sowa

Who's Left Behind? Social Dimensions

of Health Transition and Utilization of

Medical Care in Poland

MGSoG Dissertation Series, № 20

\section{Emmanaouil Sfakianakis}

The Role of Private Actors in the

Provision of Public Goods with

Applications to Infrastructure and

Financial Stability

MGSoG Dissertation Series, № 19

\section{Siu Hing Lo}

White Collars Green Sleeves: An Inter-

organizational Comparison of

Determinants of Energy-Related

Behaviors among Office Workers

MGSoG Dissertation Series, № 18

\section{Treena $\mathbf{W u}$}

Constraints to Human Capital

Investment in Developing Countries:

Using the Asian Financial Crisis in

Indonesia as a Natural Experiment

MGSoG Dissertation Series, № 17

\section{Henry Espinoza Peña}

Impact Evaluation of a Job-Training

Programme for Disadvantaged Youths:

The Case of Projoven

MGSoG Dissertation Series, № 16
2010

Fernando Santiago

Human Resources Management

Practices and Learning for Innovation in Developing Countries:

Pharmaceutical Firms in Mexico

UNU-MERIT Dissertation Series,

№ 66

\section{Zakaria Babutsidze}

Essays on Economies with

Heterogeneous Interacting Consumers

UNU-MERIT Dissertation Series,

№ 65

\section{Bertha Vallejo}

Learning and Innovation Under

Changing Market Conditions: The

Auto Parts Industry in Mexico

UNU-MERIT Dissertation Series,

№ 64

\section{Donatus Ayitey}

Technical Change, Competitiveness

and Poverty Reduction: A Study of the

Ghanaian Apparel Industry

UNU-MERIT Dissertation Series,

№ 63

\section{Sergey Filippov}

Multinational Subsidiary Evolution:

Corporate Change in New EU Member

States

UNU-MERIT Dissertation Series, № 62 


\section{Asel Doranova}

Technology Transfer and Learning under the Kyoto Regime: Exploring the Technological Impact of CDM Projects in Developing Countries

UNU-MERIT Dissertation Series, № 61

\section{Florian Tomini}

Between Family and Friend:

Understanding the Interdependency of Private Transfers

MGSoG Dissertation Series, № 15

\section{Michał Polalowski}

The Institutional Transformation of

Social Policy in East Central Europe:

Poland and Hungary in Comparative and Historical Perspective

MGSoG Dissertation Series, № 14

\section{Maha Ahmed}

Defining, Measuring and Addressing Vulnerability: The Case of Post

Conflict Environments

MGSoG Dissertation Series, № 13

\section{Pascal Beckers}

Local Space and Economic Success:

The Role of Spatial Segregation of

Migrants in the Netherlands

MGSoG Dissertation Series, № 12

\section{Victor Cebotari}

Conflicting Demands in Ethnically

Diverse Societies: Ethno political

Contention and Identity Values in

Europe

MGSoG Dissertation Series, № 11

\section{Dennis Gyllensporre}

Competing and Complementary

Perspectives on the EU as a Crisis

Management Actor:

An Examination of the Common

Security and Defence Policy through

the Lenses of Idealism and Realism

MGSoG Dissertation Series, № 10

\section{Judit Vall Castello}

Business Cycle and Policy Effects on Labour Market Transitions of Older and Disabled Workers in Spain

MGSoG Dissertation Series, № 9

\section{Keetie Roelen}

False Positives or Hidden Dimensions:

The Definition and Measurement of

Child Poverty

MGSoG Dissertation Series, № 8

Denisa Maria Sologon

Earning Dynamics in Europe

MGSoG Dissertation Series, № 7

\section{Melissa Siegel}

Money and Mobility: Migration and

Remittances

MGSoG Dissertation Series, № 6

Jessica S. Hagen-Zanker

Modest Expectations: Causes and

Effects of Migration on Migrant

Households inSource Countries

MGSoG Dissertation Series, № 5 
Alexis Habiyaremye

From Primary Commodity Dependence to Diversification and Growth:

Absorptive Capacity and Technological Catch Up in Botswana and Mauritius. UNU-MERIT Dissertation Series, № 60

\section{Yoseph Getachew}

The Role of Public Capital in Economic Development

UNU-MERIT Dissertation Series, № 59

\section{Sandra Leitner}

Embodied Technological Change and Patterns of Investment in Austrian Manufacturing UNU-MERIT Dissertation Series, № 58

\section{Semih Akçomak}

The Impact of Social Capital on Economic and Social Outcomes UNU-MERIT Dissertation Series, № 57

\section{Abraham Garcia}

The Role of Demand in Technical Change

UNU-MERIT Dissertation Series, № 56

\section{Saurabh Arora}

Coherence in Socio-technical Systems: A Network Perspective on the Innovation Process UNU-MERIT Dissertation Series, № 55
Human Development and Autonomy in Project Aid: Experiences from four bilateral projects in Nicaragua and $E l$ Salvador

MGSoG Dissertation Series, № 4

\section{Christiane Arndt}

Governance Indicators

MGSoG Dissertation Series, № 3

\section{Britta Augsburg}

Microfinance: Greater Good or Lesser Evil?

MGSoG Dissertation Series, № 2

\section{8}

\section{Rutger Daems}

Medicines for the Developing World UNU-MERIT Dissertation Series, № 54

\section{Johannes Hanel}

Assessing Induced Technology:

Sombart's Understanding of Technical

Change in the History of Economics

UNU-MERIT Dissertation Series, № 53

\section{Rifka Weehuizen}

Mental Capital: the Economic Significance of Mental Health UNU-MERIT Dissertation Series, № 52 


\section{Danielle Cloodt}

The Relationship between RED

Partnership Formation, Social

Embeddedness and Innovative

Performance

UNU-MERIT Dissertation Series, № 51

\section{Sabine Fuss}

Sustainable Energy Development

under Uncertainty

UNU-MERIT Dissertation Series, № 50

\section{Geranda Notten}

Measuring and Managing Poverty

Risks

MGSoG Dissertation Series, № 1

2007

\section{Tobias Kronenberg}

Reconciling Environmental

Conservation with Economic

Prosperity: The Feasibility of Double

Dividends in the Short and Long Run

UNU-MERIT Dissertation Series, № 49

\section{Viktoria Kravtsova}

Assessing the Impact of Foreign Direct Investment in Transition Economies UNU-MERIT Dissertation Series, № 48

\section{Suhail Sultan}

The Competitive Advantage of Small and Medium Sized Enterprises: The Case of Jordan's Natural Stone Industry UNU-MERIT Dissertation Series, № 47

\section{6}

\section{Bulat Sanditov}

Essays on Social Learning and Imitation

UNU-MERIT Dissertation Series, № 46

\section{Mamata Parhi}

Dynamics of New Technology Diffusion: A Study of the Indian Automotive Industry

UNU-MERIT Dissertation Series, № 45

\section{Andreas Reinstaller}

Social Structures and the Innovation Process: Their Role in the Demand of Firms and Consumers

UNU-MERIT Dissertation Series, № 44

\section{Rose Kiggundu}

Innovation systems and Development: The Journey of a Beleaguered Nile Perch Fishery in Uganda UNU-MERIT Dissertation Series, № 43 
Thomas Pogue

The Evolution of Research

Collaboration in South African Gold

Mining: 1886-1933

UNU-MERIT Dissertation Series, № 42

\section{Geoffrey Gachino}

Foreign Direct Investment, Spillovers and Innovation: The Case of Kenyan

Manufacturing Industry

UNU-MERIT Dissertation Series, № 41

\section{Önder Nomaler}

Technological Change, International

Trade and Growth: An Evolutionary,

Multi-Agents-Based Modeling

Approach

UNU-MERIT Dissertation Series, № 40

2005

Samia Satti Osman Mohamed-

Nour

Change and Skill Development in the Arab Gulf Countries

UNU-MERIT Dissertation Series, № 39

\section{Elad Harison}

Intellectual Property Rights:

Economics and Policy Analysis

UNU-MERIT Dissertation Series, № 38

\section{Daniel Dalohoun}

The Relationship between RED

Partnership Formation, Social

Embeddedness and Innovative

Performance: a Multi-level Approach

of Social Embeddedness

UNU-MERIT Dissertation Series, № 37

\section{Müge Ozman}

Networks, Organizations and

Knowledge

UNU-MERIT Dissertation Series,

№ 36

\section{Bas Straathof}

Product Variety and Economic

Growth: The Counteracting Effects of

Scale and Idiosyncrasy

UNU-MERIT Dissertation Series, № 35

\section{Wilfred Schoenmakers}

Knowledge Flows between

Multinational Companies: A Patent

Data Analysis

UNU-MERIT Dissertation Series,

№ 34

\section{Myriam Cloodt}

Mergers and Acquisitions ( $M$ and As) in High-Tech Industries: Measuring the Post-M and A Innovative Performance of Companies UNU-MERIT Dissertation Series, № 33 
2004

\section{Paola Criscuolo}

$R \mathcal{E D}$ Internationalisation and

Knowledge Transfer: Impact on MNEs and their Home Countries

UNU-MERIT Dissertation Series, № 32

\section{Maarten Verkerk}

Trust and Power on the Shop Floor UNU-MERIT Dissertation Series, № 31

\section{Gottfried Leibbrandt}

Adoption, Harmonization and

Succession of Network Technologies across Countries

UNU-MERIT Dissertation Series, № 30

\section{Mark Sanders}

Skill Biased Technical change: Its Origins, the Interaction with the Labour Market and Policy Implications UNU-MERIT Dissertation Series, № 29

2003

\section{Nadine Roijakkers}

Inter-firm Cooperation in High-tech Industries: a Study of RED

Partnerships in Pharmaceutical

Biotechnology

UNU-MERIT Dissertation Series, № 28
Viki Sonntag

Speed, Scale and Sustainability

UNU-MERIT Dissertation Series, № 27

\section{Masaru Yarime}

From End-of-Pipe Technology to Clean Technology

UNU-MERIT Dissertation Series, № 26

\section{Stéphane Malo}

The Combinatorial Chemistry

Revolution: Sustaining a Superior

Performance Position through

Technological Learning

UNU-MERIT Dissertation Series, № 25

2002

\section{Annelies Hogenbirk}

Determinants of Inward Foreign Direct Investment: the Case of the Netherlands

UNU-MERIT Dissertation Series, № 24

\section{Bastiaan Johan terWeel}

The Computerization of the Labour Market

UNU-MERIT Dissertation Series 


\section{Marjolein Caniëls}

\section{John Adeoti}

Technology Investment in Pollution Control in Sub-Saharan Africa: The Case of the Nigerian Manufacturing Industry

UNU-MERIT Dissertation Series, № 23

\section{Edward Huizenga}

Innovation Management: How

Frontrunners Stay Ahead: An

Empirical Study on Key Success

Factors in the ICT sector

UNU-MERIT Dissertation Series, № 22

2000

\section{Machiel van Dijk}

Technological Change and the

Dynamics of Industries: Theoretical Issues and Empirical evidence from Dutch Manufacturing UNU-MERIT Dissertation Series, № 21

\section{9}

\section{Jan Cobbenhagen}

Managing Innovation at the Company Level: A Study on Non-Sector-Specific Success Factors UNU-MERIT Dissertation Series, № 20
Regional Growth Differentials: The Impact of Locally Bounded Knowledge Spillovers

UNU-MERIT Dissertation Series, № 19

\section{8}

\author{
Aldo Geuna \\ Resource Allocation and Knowledge \\ production: Studies in the Economics \\ of University Research \\ UNU-MERIT Dissertation Series, \\ № 18 \\ 1996 \\ Reinoud Joosten \\ Dynamics, Equilibria, and Values \\ UNU-MERIT Dissertation Series, \\ № 17
}

\section{Hugo Kruiniger}

Investment, $R \mathcal{E} D$, and the Financing Decisions of the Firm

UNU-MERIT Dissertation Series, № 16

\section{5}

\section{Hans van Meijl}

Endogenous Technological Change: The Case of Information Technology, Theoretical Considerations and Empirical Results UNU-MERIT Dissertation Series, № 15 


\section{René Kemp}

Environmental Policy and Technical

Change: A Comparison of the

Technological Impact of Policy

Instruments

UNU-MERIT Dissertation Series, № 14

\section{Rohini Acharya}

The Impact of New Technologies on

Economic Growth and Trade: A Case

Study of Biotechnology

UNU-MERIT Dissertation Series, № 13

\section{Geert Duysters}

The Evolution of Complex Industrial Systems: The Dynamics of Major IT Sectors

UNU-MERIT Dissertation Series, № 12

\section{Marjan Groen}

Technology, Work and Organisation: A Study of the Nursing Process in Intensive Care Units

UNU-MERIT Dissertation Series, № 11

1994

\section{Huub Meijers}

On the Diffusion of Technologies in a Vintage Framework: Theoretical Considerations and Empirical Results UNU-MERIT Dissertation Series, № 10

\section{Theon van Dijk}

The Limits of Patent Protection: Essays on the Economics of Intellectual

Property Rights

UNU-MERIT Dissertation Series, № 9

\section{Hans Voordijk}

Naar Integrale Logistiek in

Bedrijfsketens: Ontwikkelingen in de Bouw

UNU-MERIT Dissertation Series, № 8

1993

\section{Paul Diederen}

Technological Progress in Enterprises and Diffusion of Innovation:

Theoretical Reflections and Empirical Evidence

UNU-MERIT Dissertation Series, № 7

\section{Ben Dankbaar}

Economic Crisis and Institutional Change: The Crisis of Fordism from the Perspective of the Automobile Industry UNU-MERIT Dissertation Series, № 6

\section{Hanno Roberts}

Accountability and Responsibility: The Influence of Organisation Design on Management Accounting UNU-MERIT Dissertation Series, № 5 


\section{Bart Verspagen}

Uneven Growth between

Interdependent Economies: An

Evolutionary View on Technology

Gaps, Trade and Growth

UNU-MERIT Dissertation Series,

№ 4

\section{Sjoerd Romme}

A Self-organization Perspective on

Strategy Formation

UNU-MERIT Dissertation Series,

№ 3

1989

John Spangenberg

Economies of Scale, and Atmosphere in

Research Organisations

UNU-MERIT Dissertation Series,

№ 2

1988

John Hagedoorn

Evolutionary and Heterodox

Innovation Analysis: A Study of

Industrial and Technological

Development in Process Control and

Information Technology

UNU-MERIT Dissertation Series, № 1 



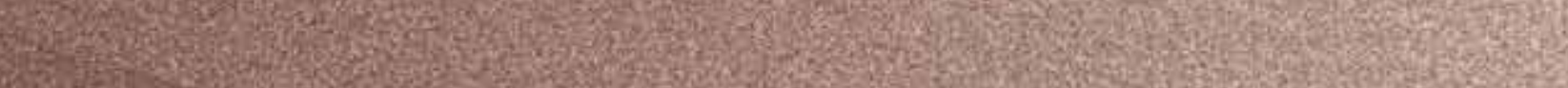

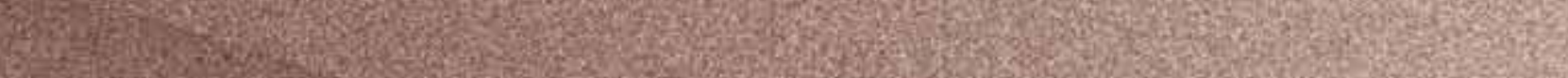
Y3. 3.

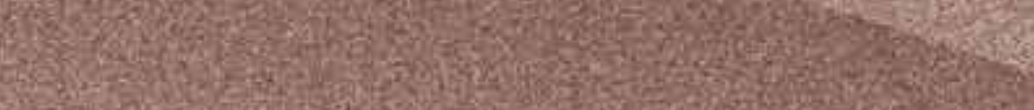

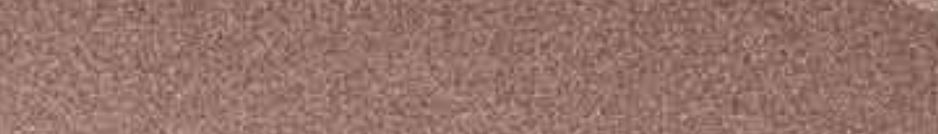
W.

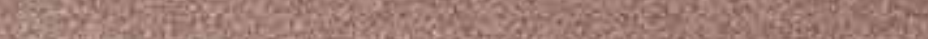

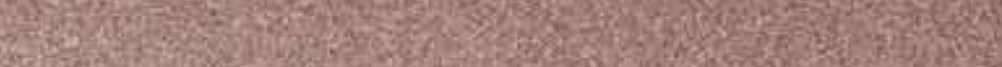

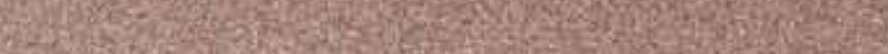
Got

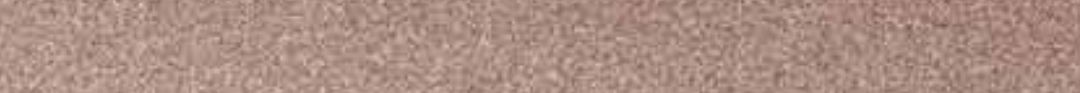

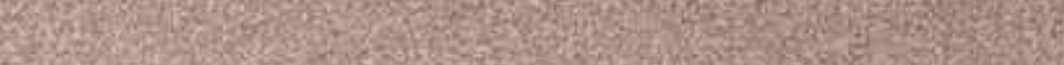
and 3. H.
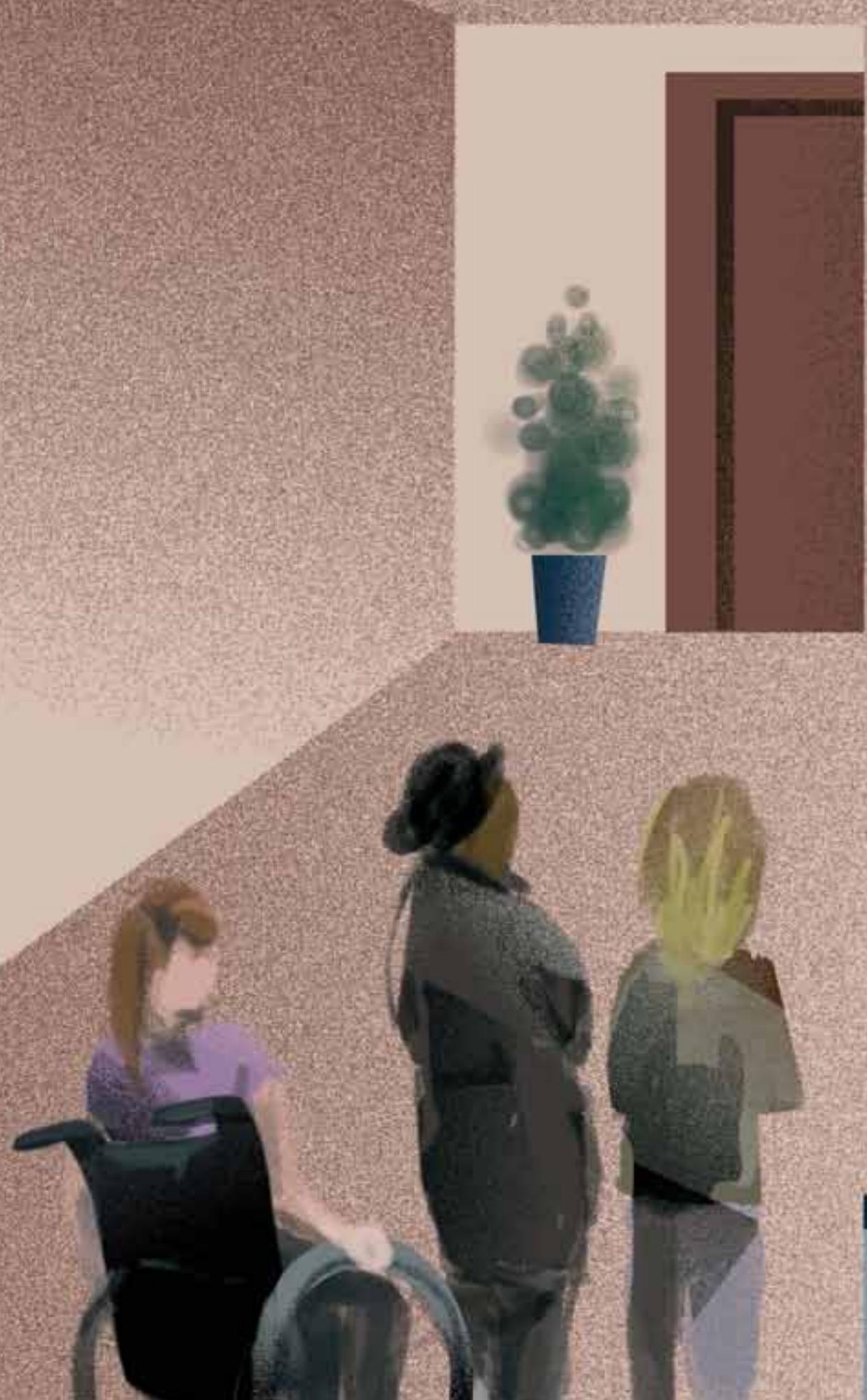